\title{
Clusea stucks.
}




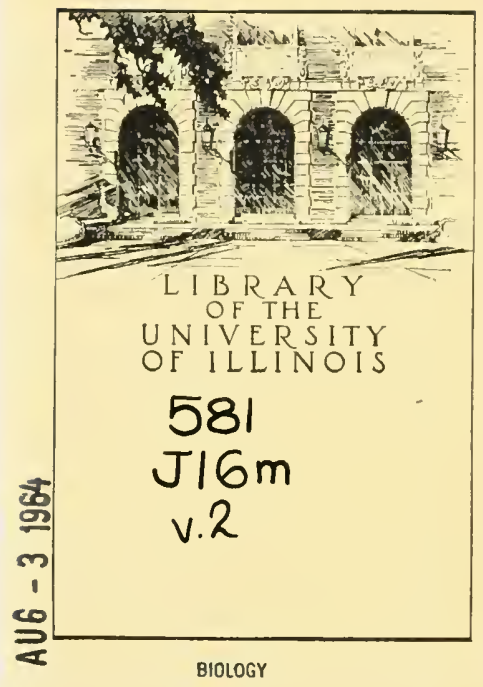




\section{Digitized by the Internet Archive in 2010 with funding from University of Illinois Urbana-Champaign}

http://www.archive.org/details/nicolaijosephija02jacq 


- 
NICOLAI JOSEPHIJACQUIN MISCELLA NEA A US T R I A C A

\section{A D \\ BOTANICAM, CHEMIAM,}

E T

HISTORIAM NATURALEM

SPECTANTIA,

$C$ U M

F $\quad I \quad G \quad U \quad R \quad I \quad S$.

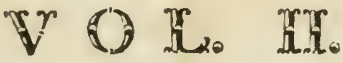

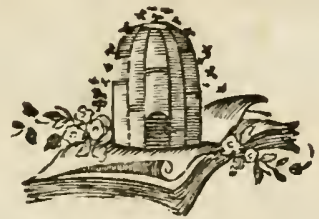

$V I N D O O B O N E$,

Ex OFFICINA KRAUSIANA.

I 78 I. 


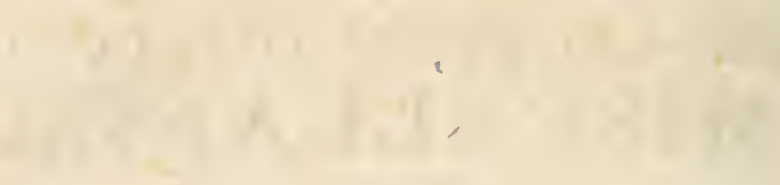

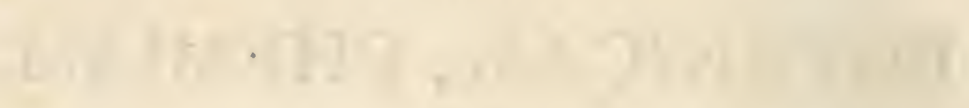

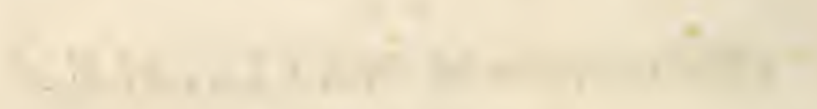

$x^{3}+x^{2}-1$ 

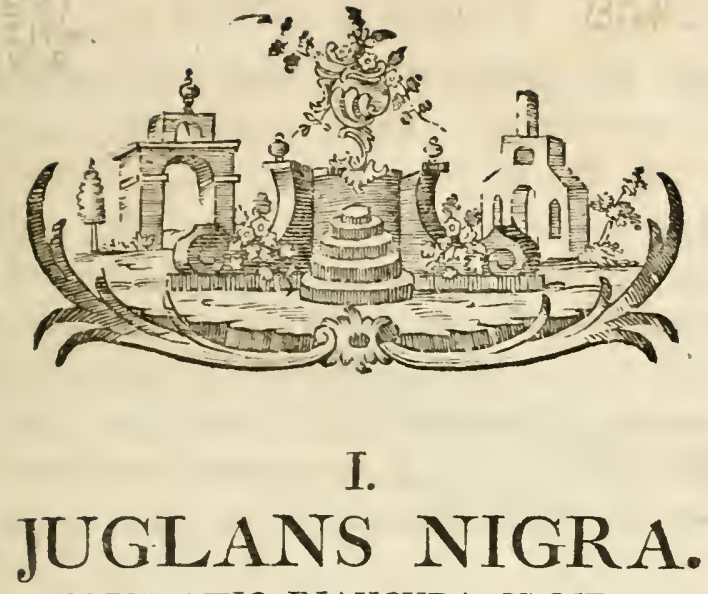

DISSERTATIO INAUGURALIS MEDICA,

PUBLICA DISQUISITIONI SUBMISSA

A

JOACHIMO FRIDERICO PLAPPART,

NOBILI STYRO FRANZENSI,

VIENNE 29. DIE AUGUSTI I777.

$A$ U C T A

JUGLANDE CINEREA.

Juglans nigra, Americæ feptentrionalis incola, materiei elegantia, qua Juglandem regiam $\mathrm{f}_{1}-$ ve europæam fuperare dicitur, fpectabilis, ob hoc ipfun 
Europæ fieri inquilina meretur; \& quod fieri poffit, jan exempla docuerunt. Egregius enim hortulanus aulicus, Richardus van der Schot, in horto cæfareo Schünbrunnenfi enatam ex nuce accepta arborem colit, quartum \& decimum rtatis annum nunc agentem, jam a quinque continuis annis plurimos fructus maturos ferentem, lætifime vegetantem, trunco infiftentem feptempedali \& in diametro octo uncias $x$ quanti, altam ipfam triginta pedes. Sobolem hæc jam plurimam ex fatis fructibus habuit. Ex eadem defcriptionem adumbravi fequentem.

Cortex pallide fufcus fiffuris longitudinalibus a duabus ad quatuor lineas profundis \& inæqualibus inciditur. Eft vero ille in ramis ( $f 1$ maxime principes, trunco fimiles, excipis, ) lævis; cæterum concolor; in extremis foliofis annotinis fordide virens. Folia funt pinnata, modo cum impari, frpius fine illo, ex foliolis utrinque a feptem ad undecim numero inconftanti, iisque oppofitis vel fubalternantibus, oblongo-acuminatis, fubfefilibus, obfolete ferratis; facie glabris, \& adultis atrovirentibus; dorfo pallidioribus, venofis, \& ad lenten villos albos brevifimosque oculo denfe objicientibus; in pagina altera fummitatem coltæ fpectante paulo brevioribus. Colta pa- 
rumper compreffa $\&$ tandem fefquipedalis eosdcm ad microfcopium villos habet.

Flores mafculi in amento pendulo cylindraceo longoque locantur, ftructura Juglandi regiæ fimiles. Ubi leve hoc difcrimen obfervo, quod in amento non pendulas, fed antheras fuas magis extrorfum verfas, fere totas $\&$ cunctas, ipectanti offerant. Tum quod floribus color magis faturate viridis fit, antherarumque apices cito nigrefcant. Ex ala folii præteriti infra geinman ramuli egreffuri unicum plerumque amentum (rariffime duo) enafcitur.

Fæminei flores etiam eodem fe modo gerunt, pauci feffiles ad ramulorum extremitates. Stigmata maxima pallide virefcunt. Drupa fubrotunda, major quam in Ju glande regia, ftyloque emarcido acuminata, cum flavedine quadam viret, faturatius punctata. Nux durifima \& craffa exteriorem fuperficiem pluribus apophyfibus habet valde exafperatam, quarum interftitia \& anfractus penetrat drupæ caro, hinc ab hac difficilius omnimode liberanda. Nucleus eft albus, ratione drupæ parvus, fapore Juglandis noftratis. Folia, imprimis vero drupa, odore pollent
A 3
fingu- 
fingulari aromatico fortiffmo \& gravi. Quandoquidem, cum Catesbæi, tum Hermanni, icones fint valde imperfectæ, nova hic icon adjicitur rami florentis, utriusque generis floribus gravidi; in quo folia, tunc nedum rite evoluta, minus profunde virent. Adftat feorfin foliolum ex folio adulto. Dein exhibentur fructus integer maturus; nux; eademque per futuras fuas longitudinaliter diffecta. (*)

Celeberrimum Linnæum non fatis intelligo, dum, Juglandem nigram cinereamque determinans,nigræ attribuit gemmas fuperaxillares, \& cinereæ foliola bafi altera breviora. Etian Juglandem cineream idem hortus cæfareus alit, fructus copiofos quotannis ferentem; \& utramquie hortus botanicus, fed adhucdum juniorem. Certe hæc, de qua agitur, arbor omnino Juglans illa nigra eft, Catesbæi

(*) Iconem hanc, tum etiam Juglandis cinereæ, in Mifcellaneis omifi, aliarumque omnium firpium, quarum figuræ propter magnitudinem fine complicatione tabulæ in hoc opere conpingi non poterant. Has omnes in opere fingulari edam absque textu, ea charta atque norma, quæ refpondent Floræ Aufriacx; quod venale proftabit apud Chriftianum Fridericum Wappler, Bibliopolan Viennenfem. 


\section{JUGLANS NIGRA.}

tesbæi \& Kalmii genuina planta, adeoque etiam eftedebet Linnæi. Ut melius de difcrimine utriusque judicari queat, fuccinctam Juglandis cinereæ defcriptionem hic fubjungam, icone illuftratam: tanto magis dignæ utraque, cruod nec hanc nec illam apud auctores exiftere ullam autumo.

Juglandi cinereæ labitus idem eft cum Juglande nigra; idem truncus \& cortex. Amenta mafculina etiam pendula; fed plerumque ex eoden loco orta gemella, rariflime folitaria; tum ad apiccm filiformem floribus deftituta. Hi fructura fituque Juglandi regiæ funt fimiles, at magis in oblongum protenfi. Pedunculi fæminei villofuli, teretes \& terminales, ad extremitatem flores a tribus ad quinque feffiles gerunt. Germen oblongum. Stigmata purpurea \& longa. Drupa ex oblongo ovata, villofa, vifcida, parum odorata. Nux ejusdem figuræ, bैuminata, externe afpera \& inæqualis ob diverfas apophyfes, quas caro corticis penetrat, tandem facile fecedentis. Nucleus faporem noftratis Juglandis habet, fed minus gratum magisque oleofum. Folia funt pinnata ex foliolis utrinque plus minus feptem cum terminante impari, oppofitis, fubfeffilibus, utrinque ad lentem villofulis, fer- 
rulatis, ovato-oblongis, acuminatis, parum odoratis, cum bafibus ad utrumque nervi latus fubæqualibus. Cofta teres \& villofa eft. Tabula reprefentat ramum florentem; alium fructigerum; tum foliolum adultum, coftæ affixum, nam in florente ramo folia modo funt in primo incrementi ftadio; dein nucem, eandemque per futuras difciffam, ut nucleus appareat, qui per nucis internam affurgentem ex bafi apophyfem profundiffime penetratur; tandem ramuli junioris partem cum abfcifis foliis, ut fola coftarum pars infuma fuperfit. Atque in hisce ramis fterilibus elongatisque, nec adeo in florigeris fructigerisve, obfervare eft fingulare illud phænomenon, quod gennne ramulorum futuri anni, fuperaxillares, a foliorum diftent urigine; quas inter \& coftas aliæ duæ confpiciuntur minores gemmulæ, altera alteri fuperpofita, ipfi axillæ folii proximæ, amenta mafcula proximo anno emiffura.

Príma apud nos floret Jiglans regia, deinde cinerea, quam ad pauciffimos dies nigra fequitur. Sed in fructus maturatione hunc ordinem non fervarunt. Quando primos fructus maturos Juglans regia octavo die Septembris fponte demittere cœpit, demum fub finem ejusdem men- 
fis hoc vifum in Juglande nigra fuit, \& ferius in cinerea - poft primos Octobris dies.

Plurima itaque effe, quæ cineream Juglandem a nigra diftinguant, patet ex ante dictis, ut facile determinatio fpecifica inde erui atq̧ue ftabiliri poflit. In nigra odor fortiffimus \& plane peculiaris, qui longe alins eft, $\&$ debiliffumus in cinerea. In illa amenta gemella, quæ in hac folitaria \& ultra flores filamentofa. Fructus figura diver$\mathrm{fa}, \mathbb{\&}$ in cinerea villofus ac vilcidus. Gemmæ in ramis ftcrilibus in cinerea fuperaxillares. Foliolorum facies glaberrima in nigra atroviret; in cinerea autem, æque hæc villofa ac dorfum, dilute \& cum manifelta viret flavedine. Eorundem bafin fuperiorem, five quæ coftæ apicem fpectat, nigra breviorem, vel potius ortu ex nervo medio altiorem; cinerea utramqque bafin æqualem habet. Et alia. Foliolorum vero numerum non moror, forte variabilem ætate, loco \& climate, certe vel hic Viennæ inconftantem. Videntur itaque Linnæi determinationes \& notæ adjectæ inverti debere, ut qua de cinerea dixit, applicentur nigræ, \& vicifim. Et omnino credibile eft, transpofitionem illam erroneam fortuito atque incuria in opus Linnæanum irrepfrfe. 
Ut completior habeatur Juglandis nigræ hiftoria \& monographia, fubjungo hisce omnia illa, quæ illuftris Petrus Kalm, in arboris patria autoptes, elegantiflime \& uberrime differuit in ACtis Academiæ Regiæ Suecicæ anni millefimi fexagefimi feptimi, ex germanica traductione in latinam hic verfa. Sic autem habet ille:

Juglans nigra. Linn. Spec. pl. 2. pag. r415. hort. upf. 287. Gron. virg. pag. 150.

Nux juglans Virginiana nigra. Herm. lugd. pag. $45^{2}$. tab. 458. Catesb. car. vol. r. pag. $\sigma_{7} \cdot t a b .67$.

Angli, Americæ feptentrionalis incolæ, arbori huic nomen Black Walnut, aut Black W alnut-tree, Sueci Swart Nötbom, fæpe etiam Swart Walnöt-träd (quæ omnia $\mathcal{F}_{u-}$ glandem nigram fignificant, ) tribuunt. Denuminatio hæc enata fuit a colore arboris hujus obfcuro aut fubfufco, quum Juglandes reliquæ in America feptentrionali crefcentes plerumque albæ fint.

Inculta per Penfylvaniam ubique, tum \& per Novæ Cæfareæ (New Jerfey) plerosque tractus crefcit. In Mary- 
Marylandia, Virginia \& Carolina vulgaris eft, uti \& in locis aliis, a mari magis diftantibus, \& fub eadem cum prioribus regionibus elevatione poli fitis. Ad feptentrionalem vero Novi Eboraci (New York) plagamevadit rarilima; locus enim ad feptentrionem maxime tendens, ubi fylveftrem inveni, polum feptentrionalem circiter ad gr. 4 I minut. 30 elevatum habuit.

Vidi tamen incolas regionum aliarum, magis adhuc borealium, inter Novum Eboracum \& Albaniam, arborem hanc in hortis fuis colviffe. Incolæ Juglandes nuces cum ex Nova Cærarea, tum ex tractu aufrali comitatus NovoEboracenfis, adferri curaverant; ex quibus enatæ arbores. optime vegetaverant; quæ nunc læte ibidem adolefcunt, ut fpem incolæ alerent, arbores hasce ex propria fobole perennaturas fore.

Solum, quod imprimis amat, reperitur in locis magis editis, humus fertilis nigra \& pinguis; in qua etiam ad fluminum ripas optime vegetat. Maris autem viciniam ferre non videtur. 
In Penfylvania anno 1749, die 7 Maji, flores explicare cœperat. Sequenti anno Juglans europæa (regia Linnæi) in Penfylvania circa Novam Cæfaream plantata, 5 Maji florere jam defierat, duin Juglans nigra primos demum ibidem protrudebat flores.

Folia fero fatis germinant. Anno I 749 circa 9 Maji; fequenti anno eodem vix non tempore.

Nuces etiam fero maturefcunt in Penfylvania ac Nova Cæfarea, circiter fub finem Septembris. Decima oftava OAtobris 1749 omnes fere deciderant. Anno 1750 pleræque jam fexta Octubris.

Folia ut plurimum brevi delabuntur, pofteaquam nuces ad maturitatem pervenerunt, nifi tempeftatis ratio hic quid mutet. Decima octava Octobris r 749 foliis vix non ommes arbores nudatæ fuerant, I 750 vero ad vigefimam octavam usque Octobris circiter perftiterunt.

Utiliffima quidem, uti mox latius demonfrabitur, arbor vario ex capite eft; his tamen non obftantibus, prata, pafcua, hortos floriferos ac oliferos, damno majori, 
quam alia ulla arbor, mactare creditur; quascunque enim plantas viciniores peffumdat, ac veluti enecat, quas inter funt mali, cerafi, feges, linum ac olera. Prope lata plantataque vegetare non poffunt, fed fenfim intereunt. Relatum mihi a pluribus Suecis eft, deftructas malos ex ea unice fuife caufa, quod Juglandes nigræ viciniores ftetiffent. Quin adleveraverit ex illis unus, plures fe quadraginta malus perdidiffe, quod annofas quasdam Juglandes nigras in pomarium reliquiffet; impoffibilem hinc effe culturam malorum vicina hac Juglande incolumi; eadem vero exftirpata, malos crefcere lætiffume. Vera quidem phrnomeni hujus caufa adhucdun latet. Plerique exhalationibus Juglandis nigrx, ad vicinas arbores delatis, attribuebant. Tritis enim arloris hujus foliis inter digitos, odor fortis \& ingratus nares ferit. Conferre quidem hoc poterit aliquid; ratiu tamen princeps videtur, quod radices ejusdem quaquavorfum copiofe difperfe, \& ultra modum productæ, fuccum omnem ac nutrimentum ex tellure in fefe rapiant, plantasque alias eo defraudent; nulla enim fere arbor hic occurrit, quæ tam cito, ac Juglans nigra, adolefcat, denfisque adeo annulis augeatur. Confirmatur hoc ex eo, quod ipfe vidi. Habebat ill. Ludovicus Evans, machinator bellicus, in horto olitorio

$$
\text { B } 3
$$


fino Philadelphiæ vaftam Juglandem nigram. Nihil omnium, quæ arbori huic propinquiora feverat, vegetabat. Cæfa hinc arbore, omnes evellebantur radices; quando vifa eft prodiiffe ex trunco magna radicurn vis, quarum duæ tresve perpendiculariter in terram defcendebant, reliquæ vero omnes horizontali, ad dimidii circiter pedis profunditatem fub terra, ductu per totum vix non hortum difcurrebant. Etfi vero arbor parieti, qui hortum Evanfianum a vicino quodam feparabat, riciniffima adftaret; prætereaque rami æque fuper hunc fefe porrigerent hortum, quam fuper Evanfianum, fata tamen in horto vicini fat bene adolefcebant, utut ab arbore non multum remota. At vero pauciflimæ radices in hortum vicini penetrabant, quum ex adverfo vix non omnes in hortum Evanfianum pergerent.

Radices, quacunque demum craffitie donatæ deprehendantur, communiter ad intima usque, arboris quidem ipfius adinftar, fufcr non funt; fed per ambitum folum externum ad duos tresve transverfos digitos colore pinguntur fufco; interius albent. Exordium tamen radicis, feu crura ejus fupra tellurem eminentia, ex integro fufcefcit; dum vero radices albæ effoffx per quoddam 
temporis intervallum extra tellurem jacent, pariter fufcæ redduntur; coloris tamen intenfitate ligno ipfi cedunt.

Roris aut pluviæ guttæ, ex arbore hac in linteamina alba delaplæ, maculas plerumque poft fe relinquint.

Nulla fere regionis hujus arbor tam celeri, quam hæc, incremento augetur, nulla tam nagnis circulis annalibus donatur. Singulare id fimul obtinet, reperiri inter fibras ejus aut interftitia, idque non raro profundius centrum verfus, demiffas arenulas fubtiles, veluti interfperfas; quilus dolabræ, aliaque inftrumenta, dum lignum hoc in operam trahitur, adeo læduntur, ut repetito acui oporteat. Cæduntur tamen \& arbores, quæ nullam plane arenulam recludant; quæ videtur diverfitas repetenda a folo, cui arbor inhæfit.

Etfi ferocior in Penfylvania ac Nora-Cælarea nonnunquam fæviat hyems, ut malum perficam, arborem juniorem Hickery (aliam Juglandis fpeciem) quin \& morum lædat, uno ore faffi tamen omnes fuerunt, ob- 
fervatum nunquam fuiffe, in Juglandem nigram damnum ex frigore acriori ullum redundaffe.

Octo decemve annorum ætatem adepta, nucum ferax fieri plerumque incipit; quo magis ætate increfcit, eo \& increfcit fæcunditate, donec tandem fenium aliæve circumftantix fertilitatem denuo minuant. In campis patentibus, ubi rami latifime diffundi queunt, fructus copiofiores, majores, gratiorique fapore præditos largitur, quam in fylvis denfis. Nec omni anno eadem arbori eft fæcunditas. Anno I 748 feraciffima fuit. Anno I749 minore copia legebantur nuces Juglandis nigræ, arboris Hickery, faginæ, caftaneæ, variæcque glandium fpecies; meflis tamen fegetis erat uberrima, malique copia fructuun gravabantur. In autumno $1750 \mathrm{nu-}$ cun modo dictarum glandiumque tanta aderat abundantia, ut in pluribus locis tellus arboribus fubjecta ad pedem integrum \& ultra fructibus denfe tecta confpiceretur, quorum pars maxima in fylvis neglecta remanfit, quum nemo colligere omnes aut poffet, aut vellet. Parcior malorum eodem hoc anno proventus erat. Sed per omnes hosce tres annos malus perfica fæcunda perftitit.

Incre- 


\section{JUGLANS NIGRA.}

Incrementi arboris hujus ratio exin poteft colligi, quod in Nova Cælarea arbores quadraginta quatuor annos natas viderim, proceritate orgyias novem, diametro vero trunci ad ulnæ unius a terra diftantiam ulnas tres cum dimidia æquantes.

Pecora folia Juglandis nigræ ob odorem fortem ac ingratum non tangunt; obferratum tamen fuit, auno 1750 , ubi larvæ phalænæ neufriæ, aut quæ certe ejus varietas fuit aliqua, maximam partem foliorum arborum Penfylvaniæ, ac Novæ Cæfareæ confumferant, ut plane denudatæ arbores fpectarentur; tandem larvas illas etiam Juglandis nigræ folia haud faftidiiffe, etfi minus avide hæc comederent, quam quercina aliave.

Arboris hujus lignum interne fufcefcit, venis maculisque obfcurioribus ac dilutioribus piłtum, ut ex eo fabricata fupellex elegantiam fummam præ fe ferat. Pulchrior conficitur ex radicibus craffioribus, quum interior harum fubftantia venis maculisque jam obfcuris, jam dilutioribus, copiofius variegetur, quo fit, ut nativam hanc materiem diceres Ipeciofifime \& fumma cum arte marmoratam. Propterea operum inteftinorum fabri 
fegmenta, ex radicibus exfcilla, in antica fupellectilis parte locant. Reperiuntur, fed rarius, integræ arbores, quæ in tabulas difciftæ dolabratæque colorem pulchre fufcum, maculis nigris paffim notatum, eleganti fpectaculo exhibent.

Ob colores hos ipfos fabris minutariis ac tornatoribus Americæ feptentrionalis Juglans nigra plurimo in pretio eft, adeo ut, non folum Juglandi regiæ, fed \& omnibus ibi loci fponte nafcentibus arboribus præferatur, fola tamen excepta pruno virginiana, quæ in eadem, vel nonnunquam in majore, æftimatione eft. $\mathrm{Ve}$ re anni I752 minutarii Philadelphiēnfes a 14 ad 20 Shilling monetæ Penfylvanicx pro roo ped. Juglandis nigræ, \& a 14 ad 22 Shilling pro æquali portione pruni virginianæe folverunt. Pluteus fcriptorius ex Juglande nigra fabrefactus, fera, bracteolis, manubriis orichalceis, omnibusque demum rebus neceffariis inftruAtus, anno I75I feptem, octo, novem, aut decem libris monetæ Penfylvanicæ veniebat; pretium communius 8 aut 9 librarum erat. $\left(^{*}\right)$

Ex-

(*) I Shilling æquivalet 12 crucigeris nofratibus; \& I libra Penfylvanica 4 florenis. - 


$$
\text { JUGLANS NIGRA. }
$$

Ex omnibus illarum regionum indigenis arboribus colorem alia nulla tam diu \& conftanter fervat. Quo vetuftior fupellex, eo pulchrior evadit. In incerata fplendor coloris multum extollitur.

$\mathrm{Ob}$ dictum hactenus ufum plurimæ tabulæ quotannis in Europam transvehuntur, caro fatis perfolvendx; unde quidem ligni pretium gravius evafit. Plures adferuerunt mihi artifices, intra decem annos illud ad duplum adfcendiffe. Alia caritatis ratio effe poterit, arbores has, aliarum quarumcunque in modum, absque ullo difcrimine facto cædi, nec parci illis, dum novæ coloniarum fedes exftruuntur, aut quando lignorum penuria eft. Loca frpe invif, in quibus foci mero ex hoc ligno ardebant.

Fructus globofi funt, Europæis juglandibus majores, multo etiam duriores, ut ad fraflgendam nucem malleus aut fimile infrumentum requiratur, quo nucleus ipfe eximi queat. Nucleus etiam magis a nucis dura fubAantia, quam in Europæis, implicatur, \& undique obvolvitur, quibus tamen fapore nibil cedunt, quare etiam libenter comeduntur. 
Ante Europxorum in Americam adventum incola - lactis exiguam aut nullam habebant notitiam, quum pecora non alerent. Lactis tamen fpeciem feqquenti ratione conficiebant. Nuces Juglandis nigre \& arboris Hickery collectas ficcatasque contundebant; exemptos nucleos, in farinam contritos, aqua mifcebant, atque fic in cibum ac potum fibi vertebant, qui dulcedine gratoque lapore lacti vero cedebant parum. Indi adhucdum fæpe lacte hoc juglandino vefcuntur.

Ex nucleis oleum exprimitur, quod in excoriationibus fiffurisque papillarum egregium prædicatur.

Sciuri cinerei, tum alii, qui fub terra degunt, nuces has autumno diligenter colligunt, ac in domicilia fua in hyemale alimentum transferunt.

Cortice arboris, imprimis autem involucro illo nigro \& carnofo, quod nuces externe ambit, lana colore fufco non emoriente tingitur.

Quam- 
Quamdiu corter nucis maturæ recens eft, manus nigro pigmento ita inficit, ut nigredo intra duas tresve hebdomadas ex integro tolli fæpius nequeat.

Colitur arbor hæc vulgo in hortis omnibus, tum ob nuces iplas, tum ob formæ venuftatem, quam rami patentes foliaque magna adferunt. Imprimis incolæ arborem plantant juxta domunculas lactarias, ut his a ramis illius magnis foliofisque perpetua concilietur umbra; in illis enim regionibus lac, durante intenfifimo æftivo calore, adfervatur in domunculis, hunc præcife in finem exftructis. Quum fcilicet regio tota fontibus fcaturientibus undique abundet, cura femper fumma fuit hortos inftruentibus, ut eflet apta fcaturigo horto ipfi vicina. Huic inædificatur ex lateribus coctis ædicula, juxta quam, ubi foli maxime exponitur, plantatur una alterave Juglans nigra, aut platanus occidentalis, cito adolefcentes, ramisque vaftis \& foliofis denfam inducentes umbram. Et hæc quidem umbra, tum \& fcaturiens gelida aqua, aërem in xdiculis mire refrigerant. $\mathrm{Vafa}$, lacti adfervando deftinata, imponuntur aquæ profluenti ex fcaturigine, quo refrigerium adhuc majus lacti detur.

\section{$\mathrm{C}_{3}$}

Sca- 
Scaturigo nonnunquam ipfa extra domunculañ relinquitur, fed tunc canalis aqquam in illam ducit.

Nuces ferendæ ab arbore non decerpuntur ; fed, donec decidant fponte fua, exfpectant incolæ; fic maturatiffimas plerumque obtinent. Ut plurimum ipfo adhuc autumno committuntur terræ; $f 1$ vero in veris usque adventum adfervandæ fint, obruuntur arena ficca in cubiculo frigidiori, ne mucore obducantur. Experientia in Penfylvania ac Nova Cæfarea docuit, plantari omnium optime eo ftatim loco, ubi arbor ipfa manere poftea debeat; $f_{1}$ enim defocliantur primum in areola, aliove loco, atque hic enatæ plantulæ in alium dein locum transplantentur, plerumque maxima pars arbufcularum hyeme prosima emoritur, quamvis frvior illa non fuerit, dum tamen aliæ non transplantatæ brumam perferunt fine ullo damno.

Juglandes nigræ, quas hic in Finlandia ex nucibus eduxi, partim in horto meo intra urbis pomœria, partim in arboreto Sipfalienfi cultr fuerunt. Priores non recte vegetarunt, quum terram, humiliori loco fitam, minus amarent. Sipfalienfes locum eminentiorem, hu- 


\section{JUGLA NS NIGRA.}

mum pinguem atram occupantes, hyemem probe fultinuerunt, quin non obftante hyemis anni I760 infolita frevitie, arbores ipfas Finlandicas fpontaneas plures enecante, Juglandes tamen dictæ Sipfalienles ne minimum quidem fuere paffre. Etfi vero ulnarum quinque proceritatem arbores jam adfecutæ fuerint, nullos tamen fruहtus hucusque tulerunt.

Arborem hanc plantaturi in Suecia dubium fors movere poterunt. Ex antea enim dictis patuit, etianfi arbores æftate tam longa calidaque in America feptentrionali, ubi fponte crefcunt, fruantur, fat longum nihilominus requiri tempus, antequam nuces perfecte maturefcant. EEftas vero in Suecia \& multo citius abfolvitur, \& longe minus calida eft. Unde fpes foret minima in climate noftro perducendi nuces ad perfectam maturitatem. At vero refpondeo, arborem hanc in nofro climate optime crefcere; dummodo congruum nacta fuerit folum. Dein,' quantumvis cogeremur pro arborum harum plantatione, ex America feptentrionali femper petere nuces; ob elegantiam tamen ligni, hujusque inlignem ufum, maximam nobis adferrent utilitatem. Conftitit autem, regetabilium multorum exoticorum, quin 
\& ipfius Americæ feptentrionalis indigenarum, exemplo, adfuefcere illa fenfim poffe noftro climati, ac elapro quodam temporis intervallo præcocius maturos fruAtus ferre, nec tunc ultra tanto quidem ad hoc amplius indigere tempore, quam dum terras noftras primum intraverant. Spem hinc alere licet eandem de Juglande nigra, fub noftro climate plantata.

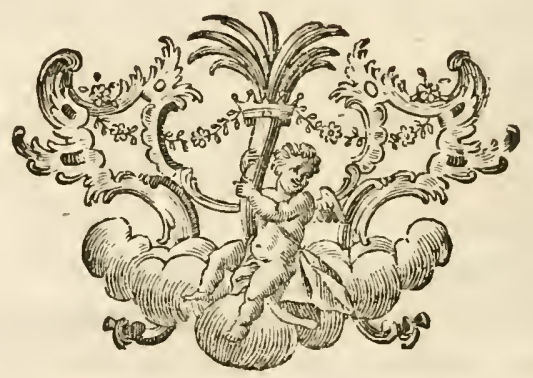




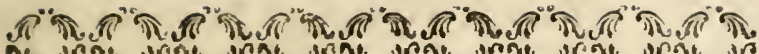

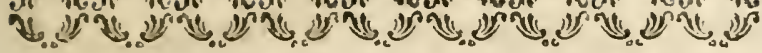

\section{II.}

Rev. Francisci Xaverit Wulfen

PLANT $\mathbb{E}$ RARIORES

CARINTHI ACÆ.

Cuntinuatio ad pag. I63. Vol. I.

IX.

HYPOCHERIS HELVETICA.

Hypochæris caule unifloro; foliis dentatis, hirfutis.

Hall. hif. helv. num. 2. tab. I.

Hieracium montanum foliis dentatis, flore magno. Bauh. pin. 128. prodr. 65.

Hieracium incanum tomentofum integro folio. Barr. ic. 233. Bocc. p. I47. t. 106. 
Hieracium alpinum latifolium, hirfutic incanum, flore magno, Cafparis Bauhini. Scheuchz. it. alp. 2. p. I35.

Per omnes hanc noftras alpes copiofe invenimus plantam, menfe Junio Julioque florentem ; in Sau-alpen inter Eberftein \& Wolfsberg; in alpe Görlizenfi inter Treffen \& Offiach; in Koralpe ad fanctum Andream; in alpibus Fladniz verfus Winterthal \& Eifenhut; in 'Taurero inter Malniz \& Gaftein; in alpibus Reichenavienfibus; inque Lcuntinis Schleinizenfibus \& Marenwaldenfibus. Igitur femper in alpibus; ubi nufpiam Hypocherin veram maculatam Linnæi reperi, quacum Hallerus, \& jam ante illum Scheuchzerus, confudit; etiamfi diftinxiffet utramque Cafparus Bauhinus; \& vere differunt, vel folo vifu facillime difcernendæ.

Eft autem noftræ huic radix perennis, fere fufformis, crafliufcula, fublignefcens, etiam divifa in crura, extus ex bruneo nigra, intus alba, lactefcens, unum (quandoque \& duos tresve caules) inter copiofiora folia radicalia efferens. Caulis plus minus fpithamam altus, totus rectus, furfum verfus incraffefcens, ut fub flore craffifimus fit, \& fiftulofus, teres, ftriatus, hiriutus, fim- 
fimplicifimus, femper uniflorus. Folia radicalia copiofa, lanceolata, integra cum oris repando-dentatis, fupra fubstusque hirfuta, nigro-maculata, fed non femper. Caulina pauca, duo aut tria, eaqque remota, felfilia, \& ipfa lanceolata, repando-denticulata, plana, hirfuta, tenfim minora. Flos unicus, terminalis, maximus, crecto-patens. Calyx cylindraceus magis quam rotundus, fquamis imbricatus aliquot ordinum, quam maxime inæqualis \& inordinatus, propterea quod fquamarum dorfum, $\&$ latera membranacea, proftent, atque fulcos longitudinales fat profundos intercipiant. Cæterum fquamæ hæ oblongæ funt, obtufe lanceolatæ, hirfutæ, dorfo carinatæ \& farctx; lateribus vero membrana latiufcula \& ferrata veluti alatæ. Adfunt etiam fquamæ exteriores nonnullæ, totæ membranacex alscque dorfo carinato; $\mathbb{S}$ hæ totæ longitudinaliter intra fulcos inter:orum fquamarum retrufx funt. Corollulæ copioffime omnes æquales, femiflofculof , ligulatæ, lonqæ, fiturate flavæ, quinquedenticulatæ, erecto-patentes, Lấ, ubi Itamina exoriuntur villofæ, villis ex albo luteis. Tubus corollæ gracilis, longus, albus. Filamenta quinq̨ue, capillaria, alba, brevia. Antheræ in cylindrum connatx, longæ, flavæ. Stylus ftaminibus altior, extra ftamina fla-

$$
\mathrm{D}_{2} \text {, vus, }
$$


vus, bifidus; ftigmatibus fimplicibus revolutis. Semina oblonga, ex ovata bafi fenfim attenuata, nuda, apice inftructa pappo feffili, plumolo. Receptaculum paleaceum, paleis lineari-lanceolatis, calycis longitudine, apicem verfus flaventibus \& fubferratis. Odor plantæ nullus.

\section{$\mathrm{X}$.}

IBERIS CEPEAFOLIA. tab. I.

Thlafpi montanum, ferrato Cepeæ folio, flore purpurafcente umbellato. Barr. rar. pag. 33. num. 365. ic. 848.

Thlafpi alpinum, folio rotundióre, carnofo, purpurafcente flore. Tourn. inft. $2 \mathrm{I} 2$.

Antequan defcriptionem elegantis hujus plantæ dem, prænotandum cenfui, eandem omnino, quam Barrelierus loco citato exhibuit cum exacta figura, præter doctum hunc Dominicanum notam quoque fuiffe Tournefortio; cæterum nulli adhucdum credo vilam. Sunma autem 
illius affinitas cum Iberide rotundifoliu Linnæi effecit, ut pro una eademqque paffin haberetur ab iis, qui rotundifoliam, licet alpinam, magis tamen obviam invenerunt; ceperefoliam vero haudquaquam viderunt. Primus hos inter Allionius Lepidium fuum caule repente, foliis ovatis amplexicaulibus, cujus bonam dedit iconem tab. 4. fig. I., eandem cenfuit effe plantan cum hac Barrelieriana; quia tamen Barrelieriana figura minus contentus fuit, ( \& quomodo potuifet alterius figura plantæ contentus effe?) novam ei fubftituendam exiftimavit. $A b$ Hallero fubinde admonitus, ad Lepidium fuum referendum etiam dixit Barrelieri Thlaspi fubrotundo folio, utriculo gruinali, ic. I $305 .$, idque jure, non enim nifi unam eandemque prorfus plantam hæ Barrelieri Allioniique icones exprimunt. Linnæus, cui neque hæc neqque illa unquam occurrit, fub uno Iberidis rotundifolix nomine utramque recenfuit, adduxitque tabulam 4. Allionii, \& iconem 848. Barrelieri; \&, quod maxime mirum, rejecit iconem 1305. Barrelieri. In eundem plane fcopulum offendit etiam Gerardus flor. galloprov. pag. 354 . Non tamen fic exactifimus Hallerus, quin illíco agnovit Iberidem rotundifoliam Linnæi, (quæ illi Lepidium num. 517. eft hift. helv. vol. I. pag. 222.) effe om-

\section{3}

nino 
nino Barrelieri Thlafpi $\mathrm{r} 305$. \& Allionii Ĺepidium tab. 4. fig. I. ; cumque jure furpectam haberet iconem 848 . Barrelieri, interrogavit præcife, an etiam inter fynonyma rotundifolix adduci debeat? Plane autem ignoro, quænam fit illa planta, quam cl. Scopoli flor. carn. vol. 2. pag. 15. num. 805. tab. 37. fub nomine Iberidis rotundifolix propofuit? Neque cepexfolian, neque veram rotundifoliam exprimit; imo neque cum propria auctoris defcriptione convenit; quæ enim folia caulina amplexicaulia in defcriptione afferit effe, in figura potius feffilia, absque hamulis, five auriculis caulem amplectentibus delineavit; \& alia.

Alterum, quod confiderandum hic venit, illud eft. Si quidem character Iberidis filiculam obcordatam aut in apice emarginatam exigat, tunc fane nec rotundifolia nec cepexfolia inter Iberides legitime recenfentur; ut nil dicam de eo, quod petala quoque omnia æqualia fint in utraque fpecie.

Iberidem rotundifoliam Linnæi in alpe Villacenfs inveni, qua ex Bleyberg verfus Lapidem fanctum vulgo Heiligenfein addcenditur, folo declivi, aprico \& ex fatifcen- 
tilcentibus faxis calcareis fabulofo; tum in alpibus Leontinis abunde; menfe Julio. Cepexfoliz vero non alibi adhuc vifa quam in valle Rabl, poft primum nivium deliquium, initio Maji, perquam copiofe ad fodinas calaminares \& unter der Vitriolwand five fub pariete vitriolico.

Cepææfolia radicem habet longam, (perennem?) teretem, fat gracilem, fungofam, in brachia divifam, $c \mathfrak{x}-$ terum nudam, extus ex violaceo nonnihil rubentem, oblique ferpentem ; cujus faporem veritus fum explorare, quum ne pecora quidem ullam fub pariete hoc plantam attingant. Ex fuperiore radicis parte caules plurimi hinc inde (furculorum inftar, qui tamen ad unam fere omnes altitudinem affurgant, vix dimidiæ (pitharmæ,) proveniunt, omnes proftrati, non tamen quaquavorfum diffufi; apicibus florentibus curvato-erectis. Sunt porro caules hi glabri, teretes, ex viridi magis magisque violaceo rubentes, foliofi, apice primum floribus corymbofo-umbellatis, tum racemofis \& diffitis. Folia copiofa, fparla, carnola, glaberrima, fature viridia, habitu nonnunquam glauco obducta, minus tamen quam in Iberide rotundifolia Linnæi. Inferiora obovato-oblonga, in petiolum vel- 
ut decurrentia, apicem verfus oris dentatis. Summa feffilia, oblonga, fubovata, integerrima, nullis auriculis caulem amplexantibus bafi aucta. Flores finguli pedunculati. Calyx tetraphyllus; foliolis ovatis, concavis, nudis, integris, æqualibus, extus ex viridi nonnihil rubellis, corolla duplo brevioribus. Hæc tetrapetala, cruciformis; petalis obovato-oblongis, patentibus, integris, æqualibus, coloris ex rubro violacei vulgo Lilac, bafi in unguem album decurrentibus. Flores eodem prorlus amcno odore pollent, quo flores Iberidis rotundifoliæ, \& quem miror a nullo auctore adnotatum fuife. Stanina fex, tetradynama; filamentis albis, fubulatis, calycem xquantibus, binis oppofitis brevioribus; antheris aquofe flavis. Germen orbiculare, nudum, obtufiffime convexum, fere planiufculum \& compreffum. Stylus brevis. Stigma capitatum. Silicula nuda, ex ovata bafi tetragono-pyramidalis, bilocularis, bivalvis; diffepimento valvulis contrario, lanceolato, ftylo permanente inttructo; feminibus binis in loculo quovis, iisque rufis. Ergo fllicula eadem, quæ in Iberide rotundifolia. 


\section{XI.}

\section{GEUM HYBRIDUM.}

Caryophyllata montana tertia. Cluf. hift. crv.

Caryophyllata aquatica floribus plenis magis rubentibus, foliis inferne quinis aut fenis herbaceis pulchre coronatis. Cam. epit.pag. 726. figuræ laterales.

Alpem inferioris Carinthiæ haud procul Pleyburgo Comitum a Thurn, vulgo Pezzen dictam, cum percurrerem die 10. Junii anni I 766 , reperi prope ftabula, bubus deftinata, plantam, eamque unicam, qualem adhuc nufquam alibi. Ad Caryophyllatarum pertinere familiam, illico obfervavi; fed, quod admirationem preprimis fecit, illud erat, quod una hacce in planta utrumque, \& montanum, \& rivale Linnæi Geum mihi fimul intueri viderer; unicus enim ex radice aphyllus caulis, feu potius fcapus, flore terminabatur fimplice magno \& nutante, cujus calyx de Geo montano, corolla vero de rivali potius defumpta videbatur. Hybrida, a patre Geo monta-

$$
\text { E }
$$




\section{4 \\ PLANTE RARIORES}

no, matre vero Geo rivali orta planta mihi tunc vifa; ac naturæ melius lufus in varietatum cenfum relegata a me fuerat. Aliud fubinde agens, opportune omnino in Clufii Caryophyllatas incidi, hasque inter pag. cIv. rar. plant. hift. Caryophyllatam montanain tertiam, a mea nihil abludentem, confpexi, cujus vir clariffimus, tanquam alius elegantis plantre, a Pennxo fibi communicate $\mathcal{E}_{3}$ jan Conrado Gefnero note, meminit. De eadem plane Caryophyllata cl. Scopoli loquitur, dum in prima Floræ Carniolicæ cditione pag. 572. num. 3. fingulare Gei montani monftrum, in Pompeagi montis pafcuis lectum, adducit. Sed neque Hallero ignota fuit, etfi hift. helv. vol. 2. pag. 52. num. II29. rivalis dumtaxat una cum Scopoli varietatem judicet. Utcunque res ifta fe habeat, verane Gei fpecies ab aliis diftincta? an varietas alicujus ex notis jam fpeciebus fit? pofteris conficiendum relinquo; idque ut eo præitent facilius, allatam mihi nuperrimis diebus, fed aliis prorfus ab alpibus, fcilicet Leontinis, plantam ad vivam pingi feci, \& fequentem adjeci defcriptionem, quum determinari poffet : Geum flore nutante; calyce foliofo, corollam polypetalim excedente. 
Radix perennis, oblique horizontalis, extus furfco-nigra, radiculis fibrofis, funium inftar, recta defcendentibus, una cum foliis radicalibus pluribus caulem unum aut plures educit, fpithamam longos, eosque aut fimplices aphyllos \& unifloros, aut foliofos \& inferne dumtaxat ramofos. Caules, rami, folia \& foliorum petioli, calycesque, hirfuta funt. Caules \& rami teretes, flore terminali, nonnihil nutante. Folia radicalia \& pauca ea, quæ plerumque in inferioribus caulis partibus ad ramorum exortum adeffe folent, longe petiolata, fubpinnata; pinna terminali maxima, ovata, plerumque triloba, per oras ferrato-dentata; pinnulis reliquis parvis, feffilibus, ovato-lanceolatis, alternis, dentatis. Stipulæ ingentes, foliaceæ, oblongæ, profunde fed inurdinate $\mathrm{f}_{\mathrm{i}}$ mul incifæ lobis oblongis \& ferrato-dentatis. Flos magnus. Calyx monophyllus, corolla major in octo, decem aut duodecim fegmenta patentia, foliacea, fublanceolata, ferrato-dentata \& alterna duplo breviora, profunde diffectus. Petala octo, decem vel diodecim, obovato-fubpedunculata, apice repando-emarginata, ereEto-patentia primum pallide ftraminea \& rubro-ftriata, tum magis magisque rubentia faturatiusque ftriata. Stamina calycina multa, corollis nonnihil breviora, erêta;

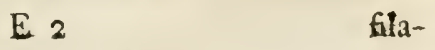


filamentis fubulaiis albis; antheris fubcordatis flavisque. Receptaculum in centro calycis erectum fubpedunculatum, obovatum, pubens. Germina copiofa, undique receptaculo infidentia, ovato-oblonga, villofa; ftylo longe caudato, \& ipfo villofo, apicem verfus rubro; ftigmate fimplice, nonnihil uncinato. Odor plantæ nullus.

\section{XII.}

\section{RIBES PETRIEUM.}

Crefcit, florens Julio, fructus perficiens Augufto, copiofe in alpibus Reichenavienfibus, fupra lacum Petaunfee dictum fub rupibus, \&c. Tum in Styriæ alpibus ad lacum Tiefingfee intra rupes, fub Winterthal \& Tur- : nau, magisque infra verfus Bergenhütten ad petras própe cafas equifonum; denique in Styria itidem, qua ex Turach verfus Stangalpen itur; \&c. Credidiffem equidem, Ribes hocce petræum a Ribes vulgari rubro flore, Clufii hift. pag. I I9. non differre, propterea preprimis, quod. fufpicari licuifet, Cluffum parum attendiffe ad notam racemorum pendulorum, aut erectorum, in Ribefiorum defcriptione, utpote qui recenfeat \& alpinum, \& vulgare, neque 
neque tamen vel verbo meminerit racemi penduli aut erecti, fed fructus tantum dulcis aut acerbi. Cum tamen Bотхฑห́́тxтоs Hallerus (quocun litigare nolim) fynonymum hocce Clufii ad Ribes rubrum Linnæi referat, in quo \& florentes jam racemi fomper funt penduli, coactun me video, fruticem hunc noltrum pro nova prorfus fpecie proponere, aliis adhuc ignota autoribus, cujus defcriptio fpecifica hac fit:

Frutex tres quatuorve pedes altus, cortice ex rubro nigrefcente, tandem cinerafcente, aculeis five fpinis nuspiam armatus. Racemi per ramos \& truncum undique fparfi, ex gemmis propriis folitariis, in flore femper ereहti,-quandoque etiam in fructu, fi videlicet una alterave hi uva onufti fint, at vero penduli, fi copiufas maturefecerint, ex earum pondere depreffi. Flores perquam elegantes, refpective magni, per racemos absque ordine fparfi, breviter pedunculati; pedunculis ex axilla braEteolæ minoris aut majoris, flores tamen nunquam adæquantis, minus fuperantis, prodeuntibus. Germen inferum, rotundum, viride, nudum; cui infidet calyx coloratus, fpeciofus, rofeus, nonnunquam fanguineus, monopetalus, pelviformis, femiquinquefidus, limbo rotato, pli- 
cis quinque faturatius rubris. Laciniæ magnæ, integræ, rotundatæ, fuberecto-patentes. Corolla pentapetala; petalis exiguis, albis, femiovatis, latioribus quam longis, rotundatis per oras, $\&$ integris; feffilibus fupra plicas calycis, \& alternantibus cum ejus laciniis. Filamenta quinque, inferta bafi laciniarum calycis, iis jue breviora, fubulata, alba. Antheræ fubcordatæ, flavæ. Stylus albus, ex conico fubulatus, rectus, antherarum altitudine, apice bifidus; Atigmatibus obtufufculis, arcuato-divergentibus. Вaccæ feu uvæ globofæ, magnæ, faturatiflime rubræ, læves, nitentes, apice coronatæ circello extante atro ex floris reliquiis, acidiffimæ, neque acerbitatem hanc cultura amittentes, cæterum fucci plenæ, \& minus quam in Ribes alpino Linnæi farinofæ aut glutinofæ. Folia, quamvis inter racemos quoque exoriantur, tamen pleraque extremitates ramorum occupant, ut racemi florigeri \& fructigeri ne videantur quidem. Et hæc fuis ex gemmis propriis enafcuntur, funtque multo ampliora illis Ribis alpini, ordinario triloba; lobis magis aut minus acutis, per oras ferratis ; cæterum nuda, primum læte viridia, tum ex virore nigricant; petiolo pilis longioribus ciliato. 
Ribes slpinum Linnæi copiofum in alpibus Carinthiacis, uti Fladnizenfibus, Reichenavienfibus, aliisque, reperitur ; etiam fpontaneum in humilioribus montibus, fic in Ulrichsberg prope Clagefurtum, prope Kreig inllocis profundis. Valet de eo obfervatio Jacquiniana, quod admodum luxuriet in floribus, fteriliorque tum fit in fructu; tum quod folia ejus a larvis lepidopterorum intacta ınaneant, dum illa Ribefii hortenfis \& petræi penitus devaftantur. Reverendus Leykauf, parochus nuper ad fanctum Laurentium, nunc Strasburgi, in utroque fuo ibidem horto plura inftituit experimenta inoculationis infitionisque. Ribes alpinum, inoculatum fuper Ribes hortenfi aut petræo, nunquam propagari potuit; fed neque hortenfe aut petræum fuper Ribes alpino. Contra petræum fuper hortenfi, \& hortenfe fuper petræo, optime profecerunt; naturam tamen nunqquam mutarunt ratione floris \& faporis. Ribes petræum per multos annos cultum intolarabilem fuam aciditatem \& acerbitatem non amifit; femel fructus albos dedit. Ribes hortenfe, rubrum Linnæi, rarum eft in Carinthia fpontaneum; crefcit tamen ad acervos lapidum in mediis agris fegetalibus Reichenavienfibus, aliisque in locis nonnullis, in quos certiffime humana indultria non transmigravit. 
Animadverfio editoris. In borto Botanico Viennenji jam per lonaam annorum feriem a larvis Phalence groffulurix depajcitur quotannis Ribes rubrum, dum in proxime adftante alpino ne folium unum l.editur.

\section{XIII.}

LASERPITIUM SIMPLEX. tab. 2. Linn. fyjt. pag. 2 Io. mant. pag. 56.

Laferpitium foliis triplicato-pinnatis, pinnulis lanceolatis; involucris femitrifidis. Hall. hift. helv. num. 796. Laferpitium fcapo fimplice, aphyllo; foliis radicalibus bipinnatis; pinnis multifidis; umbella fubglobofa; foliolis involucri trifidis. Sic ego determino.

Primum in fuperioribus apricis jugis alpis Melbingenfis in difrictu Gmindtenfi ultra pagum Malta inter Ranunculum rutæfolium, Aftragalum campeftrem, aliasque elegantiffimas plantulas alpinas; tum in Taurero Nafsfeldenfi locis confimilibus, una cum Ophry alpina, Ceraftio latifolio, aliisque", menfe Julio læte florentem magna in copia inveni. Facies Phellandrii Mutellinæ, 
quocum etiam hocce in loco vegetat. Radix longa, ramofa, multiceps, extus ex fufco nigra, intus alba, odore, ut mihi quidem videbatur, corticis peruviani, quovis ex capite inter capillitium porcino-fetofum (reliquias femitabidas foliorum annotinorum) caulem unum pluraque funul attollit folia. Caulis, aut fi mavis fcapus, fimplicillimus, dimidiæ circiter fpithamæ altitudine, erectus, apliyllus, lævis, fulcatus, cætera teres, apice umbella unica, eaque compacta \& hemifpherica, teminatur. Umbella tum univerfalis, tum partialis quævis, fupra conve$\mathrm{xa}$, radiis a duodecim ad viginti, femipollicaribus, teretibus, ftriatis. Involucrum univerfale, radios æquans, ab octo ad dodecaphyllum; foliolis linearibus, planis, apicem verfus latefcentibus, atque tri-quadri-vel quinquefidis; laciniis acutis \& integris. Involucrum partialium umbellularum cum proportione fimile univerfali ex foliolis fmplicibus, bifidis trifidisque mixtim. Germen inferum, nudum, erectum, friatum, ex viridi cæruleonigricans, compleitens femina bina, hinc convexa \& membranulis quatuor longitudinalibus alata, incle plana; calyce exiguo \& quinquedentato coronatum, aique inter calycis lacinulas gibberibus binis nigio-carulefcentibus, fuffilibus. Petala quinque, æequalia, ex ie ianceolata, 
verum, apice furfum inflexo, in obverfum corculum conformata, primum atrorubentia, tum rubra, denique maturitate alba. Styli duo albi \& longiufculi cum ftigmatibus fimplicibus. Stamina quinque, petalis longiora, alba; antheris nigrocærulefcentibus. Folia tantum radicalia, bipinnata, ex axe communi longo \& fupra canaliculato. Pinnæ trifidæ, quinquefidæ, nonnunquam etiam multifi$\mathrm{d}$; laciniis linearibus, planis, anguftis, acutis. Villus in tota planta nullus.

Animadverfio editoris. Duo hujusce plantule fpecimina inveni ad prima obvia pineta depreffa in primo jugo, dum ex Kaltenwaffer adfienditur ad Schneeberg, anno I 760, inter Phellandria Mutellinas crefcentem. Semine non vifo, at involucri diverfitate motus, aliane planta, an Mutellines effet monftrum, pronuntiare non audebam. Quare ad Linnoxum mifi, qui tandem poft Halleri luftratas Emendationes Syftemati fuo Mantifreque locis fupra citatis intulit. Poft duodecim ab illo tempore in eundem locum infituta itinera alpina plantulam ultra detegere non potui; que nec alibi hucusque in alpibus noftris inventa, rariffimas inter Auftriacas numerari meretur. 


\section{XIV.}

PHACA AUSTRALIS. Tab. 3. Linn. Jyft. 497. mani. pag. $\mathrm{IO}_{3}$.

Fhaca caulefcens diffufa, pedunculis longiffimis, leguminibus femiovatis. Ger. prov. pag. 519.

Aftragalus caule ramofo proftrato; foliis lanceolatis; florum alis emarginatis. Hall. hif. helv. num. 403 .

Aftragaloides alpina fupina glabra, foliis acutioribus. Till. pif. pag. 19. tab. I4. fig. I.

Speciofifimam plantam, amœnis variantem coloribus, fibique ipfi vel fola ætate diffimilem, pluribus in locis læte vegetantem inveni; ac primum quidem in altiffima prope Pontebam Auftriacam (haud dubie \& in adfitis Venetis obviam) alpe, Trigel aut Trog vulgo dicta, ad fummum cacumen initio Julii, \& ferius, atque hic quidem vix fpithamæ dimidiæ altitudine, totam erectam, glabram, floribus ex albo in luteolum languentibus, vere ochroleucis, Dein in alpibus Reichenavienfibus ad fanEtum Laurentium hinter den zween Speichiogeln, liber dem

$$
\text { I. } 2
$$


Petauer Seo in fic difto Garten (alpis eft) fub altifima alpe Prett nuncupata inter Tozziam alpinam, Hedyfarum obfurum, Ceraftum alpinum \&c. poft medium Junii, caulibus proftratis plus quam fpithamalibus, foliis fubtus villofis, villis tamen denique evanelcentibus floribus albis. Tum Leontii initio Julii in Isl-au maxima in copia promilcue cum Attragalo uralenfi, alpino, \& campeftri, cum Herniaria glabra \& hirfuta, cum Hippophai rhamnoide, \&c. \& quidem triplicis varietatis : prima floribus flavis, foliis villolis, quæ minor \& rarior erat; fecunda çaulibus bafi procumbentibus, floribus albis, foliis primum fubtus villofis, tum glabris; tertia caulibus bafi procumbentibus, foliis fubtus villofis, tandem glabris, floribus læte rubentibus, ut flores Ononidis rotundifoliæ effe folent. Omnes hasce varietates in unam fpeciem conjungunt ale floris femibifidx. Denique in alpe Marenwald prope Leontium, atque ibi floribus albis, foliis totis hirfutiflimis, \&c. Varietas rubra, omnium elegantiffima, nifi ipfo in loco, ubi floret, pingatur, vix aut ne vix quidem bene pingetur; tenerrimus enim ille ruber color in violaceum \& cærulefcenten denique abit. Defcriptionem ad Reichenavienfia \& Leontina exemplaria fequentem conltruxi.

Radix 
Radix perennis, compofita, multa in brachia teretia clon rata \& ipla fibrolo-ramofa abiens, coloris extus flavo-argillacei, intus albi; viminis irltar lenta, tandem fuljlignelcens, ad fuperficiem terræ cefpitem integrum caulium novorum quotannis producit, præter fuperftites anni fuperioris nonnullos caules rigidos \& lignofos. Sunt vero illi caules novelli ab una ad duas ulque fpithamas alti, ramofi, bafi procumbentes, inde ereEti, donec toti prolternantur, teretes, Atriati; primum virides \& pube albida obfiti; dein fere nudi \& ex viridi rubefcentes; tandem rubri, præprimis in inferioribus, fublignefcentes, rigidi; denique dilute fufcefcentes \& fufci. Folia alterne fparfa, pinnata, jugis pinnarum a quinque ad octo, etiam decen, cum impare; pinnis fefrilibus, lineari-lanceolatis, integris, ex glanco fature virentibus, initio fubtus $\&$ ad ora molliter villofis, fed ob villos evanefcentes demum glabris \& lævibus. Stipulæ ovato-acutæ aut ovato-lanceolatæ, integræ, ex viridi fubrubentes. Rami axillares, longi, aphylli, ex viridi magis magisque rubentes, \& pubentes, denique nudi, terminati in fuicam florum ab octo ad duodecim, initio fatis compactam, \& velut ovatam, dein vero ad unum alterumve pollicem diductam. Flores brevifime peduncu- 
46 PLANTT RARIORES

lati ex axilla brafteolæ anguftifimæ lineari-lanceolatæ \& fere fibulatæ, primum erecti, fed in fructum abeuntes penduli. Calyx tubulofus, ovato-cylindraceus, fub vexillo aliquantum gilsbus, ex albido virens, villofulus, villis demum nigris, re ipfa quinquedenticulatus; binis fummis denticulis, qui fub vexillo efle deberent, ab invicem remutilinnis, \& alis florum potius refpondentibus; tribus infimis approximatis, nonnihil longioribus. Corolla papilionacea, flavens, aut ochroleuca, aut alba, aut dilute rofea. Vexillum longius reliquis petalis, emarginatum, lateribus furfum revolutis, compreffum, ut velut lineare reddatur, licet obcordatum fit. Alæ oblongoovatæ, femibifidæ, pedicellatæ cum ungue feu denticulo laterali. Carina bipes, adfcendens, obtufa, apicem verfus rubra, aut ex rubro violacea. Stamina decem, diadelpha. Antheræ aurex. Germen teres, glabrum. Stylus incurvus. Stigma capitatum \& album. Legumen pedicellatum; initio teres, anguftum, \& erectum; tum pendulum, veficarium, cylindraceo-ovatum; denique ovale, latiufculum, inflatum, fufcum; femper glabrum, uniloculare, bivalve. Semina a duobus ad decem. 


\section{$\mathrm{XV}$.}

ANEMONE APIIFOLIA. tab.4. Scop.carn. I.pag. 385.

Anemone foliis triplicato-pinnatis, acute circumferratis; caulinis ternatis; tubis caudatis. Hall. hift. helv. num. I I 49. $\beta$.

Anemone fylveftris tertia. Cluf. hift. I. pag. 245.

Pulfatilla lutea. Camer. epit. pag. 393. Gefn. ic. cen. 18.

Pulfatilla lutea apii hortenfis folio. Bauh, hifl.3. pag. 4I I.

Pulfatilla tertia alpina. Dalech. hifl. pag. $85 \mathrm{r}$.

Pulfatilla lutea paftinacx fylveftris folio. Bauh. pin. I 77 .

Hallerus in Enumeratione ftirpium Helveticarum feparavit ab Anemone alpina Linnæi, in Hiftoria dein iterum conjunxit. Veteres diftinxerunt; fic etiam clariffinus Scopoli. Rectene? an perperam? Ego quidem ex coloris diverfitate fola fpecies multiplicare non foleo; atque fic cenfeo: Si nunquam ex feminilus Anemones apiifoliæ, five paftinacæ fylveftris folio, five longe melius chærophylli hirfuti folio, alpina Linnæi enafcatur, nec vicifim; fi neque ex radice cujus demum cunque earum alte- 
altera; aut una eademque ex radice hoc anno alpina, altero paftinacæafolia prodeat; denique fi folia paftinacæfoliæ femper magis compofita, femper anguftiora, magiscue difciffa \& diffecta fint; tunc enimvero argumenta norn deeffe luculenta fpecifice inter utramque diverfitatis. Radix fufformis, nigra extus, fuperne divifa in unum, duo vel tria capita fetofa ex petiolis fuperiorum annorum, toticlem effert caules fimplices, fpithamæ circiter altitudine, ereetos, teretes, bafi rubentes \& villo copiofo cano hirfutos, apice unifloros, aphyllos, fed involucro magno foliofo paulo fupra mediam altitudinem circumdatos. Involucrum bafi circa caulem connatum, denfe hirfutum, triphyllum; foliis tripinnatis, chærophyllo fylveftri æmılis, finguilis ex communi petiolo ftipulari fulbmembranaceo latiufculo fubvaginali \& brevi in tres magnas \& petiolatas pinnas divifis; quarum rurfus quævis tripartita, pinnulis ipfis fubfeftilibus, lanceolatis, pinnatifde ferratis; dentibus oblongis, acutiufculis, planis, integis. Folia involucri una cum petiolis fuis fupra nuda, atro graminis virore colorata; fubtus vero, villo longo, denfo, cano hirfutifima. Folia radicalia aliquot, a duobus ad quatuor, tripinnata, fimilia foliis involucri, nifi guod fint smpliora, \& petiolo gaudeant communi dimidiæe fere fpithame, 
thamæ, bafi vaginali \& fature fanguineo. Flos magnus, calyce deftitutus; petalis fex vel feptem, xqualibus, patentibus, integris, lanceolatis, firmis ac veluti fubcoriaceis, in omni ætate fulphureis, extus denfe hirfutis, facie fupera glabris \& longitudinaliter copiofeque lineatis cum lineis longe bifidis, alternis interioribus. Stamina numerofifina, triplo petalis breviora, filamentis fubulatis, una cum antheris oblongis, flava. Germina in capitulum ovatum feflilia, multa, ovato-acuta, in ftylum apice rubentem longumque terminata, \& una cum ftylo cano-vil1ofa. Stigmata obtufa, fubcapitata, luteola. Receptaculum ovatum, foraminulis pertufum. Semina ovato-acuta, villofa, longe caudata; caudis villofis; villis cinereo-canis, denfis, extantibus, fimplicibus; \& hoc demum fenfu caudæ feminum dici plumofæ poffunt, Odor nullus. Crefcit in alpibus Leontinis.

\section{XVI.}

SAXIFRAGA BRYOIDES. Tab. 5. fg. 1. Linn. $\int y /$ t. pag. 303. Scop. carn. I. pag. 295. tab. I5. 
Saxifraga foliis lanceolatis, ciliatis, compactis; caule unifloro. Hall. hift. helv. num. 969.

Saxifraga pyrenaica ininima lutea, mufco fimilis. Tourn. inft. 253 .

Sedum alpinum quartum. Col. ecphr. 2. pag. 66. Sedum mufcofum. Bauh. hift. 3. pag. 695. Scheuchz. it. alp. I. p. IO. E 2. p. I 42. t. 21.f. 2.

Floret Julio perquam copiofe in petrofis afperis alpinis Folkartenfibus, Reichenavienfibus, Fladnizenfibus, præprimis ad adfcenfum fcalarem vulgo laiterfteig, inque alpibus Leontinis, Spitalenfibus, \&c. Una eademque de radice cefpites integri caulium plurimorum enafcuntur. Argillacei feu cano-flaventis coloris radix teretiufcula eft, \& horizontaliter oblique repit. Caules fimpliciffimi, unum ant femialterum pollicem alti, parte inferiore intra terram confepulti, \& ipfi nonnihil procumbunt, foliis denfifime imbricatis ac furfum conniventibus veftiti, ipfa in telluris fuperficie in rofulas fubglobofas fediformes abeuntes. Foliorum horum pars maxima, utpote terræ identidem immerforum, femitabida eft; quæ vero ultra fuperficiem terræ eminent, e luteo virent, non inflexa aut renexa, fed furfum potius conniventia, cæteruquin linearia, 
scutiufcula, glabra, fupra plana, fubtus nonnihil convexula, integerrima, oris breviter ciliatis, ciliis mollibus. Cujusque de rofulæ centro caulis continuatur, isque ereEtus eft, teres, obfcure rubens, tandem \& ipfe e luteolo virens, glaber, foliis fparfis, anguftiflimis, feffilibus, 1inearibus, erectis, luteo-virentibus, fubtiliffime per oras ciliatis. Flos terminalis, in quovis caule unicus, isque magnus \& erectus. Calyx inferus, profunde quinquepartitus; foliolis erectis, concavis, integris, nudis. Corolla rofaceo-patens ex petalis quinque, ovato - lanceolatis, integris, calyce duplo longioribus trifte velut e luteolo albidis, \& fupra bafun aurantiaco-guttatis, guttulis in quovis petalo pluribus confertisque. Filamenta decem, petalis paulo breviora, fubulata, alba; antheris aurantiacis. Germen e fundo calycis adfcendens, album, erectum, ovato-acutiufculum, apice incifum, ftylo nullo, ftigmate bifido. Capfula unilocularis, bivalvis, \& ftigmatibus tandem divergentibus biroftris. Semina copiofa.

\section{XVII.}

ASPLENIUM ALTERNIFOLIUM. Tab. 5. fig. 2.

$$
\text { G } 2 \text { Afple- }
$$


Afplenium caule pinnato, pinis imis trifoliatis, fuperioribus fimplicibus, dentatis. Hall. hift. helv. num. I690. Adianthum novum germanicum, Rutæ murariæ facie. Breyn. cent. I. pag. I89. ic. 93.

Crefcit copiofe circa Klein-Kircheim, Radentheim, Milleftadium, \& in monte Creutzberg afcendendo verfus Fladnitz; femper ad latera faxorum ex quarzo, mica, fteatite \&c. compofitorum, vegetatque promifcue cum Acrofticho feptentrionali. Cefpites frpe magni, radiculis fufco-nigris, adınodum tenuibus, fat longis, iisque compofitis, invicem implexis intertextisque; e quibus feges, integra frondium bi-\& tripollicarium fimpliciunque enafcitur. Frons quævis annua de more gentis fpiraliter fe evolvit, tum erecta perfiftit, tamen unam verfus partem nonnunquam procumbunt omnes. Cæterum nudæ, nullo villo, fed nec ulla pube veftitæ, firmæ, rigidulæ, nitentes inferne aphyllæ atropurpureæque, furfum verfus læte virentes; foliolis planis, alternis, remotiufculis, feffilibus, obovatis feu cuneiformilus, apicem verfus incilo-dentatis. Fructificationes in pagina averfa feu inferiore per lineas longitudinales difponuntur. Cuticula fcilicet linearis, ad folii axem five longitudinem potius, obliqqua, primum albida, 
bida, tum ex albido virefcens, demum fufca, latere externo adnata folio, interiore hians aut libera, tegit globellos feminiferos, longitudinaliter difpofitos, fubfeffiles, colore fucceflivo cuticulæ.

Animadverfio editoris. Plantulam hanc jam olim crefontem inveni in Auffria circa Glocknitz in rupibus calcareis, etiam mixtin cum Acrofticho feptentrionali. Cum beatus Linnceus, quocum communicaveram, mordicus fuffineret, meram effe Rutce murarix varietatem non aufus fui pro nova fpecie proponere, $\mathcal{E}_{3}$ omiferam in Stirpiun agri Viennenfis Enumeratione.

\section{XVIII.}

SWERTIA CARINTHIACA. Tab. 6.

Plantula, fi qua alia, longe fpeciofiffima, nuffquam adhucdum quam in Grofskirchheimii alpibus mihi vifa, abunde fupra Sagriz \& Döllach in altifimis alpiun jugis apricis lapidofis inter Mocher \& auriferum Wafchgang. Medio Augufti læte florentem una cum Gentianis nivali \& amarella aut campeftri pluribusque aliis inveni, atque

$$
\text { G } 3
$$

eodem 


\section{PLANTE RARIORES}

eodem tempore, fed adınodum raram, horæ circiter fpatio ultra Tabor in valle, in der Fleifs, vulgo dicta, qua verfus glaciatos montes Goldzech itur.

Radix amnua, alba, aut pallide ex argillaceo flavens, nonnunquam tenerrima \& capillaris, dum caulis uniflorus \& fimpliciffimus, alias majoris acus craffitudine, femper in alias graciliores radiculas divifa, tandem lenta rigida \& fubligneicens. Ex hujus capite modo cauliculus fimpliciffimus, modo bini tresve, aut etiam plures ufque ad quindecim \& ultra, bafi ipfa aut prope bafin uniti, prodeunt, \& veluti ex procumbentibus eriguntur. Villus in tota planta nullus; imo glaberrima potius eft \& fubnitens. Folia ad radicis caput per binas conjugationes oppofita, feffilia, integerrima, patentia, ovato-oblonga aut lanceolata, \& obtufa. Caules duorum, ad fummum trium pollicum, ex tereti fubancipites, præcife pau1o fupra bafin foliis binis oppofitis feffilibus radicaliumque fimilibus ornati, fupra folia atrocærulei. Flos terminalis, unicus quovis in caule, magnus ratione plantulæ, ante florefcentiam globofus. Calyx monophyllus, ad bafin ufque quinquepartitus : foliolis æqualibus, fubcoriaceis, ovato-lanceolatis, corolla nonnihil brevioribus, tandem 
horizontaliter patentiffimis, corolla adhucdum in globum fature violaceum contracta. Et ipfa corolla monopetala eft, fegmentis ad bafin fere ufque partitis, tandem in flellam patentiffinam explanata; laciniis lanceolatis, integerrimis, fupra cæleftino-cæruleis, extus fecundum totam longitudinem interiorem albidis, fecundum exteriorem vero initio fature violaceis, tum ex cæruleo virentibus; intus ad bafun nectario fetofo coronatis, fetulis albis. Stamina quinque, pallide cærulefcentia, petalis breviora. Antheræ oblongæ, obtufufculæ incumbentes, cæleftinæ. Germen columnare, quinquangulo - pyramidale, obtufum. Stylus nullus. Stigma incifum; feu potius germen apice bifariam dehifcens in duo ftigmata obtufa. Capfula tandem ultra petala emergens, quinquangulo-tertiufcula, unilocularis, bivalvis, ab apice bafin verfus dehifcens. Semina copiofa, parva, argillaceo-luteola. Odor plantæ nullus. Rarius una quinta pars numeri in omnibus floris partibus deficit.

\section{XIX.}

\section{ANEMONE FRAGIFERA.}


Anemone feminibus lanatis; foliis caulinis ternatis, triplicato-trifidis; lobulis lanceolatis, acute trifidis \& bifidis. Hall. hiff. helv. num. II 5 I.

Anemone alpina alba minor. Bauh. pin. х 76 . prodr. 94 .

Crefcit in alpibus Scleiniz prope Leontium, \& Mocher fupra Döllach in Grofskirch heim. Radix perennis, lignefcens, extus nigra, intus alba, multiceps, radiculis accefforiis infructa. Folia radicalia quovis ex capite multa, quatuor, fex, \& ultra, longe petiolata, petiolo (faltem initio) hirfuto, fubtriplicato-ternata, aut, fi mavis, bis tripartita, lobis profundius \& inæquabiliter bivel trifidis \& per oras inordinate dentatis, cæterum latiufculis, planis, ovato-lanceolatis. Hirfutiem folia tandem magna ex parte exuunt. Scapus e centro foliorum radicalium fimplex, dimidiam fpithanam frpe non excedens, teres, erectus, firmulus, ex rufo virens, tomentofo-hirfutus, aphyllus, nifi quod ad tertiam altitudinis partem fupra radicem involucrum habeat foliofum, ex foliis bafi connatis, hirfutis, uti radicalia divifis, fed lobis magis lanceolatis, etiam dentatis. Flos terminalis. Calyx nullus. Petala a quinque ad feptem, alba, oblonge ovalia, extus hirfutula \& ex parte dilute purpurafcentia, de- 


\section{CARINTHIACE.}

cidua. Filamenta numerofa, receptaculi bafi affixa, petalis breviora, alba. Antherx flavx. Germina numerola, receptaculo ovato mediocri undique infixa, feffilia, ovata, ex denfa \& tomentofa hirfutie velut inflata, hirfutie ex alba tandem fufca. Stylus breviffimus, nudus, ex nigro rufefcens. Stigma fimplex. Dilapfis petalis receptaculum germinibus onuftam fpeciem fragi refert; unde denominationis fpecificæ rationem defumpfi. Odor plantæ nullus.

\section{XX.}

\section{PEDICULARIS ROSEA.}

Pedicularis pinnis foliorum acute pinnatis; floribus obtufis, purpureis, fpicatis. Allion. rar. I. pag. 52. tab. 12. fig. I.

Copiofe crefcit, \& floret menfe Julio, in folo aprico calcareo-arenofo, in fummitate alpis Villacenfis prope I.apidem fanctum, qua in Bleyberg adfcenditur; tum etiam in jugis lupremis alpis Kibeggenfis, una cum Pæderota cærulca, aliisqque plantis rariffmis. Radix ramofa, 
ex albo flavefcens, unum, duos tresve erigit caules inter folia radicalia copiofa, quæ caulibus haud multo breviora effe folent; frondes bipinnatas ianceolatas diceres. Sunt vero pinnæ admodum anguftx, lineares, pinnatifido-denticulatæ, feffiles, planx, utrinque magnitudine decrefcentes, nudæ, fupra fature virides, fubtus aquofe virentes, affixæ axi communi, primum viridi, tum e virore rubenti, denique atropurpureo. Folium in caule unicum, fummum dıo, quoad omnia radicalibus fimile, fed longe minus. Caulis erectus, ex tereti fubangulofus, colorem mutans uti axis foliorum, glaber \& nitens, verfus fpicam tamen albo-villofus, faltem prima in ætate. Spica florum terminalis, brevis, compacta, floribus fingulis breviter rubro-pedicellatis ex axilla bracter foliofx, calycen fere fuperantis, viridis, pinnatifido-dentatx; dum tamen dentes fupremarum bractearum ad duos vel \& unicum numero decrefcant. Calyx ex ovata bafi tubulofe cylindraceus, quinquedentatus, dentibus æqualibus, fimplicibus, acutis, una cum nervis longitudinalibus tubi rubentibus. Cæerum viret quidem calyx, fed ex villis lanuginofis albis \& diaphanis albent. Corolla elegans, rut bra, perfonata; tubo calycem excedente, ex rubro in album emoriente. Galea fature rubra, obtufiffima, recta; 


\section{CARINTHIA C.E.}

compreffa, femiclaufa, fub apice demum bifida. Labium inferius trilobum, lobis rotundatis, medio nonnihil breviore, omnibus integris. Filamenta didynama, alba. Antheræ flavæ, parte antica ad fe mutuo appreffr, oris lateralibus albo-villofis, "qui villi extra galeam prominent. Stylus albus, apice rofeus ; ftigmate obtufiufculo \& fubluteolo. Reliqua, uti in congeneribus.

\section{XXI.}

\section{ASTRAGALUS LEONTINUS.}

Circa Leontium in arenofis prope Ifolam crefcit, floretque Julio. Caulis procumbens, inferne ramofus, ex tereti ftriatus, primum villis proftratis obfitus, qui tandem fere evanelcunt. Stipulæ breves, ovato-lanceolatæ, femiamplexicaules, ex viridi fubrufæ, tum exoletæ. Folia pinnata; pinnarum paribus etiam decem \& ultra cum impare; pinnis fubfeffilibus, oblongo-ovalibus, integerrimis, planis, fupra at magis infra pubentibus, pube proftrata tandemque fe magnam partem pendente. Rami folia excedentes, elongati, aphylli; apice florum fpicam elevantes. Flores papilionacei, breviffime pedicellati ex 


\section{0

bracteola lineari-lanceolata \& pedicelli longitudine, ereहti. Calyx tubulofo-campanulatus, quinquedenticulatus, nigro-villofus, denticulis fubæquaỉibus, lineari fubulatis, fummis duobus fub vexillo conniventibus. Vexillum reliquis longius, obcordatum, lateribus furfum plicatis, ex albo dilute cærulefcens. Alæ carina nonnihil breviores, integræ, oblongo-fubovatæ, dente laterali obtufo inftruहtæ, infidentes ungui longiufculo, verfus carinam conniventes, albidæ cum cærulei emorientis tinctura. Carina bipes, obtufa, adfcendens, apicem verfus fature cærulea. Filamenta diadelpha, cum antheris flavis. Legumina ovata cum dorfo leviter impreffo, villofa, erecta, ad apicem ex ftylo refiduo veluti uncinata. Odor, qui adnotari mereatur, nullus. Colore Galegam officinalem æmulatur.

\section{XXII.}

\section{WULFENIA CARINTHIACA. Tab. 8. fig. I.}

Planta alpina ex claffe Diandrarum monogynarum flore infero, monopetalo, irregulari; fructu capfulari. Ad Pinguiculæ aut Utriculariæ genus pertinere non poteft, eo quod 
quod corolla, etiamfi fit ringens, tamen calcarata non fit, \&c. Sed neque Diantheris adnumerari, ob unicam in quolibet filamento antheram; tum ob alia. Ne Jufticia fit, defectus unguis elaftici in capfula facit. A Veronicis differt corollis non rotatis, fed perfecte ringentibus; tubo corollæ non breviffino, fed potius elongato; limbo non quadripartito, fed bilabiato; \&c. Cum Pæderota, fateor, plurimum convenit calyce capfulaque; difcrepat tamen fructura \& habitu corollæ, tum antheris. Corolla Pæderotæ fubringens, fauce maxime hiante, limbo participante fere æqualiter cum floribus rotatis quadrifidis \& cum floribus bilabiatis ringentibus. Contra plantæ noftræ corolla exacte bilabiata ringens, fauce fere claufa; labio fuperiore breviore fupra faucem ita furnicato, ut eandem una cum antheris penitus occultet fig. $a, b, c$. Diveritas altera utriusque corollæ hæc eft: qquod labium cum fuperius, tum inferius, in Pæderuta fit nudum; contra vero labium inferius plantæ noftrx a fauce usque ad mediam fere altitudinem fit barbatum. Tertio filamenta Pæderotæ tandem corollam excedunt, \& fere divergunt, antherasque furpendunt cordatas. Ex adverfo filamenta in noftra funt breviffima, ad fe invicem arcuato-conniventia, labio fuperiori infixa, illudque nunquam imo nec faucem

$$
\mathrm{H}_{3} \text { adæ- }
$$


adæquantia; \& antheræ fubovatæ, integræ, tandem ab apice usque ad bafin in duo hemifphæriola concava patentifima dehifcunt.

Concludo ex prædictis, plantam hanc novum prorfus Diandrarum monogyniarum conltituere genus, medium inter Pæderotam \& Jufticiam, cujus character erit fuccinctus: Corolla ringens, ecalcarata, femihians, ad faucem barbata. Completus vero erit, qui fequitur:

CAL. Perianthium monophyllum, quinquepartitum; foliolis linearibus, æcualibus, erectis, perfiftentibus. Cor. monopetala, ringens, ecalçarata. Tubus bafi fubglobofo-gibbus. Limbus bilabiatus: labium fuperius brevius, integrum, fubfornicatum, antheras occultans, faucemque femiclaudens. Labium inferius duplo longius, fupinum, trilobum, ad faucem barbatum. StA . Filamenta duo, brevia, arcuatim conniventia, fub labio luperiori recondita. Antheræ fubovatæ, integræ, ab apice usque ad bafin in duo hemifphæria concaya patentiflima dehifcentes. 
Prst. Germen oblongo-ovatum, apice compreffum. Stylus filiformis, longiffimus. Stigma capitatum, umbilicatum, papillofum.

PER. Capiula ovalis, obtufa, apice compreffo, utrinque fulco impreffo, bilocularis, apice dehifcens, quadriralvis, diffepimento nullo; receptaculo intra loculamenta fubpyramidali.

SEM. complura, rotunda.

Radix perennis, fpithamam \& ultra quandoque longa, a quatuor ad fex lineas craffa, fufformis, fed femper horizontalis, plures etiam caules ab invicem remotos efferens, coloris extus ex albo flavi \& ex flavo magis magisque fufcefcentis, copiofiffimis undique \& longis iisque rurfus compofitis fibris feu radiculis, funium inftar deorfum tendentibus, \& concoloribus inftructa. Caulis aut fcapus potius, ab una ad duas usque fpithamas altus, teres, farctus, viridis, albovillofus, tandem nudus, aphyllus, fed foliorum loco fquamulis foliaceis remote fparfis lanceolatis feffilibus fenfimque minoribus præditus, apice in Ipicam florum, duos tresve pollices longam, heteromallam feu fecundam, \& velut difticham, abiens. Duæ ergo florum feries, unum omnes latus fpectantes. Flos 


\section{PIANTE RARIURES}

quisque, breviter pedunculatus, ex axilla bracteolæ linearis angufte pedunculumque paulo excedentis oritur; ut adeo dorfum fpicæ florentis ex duabus feriebus braEteolarum erectarum, fibi mutuo velut incumbentium conftet. Brafteæ nudæ ex virore fufcefcunt tandem. Hoc etiam calyx colore gaudet. Petalum eft cæruleum; barba labii inferioris nivea denfa \& crifpa. Filamenta ex albo cærulefcunt. Antheræ primun cæruleæ, deinde fufcæ. Pollen albet. Stylus pallide cærulefcit, infima parte perfiftens. Stigma ex albo flavefcit. Capfula matura fecundum fulcum $a b$ apice verfus bafin. dehifcit in valvulas duas, fere naviculares, nullo diffepimento intermedio, ipfa tamen bafi cohærentes in protuberante communi receptaculo. Valvula demum quævis \& ipfa ab apice verfus bafin plus minus dehifcit; unde non immerito capfulam bilocularem, quadrivalvem dixeris. ' $U_{t}$ primun corollæ deciderunt, pedunculi fructigeri eriguntur, cauli nonnihil apprimuntur, \& relicta facie fpicæ heteromallæ, eundem undique fparfi cingunt. Folia tantum radicalia, eaque copiofa \& nragna, craffa, pinguiufcula, oblongo-ovalia, obtufa, in petiolum velut decurrentia, oris crenatis, plana, fature viridia, glaberrima, \& nitentia; fupra media longitudine velut canaliculata \& rubra; 
rubra; fubtus nervo medio protuberante albido \& villofo. Odor nullus. Saporem non exploravi. Crefcit \& fluret abunde medio Julii folo pinguifimo in alpe Kibeggenfi vallis Gilienfis prope fanum fancti Hermagoræ (vulgo Ermachor aut etiam Michor) paulo fupra fuprema paftorum mapalia, dum jam ultimæ, \& excelfæ, ac fere inacceffibiles illæ rupes calcareæ non fine omni vitæ difcrimine confcencluntur; a paftoribus alpicolis Hundszunge vulgo dicta.

In figura exhibentur:

a Corolla fuperne vifa.

$b$ - inferne feu fubtus.

$c$ - -- antice.

$d-$ - oblique ex latere confpecta.

e - - tubo longitudinaliter fecto quoad internam conftructionem vifa.

$\int$ Calyx quinquepartitus cum bractea.

$g$ Germen cum bafi ftyli.

h - - prope bafin horizontaliter fectum, ut valvulæe feu loculamenta potius cum receptaculo \& feminibus immaturis fpectentur. 
$i$ Calyx cum germine \& ftylo.

$k$ Germen prout intra calycem ab apice deorfum in valvulas duas fecatur.

$l$ - maturitati proximum.

$m$ - maturum dehifcens cum receptactilo \& feminibus.

$n$ Valvulæ duæ maturæ, tandem \& ipfæ bifariam dehifcentes.

o Stamina.

$p-$ - in duo hemifphrria ruptas antheras exhibentia.

Adnotatio editoris. Speciofam hanc plantam ab inventore, de Botanica meritiffimo Viro, cui tot tamque elegantes \& rariffimas firpes Carinthiacas cognitas debemus, nominavi.

\section{XXIII.}

\section{CYNOSURUS CERULEUS. Linn. fyft. pag. IOO.}

Aira varia. Facq. enum. pag. 15.

Sesleria cærulea. Scop. carn. I. pag. 63.

Sesleria locuftis unifloris, imbricatis; calyce tricorni. Hall. hift. num. 1446. 
Sesleria cærulea, culno fimplici, fpica fubcylindrica. Arduin. Jpec, 2. pag. I8. tab. 6 .

Gramen glumis variis. Buul. pin. Io. prodr. 2I. Scheuchz. gram.p. 83. t. 2.f.9. $A B$.

Ad radicem montium locis rupeftribus arenofis copiofe florerc folet primo vere, Goritiæ jam initio Martii, a.d faxofa Lifoncii littora, utraque ex parte, ad Salcanum in pede Montis fancti, \& ad fanctum Maurum ad pedem montis fancti Valentini, \&c. In Carniolia confunilibus in locis, circa Idriam, \&c. In Carinthia ad radicem montis Ratfchberg, \&c. Mira graminis hujus fata apud autores reperio, \& denominationes plane diverfas, neque tamen adhucdum exacta illius proftat figura aut defcriptio, Primus ejusdem meminit C. Bauhinus, fed nomine generali, ex quo nihil difcas. Idem nomen Scheuchzerus adoptavit. Hos clarifimus Linnæus fecutus eft, proprium plantæ nomen, tam genericum quam fpecificum, fuoque fyftemati præ reliquis accommodatiffimum tribuens, Cynofuri cerulei bracteis integris. Et fane adfunt temper biacteæ aliquæ infra fpiculas videlicet infimas duas aut tres, qux, dum fpica generalis in prima adhuc xtate eft, \& compacta, involucrum univerfale fpicæ to-

$$
\text { I } 2
$$

tius 
tius di-aut triphyllum efformant; cumque præterea fpicu$1 \gtrless$, vel in hac ipfa fpecie, nonnunquam trifloræ fint, etiamfi plerumque bifloræ tantum, hinc vir clariffumus fuo in fyftemate aptiori, quam reapfe fecerit, loco gramen hoc reponere vix potuit. Scopolius in Carniolia abunde gramen idem invenit, ignoravit tamen eo, quo primam Floræ fuæ editionem typis dedit, tempore, Linnæo aliisque notum jam fuife. Vidit etiam vir æque acutus ac diligens, exteriorem corollularum glumam in tres arifulas aut cufpidulas terminari, \& nota hac nefcio quam fimilitudinem cum Bromis nonnullis, \& fere etiam cum quibusdam Airis habere. His de caufis novun genus novo Sesleriøe fub nomine condidit. At minutia hæc qualisqualis, \&, nifi attente infpicias, vix obfervanda, Cobriilimo Jacquinio minime certe digna vifa eft, propter quam novo gramina genere multiplicarentur, cumque probe noffet, non heri primum detectum, fed Linnæo dudum aliisque cognitum fuiffe, etfi non crederet in cenfu Cynofurorum militare debere, ob bractearum (quas obferraffe non videtur) abfentiam, maluit Airis denique, quibus \& affinis eft, adfociare, fub Airce varix nomine. Arduinus, Hallerus, Turra, Adanfonius ad Scopolii caftra transiverunt. Ego quum \& in omnibus, quas 
illico adferam, fpeciebus, earundem que varietatibus, bracteas foliaceas nonnullas invenerin, \& fpiculas etiam in omnibus, faltem aliquas, plus quam bifloras viderim, apud eum potiffimum manendum judicavi autorem, qui prinus fyftematico nomine tam generico quam fpecifico infignivit, ac cum Linnæo Cynofurum ceruleum dico. Si quis purro pervicaciter contrarium tueri volet, pace mea optima Sesleriam vocet. Autorum nulli, unius, ejusque arbitrariæ, vocis caufa, diem dicam; ille vero, mea quidem fententia, plurimum præftiterit, qui defcriptionem exactifimam, figuramque dederit optimam. Mihi fequentibus cum notis fefe identidem præfentavit.

Radici uni eidemque, fordide albidr, lentæ, cum tempore etiam fublignefcenti, fat cxtera gracili, teretiufculæ, oblique defcendenti, fibrillisque auctæ, complures (feriatim etiam) inhærent culmi, qui, fuccrefcentibus quotannis novis novisque, cefpitem denique integrum efficiunt. Culmorum bafes bulbofæe credi puffent, bulbi tamen non funt, thecæ verius, aut emarcida foliorum annorum præteritorum refidua, fibi mutuo incumbentia aut fuperimpofita, per quas vel ipfas integrum radicularum capillitium demittitur. Folia radicalia intima, bafin culmorun 
morum vaginantia, annua funt, a tribus pollicibus ad fpithamæ usque altitudinem affurgentia, vix tamen culmum adæcquantia, linearia, fine acuto, plana, rigidula feu potius firma, nuda. In culmo quovis ut plurimum duo, bain verfus, nec admodum ab invicem remota, alterna, vaginantia, perquam brevia; quorum inferiori aliud oppofitum effe folet bipollicare. Culmus Ipithama altior, enodis, teres, compreffiufculus, nudus, erectus, apice fpicam denfam, compactam, ovato-oblongam, \&, nifi loci apricitas obfit, nigro-cæruleam, \& nitentem; plerumque enim locis umbrofis \& frigidis lætius provenit. Spica undique convexiufcula, dum nondum didueta eft, bafi involucro di-vel triphyllo circumvallatur; re autem ipfa bractex tres funt, quibus tres infimæ fpiculæ infident. Bracteæ hæ feffiles funt, fere orbiculatæ, concavæ, nigro-violaceæ, integræ, ora fuprema albidæ \& lacero-denticulatæ. Spiculæ undique imbricatæ, fubfeffiles, calyce plerumque bifloro, nonnunquam tamen trifloro. Calyx biglumis, glumis fubæqualibus, in ariftam brevem coloratam definentibus, dilutius aut faturatius violaceis, oris albidis. Corolla etiam biglumis; valvula exteriore majore, bafi viridi, medio oblique plus minus violacea, per oras albida, apice tricufpi feu tribus ariltulis, quaruns media 
media duplo longior, terminata, carina dorfi media ciliato-ferrata. Valvula interiore paulo breviore, planiufcula, albida, carinis dorfalibus duabus viridibus percur$\mathrm{fa}_{2}$, inque totidem ariftulas aut cufpidulas terminata. Stamina tria filamentis elongatis capillaribus albis. Antheræ flavæ, æqquilibrio infidentes, longiufculæ, utrinque fif1æ. Germen globofum, flavens. Styli duo, filiformes, albi, a bafi ad medium invicem appreffi, inde divergentes \& penicilliformes. Stigmata fimplicia. Semen corollis obvolutum, ovatum.

\section{XXIV.}

\section{CYNOSURUS SPHEROCEPHALUS.}

Sesleria fphærocephala; caule fimplici, nudo; fpica fubrotunda, involucrata., Arduin. Spec. pag. 20. tab. 2.

Gramen fummarum dumtaxat alpium, locis gaudens apricis, Julio florere incipit. Perqquam copiofum inveni in altiffumis fummitatum jugis alpium Kibeggenfium vallis Gilienfis, tum etiam in Fladnizenfibus alpibus Winterthal, Eifenhut, \&c. Tum in Leontinis. Autorem fcio 
neminem, qui ejus meminerit, præter Arduinun, apud quem \& figuram \& defcriptionem videas. Radix, radiculæ, culmorum bafes (bulbos oblongos mentientes, ) emarcida perichætia (fquallida vaginarum annotinarum refidua, ) eadem omnino, dempta proportiune, cum illis Cynofuri cærulei fpicati præcedentis. Neque aliter fe hujus culmi foliaque tam radicalia quam caulina habent. Omnis dumtaxat in eo diverfitas eft, quod $\int p h . e r o c e p h a l i$ culmus multo tenerior, aliquantum brevior, \& folia fint triplo aut quadruplo etiam anguftiora, plana tamen adhuc, fed nonnihil præ illis diluta magis. Spica \& huic unica, eaque terminalis \& erecta, fed plurimum ab illa præcedentis diverfa; capitulum allii cujusdam dixeris; vera tamen fpica eft, fed fphærocephala. Involucrum univerfale triphyllum, foliolis membranaceis, feffilibus, fuborbicularibus, concavis, fuperne lacero-dentatis, cæterum integris, dilute cærulefcentibus, tandem albidis \& diaphanis. Spiculæ undique imbricatæ, fubfeffiles. Calyx fpicularum biglumis, bi-aut triflorus; glumis fubæqualibus, primum corolla longioribus, tum, ficut \& in altero, bievioribus, cæruleis cum oris albidis, in criltulam velut terminatis, \& dorfo medio ciliatis. Corolla bivalvis, valvula exteriore majore, cærulea, oris albido-mem- 


\section{CARINTHIACA.}

branacea, dorfi medii longitudine ciliata, in criftulas tres concolores definente, quarum media duplo triplove longior. Valvula interiore breviore, planiufcula, albida, oris cærulefcentibus, bifurca, dorfo medio carinulis duabus virefcentibus percurfo. Stamina \& piftllum, uti in priore, fed breviora, utut ipfa extra corollulas emineant.

Occurrit varietas floribus albis, in qua quod adnotem, nihil eft, quam quod capitula habeat majora, utpote fpiculis conftans non bifloris folum, fed plerisque quadri-\& quinquefloris; quod ariftulæ breviores fint; \& tam involucra quam calyces \& corollæ alba fint cum tantilla viroris tinctura; imo \& antheræ ipf ex flavo albeant. Crefcit hæc varietas in Leontinis alpibus, \& Fladnizenfibus Hadnerhöhe, Leiterfeig.

Si quis ea dumtaxat gramina genus Cynofuri intrare poffe prætendit, quarum fpica, aut caudanı canis aliquo refert modo, aut fpiculas hahet unam verfus plagam, tanquam cynofuram, fpectantes, etfi characteres hujusmodi infra dignitatem verorum Botanicorum fint, multisque aliis gramineis plantis communes, tum enimvero ex recenfitis modo graminibus proprium genus faciat, Sesle- 
riasque dicat, modo fimul generi huic novo notas chara. Eterifticas tribuat involucrum commune fpicce fubtriphyllum, Ecorolle valvulum exteriorem tricufpidem.

\section{$\mathrm{XXV}$}

\section{POA DISTICHA.}

Sesleria locuftis quinquefloris, difichis; calyce tridentato. Hall. hijt. helv. num. I 44 ?.

Floret Julio abundantiffme per omnia fuprema Folkartenfium alpium juga; tum in Saualpen inter Eberitein. \& Wolfsberg maxima in copia; item in Hadnerhühe, Leiterfteig, prope reliquas alpes fupra Fladniz, \&c. Hoc ipfum eft gramen, ex quo Hallerus Sesleriam fuam fecundam fecit, fufpicaturque, Sesleriam tphærocephalam Arduini effe poffe. Sed quantum a Sesleriis omnibus differat, quisque vel ex earundem figuris, imo vel ex ipfa Halleri defcriptione, facile videbit. Involucrum adeft nullum; fed neque corollæ ariftatæ funt, etfi feneicentes ariftatæ credi poffent propterea, quod margo glumæ exterioris, latus \& membranaceus, a rachi ejusdem dorfali 
\&. fubftantiæ potius foliaceæ quam membranaceæ difcedat, atcque hinc gluma ifthæc videatur in nervulum five cufpidulam brevifimam terminari, utrinque denticulo ftipatan ex apice marginis membranacei abrupti.

Radix nihilo fere differt a radice Cynofurorum modo defcriptorum; filo nempe craffufculo, lento, firmo, \& cum tempore lignefcenti, albido, radiculis inftructo, inhærent undique bafes culmorum, longiufculorum inftar bulkorun, \& feriati velut in organo fiftulæ vocales, e quibus identidem fuccrefcentibus cefpes denique emergit. Bafes autem horum pfeudobulborum \& ipfer radiculas longas demittunt. Cæterum folia radicalia interiora, eaque annua, vaginis fuis bafin culmorum induunt, funtque e glauco virentia, fetacea, fupra tamen tenuiffimo fulco impreffo, culmis nonnihil breviora. Caulina duo circiter, verfus inferiora, eaque admodum angufta, non tamen fetacea, verum plana, linearia, acuta, nuda. Culmi enodes, teretes, foliis concolores, rigiduli, graciles \& erecti, apice terminantur fpica florum ovata, difticha, compacta, hinc plana, illinc convexa. Sunt vero fpiculæ duodecim circiter numero, fubfeffiles, ovatæ, acutiufcu$1 \Re$, oblique culmo infidentes, alternæ. antrorfum imbri-

$$
\text { K } 2
$$

catim 
catim fibi mutuo incumbentes, \& fpicam convexam reddentes; retrorfum aciebus fuis externis in eodem plano perpendiculari fitis, planan finulque difticham fpicæ univerfalis faciem conciliantes. Spicula quævis ovata, acutiufcula, fpeciofa, tricolor, ex calyce biglumi ordinario quadriflora, nonnunquam quinqueflora. Calycis glumæ fere æquales, ovato-acutæ, muticæ, bafi virentes, medio oblique cæruleæ aut violaceæ, margine lato cinctis membranaceo diaphano \& albefcente. Corolla ovatoacuta, bivalvis; valvula exteriore nonnihil majore compreffa longitudinaliter, lateribus tamen convexis, dorfo medio fubtiliffime ciliato, apice acuto, nec tamen ariftato nifi cafu per fenium, colore calycis. Valvula interiore aliquantum breviore, integra, lanceolata, nec bifida, tota alba diaphana \& membranacea, longitudinaliter intra valvulam interiorem intrufa, ut dorfo medio fulcum formet, extus duabus carinis longitudinalibus, ante marginem quemvis extantibus, viridibus aut cærulefcentibus, ciliiscue longis \& albis fimbriatis. Stamina tria filamentis albis extra corollas nonnihil eminentibus. Antheræ ex violaceo tandem flavæ. Germen rotundum, dein turbinatum, tandem oblongo-ovatum, flavens. Styli duo, longi, albi, ciliati aut penicilliformes. Stigmata fimplicia. 
Adnotatio editoris. Hoc gramen ex Carpatico Hungarie monte Cribano olin mihi beatus Lipp attulerat, uli copiofe etium crefcit. Mlifi anno I769 ad Linnxum ceu novim Cynofuri fpeciem, qui refpondit, nunquam fe antea vidiffe; habitu, culno enodi, florum fitu Cyno/uris fimile quidem, fed tamen ad Poas pertinere. Ut itaque amicifimus autor egregie hic confentientem Linnoum habeat.

\section{XXVI.}

ADIANTUM CAPILLUS VENERIS. Tab. ๆ. Lim. Jyft. pag. 790. Scop. carn. 2, pag. 299. Lightf. Jcot. pag. 679 .

Adiantum. Cam. epit. 924.

Adiantum foliis coriandri. Bauh. pin. 356.

Viginti fex elapfi funt anni, quo elegantem, olim etiam multum laudatam, plantulam Goritiæ ad fonticulum quendam ultra fornaces lateritias via qua ad fylvam $\mathrm{Co}$ mitum de la Torre ac inde ad fanctum Florianum itur, promifcue cum Marchantia polymorpha vegetantem inveni. Eodem annis I760\& I 76I redux, iterum ad eun-

$$
\text { K } 3
$$


dem fonticulum, ac præterea ad alios, fupra finiftram Lifoncii ripam inter rupes intermedias pontem inter $\&$ molas magna in copia reperi, ac cum clariffimo Scopoli communicavi. Quum vero nullam ejus exactam figuram extare, defcriptionesque autorum, vel mancas, vel ab xtate dumtaxat petitas diverfa, obfervaverim, inde allatam pingi feci. Radix ei de more gentis, prorepens, capillitium radicularum copiofum demittit, fibrillarum inftar nigrarum, frondesque ibidem permultas attollit, quæ, quod fciam, fpithamæ altitudinem non attingunt. Frondes ætate plurimun variantes, ut vix pro iisdem in diverfa ætate haberi poffent, evolvuntur primum de more totius hujus generis, ex fpira furfum verfus. Axis communis frondium tunc flavo viret, fed brevi ex virore rubet; denique ex rubro magis magisque nigrefcens, donec tandem atropurpureus \& fere ater fiat; una cum axibus ramorum pedicellisque pinnarum totus lævis \& nitens. Frons quævis decompofita. Rami alterni \& remotiulculi. Folia feu pinnæ alternæ \& terminales, planæ, fericeæ fubtilitatis, fubdiaphanæ, pedicellatæ, venis tenerrimis longitudinalibus fubftriatæ; primum (uti in a) ex cordatavelut bafi lemicirculares \& integerrimæ, mox bafi ovata, \& apice crena una altera tertiaque introlabente emarginatæ; 
dein (uti in b) cuneiformes \& lobatæ, lobis tribus, quatuor vel quinque inæqualibus, rotundatis tamen; demum in fenio (e) ora marginis loborum denticulata ex fatifcentia pinnarum fecundum venas longitudinales, quæ \& rufo-fufcr, \& polline flavo-ochraceo afperfæ elfe folent. Fruetificatio in averia feu fupina frondium parte eft $(c)$ fquamula ad apicem cujusque lobuli, fuborbicularis, bafi fixa, cæterum libera, fed tamen tobo appreffa, integerrima, initio albido-virens, dein fufcefcens, tandem nigra, fed per oras dilutius colorata. Sul fquamula hac femina funt globofa, exigua, albido - virentia primum, tandem nigro-fufca.

\section{XXVII.}

LICHEN ILAVESCENS. Tab. ๆ. fig. I.

Determinari inter leprofos fcutellatos poteft Lichen crufaceus, verrucofus, favefcens; fcutellis rubris, margine albo. Nudis rupibus inftratum reperi, ad radicem alpis Speichkögel. Proxinus Licheni tartareo linnæi, quem olim copiofum in rupibus fupra Lifoncii ripan prope Goritiam inveni; âb eo tamen diverfus; per plures enim 
annos utrumque confervavi \& colores quisque fros, tam in crufta quam in fcutellis, retinuit. Eft Licheni huic flavefcenti crufta tartarea, flavefcens, craffa, verrucofa, verruculis inæcqualibus; majoribus aliis iisque veluti hemifphærico-convexis; aliis minimis, fuperficiem majorum undique \& denfe ebducentibus. Scutellæ ubique per cruftam liberaliter difperfæ, feffiles, inæquales, jam orbiculares, jam oblongo-ovales, alias irregulares, modo integræ, modo lobatæ, plerumque concavæ, tainen etian planiufculæ aut depreffæ; femper vero fanguineæ \& margine elevato albo cinctx; dum crufta Lichenis tartarei ex albido virefcat, \& fcutellæ ex viridi flavefcant.

\section{XXVIII.}

LICHEN PROBOSCIDEUS. Tab. 9. fig. .. Linn. fyft. pag. 809 .

Lichen cylindricus. Linn. amen. 2. pag. 264.

Inter umbilicatos, fqualentes quafi fuligine, numeratur. Omnes hic depictos Lichenes pro varietatibus unius ejusdemqque fpeciei labeo, utut primo intuitu diverlas 
verfas conftituere videri poffent. Dicam primum, quod commune eft omnibus; tum in quo differant, relaturus. Folio omnes gaudent coriaceo, lento, nun admodum craffo, fimplice, peripheriam verfus inordinate lobato, crifpo, \& libero; umbilico autem fubtus faxis adnato, \& felfili; fupra cinereo, fubtus ex albido fulcefcente, utrinque lævi; oris omnibus atrocrinitis, crinibus ramofis, ramis fetaceis. Plerisque in fuperæ paginæ difco peltæ funt anthracinæ, inordinate fparfie, plures aut pauciores, minores aut majores, feffiles aut pedunculatæ, etiam feffiles pedunculatis mixtæ, pedunculo cylindrico, five refto, five obliquo, nunc cinereo, alias. atro. Peltæ ipfre convexæ funt, raro convexitate æquabili, imo vero ordinario fulcis circularibus concentricis binis, ternis, quaternis, ant \& quinis exaratæ; centro ipfo aut introlabente aut impervio. Vidi etiam convexitatem eandem bihis deinceps pofitis vorticibus concentricorum circulorum excavatam. Quod fi jain tuberculum five pelta pedunculo inttructa obliquo, verfus apicem latefcente, convexitate apicis fulcis circularibus exarata, \& centro fit perforato, tum enimvero probofcidem elephantis repræfentare videtur, atque hinc credo fpecificam denominationem de- fumptam potifimum fuifle, quanquam non optime, quum 
nota hac \& aliæ quoque fpecies, ut brevi videbitur, præditæ fint. Communibus his exiftentibus notis, difcrepant ab invicem in fequentibus. Folium fubtus in Lichene $d$ eft albidius, \& gradatim fufcefcit, aut nudum penitus, aut crinibus breviffimis fumplicibus nigris rigidiufculis parce fparfis inftruitur, nunquam radicatis. Lichenes $a \& c$ fufcefcunt, crinesque copiofiores, longiores, \& arbufculæ inftar ramofos, neque tamen radicatos poffidet. Adhuc plures ejusmodi crines ramulofi, foliumque fubtus penitus fufcum confpiciuntur in Lichene $b$. Supera folii pagina in Lichene $a$ tubercula atra, convexa, feffilia, lævia aut circulariter fulcata, nonnulla etiam fcutellarum more concava habet; in Lichene $b$ vero punctula dumtaxat funt minima, microfcopica, inæqualia, protuberantia tamen; \& pagina verfus umbilicum pulvere farinaceo candido adfpergitur. In Lichene $c$ denique nil nifi minimi fcrobiculi impreffi cemuntur, \& uno folo in lobo tubercula paucilima atra feffilia fulcisque circularibus exarata, unico præcife breviter pedunculato. In Lichene $d$ pleræque peltæ pedunculatæ funt, \& circulis impreflis notatæ, fed his pedunculus ater eft, illis cinereus. Ut circuli concentrici melius obfervari poflint, peltas $e$ in magnitudine aucta pingi curavi. Figura $f$ indicat portiuncu- 
lam lichenis microfcopio auctam. Crefcit maxima in copia fupra rupes elatas fummarum alpium in der Trafniz und gegen die rothwielander Alpen, in valle Dravana, tum in valle Melipontana in Grofskircheim, in der Zirchniz, \& in alpibus Wielizenfibus; item in der Malta in alpibus Melnicenfibus Archipresbyterii Gmündtenfis, etiam in Fladnizenfibus Leiterfteig; \&c. Character ejus effe poteft: Lichen foliaceus, umbilicatus, crippo-lobatus; oris crinitis; pe.tarum circulis concentricis.

\section{XXIX.}

LICHEN PULLUS. Tab. 9. fig. 3.

Locandus etiam hic eft inter umbilicatos, fuligine fquallentes. Pullum voco ob luctuofum colorem. Crefcit iisdem in alpibus cum probofcideo promifcue fupra nuda faxa \& rupes. Folium ei coriaceum, tenue, lentum, umbilicatum, circumfcriptione fuborbiculatum; fubtus umbilico fixum \& feffile, cætera undique liberum, fufcefcens, nudum feu non villofum, papillis tamen minimis protuberantibus ut fere in cute anferina obfitum; fupra a centro peripheriam verfus plicato-crifpum; lobatumque, lobis 


\section{PI.ANTE RARIORES}

non admodum profundis, inæqualibus, rotundatis, \& cum tempore credo per oras nonnihil fimbriatis five laciniatis, munquam vero crinitis aut villofis cirrhofisve; totum læve, glabrum, nigrum vel atrum, (an primitus cinereum fuerit? nefcio,) tuberculis peltiformibus, fubrotundis, protuberantibus, fellilibus tamen, ex convexo depreffis, \& fupra in fulcos five circulares five meandriformes fubfidentibus, anthracinis, ac fparfis.

\section{$\mathrm{XXX}$}

\section{LICHEN ANTHRACINUS. Tab. 9. fig. 4.}

Iterum hic ex eodem ordine Lichenum eft. Elegantifimum vegetabile promifcue cum probofcideo \& pullo in alpium excelfis habitat fupra rupes nudas. Hic penitus a Lichene pullo diverfus, folio coriaceo quidem, fed fericeæ tenuitatis \& rigiditatis, fupra fubtusque concolor ater, undique lævis \& glaber, \& nudus, nullis uspiam five tuberculis five peltis aut papillis, minus crinibus aut villis confpicuis. Laftucæ formam referens; fubtus umbilico fixo $\&$ feffili; creterum undique liber, a centro peripheriam verfus plicato-crifpus, \& lobatus, lobis 
rurfum crifpo-lobatis; lobulis ultimis rotundatis \& integerrimis.

\section{XXXI.}

\section{LICHEN MESENTERIFORMIS. Tab. 9. fig. 5 .}

Ejusdem ordinis cum precedentibus, copiofiffime fimul cum iisdem crefcit. Eft illi folium coriaceum, duplo craffius rigidiusque probofcideo, non folum verfus peripheriam, fed vel ipfo in centro fuperne multipliciter crifpato-lobatum lobis extantibus, fupra fubtusque læve \& nudum, nullis papillis, foveolis aut villis inftratum; fubtus albido-furcefcens, \& umbilico fixo ac feffili; lupra ex cinereo nigricans, \& copiofnitimis fatque magnis tuberculis peltiformibus, ordinario feffilibus, nonnunquan tamen pedunculatis, convexis, fupra fulcis circularibus concentricis exaratis, anthracinis inftratum. Lobi peripheriæ \& dilci irregulariter rotundati, cirrhis aut crinibus nullis fimbriati. 


\section{XXXII.}

\section{LICHEN RIGIDUS. Tab. 9. fig. 6.}

Lichen fruticofus, durus, niger, repetito dichotomus. Hall. hift. helv. num. 1966. tab. 47. fig. I.

Coralloides corniculatum, fuci tenuioris facie. Dill. $m u f c$. pag. $118+t a b .17 \cdot f i g \cdot 37$.

Quo aptius referam, quam inter Linnæi Lichenes imbricatos, ignoro. Filamentofis -tamen adfociavit Hallerus. Præter prædictas alpes etiam in Spitalenfibus mihi fæpius fe videndum dedit, femper rupibus innatus, non ea quidem forma, iisque cum fcutellis aut peltis, qua a Dillenio expreffus fuit, fed plerunque uti ab Hallero \& apud me in $b$ pictus exiftit. Cum vero etiam iteratis vicibus talem invenerim, qualis in $a$ adumbratus eft, forma videlicet exacta imbricatorum centrifugorum, dubium exiftimo fupereffe poffe nullum, quin huic fubdivifioni adnumerandus fit, maxime cum fcutellifer, Dillenio meque etiam ipfo autopta teftibus, fit'; quamobrem \& fic breviter defcribendum cenferem: Lichen imbricatus; fo- 


\section{CARINTII I A}

liolis teretibus, comprefls, ramulofo-multifidis, atris, centrifugis; fcutellis fefflibus, concavis, concoloribus. Ex alpibus redux aut nullum mecum retuli fcutelliferum, aut certo deperdidi; qua ex caufa nullæ etiam fcutellæ depictæ fuerunt. Cæterum nifi quidem madeat, flecti impatiens frangitur ilico, fi vis vel tantilla adhibeatur, ut non immerito rigidum dicas. Conftat autem foliolis, five ex uno omnia centro, five ex pluribus contiguis abeant, cefpitofis, arbufculas aut cauliculos ramulofos repræfentantibus, vix dimidium pollicem fuperantibus, teretibus, nonnihil compreffis, inordinate ramulofis, ramis breviffimis, glabris, nitentibus, fupra infraque aterrimis, fubftantiæ intrinfecæ nivex, procumbentibus, fuper fe invicem imbricatis, exacte aut minus exacte centrifugis. Scutellæ, dum adfunt, hemifphærico-concavæ funt, feffiles, pariter atræ, \& nitentes.

\section{XXXIII.}

LICHEN PUBESCENS. Tab. 9. fig. \%. Lini. fyft. pag. 810. 
Ufinea cefpitofa exilis capillacea atra. Dill. mujc. pag. 66. tab. I, f fg. 9.

Lichen filamentofus, ramofiffimus, decumbens, implexus, nitidus. Perquam abunde faxis inftratus, eaque fæpe obtegens, \& præcedentibus implexus Lichenibus, in lier Zirchniz, Wieliz, alpibusque ante memoratis. Caules diverfæ longitudinis, tenerrimi, admodum graciles, ramofiffimi, aterrimi, leves, nitentes, proftrati, mutuo plerumque implexi, tamen proportionatam rigiditatem, etfi non illam prioris, habentes.

\section{XXXIV.}

LICHEN VULPINUS. Tab. 10. fig. 4. Linn. fyft. pag. 810. Flor. dan. tab. 226.

Lichen ramofus aureus, cauliculis planis lacunatis, ramis farinofis cornutis. Hall. hift. helv. num. 1974.

Ufnea capillacea citrina, fruticuli fpecie. Dill. mu/c. pag. 73. tab. I3. fig. I6.

Fre- 
Frequentiffimus in Carinthia, nusquam tamen five in muris, five in ligneis tectis, femper autem in Pinu Cembra inventus a me fuit in der Zirchniz, transcenfis larignarum tylvarum jugis, dum Piceæ Cembræque Laricibus mixtæ occurrunt, brevique apricæe alpium $\mathrm{W}$ ielizenfium fummitates in confpectum veniunt. Tum in alpibus Rcichenavienfibus ultra fanctum Laurentium ad radicem alpis Speichkogel, \&c. Vel folo colore citrino, faturatiore aut diluto magis, fe a congeneribus diftinguit eminus. Semper erectus, nifi cafu aut fenio deprimatur. Fruticuli elegantis fpeciem refert, caule ramofifimo, jam pyramidis inftar adfcendens, alias divaricatus magis expandendo fe diffundens. Prima in ætate caule ramisque teretibus, lævibus, fature citrinis \& fere aurantiacis; qua transacta, lacunola fieri folet caulium ramorumque fuperficies, velut ex reliktis variolarum veftigiis inordinate concavis; imo comprimi etiam divaricationes ramorum, ut planiufculi potius quam teretes deinceps exiftant; provecta in ætate flavovirens, lacunofus, \& pulvere farinaceo concolore undique afperfus, indeque fcaber redditur. Hallerus dubitavit de Dillenii tynonymo propter ramos teretes a Dillenio dictos; at certe tales primum funt. 


\section{XXXV.}

LICHEN FAHLUNENSIS. Tab. 10. fig. 2. Linn. $\int y /$. pag. 806.

Lichenuides tinctorium atrum, foliis minimis crifpis. Dill. . $m u f c . p a g$. I $88 . t a b, 24 \cdot f i g .8 \mathrm{I}$.

Pertinet ad imbricatos Linnæi. Rupibus nudis increfcit una cum Lichene pubelcente iisdem in alpibus. Folium coriaceum, tenue, rotundato-expanfum, faxis absque vellere aut radiculis accrefcens, fupra fubtusque nitens, ex fulco denique atrum, peripheriam verfus crifpe lobatum, lobis rotundatis, fubftantia folii interna nivea. Difcus folii fuperior totus fcutellis confertifime aggregatis obfitus, quæ funt hemifphærico - concavæ, margine nonnihil elevato, \& (forfan per ætatem) contracto ac inde crenato fæpiufcule, atræ \& nitentes.

\section{XXXVI.}

LICHEN MINIATUS. Tab. 10. fig. 3. Linn. $f y f t . p a g$. 8०9. Flor. Dan. tab. 532. 
Lichen fronde imbricata, rotunde lobata, cinerea, pun-

Etata; inferne ochrea, fubafpera. Hall. hift. helv. num. I 999.

Lichen pulmonarius faxatilis, e cinereo fufco, minimus. Nichel. gen. pag. IOI. tab. 54. fig. I.

Lichenoides curiaceum, nebulofum, cinereum, punctatum, fubtus fulvum. Dill. mufc. pag. 223. tab. 30 . fig. $12 \%$.

Rupibus innafcitur elatis per plerasque Carinthiæ alpes, auf dem Ulrichsberg, in alpibus Gmindtenfibus; Fladnizenfibus, Grofskirchheimenfibus, aliisque. Si Lichenum ulli, huic præprimis folium coriaceum eft, craffum, tenax, lentum ac durum. Umbilico folo quam arEtiflime rupibus adnafcitur, cæterum liber. Variare multipliciter forma \& circumfcriptione folet, jam cupularis Elvelæ ceraceæ inftar, jam orbicularis peripheria integra; etiam auriformem vidi. Plerumque in lobos irregulares verfus ambitum fubcrifpatur, unde verfus difi centrum gibbi inordinati oriuntur. Coloris fupra eft albido-(non cærulco-) cinerafcentis, quafi potui Coffeæ lac liberali manu affuderis. Squamulis minimis fuperficiem hanc exafperatam crederes; fquamulx tamen non funt, fed pun- 
Etula minima fufca, dein nigricantia. Subtus non quidem miniatus, fed rufo-ochraceus, papillisque micrufcopicis obfitus. Siccitate mirum in inodism intorqquetur, \& diftringitur.

\section{XXXVII.}

LICHEN FRAGILIS. Tab. 9. fig. 6. litt. c. Linn. fyft. pag. 809. Flor. lapp. 440. tab. Ir. fig. 4.

Coralloides alpinum, corallinæ minoris facie. Dill. $m u f c$. pag. I16. tab. I . fiy. 34 .

Non eft Lichen fragilis Scopolii. Rupes amat alpeftres; in der Zirchniz gegen die Wielizer Alpen promifcue cum Lichene rigido crefcentem inveni. Eft vere coralloides, fruticulofus, folidus; ramulis teretibus \& obtufis. Quem hic pingi feci, majufculus eft; fed \& minimus datur, vix tres lineas Parifinas altitudine excedens, \& tamen ramulofus. Caulis ramique breves, teretes, farcti, fragiles, obtuf, læves, nonnihil nitentes, obfolete albidi; apicibus plerumque fubrufefcente tinctura; fubftantia interna nivea.

XXXVIII. 


\section{XXXVIII.}

LICHEN LANATUS. Tab. 10. fig. 5. Linn. $\int y f t . p a g$. 810.

Ufnea lanæ nigræ inftar faxis adhærens. Dill. mufc. pag. 66. $t a b$. I3. fig. 8 .

Iisdem in alpibus crefcit, rupibus innatus, perfæpe modo memoratis Lichenibus implexus. Parum admodum a Lichene pubefcente diverfus; eo tamen (uti ego quidem inveni) multo tenerior, \& fere capillaris, minus rigidus, imo mollis potius, ramofiffimus, decumbens, ex viridi niger, opacus, $\&$ nitoris expers.

\section{XXXIX.}

PHACA ALPINA. Linn. $\int y /$. pag. 565.

Phaca leguminibus pendulis, feminibus ovatis. Gmel. fib. 4. pag. 35. tab. I4. 
Aftragalus caule erecto, ramofiffimo; foliis ellipticis, hirfutis; filiquis veficatis, pendulis. Hall. hift. helv. num. $40 \mathrm{r}$.

Aftragaloides elatior erecta, viciæ foliis, filiquis pendulis. Amman. ruth. pag. I 4,8 .

Crefcit in alpibus Marinwald, \& inde delapfis feminibus in arenofis littoribus Ilolæ, haud procul Leontio, Julio florens. Perenni gaudet radice, fimili Phacæ auftrali, plures etiam caules efferente; qui funt plus quam fpithamam longi, erecti, nonnunquam bafi procumbentes, teretes, ftriati, primum villofi aut faltem pubentes, dein fere glabri. Folia pinnata, jugis pinnarum a duodecim ad quindecim cum impare; pinnulis feu foliolis breviffime petiolatis, oblongo-ovalibus, irtegerrimis, ad apicem cufpidula brevi donatis, fupra glabris, fubtus villofis. Axis communis pinnarum etiam villofus. Stipulæ fefiles, integræ, longiufculæ, lanceolatæ, villofæ. Pedunculi communes ex omnibus fere axillis erecti, villof, foliis longiores, fuperne fpicam florum compactam fuftinentes, quæ demum diducitur, floribus tunc ab invicem remotiufculis. Flos papilionaceus, breviffime pedicellatus ex ala bracteolæ exiguæ \& lineari-fubulatæ, erectus. Ca- 
lyx monophyllus, tubulofus, bafi fub vexillo fere gibbus, quinquedenticulatus; denticulis anguftiflimis, fubulatis, fubæqualibus, binis fub vexillo velut conniventilus; perfiftens, \& villis nigricantibus obfitus. Corolla flava, unicolor. Vexillum alis carinaque longius, obcordatum, lateribus retrorfum aliquantım plicatis. Alæ ad æquilibrium infractx, circa carinam conniventes, integerrimx, oblongo-fubovatæ, longiufculo ungui infidentes, denticuloque laterali auctx. Carina alarum longitudine, adfcendens, obtufiffima, \& ipfa utrinque fimili laterali denticu10 appendiculata, bipes. Stamina diadelpha, novem \& unum, antheris flavis. Germen pedicellatum, lineare, compreffum, nigro-rubefcens. Stylus brevis, fubulatus, infractus. Stigma fimplex. Corolla delapfa, \& ftaminum cylindro difrupto, germen increfcit, fitque fubcylindrico-falcatum. Nutare tum novella legumina, donec, perfectam ætatem adepta, etiam pendula evadant, naviculari velut forma, inflato ventre, dorfo tantisper impreffo, ut fesnibiloculare fiat. Maturum legumen, fi attente infpiciatur, adhuc villofum eft, etfi villi, proftrati, laxiusque nunc pofiti minusque nigri, non illico oculos offendant. Semina plura, rotunda. Odor plantæ nullus. 
An ab hac alpina, illa Phaca, quam Gerardus in Flora Galloprovinciali defcribere videtur, vere diverla fit, inquiram, ubi plus erit otii. Etiam hic locorum vegetat, flore flavo, foliis nonnihil diverfa, undique tamen villofis, feffilibus, acutis, \&c. Habitu certe non parum differt.

\section{XL.}

BRYUM SETACEUM. Tab. I2. fig. I.

Antheris fubrotundis, pedunculis reflexis, \& foliis fetaceis, diftinguitur ab affinibus. Vegetat lætiffine ad, nivis deliquium, quod hocce in loco ad Martii exitum aut initium Aprilis contingere folet, in nudis rupibus declivibus, etiam perpendicularibus retro montem Calvariæ, plane diverfum a Bryo pulvinato Linnæi, quod pilis albis canefcit, \& pedunculos adeo reflexos poffidet, ut antheras plerumque intra cefpitem occultet. Qui Hypnum clavellatum Linnæi in Dillenii Tabula 85. figura 17. fculptum vidit, \& forte fortuna Bryum ifud hisce in rupibus primum confpiceret, vix dubitaret equidem, unam eandemque effe plantulam. Ego Bryo hoc aliud minus 
novi nullum. Sunt autem illi ftrata magna, plerumque fecundum longam lineam horizontalem diffufa; ut videlicet admittit faxum quarzo \& featite mixtum fiffile cinereum $W$ allerii, extus ab aeris intemperie rubiginofum. Surculi fimpliciffmi, læte ex flavo virentes, vix ad cluarum linearum altitudinem affurgentes, erecti, denfe in cefpitem aggregati; foliis undique fparfis, iisque fetaceis, nullo pilo difcolore præditis, erefto-patentibus, per ficcitatem dumtaxat nonnihil incurvis aut crifpis. Setæ terminales trium vel ad funmum quatuor linearum, ultra turculum elevati, arcuato-reflexæ fecundum unam omnes plagam, non tamen ad celpitem usque, dilute virentes; infidentes bulbillo cylindraceo, farcto, faturatius viridi, nudo \& omnis perichætii experti. Anthera ovata aut fubrotunda, quandoque etiam obovata, viridis. Ofculum pluribus abhinc annis in plantula recente credo me vidiffe ciliatum; hoc vero anno, quo. pingi feci, neque ego, nec pictor, ad rem hanc attendimus; certe in matura capfula cilia nulla aderant. Operculum conicum, acutiffimum, inı conico-fubulatum. Calyptra bafi ligulata, partem antheræ tegens, aquofiffime ex virore flavefcens, \& apice conico-fubulato operculum cbvelans, ex virore nigricat, demum decidens. In fenio planta tota 
ex nigro viret, \& fetæ una cum antheris, jam capfulam efformantibus, eriguntur, \& fufcefcunt.

\section{XLI.}

\section{CLAVARIA CESPITOSA. Tab, 12. fig. 2.}

Determinari poteft, Clavaria cefpitofa, caulibus fimpli.ciffimis, bafi nonnunquam unitis, oblongo-clavatis, farctis, aquofe luteolis. Initio Augufti reperitur in fylvis abiegnis. Clavæ cefpitofe aggregatæ, bafi fæpius unitæ, fimpliciffinx, erectx, ad unum duosve pollices affurgentes, læves, extus colore argillæ aquofe luteolæ, intus vero carne fungofa compacta albaque farktæ, neque fiftulofr. Qui veram piftillarem \& militarem Linnæi nofcit, nunquam hanc cum alterutra illarum confundet.

\section{XLII.}

CLAVARLA CORNUTA. Tab. I4. fig. 2.

Clavaria ramofa; ramis fimpliciffimis, conoideis, planotruncatis, determinanda: In fine Julii in fylvis Victorienfiluus 
enfibus inter mufcos crefcit. Subftantia coriaceo-fungofa, firma, ficca, corpus conflituit craffum, breve, feffile, digitato-efflorefcens in cornua brevia, \& ipfa craffa, fimplicia, nonnihil incurva, conoidea aut cylindracea, apice obtufiffina \& plano-truncata, lævia. Color extus nigricans, habitu obductus tincturæ aquofe violacex. $\mathrm{Ca}$ ro intus alba, fed brevi fubviolacea, fi pellicula extina difcerpatur.

\section{XLIII.}

CLAVARIA ELVELOIDES. Tab. 12. fig. 3 .

Elvela decima fexta. Schreff. fung. tab. 164. fig. I.

Dici poteft Clavaria ce/pitofa, caulibus fimpliciffimis, crafiffmis, bafi unitis, obverfe pyramidatis, friatis. Initio Augufti in fylvis abiegnis Clagefurtenfibus in ligno cariofo mufcos inter habitat. Circa Hüttenberg quoque copiofe in fylvis; ubi, prout mihi relatum fuit, in cibum a pauperibus aftumitur, \& Hafenöhrl, five Auricula leporis, vocitari folet. Subftantia coriacea eft fungofa, firma, ficca, duriufcula. In corpus abit craftum, compofitum e

$$
\mathrm{N}_{2} \text { plu- }
$$


pluribus conis inverfis, aggregatis, \& bafi plerumque unitis, approximatis, appreffis, erectis, farctis, apice ipfo plano-truncato, lateribus longitudinaliter ftriatis, extus undique coloris intenfus aut dilutius fufcefcentis, intus vero carne omni alba. Elegantem ejus varietatem vide apud Schæfferum tab. 164. fig. 2. 4. 6. tum etiam tab. 276.

\section{XIIV.}

\section{CLAVARIA CRISPA. Tab. 14. fig. I.}

Hanc determino foliaceam, ramofiffimam; ramis planis, cripis, per oras ferratis. Crelcit in fylvis Clagefurtenfibus menfe Otobri; in cibum recepta. Ex craffufculo tubere velut trunco exfurgit caulis fungofo-foliaceus, longitudinaliter rugofus, atque illico in cefpitem bi-vel tripollicarem, rofæ inftar, expanfus, amplifimus, ramofiffimus; ramis veluti fupradecompofitis, foliaceis, planis, compreffis, apice dilatatis, crifpatis, undique ferratis. Ex lateribus vidi nonnunquam aculeos molles, inæquales, horizonti parallelos enafci, affinitate quadam cum Hydnis. Color aquofe flavens, oris extimis faturationi- 
tioribus. An Halleri Clavaria num. 2200 ? Sed nihil cun Schæfferi tabula $\mathbf{1} 72$. habet commune.

\section{XLV.}

CLAVARIA PLEBEJA. Tub. I3.

Poterit determinari fpecifice Clavaria ramofiflima; ramis fimpliciufculis, fubovatis, apice denticulatis. Clagefurti verfus finem menfis Septembris provenit in fylvis. Subltantia coriaceo-fungofa, firma, admodum craffa, extus aquofe ochracea feu flavens, apicibus pallide rofeis; carne intus alba, eduli. Truncus perquam craffus, humilis, ramofiffimus; ramis approximatis, cefpitofis, brevibus, craffis, oblongo-clavatis aut cylindraceis, obtulis, apice fubcompreflis \& denticulatis.

\section{XLVI.}

AGARICUS AURANTIACUS. Tab. I4. fg. 3 .

Agaricus ftipitatus; pilio fupra aurantiaco ; lamellis teneris, ex aurantiaco rubris. Frequens menfe Cetobri $\mathrm{N}_{3}$ in 
in fylvis abiegnis Clagefurtenfibus, ad fanctum Primum, Falkenberg, Kefslin, Ziguln ; item in Victorienfilus. Facie Agarici Cantharelli, quocum ab imperitis confundi poffet; eft vero naturæ ab eo diverfifimæ. Nam Cantharellus edulis eft, aurantiacus vero de pernicioforum genere. Illi caro eft copiofa, eaque firma, \& lamellæ craffufculi, coftarum inftar, parciores \& plerumque irregulares, toti fungo concolores; huic autem aurantiaco contra caro pauciffima; piletıs \& lamellæ regulares; atque hæ teneræ, tenues, aurantiaco-rubrr, copiofiflimæ. Denique ftipitem habet ille pileo continuum, craffufculum, plerumque diametro pilei longiorem, copiofa carne farctum; at vero ftipes hujus noftri eft gracilis, exfuccus, nec tamen fiftulofus, vix unquam diametrum pilei æquans, potius lamellis quam pileo concolor. Locis umbrofis magis humentibus in terra, præprimis vero in marcidis refectarum arborum truncis, provenire amat; aggregatus, humilis ratione pilei, nam ftipitis altitudo raro pollicem excedit. Eftque hic gracilis, teres, æquabilis, nudus, farctus, exfuccus, tandem ex aurantiaco ruber, volva \& annulo deftitutus. Pileus prinum convexus, tum orbicularis, planiulculus, denique umbilico parum introlabente, exfucco, carne vix ulla, glaber, aurantiacus, ætate aquo- 
fius expallefcens, diametri pollicaris, tandem paulo amplior. Lamellæ teneræ, papyraceæ, confertæ, bis terve dichotomæ, ex aurantiaco rubræ, perfiftentes. Odorem peculiarem non obfervavi. Apud autores defcriptum haud invenio, nifi quidem fit Michelii nov. gen. pag. 159. Fungus pileo hemifpherico croceo, inferne Lamellis $\mathcal{E}$ pediculo rubris. Pingi feci diverlos, juniores \& adultiores, etiam bafi ftipitis \& pileo connatos.

\section{XLVII.}

\section{AGARICUS ESCULENTUS. Tab. 14. fig. 4 .}

Agaricus fipitatus; pileo convexo argillaceo; fipite sracili, fifulofo, ex albo jordide flavente; lamellis albis. Corbes integros primo vere ad Aprilis exitum adferre folent in formm venales, qui demum aut illico manducantur in cibum fub nomine corrupto Nagedl-Schwaminen, qui mihi, fi condimentum demas, non admodum fapiunt, propterea quod exfucci fint, \& guftu amaricante. Stipes ordinario pollicaris, etiam brevior, nifi quidem poft longiorem pluviam magis fit elongatus, aucta cum proportione pilei diametro, quales nonnullos in figura adjeci. 
Elt admodum gracilis, teres, æquabilis, fiftulofus, albus, - fed brevi ex albo in fordidum argillæ flaventis colorem vergens, imo \& tandem velut fufcelcens, annuli volvæque expers. Fileus convexus, hemifphæricus, carne vix ulla eaque alba, ætate planiufculus, extus argillæ flaventis colore, tandèn ex nigro fufcefcente; cæterum nudus; epidermide ficca, lievi, ad peripheriam per exficcationem fubltriata. Lamellæ albæ, tenues, fat altæ, integræ dimidiatis mixtæ, laxæ, nec tamen pauciffumæ. Odor peculiaris nullus. Eundem fufpicor effe, quem Schæfferus tabula 59. propofuit. Ratione nominis vulgaris, \& quod in cibum recipiatur, credi poffet idem effe, qui apud Linnæum Agaricus clavus audit; fed obftant figura Vaillantii, \& quod ftipitem dicat farctum.

Obfervatio editoris. In Auftria etiam vulgatiffmus eft, $E_{3}$ jub titulo Nagel-Schwammen copiofus in forum Vindobonenfe transportatur venalis.

XLVIII.

AGARICUS VIRGINEUS. Tab. I 5. fig. I.

Determinetur Agaricus Jtipitatus, niveus; pileo hemiJpherico; lamellis arcuatim per ftipitem decurrentibus. Se- . ptem- 


\section{CARINTHIACA.}

ptembri exeunte frequentius occurrit in apricis colliculis ante Ziguln, verfus fanctum Primum, in fylvula Wilzenegg. Totus ut cera virgo candidus, lævis, opacus, poft pluvias illico pelluciditate vitri, non tamen vifcidus, carne non pauca, eaque firma \& ficca; nec tamen in cibum recipi, intellexi. Stipes unius aut femialterius eft pollicis, cylindraceus, farctus, lævis, annulo volvaque deftitutus. Pileus henifphæricus, integer, fat pertinaciter cunvexitatem retinens, \& poft copiofas dumtaxat pluvias complanatus aut umbilicatus. Lamellæ firmæ, laxiufculæ, integræ dimidiatæque, a peripheria pilei per arcum in ftipitem defluentes, \& decurrentes. Saporis \& odoris expers.

\section{XLIX.}

\section{AGARICUS CERACEUS. Tab. I5. fig. 2.}

Agaricus firitatus; pileo hemifpharico fipiteque fubfifulofo favis; lamellis aquofe luteolis. Menfe Septembri in colliculis apricis \& ad fylvarum margines crelcit. Stipes cylindricus, æcquabilis, plus minus pollicaris, craffuiculus, fature flavus, copiofiore \& concolore carne prædi- 
tus, ad intimam tamen medullam inftar tubi capillaris fiftulofus, ut non fimpliciter dici faritus poffit, nullo annulo nullaque volva inftuctus, fuperficie ficca nec vifcofa. Pileus hemifphæricus, \& ipfe ficcus \& lævis, nec vifcofus, \& friatus, fature flavus, carne quidem videtur multa refertus, quæ tamen perparca eft, \& concolor. Lamellæ tenues, admodum altæ, fatis diffitæ, integræ dimidiatæque, coloris pallide luteoli. Non eft efculentus, nec odore notabili. Defcribendum cenfui, tum ut diftingueretur a nonnullis aliis, quibus aut pileus eft conicus, aut vifcofus, aut certe ftipes procerus, graciliffimus, totusque fiftulofus; tum etiam, ut diverfitas ejus ab Agarico coccineo, cui proxime accedit, tanto facilius pateret, fi qua tamen vera inter utrumque eft.

\section{L.}

\section{AGARICUS COCCINEUS.}

Agaricus centefimus quinquagefmus primus. Schaff. fung. tab. 302 .

Agaricus fipitatus; pileo hemifphcrico fipiteque fubfffulofo coccineis; lamellis aurantiacis. Reperi copiofum medio 
medio OAtobris Villaci in betuleto intra hypna in collibus ante Judendorf. Stipes fere bipollicaris, cylindraceus, æquabilis, crafliufculus, \& iple carnofus, ad intimam precile medullam fiftulofus, annulo volvaque deftitutus, intus aurantiacus, extus vero coccineus, \& cum tempore folum flarus. Pileus hemifphæricus, coccineus, tandem flavefcens, ficcus, nec vifcofus aut ftriatus, haud unulta carne inftructus, \& quam habet, aurantiaca. Lamellæ dilfitæ funt, \& profundæ, tenues, integræ cum dimidiatis altemantes, in prima mox ætate velut ex albo flaventes, fed dein aurantiacæ. Neque hic edulis eft, aut peculiari preditus odore. Tam coccineo quam ceraceo proprium eft, ut in omni ætate careant pileo conico; dein \& uterque ampliari, dilacerari \& crifpari folet; \& pileus quidem a peripheria verfus centrum, ftipes vero fecundum longitudinem veluti in filamenta. Hunc pingi non feci, quum fat elegans ejus habeatur figura apud Schæfferum; quia vero hæc defcriptione caret, illam adjeci.

\section{LI.}

AGARICUS SANGUINEUS. Tab. I 5. fig. 3 .

Agaricus fipitatus, fanguineo-ruber unicolor; annulo araneofo fugaci aurantiaco. Habitat copiofus in fylvis
$\mathrm{O}_{2}$
abic- 
abiegnis Clagenfurtenfibus; initio Octobris inveni in collibus fylvofis fupra Kelslin, dein in fylvis ante Ebenthal; tum in fylvis prope Falkenberg \& fanctum Primum. Speciofiffinus totus extus faturatiflime ruber, pileo, lamellis, ftipite. Sat exiguus prima in ætate, tanulem Chantarellum ipfun feu Capreolinum magnitudine excedit, qualem nimirum poft plufculas pluvias in collibus Falkenbergenfibus vidi. Pileus convexus, integerrimus, glaber, nitoris \& vifciditatis expers, fegmentum fphæræ repræfentat diametri (in maximis) unius femi-alteriusve pollicis; infantili in ætate peripheria ad ftipitem annulo araneofo aurantiaco contracta; explicato demum pileo fugax hicce annulus evanefcit, diductis magis magisque araneofis filamentis. Lamellæ integræ dimidiatæque, ejusdem plane \& fere intenfioris adhuc coloris. Stipes transverfam pilei diametrum excedit, æquabilis, cylindricus, farctus nec filtulofus, fub pileo primum aurantiaco-fericeis filis præditus ex dilacerato araneofo annulo. Bulbus radicis nullus, neque volva. Caro interna pilei ftipitisque non admodum copiofa, eaque ficca, coloris rubro-aurantiaci. Vetulus pulchritudine omni exuitur, trifte flavere incipit, primum pileus, tum ftipes, dein lamellæ; denique marafmo interit, non edulis. 


\section{LII.}

AGARICUS MUSCOIDES. Tab. I6. fig. I.

Agaricus fipitatus, cinereus; pileo pulvinato, umbilic prominente, oris inflexis Eु integris; lamellis albis, adjcendentibus, bis terque dichotomis. In iisdem eodem plane tempore cum Agarico fanguineo fylvis inter montem Ca. variæ \& Kefslin, Ebenthal, Falkenberg, femper inter cefpites Polytrichi communis Linnæi, crefcentem inveni. Ex eadem velut radice multiplex, feu bafi potius plurium ftipitum connata in vellere araneofo albo lanuginofo exoritur. Stipes cylindraceus, æquabilis, trium etian pollicum altitudine, diametri unius alteriusve lineæ, farctus, ficcifinus, lævis, aquofe cinereus, nec bulbofus, nec annulatus, nec volvatus, imo neque fquamofus. Pileus in juniori duarum in diametro triumve linearum, pulvinatus cum umbilico prominente $\&$ acutiufculo, oris peripheriæ deorfum revoluto-inflexis, integerrimis, cinereus, ficcus, lævis; tum planus, circularis, umbilico adhucdum nonnihil protuberante; tandem infundibiliformis, ac tunc cinereo-fufcefcens. Lamellæ femper albæ, in fenio, ubi
() 3
pileus 
pileus in infundibulum fuperne dehifcit, a petiolo furfum divergendo adfcendunt, ut inverfum conum forment ; funtque bis terve dichotomæ. Caro interna pilei ftipitisque perpauca, ficca, alba. Ilaud edulis.

\section{LIII.}

\section{AGARICUS OCHRACEUS. Tab. 16. fig. 2.}

Agaricus acaulis, flabelliformis; fupra pulvinatus ochraceus; lamellis albidis, margine cinerafcentibus. Initio Decembris extra clauftum Victorienfe in emortuo arboris ingentis trunco, rurfumque Septembri menfe circa Clagenfurtum inveni. Id peculiare huic Agarico eft, quod, quanquam parafiticus, fubftantiæ tamen fit non coriacex aut femilignelcentis, uti congeneres plerique, verum fungolæ, fere ut caru Agarici integri Linnæi, \& qui adeo non perennet in arboribus, lignofior factus, fed eodem, quo natus fit anno, marafno pereat. Squamæ (nifi laminas malis vocare) fimplices aggregatæ, horizonti parallelæ, feffiles, oblongæ, flabelliformes, obovatæ, bafin verfus contractæ in brevem \& craffum petiolum, in quem fulutus lamellæ omnes convergunt, ea fere ratione, uti in 
conchis marinis friæ aut fulci folent verfus nates. Pars fuperior convexa, glabra, Iævis, pellicula fubtilifima nec villofa, in fquamulas tamen furfuraceas difrumpenda, obducta, coloris ochræe five argillæ trifte flaventis. Caro interior copiofa, fungofa, alba. Lamellæ non coriaceæ, nec rigidæ, fed tenues, molles, albidæ, ora cinerafcentes, tandem \& ipґæ ochreæ feu parti convexæ concolores. Inter edules haudquaquam recipitur.

\section{LIV.}

BOLETUS LACRYMANS: Tab. 8. fig. 2.

Boletus acaulis, coriaceus, femiovalis, aurantiacus, migofo-reticulatus; fafcia marginali lata, nivea, fornicata. Habitat fupra afferes locis humori obnoxiis, ubi muro communicant. Crufta, corii fimilis, fæpe ampliffima, in plures femielliptoides divifa, lenta, ficca, craffitudinis unius alteriusve lineæ; facie inferiore afferi inftrata alba (uti reliqua caro interna,) lævi, nullis poris pertufa; fuperiore autem inæquali, rugofa, reticulata, aurantiaca; fafcia marginali lata, convexa, nivea, guttas aqueas lacrymante. Similes portiones complures contiguæ vifebantur, 
bantur, dimidiam fpithamam longæ, nonnunquam plures in unam lobatam confluentes; fed pleræcue, ubi muro communicabant afferes, inde per murum perpendiculariter ad altitudinem duorum triumve pollicum adfcendebant, novumque femielliptoidem coriaceum, fed priori horizontali ful angulo recto feu perpendiculariter infidentem, efformabant, cujus pars interior, muro adhærens, plana $\&$ lævis erat; exterior vero aurantiaca $\&$ ipfa, per difcum undato-gibbofum tubulos perpendiculares, oblongos, quadrangulos, compreffosque habuit. Oram rurfus fafcia lata fornicata nivea foraminulata \& ex foraminibus guttas aqueas lacrymans occupabat.

\section{LV.}

ELVELA COCHLEATA. Tab. I7. fig. I. Linn. Jy/t. pag. 823 .

Elvela octava. Schreff. fung. tab. I55.; an etiam tab. 158.? Peziza bracteata, fordide lutea, fubvillofa. Hall. hift. helv. num. 2223.

Fungoides, auriculam Judæ referens, intus rufefcens, extus candicans \& quafi farinofum. V'aill. botan. pag. 57. tah. II. fg. 8.

Elvela 
Elvela coriacen, feflits, hemifpherica, auriformis, fubcochleata, fupra ex fufio nigra, fubtus alba, venis coftatoramofis. Menfe Aprili ad Maria-Elend inveni. Judicat Hallerus, eandem cum Peziza Acetabulo effe, cum Michelii tabula 86. fig. I., cum Vaillantii tab. I3., cum Schæfferi tab. I56., tum etiam cum ejusdem tab. 150. Neque fortaffe defunt rationes. Verum $f i$ in parte Botanices, adeo parum adhucdum elaborata, tam diverfa individua fub una militare fpecie, pofuerimus, quinan erunt characteres fpecifici, qui finguliš hisce individuis communes fint ? Et cur non fub eadem fpecie Elvela quoque coccinea Schæfferi tab. 148., quæ Halleri Peziza num. 2222. eft; cur non \& ea, quam Schæfferus tab. I52. propofuit, connumeretur ? \&c. Elt Elvelæ cochleatæ fubftantia ceraceo-cartilaginea, vix dimidiam lineam craffa, firma, feffilis, primum fubrotunda, tum apice hians, hemifphærica, auriformis, fenfim explanata, integra aut etiam lobata, \& velut crifpata, donec a peripheria verfus centrum inordinate difcerpatur; fupra nuda, concava, fufca, tandem ex fufco nigrefcens; fubtus magis minusve convexa, alba, \& ex centro venis nonnihil exftantibus coftato-ramofis. 


\section{LVI.}

VALERIANA SUPINA. Tab. I\%.fig. 2. Linn. Syf.pag. 73. mant. pag. 27. Arduin. Jpec. 2. pag. 13. tab. 3. Valeriana alpina, foliis integris, radice repente, inodora. Raj. hift. I. pag. 389. fyll. ext. pag. 259. Hall. opufc. pag. 187. Morif. hift. 3. pag. 102. Plukn. alm. 380. Tourn. inft. pag. I3 I. Till. pif. pag. 169.

Valeriana montana minor italica, foliis integris, radice repente. Barr. rar. pag. I5. tab. 868.

Hanc determino Valerianam floribus triandris fubtetrandisque; foliis integris, ciliatis; radicalibus obovatis: caulinis lancoclatis. Humida, eaque pinguia, nonnunquam tamen \& arenofa ad rivulorum latera, fummarum, Tyrolim inter \& Gilienfem Carinthix vallem interjectarum, alpium, incolit loca, in dem innerften Laserz gegen die Luggau $z u$, tum ubi ex fumma alpe Kirlchbaumenfi prope Lienz ultra adfcenditur per horam, parumper verfus orientem, ad ipras nives; denique, ex delatis inde feminibus in der öden Au bey Lienz, wo der Dragg fich zu ergiefsen pflegt. \&c. 
Rara fi qua alia, \& quam rara, tam fpeciofa fimul altifimarum alpium planta, non minimum præftantiffimis Botanicis faceffivit negotii. A clariflimo Rajo primum, qui referente Hallero novam ftirpem in Helvetiæ montibus legit, fub exitum fere fuperioris fæculi recenfita, notisque infignita perquam naturæ fuæ congruis fuit. Tamen $\&$ eodem plane tempore (nifi forfan vel jam prius) præclariffmum ordinis Prædicatorum decus Barrelierius eandem noverat; etfi defcriptionem ejusdem, e fugitivis viri chartulis excerptam, fub initium dumtaxat labentis frculi vulgaverit Juffixus, adjecta etiam plantæ ipfus figura, non illa quidem optima, tali tamen, qualem e fpecimine fperare poffis, quod ex inclemente alpium folo in luxuriantem hortorum rcmanorum terram translatum, non potuit non egregie adulterari. Cblivioni deinceps per fexaginta \& amplius annos cœpit dari, usque ad ea denique tempora, quum clariffimus Arduinus alterum Animadverfionum fuarum Botanicarum Specimen cum erudito communicavit orle. Quanquam enim per intervallum, quod fpatia inter ifta interceflit medium, mentionem illius fecerint \& Morifonus, \& Pluknetius, \& 'Tillius, \& cum Vaillantio Tournefcrtii interprete Hallerus, tamen cum aut novæ lucis nihil addiderint ifti, \& præter 


\section{16

nuda Raji verba dixerint de illa nihil; aut quod de plantula denique dixerunt, nunquam fibi ipfis vifa, perperam plane dixerint; factum inde omnino eft, ut Vaillantius, tefte Hallero, minus recte eandem cum Valeriana faxatili Linnæi confuderit; Hallerus ipfe a Barreleriana, hoc eft, illam a fe ipfa diverfam crediderit; Linnæus vero plantulæ, adeo per autores confufæ, ne verbo unquam meminerit; \& Arduinus denique iple, anno adhucdum fexagefimo tertio hujus fæculi, pro nova, \& cujus apud rei herbariæ fcriptores mentio plane nulla exiftat, propofuerit. Arduiniana ut primum prodiit plantæ figura, ratione foliorum optima, minus tamen refpectu florum bona, illico, quam incognitam autor credidit, perfpicaciflimus Linnæus in Mantiffæ tomo primo cum Rajana \& Barreleriana agnovit effe eanden, $\&$ in cenfum fuarum retulit plantarum. Quod autem miratus femper fui maxime, illud eft; quod cum $\mathrm{Hal}$ lerus anno feculi hujus trigefimo nono Helveticam Raji plantam a montana Linnæi montis Wafferfall diverfam crediderit, atque Vaillantium etiam hoc ex capite reprehendendum judicaverit effe, tamen in editione firpium fuarum Helveticarum anno fexagefimo octavo, Arduinum præ manibus oculisque habens, ipfe Valerianam 
hanc Raji alpinam foliis integris radice repente inodorem cum Valeriana montana Linnæi confuderit rurfum; tum quod Arduinus (fi tamen veram celticam unquam novit,) radici Valerianæ hujus fuæ fupinæ eundem plane $\&$ odorem \& faporem, qui celticam a congeneribus terrarum noftrarum diftinguit omnibus, attribuat. Atque ea potifimum propter, elegantiffimam plantam, difcuffis denique, quilbus obruta adhucdum eft tenebris, plenam in lucem protrahendam, \& figura defcriptioneque ad vivum factis, adumbrandam cenfui.

Eft ergo fupinæ huic Valerianæ radix perennis, fordide ex albo demum fublutefcens, teres, vix calami anferini craffitudine, lenta, nodofa, nuda, repens, ramo$\mathrm{fa}$, ramis aut fummo ex cefpite, aut certe e gemmis undique fparfis, vage enatis, diffufis, \& ipfis rurfum teretibus, nudisque, caulifera; odore \& fapore prorfus non infigni, minime vero eo Valerianæ celticæ; fummum quo congener faxatilis pollet; ut jure inodoram dicas. Caules humiles, plus minus pollicares, erecti fuberectique, teretiusculi, leviffime (faltem in prima ætate) villofuli, duorum triumve, rarius quatuor, geniculorum, apice corymbo florum terminati, foliis non aliis quam

$$
P_{3}
$$

ad 
ad geniculorum exortum onuft; iisque fimplicibus, oppofitis, connato-feffilibus, oblongis, integris, nudis, per oras præcile pilofo-ciliatis, inferioribus fubovato-lanceolatis; iis contra foliis, quix ad caulis bafin caput radicis cujusque, polypetalæ inftar rofæ, coronant, plurimis, craffufculis, aveniis, erecto-patentibus, nudis, margine folo pilofo-ciliatis, cæterum integris, oblongo-obovatis, etiam, quod rarius accidit, oblongo-fubovatis cum fine obtufe acutiufculo; qualia autem demum fuerint cunque, femper in petiolum longiufculum veluti decurrunt. Flores in corymbo terminali jam parciores, jam copiofiores, maǵisque ftipati; ordinario paulo infra verticem pedunculis binis, brevibus, axillaribus, oppofitis, ad eandem cum caule altitudinem adfcendentibus, trifloris. Flos quisque intra bracteolas binas, lineari-lanceolatas, margine ciliatas, feffilis; hocque demum illud Linnæi involucrum hexaphyllum, bracteolæ fcilicet trium univerfe florum fex. Germen inferum, feffile intra dictas bructeolas, iisque primum brevius, erectum, ovato-obloagun, flriatum, nudum, in apice margine circulari protuberante coronatum ex pappo plumofo, hac in ætate fpiraliter adhuc furfum convoluto. Calyx nullus. Corolla rubella feu'aquofe rofea; tandem plus minus albelcens, ob- 
obverfe conica, tubulofa, tubulo brevifimo, intra umbilicum germinis leviffime hærente, feffilis, gilbbo laterali nectarifero, paulo fupra bafin hinc exftante, fauce pervia latefcente ampla, limbo quirquepartito, erecto-patente; laciniis oblongo-ovatis \& integerrimis. Stamina regulariter tria, tamen etiam quaterna, parieti interno corollæ fupra tubum inferta; filamentis fubulatis, albis, ultra faucem exfertis, ipfaque tandem corolla longioribus. Antherx fubrotundx, albidx cum rubedinis tinctura, polline dilute flavente. Stylus altitudine corollæ, albus, apice in ftigma obtufum fulscapitatum abiens, denique deciduus. Semen oblongo-ovatum, compreffiufculum, friatum, dilute fufcefcens, apice ipfo ftrangulatum, \& coronatum pappo plumofo longo in hemifphærium connatum patente.

\section{LVII.}

Etfi Gunnerus in Flora Norvegica ampliffime conatus fit oftendere, Saxifragas gronlandicam \& ce/pitofam Linnæi non nifi unius ejusdemque fpeciei effe varietates diverfas, eoque demum rem perduxerit, ut Linnæum ipfum, ultima in ætate, fuam in fententiam pertraxerit, tefte 
tefte Mantiflæ Tomo fecundo; tamen infiftendo charaEteribus a Linnæo alias datis, recte adhuc inftar duarum, inter fe diftinctarum Specierum, meo quidem judicio, proponerentur, fi videlicet cefpito $/ a$ falutaretur, cui folia effent angufta linearia integra, frifidis cuneatis mixta; Grenlandica contra, quæ haberet folia latefcentia, palmato-multifida trifidaque. Atque tum ad priorem referrem fpecimen fuecanum, a clar. Jacquin mecum communicatum, tum figuram Dillenii in Horto Elthamenfi. Ad pofteriorem vero omnes Gunneri figuras, una cum Oederiana. Sed quoniam denique inter eruditos polarium terrarum ita jam convenit, ut easdem deinceps inftar unius ejusdemque plantær, fub cefpitofer nomine, accepturi fint, demus illis \& nos iftud; neque, nifi quam certiffime eandem noftris in terris invenerimus, grœnlandican five cefpitofam, nos noffe \& defcribere clamitemus. Nam ea quidem Saxifraga, quam Hallerus num. 988. refert, \& cujus fat bonam in Opufculis figuram dedit, quamque præter Seguierium \& Scopolius, non in Ann. hift. 2., fed in Flora Carniolix, adducit, atque ego ipfe infra defcripturus fum, necque gronlandica, neque cefpitofa unquam fuit aut effe poteft, quidquid Linnæus, Gunnerus \& Oederus, folo foliorum integrorum \& trifidorum 


\section{CA K I N TH I A C}

charactere, (qui pluribus fpeciebus communis eft,) delufi, dixerint, \& porro dicant.

Fallaciffimus ifte character, quamdiu folus, neglectis aut exclufis aliis, confideratus fuit ab autoribus, ita eosdem perturbauit, ut fe mutuo citarent, dum minime deberent, ad plantas videlicet inter fe diverfiffimas; \& citationibus his fuis mutuis, trium quatuorve rariffinarum plantarum hiftoriam in chaos fibi ipfis inextricabile adduxerint. Perperan certe Linnæus ad Saxifragan cefpitofam fuam citat Halleri figuram ex opufculis, Minus item recte Hallerus ad Saxifragam num. 988., quam ego infra Saxifragam mufcoidem dicturus fum, coacervavit fynonyma tot tamque inter fe differentium plantarum. Nam hanc unam eandemque putat (I) cum cefpitofa Linnæi. (2) cum Tridactylite alpina Joannis Bauhini, quæ mea mofchata eft, gratiffimi fenper odoris \& quam vel ex hoc capite Gefnerus Sedum, quod Nojchiftella alpina lutea vocari poteft, jure optimo dixit. (3) cum $S a$ xifraga alpina minima Seguierii I. tab. 9. fig. 2., quæe profecto Saxifraga cæefia Linnæi eft. (4) interrogans, nunquid etiam fit Saxifraga Seguieri alpina mujcoides, foliis \&c. Suppl. tab. 5. fig. 3.? quæ certe Saxifraga 1c- 
doides Linnæi eft. (5) Saxifragæ Oederi tab. 71, quæ Linnæi Grevlandica, magnitudine.floris excepta, fimilem afferit.

Præterea Hallerus Saxifragam fuam num. 990., quam ex citatione Linnæi pro Granlandica habet, a cejpitofa Linnæi diverfam aperte afferit, non per notas Linnæi, fed per longe alias. Glabritiem imprimis illi tribuit, quam alii villo præditam dicunt, $\&$ in figuris exprimunt. Ergo quam Hallerus pro Gronlandica habet, a vera Grœnlandica diverfa eft. Tum etiam Saxifragam fuam num. 985. pro nova aliisque incognita propoluit, quæ tamen vera Saxifraga fedoides Linnæi eft. Ei præterea gratum \& aromaticum concedit odorem, quo nullo pollet, nifi quidcm promifcue cum Saxifraga mea motchata crefcat, quo in cafu cefpes late totus fuave redolet; odore tamen non a fedoide, fed a mofchata repetendo. Certe Saxifragam fedoidem Hallerus, Linnæus, Seguierius, Scopolius \& ego defcribimus; fed nullus præter Hallerum odoriferam invenit. Denique \& male Scopolius Saxifragrm mufcoidem meam in Flora Carniolica cum cefpitofa Linnæi conjungit; \& pejus adhuc, cui in Flora Carniolica tribuit \& pinxit folia trifida, in 
Anno fecundo hiftorico - naturali, fimplicia \& integra dat, conjungens eandem cum Saxifraga Seguieri \& Linnæi fedoide, hac eft, cum fua trichode Florx Carniolicx.

Reliztis itaque Saxifragis Grenlandica \& vera cefpitofa Linnæi, five demum illæ una eademque fint planta, five duas diftinctas efficiant; id quod eruditis Suecix, Daniæ Norvegiæque demonftrandum incumbit; cum nemo unus autorum, quod fciam, evidenter oftenderit, five hanc, five illam, aut utramque fe ad hunc usque diem, in Helvetia, Tyroli, Carinthia, Carniolia, Styria aut Auftria, inveniffc; utiliter me facturum exiftimo, fi plantas illas, quæ huc usque perperam plane, \& inter fe, \& cum Saxifraga cefpitofa Linnæi, confufæ fuerunt, genuinis fuis inftructas notis defcribam.

\section{SAXIFRAGA MUSCOIDES.}

Saxifraga foliis integris \& trifidis; caule fubnudo, paucifloro. Hall. hift. helv. num. 988.

Saxifraga pyrenaica, foliis partim integris, partim trifidis. Hall. opufc. pag. 292. tab. I. Seg. ver. 3. pag. 205.
Q. 2
Saxi- 
Saxifraga foliis partim integris, partim trifidis. Seg. ver. I. pag. 45 I. tab. 9. fig. 4 .

Saxifraga cefpitola. Scop. carn. 1. pag. 293. num. 494. tab. 14.

Vegetat fimul cum Saxifraga burferiana in rupibus illis præruptis, vulgo die weiffen $W \ddot{a} n d e$, alpium Ortenburgenfum prope Spital; tum in arduis pariter rupibus, una cum Saxifraga oppofitifolia, alpium Fladnizenfium, cum ex Winterthal \& Eifenhut defcenditur verfus Büfchelberger Hiitten. Rurfum in abruptis rupeltribus alpium Leontinarum, dum Rauhkogel \& Kerfchbaumer alpes confcenduntur. Denique in alpe Pezzen inferioris Carinthiæ paulo infra apicem, dum verfus Feuersberg \& Klebasniz defcenditur, eo cumprimis loco, ubi congregandis cervis efca jacitur, latiffimis faxa cefpitibus obtegit, floretque Junio \& Julio.

Diu, autoritate Linnæi, Halleri \& Scopolii fretus, elegantem hanc plantulam pro Saxifraga Linnæi cefpitofa habui, atque vel ideo, cum in Botanicis Halleri opufcilis tatis exactam ejusdem vidiffem figuram, pingi eam ipfe haudquaquam feci, fed nunc denique certis argu- 
mentis errorem dedoctus, fub novo fpecifico nomine candem propono Saxifrage foliis radicalibus aggregatis, linearibus, integris triftdisquie; fcapo gracili, fuberecto, paucifloro; floribus citrinis, fubfefflibus. E radice perenni, multicipite, atque potius lenta quam vere lignofa, cefpites rofularum fediformium longiffuni erumpunt, quibus magna frpe rupium pars late obtegitur. Rofulæ hæ aliud non funt, quam plurimorum congeries foliorum, denfiffime circa capita radicis ftipatorum, atque fuper $\mathrm{fe}$ mutuo velut imbricatorum, erecto-patentium. Horum infima, utpote fuperiorum annorum reliquiæ, emarcida, femitabida \& ferruginei funt coloris; alia læte virent. Non unius vero generis funt omnia, fed iisdem in rofulis integra, fimplicifima, panculis bifidis, \& plerisque trifidis mixta. Hæc apicem verfus, obverfi inftar cunei, latefcunt, inque tridentem abeunt fat profunde te¿tum, dente medio parumper productiore; atque inde rurfus magis magisque confricta, in linearcm velut petiolum bafin verfus decurrunt denique. Illa ejusdem cum iftis longitudinis, fed anguftiora, fimpliciffma, integerrima, lineari-lanceolata dicas. Non autem memini, the in foliis hilce aliquid vifciditatis five hirfutiei detexiffe unquam. Exigux, ejusque raræ, fi quid pubis

$$
\text { Q } 3 \text { micro- }
$$


microfcopio reperitur, id certo jam a prima inde ætate plerumque deponitur. Scapus (nam profecto potius fcapos quan caules dicere licet,) unum alterumve pollicem altus, adeo gracilis, ut, quanquam erectus fit, ab exiguo tamen pauculorum flofculorum pondere, ut plurimum curvetur, cæetera teres, ex pube, faltem in fummitate cum calyculis, hirfutulus \& fubvilcidus, fubaphyllus dici poteft, eo, quod non aliis onuftus fit foliis quam uno alterove, iisque longius a fe invicem remotis, plerumque ligularum inftar integris, nonnunquam tamen \& trifidis, uno faltem. Flores ad fummitatem dumtaxat fcaporum, pauci, unus, duo, plerumque tres vel quatuor, haudadmodum ab invicem diftantes, mediocres, \& fi velis majufculi etiam, non tamen ea magnitudine, quam - feptentrionales Grœnlandicæ five cefpitofæ Linnæi tribuere folent. Extimus reliquis major eft, fub quo bini \& terni reliçui fubfeffiles, non nifi breviffimo pedicello in axilla bracteolæ linearis fuffulti funt. Germen inferum, ovatum, ex pube hirfutulum. Calyx quinquepartitus, germini innatus; foliolis ovatis, æqualibus, integris, tandem patentibus, coralla brevioribus. Hæc pentapetala, petalis demum patentibus, cum foliolis calycis alternantibus, oblongo-ovatis, obtufis, integris, lineatis, nun- 


\section{CA R I T H I A C E.}

quam albis, ut ex autopria in flofculis modo enatis habeo, fed ex virore femper luteolis \& pallide citrinis. Stamina decem, partim calyci, partim petalis alterne affixa, corollæ fubæqualia; filamentis fubulatis, dilute flaventibus; antheris fubrotundis, faturatius flavis. Germinis apex intra calycem carollamque interceptus, primum planus, flavefcens, vifcidus, in centro tuberculo bina five gibbos juxta fe pofitos exhibet; dein umbilico centrali introlabente, gibberibusque illis magis magisque in tubos five ftigmata obtufa elongatis atque a fe invicem divergentibus. Capfula oblonga, biroftris, bilocularis, polyfperma. Odorem in planta tota neque ego, neque citati autores invenerunt ullum: Ex his fatis liquet, credo, in quo a vera Linnæi Saxifraga cefpitofa five Grœnlandica difcrepet; quando huic verus caulis, \& ut Gunneri exhibent figuræ, foliofus, ramofus, firmus, multumque noftrate fortior, \& folia magis digitata aut palmata, etiam plerumque hirfuta, \& flores magni, longe ut plurimum pedunculati, \& corolla femper alba, nec nifi per exficcationem lutea five florefcens. 


\section{LVIII.}

SAXIFRAGA MOSCHATA. Tab. 21. Fig. 21.

Tridactylites alpina. Bauh. hif. 3. pag. 754.

Sedulum, quod Mofchatella alpina lutea vocari poteft. Gefn. fafc. pag. 25. tab. 6. fig. 31.

Determino hanc plantulam Saxifragam foliis radicalilus aggregatis, linearibus, integris trifilisque, una cum caule glutinofis, hirfutis, E3 odoratis; floribus citrinis, longe pedunculatis. Crefcit in excelfis Schleinitzenfibus alpibus prope Leontium, lætiffimis latiflimisque \& ipfa cefpitibus, \& nifi fallor, cum Saxifraga fedoide, floretque menfibus Junio \& Julio. Rariffima vel inter rariores alpium plantas, probe eruditis cognita jam inde a ducentis \& amplius annis; fed a Bauhinorum dein temporibus immerito neglecta; oblivioni etiam penitus data; \& quod mirum omnium maxime, ignorata plane nuperrimis, quarum in manibus non poterant non effe Bauhini opera, \& ex iis de natali plantulæ loco, Braulio monte, adfitisque Genevæ alpium jugis, conftare debebat; digna, quæ vel poftliminio revivifcat, \& priftino peculiaris fpeciei refti- 


$$
\text { CAKINTHIACA. }
$$

tuatur honori. Specificum mofchatie nomen eidem ea potiffimum ex caufa dedi, quod amœniffimo, \& vere balfamico odore, non recens modo, verum \& ficcata, per annum \& ultra, adhucdum fragret; qui odor \& Bauhinum inventorem non fefellit, \& Gefnerum ferius induxit, ut Mofchatellinam alpinam luteam diceret. Videtur autem unice a refina five glutine aut vifcofitate illa repetendus, qua plantula tota fcatet uberrime, quam identidem exfudat, quæque illam longiore etiam tempore a corruptione, a putredine \& a promptiore prælervat exficcatione, \& diutifime in recente virore retinet. Jam ultra medium annum plantulas intra chartam bibulam, prælo infuper ante confrictas, fervo; late tamen adhucdum magna ex parte virent, humidulæ perfant, \& refinofo nondum penitus fpoliatæ glutine, manui, papyro aliisque facile adhærent corporibus, ut hac fola demum nota, fi aliæ deeffent, fatis \& a mufcoide, \& a cefpitofa, \& ab aliis congeneribus omnibus diltingueretur fpeciebus. Non tamen defunt $\&$ aliæ, quibus ab iisclem diverfa effe oftendatur,

Gefnerus cum Bauhino mecumque convenit. Bene etiam Pennæus miuus exactam Gefneri figuram corrigere conatus eft ex propriis in monte Saleva factis obfervatio- 
nibus, per quas videlicet didicit, in icone Gefneriana plures debere efre undique ramulos, (intelligit caules, fingulos e fingulis rofulis adfcendentes, aut etiam pedunculos plures e quovis caule, ) flores triplo majores, totumque illud nigrum (fcilicet fpatium, re ipfa cefpitem) coopertum effe debere foliis fquamatim pofitis, id eft, foliorum rofulis fediformibus.

Quidquid dein clar. Schmidel addidit, perperam addidit. Nam primo ad Bauhinianam \& Gefneri plantam non pertinet fynonymum Tournefortii Saxifraga pyrenaica foliis partim integris, partim trifidis, quæ, telte Hallero in Opufculis \& in Hiftoria firpium Helveticarum, eft $\mathrm{Sa}$ xifraga mea mufcoides, quam Hallerus crediderat effe cefpitofam Linnæi. Sed neque eo pertinet vera cefpitofa Linnæi, quam Botanici feptentrionales cum Saxifraga grœnlandica eandem effe prætendunt. Minime autem omnium eo pertinet Scheuchzeri fynonymon it. alp. I. pag. 49.; nam plantulam hanc contendit Hallerus in Opufculis effe Saxifragam folitariam alpinam fubhirfutam, foliis longis rariter dentatis, id eft, Saxifragam androfaceam Linnæi.

Secun- 
Secundo etfi nec Bauhiniana nec Gefneriana figura admodum bona fit, tamen minus recte Schmidelius ex binis erroneis (licet diverfis ex caufis erroneis) iconibus ejusdem plantæ inferre videtur velle, Gefnerianam a Bauhiniana differre; neque recte ex caulibus floriferis bene ramofis minus bonam Gefneri, minus malæ Bauhini præferendam cenfet; nam quod iftud attinet, poteft planta eadem, fi fertiliori loco, aut propitio magis ad ejusdem incrementum tempore \& cœlo crefcat, \& altior, \& ramofa magis evadere; quod vero illud prius concernit, cur verba illa adduxit: Sic $\mathcal{E}$ defcriptio Bauhini de duabus firpilus loquitur? nonne ut inferret, Gefnerianam a Bauhini diverfam effe plantam? quod a veritate eft quam maxime alienum. Sed tamen quam certiffime Joannes Bauhinus eo loco de duabus loquitur plantis. At de quibus loquitur? Dicit Bauhinus, odoratam fuam Tridactyliten alpinam a fratre quoque Cafparo inventam, \& nomine compellatam Alfines Tridactylitis alpinæ; \& dein continuat hifce: Frater meus Cafparus idem Alfines tridactylitis alpinæ nomen \& alteri quoque plantæ, $S a$ xifragi.e videlicet allwe petrece Ponæ, fed perperam, indidit. An hanc fpetant Schmidelii verba, quarum ultima certiffime planta Gefineri eft? Id vero vix admillurus 
fuiffet Schmidelius; planta enim Ponæ, quam in Hiftoria ftirpium Clufii videas, quam certiffine eft Saxifraga petræa Linnæi, parum juxta Mantiffæ Linnæi vol. 2. a Saxifraga adfcendente fua, fed quam plurimum a Saxifraga mofihata, mufcoide, grculandica, \& cefpitofa diverfa. Cur autem Schmidelius fic fcripferit, credo ego, quia conciliare \& unire, ad Halleri exemplum, inter fe voluit plantas, quæ a fe invicem diftant quam maxime. Inveniffe videtur ipfe, (nam defcriptionem certe congruam addit) non quidem mofchatam noftram \& Bauhini, fed mufcoidem meam; hanc plurimum cum Halleriana Saxifraga pyrenaica Opufc. convenire vidit, cum reipfa eadem fit. Obfervavit quoque, Halleri iconem propius accedere ad iconem Gefneri, quam ad illam Bauhini. Denique vidit, Hallerianam plantam a Linnæo citari ad fuam cefpitofam, \& viciffun cefpitolam Linnæi ab Hallero adduci inter fynonyma Saxifragæ fuæ pyrenaicæ foliis partim integris, partin trifidis. Hinc itaque, quum præterea nec Mofchatellam, nec vcram cefpitofam Limæi unquam inveniffe videtur, omnes hafce plantas, ut fynonymia adducta indicat, finul in unam conjungere voluit. 
Radix eft perennis, lenta, repens, ex glutine tandem evanefcente rufa, ramofe multiceps, \& cefpitofa. Cefpites ampliffimi, lætiffime virentes, \& ex virore flavefcentes, rofulis foliorum radicalium conftant denfffimis, iisque proliferis, ut per intervalla fingulorum fuperiorum annorum rofulas, prouti fibi ipfis fucceffive fuperincreverunt, manifefte diftinguas. Atque hi illi funt, in figura Bauhiniana non optime a fculptore expreffi, caules pure foliofi, de quorum fcilicet hac vel illa rofula florifer caulis forte deciderit. Folia rofulas conftituentia parum a foliis Saxifragæ mufcoidis differunt; plerumque tamen quæ linearia $\&$ integra funt, trifidis fubjacent; longiora fere etiam, \& refpcetive etiam anguftiora illis prioris Saxifragæ funt; eo quam maxime differunt, quod vifcola, odorats, \& pilis tenerrimis longiufculis, facile tamen deciduis, obfitæ fint. Caulis erectus, firmior, altiorque qúam priori, teres, hirfutulus, vifcofus, odoratus, praditus foliolis ligulatis, fparfis, utplurimum integris linearibus, quandoque $\&$ trifidis, usque ad quinque, apicem verfus florifer. Flores quam in priore copiofiores, a tribus ad fex, longe pedunculati, nulla in re adeo ab illis plantæ antecedentis diverfi, quam quod odorati fint, petalisque tantifper longioribus, nec lineatis, verbo el-

$$
\text { R } 3
$$

liptoi- 
liptoidicis potius quam ovatis, conftent. Color tamen eorum idem feu dilute citrinus.

\section{LIX.}

SAXIFRAGA SEDOIDES. Tab. 21. fig. 22. Linn. $\int y /$. pag. 343 .

Saxifraga alpina minima, foliis ligulatis, in orbem circumactis, flore ochroleuco. Seg. ver. r. pag. 450. tch. 9. fig. 3 .

Saxifraga alpina mufcoides, foliis fuperioribus oblongis, inferioribus rotundioribus \& circumactis. Seg. ver. 3 . pag. 203. tab. 5. fig. 3 .

Saxifraga foliis mollibus, ellipticis, fubhirfutis; caule pancifloro. Hall. hift. helv. num. 985.

Saxifraga trichodes. Scop. carn. I. pag. 295. tab. 15.

In faxofis rupeftribus, folo calcareo, alpium Villacenfium, qua ex Bleyberg adfcenditur ad Heiligenftein, perquam copiofos ejusdem cefpites inveni circa finem Junii, tum menfe Julio in alpibus Leontinis non minus frequentem. Mira \& hujus funt plantæ fata. Qui eam fere 
cunque invenit, aliis ignotam credidit, fibique demum ipfi inventionis gloriam vindicavit; cum in eo laborandum fuiflet plurimum, ut, (fi ex hifce quærendus effet;) honos a genuina \& exacta quæreretur ejusdem defcriptione. Quadraginta nondum elapfi funt anni, quo Seguicrius omnium, quod fciam, primus in Elencho Veronenfum plantarum ejusdem meminerit. Frequens dein in Helvetia Hallero, \& Scopolio in Vochinenfibus Carnioliæ alpibus occurrit; tamen præter Linnæum nullus in Seguieriana fuam fine hæfitatione agnovit plantam. Fecit ad hoc, nullus dubito, plurimum, qua ludere folet in diverfa ætate, variabilis ejusdem indoles, ratione altitudinis \& præprimis foliorum, quorum infuna, etfi jam femitabida, multo reliquis breviora, ovato-lanceolata, \& in rofulam fediformem perfæpe explicata funt, cum quæ undique per reliquum affurgentem caulem fatis denfe Iparfa funt, non nifi lineari - lanceolata \& fere erecta fint; tum denique five Seguierii, five fculptoris incuria, ob quam petala calyce longiora floribus data funt. Ego in locis prædictis omnes hafce fimul vidi, \& inveni varietates, atque hanc in adverfaria nea eorum intuli defcriptionem, quo primum Villacenfem alpem confcendi anno fexagefimo hujus ixculi octavo.! 
Radix perennans, mufcofa, lenta, undique derpens, \& ferpendo demiffis radiculis fibrofis iterum iterumque radicata, latiffmos caulium cefpites, fed laxos illos \& virore fuo lutelcente jam eminus oculum prætereuntem percellentes in folo aprico petrofo calcareo arenofo undique diffundit. Caulium horum alii perbreves funt, quales circiter in Tab. 9. fig. 3. vol. I. Seguierii vides, quorum folia ovato-lanceolata rofulam formant, e cujus centro rarius pedunculus florifer attollitur; alii duos tresve pollices longi, fere procumbentes, quorum annotina, etfi jam emarcida rolula, adhuc tamen perftans, in novum recentemque \& foliofum recrevit caulem, \& ejusmodi apud Scopolium exacte expreffum cernimus; ut plurimum, prout noftra in figura confpicis, caules de radice repente, fecundum ejusdem longitudinem, inftar fiftularum organi erumpunt, nec nifi absque bafeos fure inclinatione affurgunt; in his rofula illa jam deperiit, foliorumque pars inferior humore nimio corrupta ex rufo fufca elt. Folia ipfa quod attinet, homogenea ea funt, lineari-lanceolata admodum tenuia, tenacia tamen ferici inltar, plana, feffilia, erecta, laxius interdum, alias conferte magis, \& absque lege per caulem fparfa, integerrima, læte cum flavedinis tinctura virentia, 
pilis fubtilifimis \& longiufculis per oras laxe exftantibus ciliata. Pedunculi florales femper terminales, unicus, aut bini, rarius terni, fed interdum ex caule humili, cauli altero magis elongato adfito, ut credere poffes de bafi caulis elatioris prorupiffe, vide tab. 5 . fig. 3. fuppl. Seguieriani alias ex apice enati caulium altius extantium, mixtique funt caulibus his floriferis etiam alii non infrequentes, pure folioft. Pedunculorum longitudo unum aut femialterum æquat pollicem; funtque teretes, villulis extantibus hirfutuli; aut aphylli penitus, aut uno alterove brevi foliolo onufti, præprimis ubi de pedunculo principali alter brevior enafcitur. Flos femper pedunculum quemvis terminat folitarius, quoad omnia flori Saxifragz mufcoidis fimilis, nifi quod petala fedoidis femper fint calyce duplo brcviora \& ovato-acuta. Meminit Hallerus aromatici, quo plantula polleat, odoris; fed enim quam certus fum, nos de una eademque loqui planta, tam item certus fum, nullum me unquam in eo detexiffe odorem peculiarem; fed neque Seguierius, neque Scopolius invenit ullum. Forfan, ut fupra innui, in eorlem utramque celpite vegetantem invenit, mofcatam \& fedoidem. 
I38 Plante Rariores Carinthiace.

Hæc determinari poterit: SAXIFRAGA foliis caulinis lineari-lanceolatis, integris, per oras pilofo-ciliatis; floribus longiffime pedunculatis; petalis ovato-acutis, citrinis, calyce brevioribus.

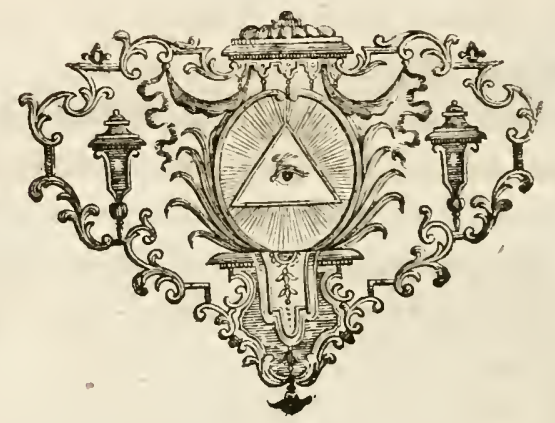

III. 


\section{9 解造 89}

14. एक 24.

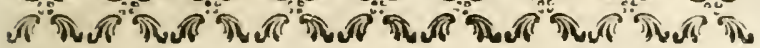

\section{I I.}

Rev. Francisci Xaverit Wulfen

MINERA PLUMBI SPATOSA CARINTHIACA.

$P_{\text {arum adhuc nota videntur, qux frcundiffimo fuo in }}$ finu, Provinciarum feliciffima complectitur Carinthia. De plantis dicam nihil, quarum rariffimas liberali plane manu undique diffeminavit provida omnipotentis Dei benignitas. Incremento earum lætiori favet cumprimis ea, qua in valles, alpiumque alternas feries, regio omnis divifa eft, conftitutio. Zuanta enim quanta eft Carinthia, alpeftris fere tota eft. Sed vel hæc ipfa illius indoles, quam Floræ propitia eft, \& Faunæ; tam metallorum generationi, vei bo Mineralogiæ univerææ, perquam eft amica. Et fane, quodnam fere metallorum eft, five 
perfectum? five, ut vulgo ajunt, imperfectum? nobile? aut ignobile? quodnam terrarum? lapidum? faxorum? caeterorumque foffilium genus? quod aretos intra ejusdem limites deficieretur denique? Eruditorum equidem haud ulla unquam fuit hifce in terris penuria; fed nec hodieque ullus eft eorum virorum defectus, quorum ampla in tribus naturæ regnis peritia, plurimum ad fcientiæ naturalis hiftoriam promovendam conferre poffet; cur tamen filuerunt illi? cur adhucdum tacent ifti? an illos labor deterruit? an animus deeft iftis? Tot, tamque doctos inter, nemo unus vel verbo auri meminit Grofs - Kircheimenfis, \& Sifflizenfis; nullus de aurifero quidquam dixit Pyrite, qui ex vifceribus Wafchgangenfibus, æternaque confepultis nive Goldzechæ jugis, eruitur ; fed nec de argenti divite ferro fpatofo vallis Lavantinæ ad fanAtam Gertrudem; nec de cinerea cupri minera, \& ipfa argenti haud inope, quæ in Rofarum, \& Gilienfi vallibus prope fancti Hermagoræ, \& Roffegg proveniunt, ullus adhuc cum literato quidquan communicavit orbe; vel ad præfenten usque diem notitia ad exteros pervenit nulla de magnete Gmuindtenfi; de ferro fpatofo cryftallino multicolore \& diaphano Lobenfi ad fancti Leonardi; aut de multiplice magnefia Paludnigenfi, Lellingenfique ; 
fique; five de multicolore fpeciofiffmis pioto dendritis chalcedonio Maffinzenfi; \& minera Zinci fpatofa Bleybergenfi tam elegante, quam rara; ditifimæ ferri Hüttenbergenfis, Sittmofenfis, Gmindtenfis, \& Frifacenfis; tum plumbi Bleybergenfis, \& cupri Fragantenfis; \& hydrargyri Stokambojenfis, Glatchachenfisque fodinx, non minus, quam cumulatæ illæ cadmiæ lapidofæ venæ montis Jauken, montisque Regii in Rabl; \& cupri cinerei Hüttenbergenfis in der Hündlerinn, pro minera wifmuthi paffim habiti, fed non als aliis, quam qui Chemiæ prorfus ignari funt; antimonii Lembergenfis; arfenici Seltichachenfis, Geisloergenfisque \&c. vix vel de nomine, nifi perpaucis illis, innotuerunt.

Fuerunt tamen, ut ne vel hoc diffiteamur, qui de Carinthix fcripferunt fofililibus; fed hi exteri omnes, qui in Carinthia aut nunquam fuerunt, aut nonnifi per tranfennam, aut mineras, earumque defcriptiones habuerunt ab aliis Mineralogiæ fæpe parum peritis communicatas. Cum admiratione profecto me legiffe memini, ftannum ifthic dari inordinate cryftallinum in pyritacea matrice, quod tres ftanni libras in centumpondio largiatur! adeffe quoque fpumæ lupi fpeciem, quæ ditior multo, fexce-

$$
S_{3}
$$

cim 
cim etiam Jovis libras præbeat! fed \& nativum in Carinthia plumbum inveniri, nefcio, quis primus dixit, fuaque autoritate ipfum Mineralogiæ decus \& ornamentum princeps hanc in fententiam induxit. Iteratis Bleybergæ vicibus fui; nunquam vel ipfe inveni, aut a quoquam inventum intellexi Granatum martialem flavum Cronftedti; nifi quidem, quæ plumbi mineram incruftare folet, Pfeudogalenam cubico-cryftallinam, attritu phofphorefcentem, coloris granatini, pro granato iplo quis habeat. Villacum paffim pro Bleyberga citatum, Neoforulum item, \& Vochinenfes alpes in Carinthiam translatas invenio; re autem vera nullæ unquam Villaci five plumbi, five alterius metalli exftiterunt fodinæ; \& Neoforulum æque, ac Vochinenfis diftrictus ad Carnioliam plane pertinent. Adeo verum eft, rem femper perquam difficilem, \& periculi plenam effe, de locis, eorumque productis fcribere, in quibus ipfe nunquam fueris!

Atque hac demum potiffimum de caufa (cum \& novis, novisque amicorum follicitacionibus, \& propria animi in res naturales propenfione ad colligenda, confcribenda, \& typis vulganda Carinthiæ folfilia ftimularer identidem) dudum jam tale quid molitus fuiffem, fi post fufce- 


\section{CARINTII ICA.}

fufcepta complura hunc in finem itinera, otii fuperfuiffet fatis, ad ultinam denique operi manum imponendam. Tot vero femper diftentus curis laboribusque, alius præfertim ab inftituto hoc generis, quietis otiique nunquam inveni tantum, ut voti tandem compos fierem mei; fed nec vel hodieque tantumdem illius fuperat, quo tuto fperare poffim fore, ut in re, non minimi certe momenti, fi deproperem, aut temere perperamve fcribam aliquid, eruditorum exfpectationi, \& quod magis adhuc percellit, propriæ fatisfaciam mei ipfus voluntati. Tentaminis igitur potius loco, eas imprimis plumbi fpatof, quas Bleybergæ, alibique conquirere raptim potui varietates, cum Mineralogis ævi noftri communicare volui; vifurus, quam benevole, aut fecus, fufcepturi fint conatus quales quales hos meus; indeque omen capturus, num porro profequar, aut a copto fua jam in origine defiftam labore? (*)

Mi-

(*) Reverendus autor plerarumque Speciminum plumbi fpatof icones coloratas elegantiflumas editori transmifit, quæ non potuerunt in Mifcellaneis adjici, ne præter modum augeretur libri pretium. Spes autem eft, fore ut in peculiari traEtatu apud bibliopolam Viennenfen Wappler brevi prodeant. 
Mineram fpatofi plumbi dum dico, eam plumbi fpeciem intelligo, quam Linnæus Syft. Nat. Tom. 3. Edit. Vindob. 13. pag. 355 . N. 9. Plumbum, dixit, arfenico mineralifatum fragmentis fpatofis, fixum, nec effervefcens. Quamque Wallerius Syft. Mineral. Tom. 2. Edit. Vien. pag. 30\%. N. 6. Plumbum, definivit, terreftre vel lapideum, minera fpatiformi alba vel grifea, vel \& parum favefcente, pellucida vel opaca, textura lamellofa, fibrofa rhomboidali, aut cryfallifata, aqua forti effervefiente, fulphuris nihil, arfenici vero plus minus, nihil é̉ argenti continente. Cronftedtus, Brunnichio interprete Edit. Hafn. \& Lipfi. \$. I84. Mineram plumbi calciformem compellat, puram, vel partibus heterogeneis minori portione mixtam, $\mathcal{G}$ induratam. Videtur autem \& ipfe, faltem in exemplo a Brunnichio relato, claufo vafe in eadern arfenici detexiffe veftigia. Bornius deniqque in Foffilium indice Part. I. pag. 90. Plumbum vocat, Jpatofum calciforme induratum opacum album amorphum - \& - favefcens effervefcens Villacenfe.

Acido, nefcio cujus falis, fotam, Sage, \& Spielmannus, autumant, quod tamen penitus ab ea abeffe Bourdelinus, Malouinus, Macquerus, Cadetus, Lavoifierus, 
fierus, Baumæus, \& Woulfe, referente Gmelino, fatis fupereffe exhibuerunt; quorum ifte non veretur præterea afferere, fi quid unquam fpatofa hacce in plumbi minera falini inventum eft, forte fortuna id demum eveniffe, eo plane modo, quo $\&$ arfenicum nonnunquam, (fed ex accidente duntaxat, non ut principium effentialiter ingrediens, aut pars conftitutiva) in eadem detectum fuit.

His adjungo Scopolium, qui fpeciatim de Carinthiaca loquitur minera in Introductione ad Foffilium notitiam pag. 157. Elt huic Plumbum apyrum, fulphuris expers, \& tamen pyriticofum! informe, ochraceo-flavefcens induratum, $27-30$. plumbi libras in centumpondio probens, cum perquam exigua argenti portiuncul', qux ipfa non tam plumbo, quam admixto pyriti (pyritæ) favo infit.

Has tam diverfas inter fe præftantiffmorum ætatis noftræ Mineralogorum de re eadem fententias, non eo certe adduxi fine, ut eosdem inter fe collidam mutuo; aut contradictiones nelcio quas evincam; vel in iis, quæ pofteris fcripto reliquerunt, carpam, five melius in medium producam aliquid: quanta enim mea in Mineralogicis? quanta in Chemicis effe poteft fcientia, qui caftra 
I46 MINERA PLUMBI SPATOSA

jam inde a puero lecutus fanctiora, felicioraque, nunquam difciplinis hifce vacaverim, \& heri, ut quod re ipfa eft, candide fatear, primum ad eas incumbere cœperim? Confummati hi in arte Viri, imo verius Magiftri artis, optime de literaria re omni ex parte meriti, \& quibus ipfe, fi quid demum hac in re fcio, totum me debere profiteor, licet ad fpeciem aliter inter fe fentire videantur, poffunt tamen eodem plane fenfiffe modo, ut omnis denique opinionum diverfitas ex eo duntaxat repetenda fit, non quod nimeræ ipfi effentialiter ineft, quam potius quod ex accidente, ut laudatus fupra Gmelinus ait, cum eadem, ifthic locorum, non item alibi, fumul effe, aut non effe, folet. Atque hanc demum, diverfas eorumdem ad fpeciem locutiones conciliandi, \& benigne interpretandi rationem, moribus meis apprime conformem, tanto lubentius declaratam ifthic volui, ne a quoquam in fufpicionem vocer, fugillare me voluiffe illos, quos hac fola ex caufa adduxi, quia \& præcipui funt, \& ex fplendore illorum fplendoris aliquid $\&$ in mea hæc fcripta redundare poffe fperabam.

Vidimus, ut de fpatofa plumbi minera locuti funt, quos in Mineralogia maximos veneratur orbis. De fua qृuis- 
quisque locutus eft, quam præ manibus habuit, quacum chemica inftituit experimenta, cujus principia, proprietates, valorem internum, \& externam faciem, configurationem, colorem \&c. fyftematica analyfi inquifivit. Carinthiacæ qui meminerint, alii haud funt, quam Scopolius, Bornius, atquue ex his Gmelinus; finguli verbis quam pauciflimis: videntur vero fruftula habuiffe jamjam fatifcentia, aut qua demum cunque ex caufa egregie vitiata, ut ne elegantiam in ea ullam, nec diftinctam cryftallorum figuram detegere potuerint, \& amorpham uno omnes ore dixerint.

At vero quid fpeciofius illa? quid ordinatum magis? quæ lamellarum teneritudo? quam exacta polygonorum circumfcriptio? \& partium fingularum venuftas? \& earum inter fe mutua proportio ac fymmetria? quam multiplex cryltallorum varietas, nitor, elegantia? ad geometricas exactam leges verius dicas, quam informem. Antea tamen quam fingulas, quæ fe mihi obtulerunt percenfeam varietates, liceat generalem ejusdem defcriptionem dare; \& partitionem magis late patentem ftatuere; naturam, indolem, proprietates, \& harum phænomena inquirere; quæ in eam acpuæ fortis vis; ut fe in diverfis

$$
\mathrm{T} 2
$$

ignis 
ignis gradibus habeat; quantum plumbi contineat; \& quæ denique ejusdem, qualis faltem in Carinthia occurrit, principia; aut fi mavis, partes fint conftituentes.

Ac primum metallici quidem in ea plerumque nihil ufpiam affecuturum te oculo, fed ne vel conjectura fperes; five colorem, five duritiem, nitorem, aut denfitatem perpendas animo, terram, aut lapiden certe, non metallum, te videre exiftimabis; adeo etiam ut plurimum vitro fimilis, ut \& rigiditatem, \& fragilitatem, pelluciditatem, \& fracturam vitri, aut omnino habeat, aut affectet faltem: hæc tamen major ratione faciei externæ cum vitro, quam cum metallo fimilitudo, haudquaquam impedit, quo minus pondere, aut ut dicere amamus gram vitate, metallis propius, quam lapidibus accedat. Neque id mirum, cum vel communi docimaftices explorata methodo, addita quamquam tantilla boracis, limaturæque ferri portione, quatuor minimum fupra quinquaginta plumbi libras in centumpondio largita fit. Perfonatum itaque fub aliena lapidis, vitrive larva plumbum effe, quis porro inficias ibit?

Quod 
Quod fi jam ad colorem, quo fucata fefe oculis exhibere folet, attendas, nullus fere elt, quo illitam, qui de Mineralogia fcripferunt, non viderint: cenfet apud Linnæum pag. 134 Lehmannus, \& cum co facile omnes, colorem ab admixto repetendum metallo; \& recte id quidem; five enim natura ipfa, five naturæ xmula ars, pingenda fufceperit corpora, a metallis duntaxat mutuari affolet colores. Cronftedtus, Wallerius, Bornius, Gmelinus, aliique, albæ, hyalinx, flaventis, rubræ, viridis, cinereæ, cærulefcentis, faphyri inftar cæruleæ, quin \& nigræ meminerunt, plerumque tamen extra Carinthiam alba effe folet; in Carinthia autem Bleybergæ, fi quidem Galenæ, aut Plumbagini adhæreat, aut etiam inhæreat, plerumque albens, alba, etiam nivea, hyalina, excolor, pellucida, aut metallica eft; contra ubi terræ, aut lapidi infidet, rariffime alba, femper fore flava, flavo-virens, aurantiaca, flavo-rubra.

Eft \& illud, quod de Carinthiaca præterea adnotem, fcilicet ut vitream nunquam non faciem præfert, ita modo recenter eruta fit, \& non aëris, terræve fodata injuriis, vitreum femper nitorem, imo fpecularem quoque polituram, in ea, qua externe patet, fuperficie exhibet:

$$
\mathrm{T}_{3}
$$


in eo forfan folum a vitro diffidens, quod cum iftud nunquam non pellucidum fit, hæc nonnunquam pelluciditate careat omni. Sæpe enim opacam, quæ lucis radiis impervia prorfus' fit, præ manibus habui; etfi frepius, imo plerumque, in quovis five craflitudinis five fubtilitatis gradu pellucidam, diaphanam, aut fubdiaphanam faltem. (*) Atque iltud etiam in ea verum effe, propria didici experientia, quam Wallerius fub nomine plumbi fpatofi nigri cryftallini (b) (c) recenfuiffe videtur, quæ reliquis elegantior, rariorque, etfi fpeculari galenæ nitore refplendeat, imo metallica conftare videatur confiftentia, metallica tamen haudquaquam eft, fed vitrea, \& ante lucem afpecta, pellucida tota eft, limpidiffimæ ad inftar cryftalli montanæ. Ad peculiare prorfus phænomenon fæpe attonitus fateor hæfi; nec hodieque fatis affequor, undenam vitreo huic plumbo metallicus ille galenæ nitor, nifi quidem fuperficiali plane inftratum dicas galena, illius prorfus tenuitatis, fub qua, diaphana aut pellucida effe poffit vel ipfa galena; quod, utut vulgo paradoxum $\&$ incredibile, adeo tamen abfurdum non eft, ut phyfi-

ces

(*) In toto hocce tractatu accipio peliucidum \& dinphanum ad mentem Linnæi Syft. Mineral. pag. 30. 
ces potius confonum principiis dudum agnoverint philolophi omnes, qui probe norunt, corpus quodvis opaciffimum, fimulque denfifimum, in lamellas tamen infinite, ut ita dicam, tenues difciffum, non diaphanum modo, verum \& pellucidum fieri poffe; \& ita reapfe fieri, faEtumqque effe, infra vifuri fumus.

Supereft, ut poftquam, quæ de externa ejus facie dici poterant, exfecuti fumus, jam \& illa, quæ intrinfecam illius ftructuran, ac ut vulgo dicere folemus, texturam fpectant, quam breviffime adferamus. Spatum plumbiferum in practico minerarum fyftemate dixit Vogel pag. 194. album, cinereum, allt fufcum, ponderofum, granulare, Squamofum, fchiftiforme, rhomboidule, cryftallinum, vel denique druficum. Spato eamdem \& alii jam multo ante compararunt; nec injuria; ut quæ proprietatibus fpati quam plurimis gaudeat: de calcis enim materie aliquid certe participat femper; \& acidis quoque magis, aut minus, movetur mineralibus, folutionem in illis, etfi quandoque perexiguam, aliquam tamen femper paffa. Sed \& in eo illi cum fpato apprime convenit, quod partium fuarum non vaga quavis, fed fingulari, \& determinata femper prædita eft figura, cubica, rhomboidea, parallelo. 
grammica, felenitica; fuperficiebus non planis modo, fed lævigatis etiam nitens, more fpati; \& in parallelas, fiffilium inftar lapidum, abiens lamellas, plusquam papyraceæ interdum tenuitatis : idque non fortuito duntaxat quodam eventu, aut cum talem plane fe inermibus videndam prabet oculis, verum etiam eo in ftatu, quo fufi inftar vitri, aut fub cryftallorum quarumvis fpeciali figura, aut rudis compactique, \& informis adinftar corporis corporum aliarum venas rivofe pererrans comparet, \& cum nullas in ea laminas, plana, paginas, fed neque fibras aut frias, armato quamvis oculo, difcernas. Etfi enim hocce in ftatu a fua velut recedere credi poffet indole, quam pertinaciter tamen vel tum fuæ retinens fit naturæ, illico perfpexeris, ubi adhibita mallei vi eamdem diffregeris, aut fuper ignitos repofueris carbones; etenim aut in rhombea, quantumvis exilia, continuo abit fragmenta, aut in minutiffimas non absque fremitu undique difflit \& difpergitur lamellas.

Dicendum nunc eft, quæ phænomena obfervata fuerint in inflitutis de induftria cum minera hac Carin hiaca experimentis. Plerique enim, quos legi Mineralogos, difficillimæ reductionis effe inquiunt mineram fpatofi plum- 
bi; tentandam itaque aleam cenfui cum diverfis ejusdem, diverfeque coloratis varietatibus, in diverfis pariter ignis, femper tamen aperti, gradibus. Dicam quam candidifime absque ullo refpectu autoritatis, exiftimationis, aut affectionis erga quemcunque, licet primi nominis mineralogum, fed etiam absque ullius contemptu vel minimo, quæ obfervarim phænomena.

Super emortuo carbone in fcrobe majufcula efforta, vehementifimis folis radiis, in foco lentis caufticæ, avulfas cryltallos, aut lamellas plumbi fpatofi, iteratis fæpe vicibus expofui, flavas; albas diaphanas quarzi aut aluminis facie \& colore; tum excolores pellucidas; denique femipellucidas fulgentifimo galenæ nitore refplendentes. Cum fridore femper diffilierunt quaquaverfum difperfæ, quæ flavo, aut albo aluminis erant colore; parum autem, quandog̣ue etiam nihil, quæ excolores, aut metallicolores erant. Fruttula, in quæ diffiliere, diligenter collecta, rurlum foli objeci in eodem lentis foco; adhucdum fubfilierunt, inque minora adhuc fragmentula dilacerata funt ea, plun:bi fpatofi flavi; conquievere tandem immobilia, fed nec primævum exuerunt colorem, nec ulla vi in plumbi regulos fufa funt. An lens cauftica ma- 
I54 MINERA PLUMBI SPATOSA

joris diametri (mea feetionem circuli maximi pomi mediocris magnitudine æquabat) effectum præftitura erat majorem? indulsie. An fluor quidam mineralis adthibendus fuifet præterea? tentandum erat. Exigua boracis fruftula immobilibus illis plumbi fpatofi flavi mifcui fruftulis, experimentumque repetii; illico borax in fungofum album opacum tumidum abiit corpus, cui involuta erant plumbi fpatofi fragmenta; in fluxum tamen uberiorem haudquaquam perducere potui, licet diutifime foli obverfum teneren apparatum illum omnem. Sufpicari fubiit, an non æquo majus foret boracinum illud corpus, pro exilitate campi foci? nimiumque etiam a folis actione protecta effent plumbi frufula, qramdiu involuta undique effent boracino illi indumento? Calcinatum ergo boracem una cum plumbi fpatofi fruftulis contrivi, atque iterum concentratis ope vitri cauftici folis radiis objeci; $\&$ intra brevius minuto fpatium fphærici \& refplendentes plunbi reguli, licet ninutiffini, aderant. Minor longe difficultas erat in reducendis illis, quæ albo, hyalino, aut métallico erant colore: nam hæ polt ftridentem diffilitionem, collectæ iterum, iterumque concentratis radiis folis objectæ, lateritio-rubrum induerunt permanentem colorem; \& uberius in foco lentis retentæ, abs- 
que omni alio eliquationem promoventis fluoris adminiculo, in plumbi regulos fufæ funt illico. Amœnum plane hac in operatione videre fuit, afcendentem ex quovis rubræ calcis frufulo, quod in focum perductum fuit, brevem, fubtilifimamque $\&$ cæruleam fumi virgulam, atque illico fubfecutam in foco ipfo bullitionem metalli, \& poft momentaneam bullitionem, conquiefcere globellum regulinum plumbeum nitentiffunum, circello flavo, halonis ad infar, cinctum. Atque hæc ope caufticæ lentis prættita funt.

Eadem, \& multo major etiam, celeriorque particellarum rhomboidearum difperfio; idem etiam, majorque in diffractione earumdem ftridor obfervata fuere, quoties vel vivis prunis impofitæ cryftalli, lamellæve fpati plumbiferi, vel emortuo quidem carboni, directa tamen in eas per. ferruminatoriam fiftulam flammæ cufpide, ignis perfentifcere vim cœperunt: ut adeo non in fcrobiculum duntaxat carbonis demergendæ, fed altero quoqृue obtegendæ carbone, aut certe liquefcente, fpumefcenteque obvolvendæ antea fuerint borace, ne qua data: porta difugerent illico. His confrictæ vinculis earumdem quidem diffipatio, non vero elaftica, frepitansque: 
difractio impedita fuit; utpote quæ \& a vicina exaudiri aure, \& continuata porro fufione, in pluribus, iisque admodum exiguis plumbi regulini globellis intra boracis vitrun, oculo etiam videri potuit. Iterum cum lamellis, cryftallisque plumbi fpatofi flavi prima feci experimenta, tum cum aliter coloratis, aut excoloribus. Hæ peracta non fine ftridore, diffractione \& diiperfione, collectæ iterum, ad flammæ cufpidem calcinatæ funt in terram coloris lateritio-rubri non permanentis; fiquidem ut a Aamma remota fuit terra hæc calcinata, iterumque frigefacta, in citrinum ruber abiit colorem; $\&$ ex citrino ad flammam denuo in rubrum; continuataque porro fifulæe ferruminatoriæ actione, abfque omni falis aut fuoris mineralis adminiculo, in plumbi fufa regulum, fulphureo cinctum nimbo. At illæ difficilioris paulo reductionis erant; longiffimo quamvis tempore calcinatæ, nunquam calcinatione rubræ factæ funt; continuata rurfum per longius temporis fpatiun flammæ vi, fufæ quidem tandem funt particellæ illæ calcinatæ, in fcoriam vitri fimilem, fed quæ abfque borace non nifi ægerrime aliquid plumbi largiretur; citius aliquantum, etfi non citiffune, adhibito fimul borace; addito denique mícellæ ex fyato plumbifero flavo, \& borace, tantillo nitri, cum inftantanea ni- 
tri detonatione, numerofiffimi fimul plumbi reguli, in liquido boracis, nitrique jufculo cernebantur.

An hæ cryftalli arfenico mineralilatæ fint? illud neque afferere, neque negare adhuc poffun, quamdiu in vafis claufis nulla cum is feci experimenta. Illud fcio, nec in earum uftulatione, nec in calcinatione, nec denique in fufione \& reductione, vel minimum alliacei odoris me obfervare potuife, quamvis de induftria attenderim. Si de flava concederemus varietate arfenici illan continere nihil; fundamento nondum careret per id fententia, ejusdem prafentiam in aliter coloratis varietatibus adftruens. Obfervabam porro, varietatem albam, hyalinam, pellucidam, metallicolorem, peracta diffilitione, \& calcinatione, illico absque omni adminiculo, aut difficultate reduci; cum tamen ea, quæ flavo tincta eft colore, pertinacior multo, plumbi fit retinentiffima; illudqque fola, non nifi avarifime largiatur; imo nec cum borace citiffme, nifi quidem addito fimul nitro; cujus demum detonatione, ubicunque vel tantilla plunbi particella reperitur, protinus illam excuti neceffe eft : cujus cum apud me caufam indagarem, non alia fateor verifimilior mihi vifa eft, quam modicifima illa verri, quæ varietati flavæ præ-

$$
\mathrm{U}_{3} \text { terea }
$$


158 MINERA PLUMET SPATOSA

terea ineft, portio. Nam cum nullum non plumbum fpatofum aliqua faltem calcis fœtum fit quantitate, ut ex ejusiem in aqua forti folutione compertum habemus; tamen quæ flavæ varietati ineft calx, intime fimul argillæ, mixta eft, nec. qualicunque argillæ, fed argillæ martiali flavæ. .

Ut ne tamen in re, non leviflimi certe momenti, quidquam ex tripode, imo temere etiam, ftatuerem, ad amicum Dominum de Hanftadt, lithargyrii fornacibus Bleybergæ Præfectum, Nirum Mineralogiæ æque ac chemix peritifimum fcripfi, rogavique, ut fi quæ cum fpatofo hocce plumbo experimenta feciffet, benigne mecum communicare vellet. Noft, refcripfit, lamellas hafce, non minus, quam cryftallos, de more alius cujusque fpati, prunis. impofitas fridere, $\mathcal{E}$ fridendo quaquaverfim disjici; id quod earumdem reducfionem perdifficilem femper absque borace reddit; fieri tamen hanc denique, fi liquatis fimul, boraci, lamellisque plumbi fpatofi, tantillum nitri infperferis. Ut nihilominus de earumdem phonomenis certi quidpiam ficirem, indeque aliqua ratione ad principia illarum concluderem, fola igris vi traitandas fufcepi. Cryftallos ergo fpati plumbiferi flavi aliquot fuper calentitifima per tempus aliquod fornace 
privvie repofitas, calentiflmas $\mathcal{E}$ ipfas reddidi; tum eas tales confepelivi in fovea Juper carbone facta, alteroque conte$x i$; famme cufpidem acutifimam mediante fiftula ferruminctoril defuper immifi, eo denique fuccefu, ut intra tempus breviufculum fcoriam obtinuerim fpongiofam, ex qua complures, minutiffime quamuis, plumbi fpherule undique exfudare coperunt, peripheriam interim carbonis circa foveam, iridis inftar obducente halitu ex viridi-flavo. Fïeri equidem E alia plura poffent experimenta ad decompofitionem ninerse iffius uberius infitituendan, $f i$ modo requifito ad id apparatu chemico ifthic locorum inftructus forem amplius; fed vel ex hoc fatis fipperque conftcre arbitror, eamdem arfenici continere niht, verum preter pauxillum fulphuris, \& plumbi in centumpondio libras quinquaginta aliquot, terram proterea culcaream argillie mixtam, feu margam friabilem rubro-fuscam Cronfedti, eam nimirum, qua plerumque $\mathcal{E}_{3}$ cryftalli ip/ix, Ev lamellhe, EJ cui ifte infident calcareus lapis obduci folent: hæc ille de flava varietate.

Supra jam indicatum fuit, mineræ huic noftræ, cum calcarei natura fpati eo etiam ex capite plurimum convenire, quod perinde ut illud acidis effervefcat mineralibus. Wallerii certe fententia hæc eft Tomo 2. pag.307. N.6. 
Bornii etiam, faltem in varietate flavefcente Carinthiæ part. I. pag. 90. Scopolius "contra pag. I57. N. 2. non effervefcere acidis Carinthiacam lythargyriformem fuftnet. Gmelinus Torn. 3. pag. 229. plumbum ipatofum cujusdemumcunque coloris aut figuræ, fæpe duntaxat, non femper, aqua, quam fortem dicimus, effervefcere inquit. Linnæus denique eam præcife moveri acidis exiftmat, quæ quarzi polleat facie, hyalina pellucida rafilis; reliquis, five albæ five flavæ dein fint, haudquaquam effervefcentibus, utpote fixis. Hoc ut certis tandem convictus experimentis comperirem, \& ipfe fortem fingulis aquam adhibui varietatibus. Guttam acidi hujus calamo exceptam fuperimpofui diverfis per vices jan cryftallis, jam lamellis: flavis, viridibus, rubris, albis quarzi facie, hyalinis, pellucidis, metallicoloribus, corneo-cinerafcentibus. Illico nonnunquam effervefcebant fpumantes; immobilis alias perfitit, \& excolor defuper gutta : hæfi ad novitatem rei tantifper: obfervavi deinceps, defluxiffe łæpe fæpius tantillum acidi in calcaream, cui infidebant matricem; aut in margaceum, quo obducta hæc fuerat, lutum; attigiffe etiam interdum cruftam cryftallino druficam fpati calcarei; aut Zincum falactiticum nudulofum niveum, quod perquam copiofum Bleybergæ; in Rabl; 
in monte Jauken \& c. reperitur, ac nunquam non acido - nitri movetur, ob admixtas indubie calcareas particulas. Avulfas igitur fuis de matricibus cryflallos, lamellasque iterato fubjeci examini. Hexagono-prifmaticæ virides, (num. 2.3.) ne minimam unquam five effervefcentiam, five motum cum aqua forti prodiderunt: idem plane effectus, aut potius non effectus erat, quoties flava varietas adhibita fuit, nondum fatifcens, imo recens, omnisque fpurcitiei pura; quodfi fæculis hæc margaceis magis, minusve oblita, nec lota prius fuit, utique his, non illi, quæ fubito fe manifeftarent fpumantes bullulæ, attribuendæ erant. Grana quoque cryftallina, inordinate octoëdrica plumbi fpatofi rubri, \& octodecaëdrica flavi, diaphana, diligenter antea lavata in aquam injeci fortem copiofufculam; bullulæ aëreæ, effervefcentiæ manifefta indicia, fuperficiem fludi petierunt nullæ; fed \& excolur præterea acidum, \& immutatæ perftiterunt per plures dies in eodem demerfæ cryfialli; donec poft hebdomades denique aliquot cryfallorum fuperficiem tenui velut obductam pituita, \& acidum dilutiffme flavo-virente tinEtum colore, indubio folutionis qualis qualis factæ figno, inveni. Cuod reliquas plumbi fpatofi Carinthiaci varietates attinet, albas, hyalinas, exculores, pellucidas, 


\section{I62 MINERA PIUMBI SPATOSA}

metallicolores, corneo-cinerafcentes omnes, præprimis quæ quarzi funt facie, \& colore ad primum ftatim aqua fortis contactum efiervefcunt aliquantum, aqua tamen forti cito imbibita, etfi longifimo intra eandem remaneant tempore, absque omni deinceps motu \& ejusdem coloratione, perfiftunt; id folum inter easdem difcriminis obfervatum fuit, quod albæ quarzi aut boracis facie cry1talli, albedinem; excolores, hyalinæ \& :pellıcidæ, "pelluciditatem; metallicolores denique \& metalli nitorem \& pelluciditatem amiferint, \& deinceps omnes fibi prorfus finiles fuerint, fcilicet hyalino-fubalbentes, \& fubdiaphana. Mctallicolores præterea, fi admodum refplendente erant nitore, nonnifi poft aliquam denum moram, ubi magis magisque tefe diffudit per eas acidum nitri brevifimoque movebantur tempore; at contra, quas, numero 55 . defcriptas, rufas vocare folco, quandiu vel tenuiffme inftrata ochra illa martiali incruftantur, fixæ immobilesque funt; lotæcue primum, \& per loturam pellucidæ redditæ, eadem cun pellucidis phrenomena præftiterunt.

Obfervationes has meas cum ad laudatum fupra HanItadium perfcripfiffem, fuas viciffim, cum varietate fla- 
va factas, refponfi loco, ad me transmifit, quas hic tanto lubentius adferendas judicavi, quod a meis ne latum, ut dicimus, unguem recedant.

Ad abruptas plumbi fpatofi fluvi cryftallos aquam fontanatm per vices iteratas fudi, eo potiflimum fine, ut easdem ab immunditiis illis terre margacese flavie, quibus utplurimum totx, aut ex parte, obductex funt, depurarem. Sic lotis fuperinfudi nunc aquam fortem, alias oleum vitrioli; at neque cum hoc, neque cum illa quidquan efferbuerunt. Plures interea lapides dantur calcarei, filicex prafertim $\mathcal{S}_{3}$ impalpabilis texturce, qui non'nifi poft moram, aut in pulverem contriti, acidis moveantur. (Eos propterea gypfaceis Jufti terris adnumeravit, reclamantibus licet Crunftedto, Linnæo, \& Wallerio, quorum ifte in cenfum illos calcareorum fuorum æquabilium, ille tanquam totidem varietates, inter Marmora fua tarda relegat.) Hoc probe cum haberem perfpectum, houdquaquam nullius cryftallos hafce folutionis capaces effe judicavi ex eo, quod acido nitri non effervefcerent; fed in fubtiliffinum immo earum nonnullas comminui pulverem, non jam flavum illum, verum fublato precife partium nexu album; aquam dein fortem albre huic \& pulverulentre terrx affudi largius; 
bullula ä̈rece, effervefientix Ejolutionis certa indicia, afcendebant vel hoc in cafu nullie; repofui tamen adhuc operculo tectum vitreum illud vas una cum fluido ह pulvere fuper calida cubiculi fornace, vifurus an, Ė qui denique digeffionis forent effectus? Viginti $C$ aliquot horarum fpacium ubi elapfum fuit, tincta demum vifa eft colore ex viridi flavente aqua fortis, ut nullus deinceps dubitationi efe pofjet locus, facte per eamdem folutionis. Decantavi tum fuidum folutionis a materie in fundo vafis refidua, vafique magrio meo cum fupore, quam firmifime adglutinata, in vas aliud mundiffimum; guttatim defifer oleum tartari per deliquium ad faturationem usque infudi; qua operatione facta niveum denique procipitatum fuit Magifterium plumbi.

Recenfui, quæ cum minera plumbi fpatofi Carinthiaci facta funt experimenta; paucula funt; fed quid pluribus denique opus, quando vel ex pauculis his fatis demum \& de ejusdem principiis, \& certis, quæ ex natura illius promanant, proprietatibus, conftare poteft. Referam jam, quorum ad hunc usque diem mihi facta eft varietatum illius videndarum copia. Ludere in illis naturam, five verius fuprenum Ens, quis non videt?- ludit; fed vel dum ludit, adorandum. Nihil enim in tanta va- 
riationum rei unius ejusdemque multiplicitate, temere, aut tumultuarie, five forte fortuna factum videas; fingula potius irrefragabilibus Mathefeos legibus; erravi, fingula immo divinæ confona menti, non nifi omnipotentem, ac qualitercunque egerit, falli nefciam loquuntur fapientiam.

\section{I.}

PLUMBUM fpatofum flavum, atomis, teffulisque microfcopicis micans. Nafcitur intra cretam in cuniculo fanctæ Cunegundis Bleybergæ:

Poffideo ex prædicto cuniculo cretæ frufta, quæ diffracta per niveam æquabilem feu impalpabilem, aut etiarn per rufo-flaventem pulverulentam fracturæ fuperficiem, tractus exhibent fparlos, aut nullo ordine difcurrentes oblongos, latiufculos, contractiures, etiam venarum, fibrarumve tenuium inftar ferpentes, coloris fulphurei, aut lulphureo dilutius flaventis. Probe infpecti aliud haud funt, quam flavorum congeries pulvifculorum. Hoc fi quidem foli obverteris, aut oblique afpexeris, vel denique microfcopio examinaveris, atomos, teffulasque planas

$$
\mathrm{X}_{3} \text {-mi- }
$$


minutiffimas, vereque microfcopicas quadrilateras, fachari adinftar micantes, plumbi fpatofi citrini effe deteges.

\section{II.}

PLUMBUM fpatofum flavum lomellofum, lamellis exiguis planis, quadrilateris aut inordinate angulato-rotundatis, pallido auri colore micantibus. Ex eodem S. Cunegundis cuniculo.

Nefcio fi pulchrius quid videri poffit? cretam fcilicet niveam cohærentem folidam particulis impalpabilibus conftantem, intra digitos tamen friabilem, fafciæ tenues, flavo-rufæ, parallelæ, undatæ, jam approximatæ, jam longius remotæ, horizontaliter fecant ftratis concoloribus pulverulentis, \& ipfis cretaceis, fed marte faturatis. Planum fectionis verticalis promifcue infternunt denfius aut rariter magis aggregata punctula, maculæque rotundatæ, aut afteroideo-dendritiformes, nigræ, mixtæ lamellis plumbi fpatof citrini exiguis, perquam tenuibus, planis, diaphanis, partim quadrilateris, partim inordinate angu'ato-rotundatis, inæqualibus, pallido auri nitore micantibus, fectioni verticali parallele incum- 
bentibus, ac propterez ad planum horizontale perpendicularibus.

\section{III.}

PLUMBUM fpatofum farum lamellofim, lamellis fimplicibus quadratis, parallelogrammicisque poftratis fparfis. Intra eamdem cretam ad $S$. Cunegundem.

Sunt lamellæ hæ fimplices, admodum graciles, papyro tenuiores, diaphanæ, lævigatiffimæ, nitentes, jam faturatiore, jam diluto magis citri colore, quadrati, aut etiam parallelogrammi figura, quarum latus unam, aut interdum vix dimidiam excedit lineam parifnam, planæ, ac fuper eodem plano cretæ ipfius five verticali, five horizontali proftratæ, prodiga alias, alias avara tantum ma1II fparfr, cretam matrem, de fe fpeciofam, diverfisque luxuriantem coloribus, \& dendriticis piftam ornamentis fpeciofiorem ex communi tot elegantiarum commixtione reddentes. Quoniam vero cretæ hic facta eft mentio, $\&$ (çuod fingulare plane eft) cretam metallorum etiam exiftere poffe matricem, vidimus; juvat ipfius quoque cretæ hujus, varietatumçue illius, uberiorem tantifper defcri- 
defcriptionem dare. 'Tres ejusdem cum Linnæo, Wallerio, Cronftedto, ac Bornio ad fanctam Cunegundem deteximus fubalternas fpecies, cohrfione potiffimum, ac fubtilitate partium, inter te differentes, omnes acido effervefcentes, ac folubiles.

\section{a. CRETA FARINACEA.}

Creta folubilis, pura, farinaceo-pulverulenta, mollifima. Creta farinacea, fpongiofa, mollis. Wall. min. tom. I. pag. 3o. num. 3 .
r. Nivea.
2. Albida.
3. Albido-flavens.
4. Flava.
5. Flavo-rufa.

Inveftit nonnunquam calcareum ex albo cinerafcentem, brevi defcribendum, alias inter Arata ejusdem alterna interjacet, ex fatifcentia ejusdem procul dubio orta, fequentis filia. Eft autem pulvis fubtiliffimus farinaceus, tactui mollifimus, cypriorum inftar pulverum; non, 
aut non nifi levifime cohærens, inquinans, effervefcens, jam niveus, alias fordidius albidus, aut ex tinctura martiali, aërisque attactu, ex albido flavens, aut flavus, aut flavo - rufus.

\section{CRETA ARENOSA.}

Creta folubilis, pura, arenofo-pulverulenta, fcabriufcula. Creta tophacea, pulverulenta, rudis. Wall. min. tom. x. pag. 26. numt. 2.

Calx (marmorea, ) folubilis, pulverea. Linn. Syft. pag. 206.

Terra calcarea pura pulverulenta. Cronft. $\$ .5$. Terra calcarea pura pulverulenta alba. Born. ind. fols. r. pag. I.

$$
\begin{aligned}
& \text { 1. Alba. } \\
& \text { 2. Albido-favefcens. } \\
& \text { 3. Flavo-rufefcens. }
\end{aligned}
$$

Eumdem calcereum fub priore creta nonnunquam inveftiens; alias fubfequentem cretam includens, aut per fafcias, ftrataque horizontalia alterna percurrens. Pul- 
vis \& hæc perexilis, non, aut vix, cohærens, minus aliquantum priore inquinans, tamen $\&$ ipfe effervefcens, particellis compofitus mollifimis aliis, aliis tactui fcaloriutculis, arenaceis, calcareæ naturæ, inter digitos friabilibus. Prima indubie calcarei dicti deftructio, in cret $\mathrm{m}$ priorem denique abiens.

\section{c. CRETA SOLIDA.}

Creta folubilis, pura, cohærens, folida, friabilis. Creta cohærens folida. Wall. min. tom. I. pag.25. num. $\mathrm{I}$.

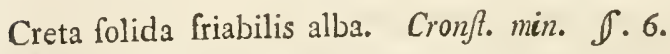

Calx (Creta) folubilis impalpabilis cohærens. Linn. $\int y / t$. pag. 206.

Terra calcarea folida friabilis alba. Born. ind. foff. tom. 1. pag. 1. $\mathcal{E}$ tom. 2. pag. $7^{6}$.

1. Nivea immaculata.

2. alba.

3. flavens.

4. ex luteo $\&$ albo varia.

5. al- 
5. alba lineis horizontalibus parallelis flavis, approximatis vel remotis, rectis aut undulatis, $f_{1}$ fciata.

6. albu firatis flavis cretaceis inclufa.

7. alla, aut flavens, punctis maculisque afteroideo-dendriticis fubrufis aut nigricantibus variegata.

8. alla, ant flavens, atomis teflulisque microfcopicis micantibus, aut lamellis angulato-r_undatis auricoloribus, vel denique Limellis quadratis tenerrimis ci-' trinis plumbi jpatofi inftrata.

9. nivea alba aut flavens fractura arida, particulis impalpabilibus, tactui molliffimis.

10. nivea compacta impalpabilis, tactui mollifima, fuperficie indurata, lievigata, fpeculari nitente, maculis dendriticis majufculis nigris picta.

Omnes hæ, cretæ folidæ, varietates, eodem in cuniculo, fupra, aut inter calcareum præditum reperiuntur. Quod ad cretam ipfum attinet, in fodina quidem, arY 2

gillæ 
I72 MINERA PLUMBISATOSA

gillæ fubterraneæ inftar, fubhumida, cohærens tamen effe folet, libero in aëre ficcifima evadens, itaque demum cohærens \& folida, ut fracturæ ejusdem fint planæ æণฺıbiles, aut etiam, filicum more, conchacex, impalpabiles. Crteroquin particulis conftat maxime femper, facillimeque inter digitos friabilibus, mollifimis, aut fubarenaceis, açu forti egregie effervefcentibus.

\section{IV.}

FLUMBUM fpatofum faturo cerie flavx colore lamellofum, lamellis fimplicibus quadratis, ochre plumbi cinereo-incane indurate innatis. Bleybergæ ex cuniculo Maria-Lichtmeffe.

Non nifi colore \& matrice, hæc a priore differt varietas. Lamellæ plumbi fpatofi, teneræ illæ, diaphanæ, nitentes, fimplices, quadratæ, coloris ceræ faturatæ flavæ, aut etiam ex flavo aurantiaco-rufæ, confertim aggregatæ, non matrici lapideæ, neque mineræ plumbi ipfi, fed ochræ ejusdem innatæ, partimque eidem infiftentes fub quavis inclinatione, partim horizontaliter eidem inftratæ, \& decumbentes funt. Et hoc ipfum peculiare omni- 


\section{CARINTHIACA.}

omnino phænomenon! \& hoc ipfum phænomenon manifefte docens, ferius longe larvatum hocce plumbum, fpati facie, plumbo ipfo generatum, filicet poftea generatum duntaxat, quam folida plumbi galena, ea qua injuriis aeris parte patebat maxime, deftructa, novamque pafta eft metamorphofin pulverulento-ochraceam. Cruitæ itaque inore folidam plumbi galenam, area majufcula micantem, non rariter infperfæ, fed denfæ, compactæque inftar argillæ, ex cinereo-incana plumbi ochra obducit, cui arctius cohærenti, \& fere induratæ, tamquam matrici innafcuntur præditæ lamellæ. Ochraceæ hujus terræ fruftula complura, cultello abrafa, emortuisque impofita carbonibus, ope folius fiftulæ ferruminatoriæ, absque ullis adminiculis aliis, in plumbum illico fudi iteratis vicibus. Cinereus primum ad flammæ culpidem in lateritio - rubrum mutatus eft color, tum fundi, bullire, in fphæroidicum, metallicolorem, \& refplendentem plumbi regulum glebula rubræ hujus terræ abire cœpit. Alinuam tamen, utcunque modicam, calcareæ terræ portiunculam, vel huic adhucdum ochre inefle debere, inde concluf, quod fuperinfula eidem arqua forti, complures, licet perquam exiguæ, ex eodem efferbuerint bullulæ. 


\section{$V^{\top}$.}

PLUMBUM fpatofum citrinum lamellofunt, lamellis fimplicibus quadratis infidentibus cruftex fpati calcarei partim drufici botrytico-nodulofi, partim cryffallini, cryfallis dodecaëdris duplicato-pyramidatis. Bleybergæ ex cuniculo veteri fancti Matthæi.

Obtegit calcareum album fubcinerafcentem æquabilem crufta bracteata calcareo- fpatola drufica, botryticonodulofa, ex hyalino - albida, diaphana facchari cryftallifati inftar micans; ex parte etiam rubro-aurantiaca, \& opaca ex marga martiali, quæ fluida quondam, ac tuper illam defluens, fuo eandem inquinavit colore. Nodulo$f x$, aut $f_{1}$ mavis glandulofæ illæ eminentix aut ipfær ruyfum minimis undique tuberculis, rotundatis, aut certe cryftallulis fpatofis acaulibus, perquan \& illis exiguis tetraaut hexagono-pyramidatis muricatæ funt. Sparæ per cruftam hanc talem, quovis in fitu, inclinatione, directioneque funt quadratæ, fed magnitudine differentes plumbi fpatofi citrini lamellæ, ac cum illis interpolatæ majufculæe cryttalli, pariter calcareo-fpatofæ, horizonta- 
liter incumbentes, dodecaëdræ, hyodontis, feu dentium apri formam referentes, ex pyramidibus binis hexagonis, bafibus absque intermedio prifmate cualitis, compofitx, quarum triangula lateralia cun æquiangula minime fint, fed fcalæna, etiam magnitudine differant, neceffe eft. Memini autem me in Bieybergenfibus fodinis cryftallos has hyodontis forma perfæe vidife admodum variantes; maximæ nonnunquam erant, alias minores; nunc albæ, opacr, nitentes lævigatæ, \& velut pingues; alias hyalinæ, transparentes, echinatæ, aut etiam fcalares; ftructùra interna femper lamellata, etfi lamellis ita coalitis, ut veftigia earum extus detegi poffent nulla, nifi frangerentur. Omnium elegantifima ea eft varietas, dum depreffx, \& planiufculæ funt cum exigua obtufifimaque sonvexitate, triangulis lateralibus nonnullis ampliffimis obtufangulis, aliis anguftiffimis acutangulis.

\section{VI.}

PLUMBUM fpatofum aquofifjime topazinum lameliofum, lamellis fimplicibus aggregatis quadrilueris pellucidis. In Kabel e cuniculo S. Sebaftiani im tiefen Schacht. 
Tum etiam in fupremis cuniculis Schaben-Rucken diktis.

Hoc primum anno paucos ante menfes e cumulatis plumbi venis montis regii Rablenfis erutum denicque fuit plumbum fpatofum nunquam antea vifum ifthic, aut certe nulla habitum ad hoc usque tempus attentione dignum. Non paucis a Bleybergenfi differt notis. Pellucidum primo eft, utut coloratum plerumque; \& colore eo, quo Bleybergenfe tinctum nondum vidimus; fcilicet topazino; adeo tamen diluto, ut non nifi aquofifima tinctum flavedine credas; alias flavefcensne fit? an potius viridefcens? dubites; imo emori Havedinem dicas omnem, \& excolores fieri lamellas, uti vulgo tolent 'Topazii bohomici quidam, quos fpurios inter adamantes connumerant. Lamellarum praterea teneritudo \& fubtilitas fumma, ut quæ vix majore, quam capilli fint craffitudine; \& politura lævigatifima; \& nitor micans dicam? an fcin- tillans potius? ab aliis plumbi fpatofi flavi varietatibus omnibus hanc diverfam effe indicant. Lamellæ ipfæ, utut non eadem omnes exilitate funt, exigur tamen femper, fumplices, rariter fpariæ, aut accumulatæ, erectæ, ut plurimum quadrilateræ, quibusdam \& octilateris interdum 
dum mixtæ. Hæ quandoque fpato calcareo albo infident; alias calcareo itidem albo æquabili, fed fatifcenti; nonnunquam plumbi galenam folidam, fuperficie erofam incruftant.

\section{VII.}

PLUMBUM fpatofum favo-rufum lamellofum, lamellis quadratis fimtlicihus aggregatis, imbricatisque in rofam polypetalam erecto-patentem. E vetere S. Matthæi fodina Bleybergx.

Exhibet lamellas graciles tenues quadrilateras rectangulas fumplices, fed confertim fimul accumulatas, quandoque proftratas, plerumque tamen aut perpendiculariter, aut certe fub angulo quovis acuto erecto - patentes; quin \& perfæpe imbricatim fibi mutuo infiftentes, rofulasque polypetalas peculiari hoc fuo fitu efformantes. Superficies earum lævigata eft, \& nitens. Color dilute flavens, citrinus flavus, aut faturate magis e flavo rufus, prout aut puriores exiflunt, aut intime, vel externe faltem, a diffundente fe fuper eas martiali marga, rufa imbutæ lunt tinctura; quæ $\&$ fola majoris, aut mino- 
ris eorumdem diaphaneitatis, fi bdiaphaneitatisve caufa videtur effe. Matrix illarum, cæterarumcue mox commemorandarum e fodina hac varietatum, una fere, eademque lemper eft Calcareus Cronfledti particulis impalpabilibus albus, $\&$ ex albo fubgrifefcens, rivis fpati calcarei hyalini nonnunquam percurfus. Verum plura funt, quæ in lapide hoc attentione paulo digniora notavimus, quam ut generali calcarei notione contenti poffimus effe. Specularis cumprimis, quam ob partium æquabilitatem, denfitatemque fummam fufcipit, politura, \& qua marmoribus unicoloribus Wallerii non immerito adnumerandus eft; tum picturæ, quas dendriticas vocant, nigræ, furculis hypni proliferi, aut abietini Linnæi, quam fimillimæ; quas non tam ferro cum Cartheufero, quam fuliginofæ potius Magnefiæ Wallerii adfcribendas effe infra oftenfuri fumus; denique magni, quilus non raro fotus eft, nuclei. Hi non nucis duntaxat majoris, fed pomi etiam magnitudinem interdum æquant, ejusdem plane, cum matre lapide materiei calcareæ, intra cujus cavitates confepulti, easdem exacte replent, etfi cum eodem continui haud funt, propterea quod plerum. que aut glutine margaceo rufo, aut crufta tenui cryftallino-drufica fpati calcarei albi ubducantur. Forma nucleis his, inftar immobilium embryonum intra aètiten mar- 
moreum latitantium, non vaga quævis eft, fed fpecifica teftacei bivalvis trianguli, nec coftati, nec ftriati, fed nudi, marga, aut fpato drufico Cronftedti obducti identidem; ejus nempe, quod cor bovis cum Helminthologis haud injuria dicas. Walchius fub Bucarditæ nomine in Tabulæ XV. Fig. I. loco dextimo fatis adumbravit bene. Nates illi etfi ultra cardinem procurrant altius, umbone tamen funt recto obtufiufculo potius, quam curvato, aut arietini inftar cornu fpiraliter intorto; quæ fola demum ratio fuit, quod a bivalvi illo, fub quo tamquam foffilis varietas militat, quodque Linnæus Chama cor compellatum voluit, removerim. Anus \& ipfe cordatus eft, fed oblongus, lateribus verfus rimam dehifcentem declivibus, \& vallem profundam, amplam intercipientibus. Quod ad memoratos fupra dendritas attinet, qua demumcunque in fubftantiæ lapideæ profunditate deprehendantur, leviffime eamdem, \& ut dicere folemus, fuperficialiter duntaxat perftringunt; deteri itaque earumdem pulchritudinem neceffe eft femper, quoties nitentem lapidi polituram inducere volueris; quod nifi foret, non tam marmor unicolor albido-grifeum $\mathrm{W}^{\mathrm{r}}$ allerii, quam Alberini Florentinorum fpeciem, feu marmor piftorium dendritis ornatum ejusdem $\mathrm{W}_{\text {allerii absque hæfitatione dixiffem. }}$

$$
\mathrm{Z}_{2} \text { VIII. }
$$




\section{VIII.}

PLUMBUM fratofum dilute flavens lamellofum, lamelis quadrilateris difco dilutiore, peripheria faturáca mugis. Tab."2r. Fig. r. Ex eadem cum priore fodina, eademque in matrice.

Subtiliffimi inflar pulveris, arcte tamen matrici adhærentis, inftratum video prædictum calcareum marga, feu terra calcarea argillæ intime mixta Cronftedti; quæ fluida olim per extimam lapidis fuperficiem ftillando utique defluens, fui in eodem veftigia depofuit pulveru1enta. Ferro participare, color indicat flavo-rufus, e rufo ruber, e rubro ætate denique niger; aqua forti egregie femper effervefcens. Huic tali teneræ admodum infident plumbi fpatofi lamellæ fimplices fparfæ erectæ fuberectrque, aut normaliter, aut oblique, aut penitus etiam decumbentes, \& proftratæ. Ut magnitudine cæteroquin differunt inter $\mathrm{fe}$, ita figura pariter; ut quadratam nonnulie, aliæ rectangulam potius, triangularem denique habeant aliæ; prout aut lateri quæque fuo, tamquam bafi aut diagonali precife infillit. Gracilitas, teneritudoque eartund in perquam eft fingularis, ut craffitudinem fere neges 
neges habere: neque perperam loquatur, qui feneftratas appellavit, adeo quadrilateras feneitrarum tabulas plumbeo margine inclufas referunt, campo medio dilutiffime flavente \& pellucido, cum peripheriæ margo faturatus magis fit, obfcurior.

\section{IX.}

PLLMEUM fpatofum favo-viride lamellofum, lamellis fimplicibus quadratis erectis confertiffme accumulatis diluphanis nitentibus. Tab. 2I. Fig. 2. Fodina, \& matrix eadem, quæ priori.

Specimen, vel Bleybergæ, admodum rarum. Lamellx hoc in lapidis calcarei frufto perexiguæ pleræque lunt, paulo majoribus aliis mixtæ, fimplices, quadratæ, erectæ, confertiffine accumulatæ, teneræ quidem \& graciles, minus tamen, quam antecedentes, utpote quæ cral. fitudine tamen polleant aliqua, diaphanæ cæterocjuin omnes, micantes, \& ex nitore refplendentes. Singulare illis id eft, quo fe a reliquis, quas Bleybergæ adhuc vidi, varietatibus diflinguunt omnibus, quod flavus earundem color magis viridelcat femper, magisque, donec $l x-$

$$
Z_{3}
$$
tiffine 
tifime virides, absque omni flavedinis tinctura evadant denique, grato, fi quo, oculis fpectaculo.

\section{X.}

PLUMBUM Jpatofum obfolete flavens lamellofim, lamellis fimplicibus rhombeis diaphanis, macula centrali $\mathcal{E}$ ipfa rhombea, parallela, faturate rufa $\mathcal{E}$ opaca. Tab. 2 I. Fig. 3. Indidem fuper calcareo eodem, luto margaceo extus obducto.

Varietatis hujus lamellæ, fi paucas proftratas demas, ereçæ, aut inclinatæ tamen ad horizontem funt omnes, utut permodica, aliqua certe craffitudine femper præditæ. Quod earum concernit figuram, rhombi ea, non quadrati eft; lateribus in obliquum potius, quam erectum angulum concurrentibus, iisque inter fe omnibus, at vero angulis, non nifi fibi mutıo oppofitis quibusve, æqualibus. Earum aliquæ lateri infiftunt, \& hæ quidem integræ funt; quæ contra integræ non funt, aut rhombi diagonalem pro bafi habent, aut parallelam diagonali, quamvis fupra aut infra centrum, lineam. Admiratione id maxime in is dignum eft, quod cum coloris fint perquam dilute, etfi obfo- 
obfolete fimul flaventis, \& diaphanæ, \& nitentes, infcriptam tamen quævis habeat maculam centralem duplo triplove minorem, \& ipfam pariter rhombeam, lamellis ipfis confimilem \& parallelam, faturatiffime rufam, opacam, nitorisque omnis expertem.

\section{XI.}

PLUMBUM fpatofum citrinum lamellofum, lamellis fimplicibus rotundato fubquadrilateris nitentibus diaphanisque, macula centrali rhombea dilute lateritia opaca. Ex S. Matthæo in Calcareo fupradicto, narga ex flavo magis magisque rubra, tandemque nigra fordefcente.

Parum ipfa re, facie vero plurimum ab antecedente differt varietas ifta. Lamellx huic minus regulares, nulla certe lege figuratæ, circumfcriptione potius rotundata, fubquadrilatera; fimplices cætera; jam parcius fparfæ, iterumque cumulate magis àggregatæ; erectæ fuberectis, \& decumbentibus promifcue mixta. Teneritudine prioribus antecellunt multo, fed \& vivacitate nitoris, \& colorum elegantia; fiquidem longa præ illis graciles ma- - 
gis funt, lævigatiffimæ, refplendentes, diaphanæ, flavedine haud obfoleta, fed læta, citrina tinctæ; macula difci centrali rhombea, aquofe lateritia, absque nitore opaca.

\section{XII.}

PLUMBUM fpatofum citrinum lamellofum, lamellis fimplicibus quadratis, octilaterisque nitentibus diaphanis, difco rhombeo, lamellis contrario, $\mathcal{E}$ difcolore. 'Tab. 2I. Fig. 4. Pariter ex S. Matthæo in fæpius jam memorato calcareo, qua extus patet fuperficie ex marga rubro-aurantiaca, nigrave fqualente.

Perelegans fane plumbi fpatofi varietas! plures alias fub fe complectens inferiores varietates. De cryftallis, quarum nonnullas lamellis intermixtas, ad dextrum latus fpecimen habet, nihil hic commemorabo, uberius de iisdem brevi locuturus. Lamellas vero quod attinet, quadruplicis eæ generis funt; ac primo quidem quadiilateræ; \& octolateræ; feu quadratæ angulis non refectis. Forro tam hæ, quam illæ id commune quidem habent, quod ad rectum, five obliquum matri lapidi in- 
fiftunt angulum ereftr; quod teneritudinis, aut fi ita vis, tenuitatis utræque fint plusquam papyraceæ; utræque lævigatæ, nitentes, diaphanæ; utræque demum rhombum infcriptum habeant, non exiguum illum, \& centralem, fed ejusdem plane cum lamellis diametri, etfi lamellis nec concentricum, nec parallelum, fed contrarium, utpote cujus anguli, non angulis lamellarum, verum earumdem lateribus potius refpondeant. Rhombum hunc lamellis infcriptum, earumdem difcum compellare foleo; \& cum attentius infpicio, alius plane coloris, aliusque diaphaneitatis ab is lamellarum ipfarum femper video eundem effe. Etenim aut difcus minus flavet, quam reliquæ lamellarum partes exftantes, \& obfoleto, hyalinoque proximior colori, transmittendis quoque lucis radiis accommodatior exinde redditur, magisque, ut ita dicam, diaphanus pellucidusque fere eft; aut contra citrina faturatiore tinfura intimius penetratus, quam lamellarum ambitus, reflectendæ potius, quam refringendæ luci, magis fimul idoneus fit; ut adeo nunquam hac in varietate ejusdem five coloris, five tranfparentiæ fint difcus, \& circumferentia; ex quo demum alteram varietatis hujus fubdivifionem opus eft oriri. Meminiffe præterea necelle vix eft, immixtas quadruplicibus hifce lamellis alias quo- 
que effe dimidiatas, quæ prout aut diagonali ipfarum lamellarum, aut diagonali rhomborum infcriptorum, tanquam bafi infiltunt, triangula cum infcriptis parallelogrammis, aut parallelogramma cum infcriptis triangulis efformant.

\section{XIII.}

PLUMBUM fpatofium flavum lamellofum, lamellis fimplicibus rhomboidalibus, quadratisque fubdiaphanis, difico macula maxima, $\mathcal{E}$ ipfa rhomboidali parallela opaca. Tab. 2I. fig. 5. Cuniculus \& Matrix eadem.

Hlud varietati huic fingulare eft, quod cum calcareus, frepe jam dictus, cui lamellæ infident, aut non, aut vix, ullo margæ ex argillaceo flaventis luto infternatur, fingulæ tamen lamellæ plumbi fpatofi maculam ejusdem margæ maximam medio in difco lamellis ipfis confmilem rhomboidalem concentricam, parallelanque infcriptan habeant, idque ex una duntaxat, eademque femper in omnibus, non utraque parte. Hæc, cum lutulentæ fit naturæ, non opaca folum eft, \& nitoris expers, fed facile etiam cultro abradi poteft, ut quæ lamellarum fubltantiam 
tiam minime penetret, nec ex averfa earumdem parte compareat. Qua id factum denique fit ratione, ut lutum hocce, quamdiu fluidum exftitit, in lamellarum quamvis, utcunque ad horizontem inclinatam, deftillaverit? fuper ea in confimilem præcife lamellæ fe diffuderit aream? $\&$ hanc adeptam figuram conftiterit? exficcatumque fuper ea fuerit? quis demum appofite explicaverit latis? Lamellæ iplæ majufculæ funt, lævigatæ, nitentes, fimplices, fed aggregatx, imo nonnunquam etiam fibi mutuo infiftentes, aut fe invicem decuffantes, erectæ, paucioribus profratis, vix diaphanæ, fummum fubdiaphanæ, maximam partem rhomboidales, angulis tamen obtuffufculis, feı rotundatis velut, nonnullæ \& quadratæ, pauciffimæ inordinate penta - aut hexagonx. In poftremis hifce unus alterve figuræ angulus nonnunquam ex prædicta marga \& ipfe lutulentus.

\section{XIV.}

FLUMBUM fpatofum favum lumellofum, lamellis fimplicibus quadratis, pentagoris, fulhexcryonisque, area centrali, peripheriaque citrinis, annulo intermedio fimiliter

$$
\text { A a } 2
$$

figu- 
figurato difcolore. Tab. 21. fig. 6. Ex fancto Matthæo fuper Marga argillacea Wallerii.

Elegans \& hæc varietas, tamque elegans, quam rara. Non fuper lapidea matrice, fed infidentibus frufto terræ calcareæ argilla intime mixtæ Cronftedti; margæ fcilicet albido-grifeæ, extus luto pariter margaceo rubro obductæ, lamellis fub quavis inclinatione erectis, fimplicibus, tenerrimis, diaphanis, nitentibus, aggregatis, tam magnitudine, quam circumfcriptione differentibus, quadratis, rhomboideis, pentagonis, \& inordinate hexagonis. Characteriftica, qua inter omnes fe diftinguunt alias, ea earundem eft nota: quod cum citrino cæteroquin fint colore tinctæ, annulum tamen in media difci area habeant, ipfi cujusque lamellæ polygono plane fimilem, concentricum, \& parallelum, difcolorem; feu quod idem eft, non citrinum, fed ex obfoleto luteolo hyalinum, majoris, quam quæ in reliqua fit lamella, transparentiæ, \& fubpcllucidum. Lamellæ exinde exiftunt, quarum area centralis quadrata, rhomboidea, pentagonave elt, dilute citrina, \& diaphana; quam latiufculus undique cingit annulus ex luteolo hyalinus, femipellucidus, \& ipfe quadiatus, rhomboideus, aut pentagonus; margine \& ipfe cir- 
circumfcriptus latiufculo circumferentiali quadrato, rhomboideo, aut pentagono, fed citrino rurfum, \& diaphano.

\section{XV.}

PLUMBUM Jpatofum flavum lamellofum, lamellis fafciculatis quadrilateris, imbricatis fihififormibus. Tab, 2 I. Fig. 7. Ex S. Matthæo fuper calcareo prædicto, marga aurantiaca obducto.

Nil nif fafciculos ifthic videas exiguos horfum vorfum projectos, jam decumbentes, alias erectos lamellarum perquam gracilium, gradatim magnitudine crefcentium, aut etiam decrefcentium, quadrilaterarum, imbricatim fibi mutuo incumbentium, arctiffimo inter fe cohærentium nexu, licet fchiftofi inftar lapidis fiffiles fint, \& facile findendæ credi poffent. - Fafciculus quisque tres minimum, plerumque quatuor, aut quinque, etiam fex ejusmodi conglutinatas complectitur lamellas, unam verfus partem minores femper minoresque; licet interdum organi inftar utrinque decrefcant. Flavedo illis pallidior, nitor vero idem, qui cæterarum plumbi fpatofi varietatum; fed \& diaphaneitas eadem, fi quidem de lamellis

$$
\text { A a } 3
$$


fingillatim, non de collectim fumptis, feu integro plurium lamellarum fafciculo loquaris.

\section{XVI.}

PLUMBUM Jpatofum flavum lamellofum, lamellis cum marga impura flavefcente, lapillisque calcareis in maffam lithargyriformem congmentatis. Ex eodem S. Matthæi cuniculo.

Indubie Terra plumbaria citrina Jpato/a Wallerii Syft. Mineral. 'T. 2. pag. 313. aut eodem certe, ut ifta, modo. progenitum, ex abruptis fcilicet unde unde, diffractisque plumbi fpatofi lamellis, perenni lubterranearum aquarum ftillicidio aliorfum devectis, terræ calcareo-argillacex, fabuloque commixtis, cum iisdem demum aëre ferruminante induratis. Plumbum apyrum lithargyriforme Carinthiacum Scopolii, notum, fateor, mihi haudquaquam eft. Unde demumcunque labuerit, a meo ifthoc diverfum effe, diverfæ utriusque evincunt proprietates.

\section{XVII.}

PLUMBUM fpatofum rubro-aurantiacum lamellofum, lamellis mutuo fe intercuffantibus, in cellulas ordinatis. Domicilio \& Matrice priorum. 
Si quæ, hæc utique, præ reliquis fpeciofa plane varictas; eminentifimo, fulgentifimoque nitore refplendet. Color illi rubro-aurantiacus perquam elegans. Lamellæ majufculæ, fed teneræ, contra lıcem diaphanæ, multis modis quadrilateræ, etiam pentagonæ, aut irregulares, fimplices, fed accumulatæ fimul, fuperque fe mutuo ad angulum five rectum five obliquum crectx, ac totis le planis intercuffantes, $\&$ in cellulas, concamerationesque non tot, quin plures, ordinatæ.

\section{XVIII.}

PLUMBUM fpatofum flavum laminofum, laminis planis inordinate fparfis, congeftisque, pafin etiam triquetroconniventibus, aut in communem cunei aciem convergentibus, fructura interiore cellulofa. Nativitatis 10cus idem, eadem etiam Matrix.

Non graciles lamellæ; laminæ verius, aut fi mavis tabulæ majufculæ varietati huic propriæ funt. Hæ terream fere potius, quam vitream; præ fe ferunt \& confiftentiam, \& faciem, graves, craffiufculæ, opacæ, magnitudine, \& figura perquain fæpe differentes, nulla autem cer- 


\section{MINERA PLUMBISPATOSA}

$\mathbf{t a}$, determinataque; planæ tamen, \& fupcrficie æque polita, ac nitente; coloris ejusdem femper, dilute flavo-argillacei; rarius funplices, erectæ, liberæ, \& regulari prædiłæ figura; ut plurimum quaquaverfum fparfæ, inordinate congeftæ, nulloque ordine in plana affurgentes inclinata, more fpati arenarii $\mathrm{W} /$ allerii, atque vel ideo mutuo fibi undique occurrentes, fefeque intercuffantes mutuo; paffm etiam triquetro-conniventes in pyramidem triedram, uti Mica cryftallina Linnæi; aut in communem denique cunei aciem convergentes; Aructura interiore cellulofa, externa vero admodum inæquali; variantibus inter fe acclivitatibus, alternisque vallibus.

\section{XIX.}

PLUMBUM Jpatofum flavum cryftallinum, cryftallis cubicis. Tab. 21. Fig. 8. Ex eadem cum antedictis fodina, eidemque infidens calcareo.

Infternitur denuo margâ ex rufo tandeın nigrâ idem calcareus, diffeminatasque fuper fe plumbi fpatofi gerit, non jam lamellas, fed cryftallos, \& cryftallos cubico-hexaedras, funtque aut rariter magis íparfæ, aut fti- 
pate magis accumulatix, mäjores minoribus nullo difcrimine mixtæ, diaphanæ, nitentes, coloris fulphurei, aut aquofius faltem flaventis. Laterum uni infiftunt alias, atque tum quidem perfectas dant aleas, leu regulares plane cubos, planis quadratis æqualibus fex comprehenfos; cubi alias diagonalis pro bafi illis elt, neque mirum dein, fi cryftallus inde nata, cunei, feu prifmatis trigoni irregularis faciem referat potius; fectioni cuivis alix, ad folidum cubi angulum obliquix, aut parallelæ ubi infident, truncatus tum exiftit cuneus, aut irregulariter polyëdra cryftallus alia. Eft, quod præterea adnotemus ifthic: eminentias quasdam ex rufo-fufcefcentes, ac denique nigras, cubicas inter cryftallos, undique difperfas inveniri; has microfcopio cum confuluiffem, cululos \& ipfos inveni effe jamjam fatifcentes ejusdem omnino fpatofi plumbi: pofficleo vero \& aliud quoque fpecinen anthracino-nigrum, cryflallos in eo quasdam atras, ex flavo magis, magisque nigrefcentes alias, alias etiam quam fimillimas ochræ martis flavæ, ex parte corrofas, confpicio; ut adeo non perperam me concludere credam poffe, fi plumbum fpatofum flavum, in ochram, non rufam folum, fed nigram etiam fatifcere denique, \& terram hanc plumbariam rubram, ac etiam nigram $\mathrm{W}$ allerii effe dicam, qux 
ex deftructione mineræ plumbi, ochra martiali, aut argilla ochracea mixta oriatur.

\section{$\mathrm{XX}$.}

PLUMBUM fpatofum aurantiacum cryftallinum, cryftallis partim cubicis, partim hexaëdro prifmaticis, promifcue mixtis. Tab. 2I. Fig. 9. Nec alia huic, quam varietatibus prioribus Patria, \& Mater.

Colorem cryftallorum cubicarum fi demas faturatum magis, vereque aurantiacum varietatis hujus, nihil a priore diverlum in ifta invenias; intermixtæ tamen cubicis \& aliæ cryftalli funt ifthic, regulari parallelepipedi feu prifmatis quadrangularis proftrati forma; hæ duplo, triplove cubicis longiores, vix tamen cubicarum five latitudinem, five profunditatem, plerarumque faltem, adæquant, corporaque dant hexaëdra, exiguis quadratis duobus oppofitis æqualibus, \& quatuor, inter fe denuo æqualibus, parallelogrammis comprehenfa. Reliqua ex datis in fpeciminibus fuperioribus defcriptionibus patent; neque quis etiam eft commemorare, maculis afteroidico-dendriticis calcaream matrem ornatam effe. Id folum haud- 
quaquam filentio prateribimus, inveniffe me elapfo proxime anno in fodinis illis plumbiferis, qux in monte, Velacherberg vulgo difto, prope fancti Hermagoræ vallis Gilienfis, dantur, Plumbum compactum Linnæi (Bleyfchveif) calcareo rquabili albido-grifefcenti, tardeque effervefcenti $\mathrm{W}$ allerii innatum; innatumque eidem fimul Zincum fpatofo-cryftallinum, figuratum, globofum, lamellis vitri facie, pellucidis, connatis, ex centro radiantibus, contro ipfi infidente cryftallo cubica aurantiaca plunbi fpatofi.

\section{XXI.}

PLUMBUM fpatofum aurantiacum cryfallinum, cryfallis inordinate hexaïdris. Pariter ex vetere S. Matthæi cuniculo.

Tulcherrimum fpecimen, femper cum admiratione fpeEtandum, nullis tamen unquam verbis fatis, aut tam eleganter defcribendum, quam elegans fcfe reipfa oculis videndum exhibet in natura. Hexaëdræ quidem funt cryftalli omnes, non tamen, ut dicere folemus, regulariter hexaëdræ, ejusciemque omnes generis cubos, five rectos, five obli-

$$
\mathrm{B} \text { b } 2
$$$$
\text { quan- }
$$ 
quangules \& rhomboidales, parallelepipeda, felenitasqque præ fe ferre videntur; illis tamen aut altitudo non eadent cun longitudine, latitudineque; aut longitudo abeft prifmati cæteroquin debita in iftis; aut denique in ultinis inferior affurgens deficit pars, ut cryftallus exinde orta, pyramidi quadrangulæ paulo fupra bafin infimam truncatæ potius, quam felenitæ, fimilis fit. Color illis amcne aurantiacus, \& nitor ex diverfis, prout vertuntur, punctis fcintillando refplendens. Facit ad id plurimum, quod - y n... - -..mmimis natx videantur fuiffe tempore, quo calcareus, cui infident, five loci iniquitate, five aëris fubterranei injuriis, vitiari, fatifcere, in cavernofos anfractus dehifcere, rurfumque in bracteatas affurgere laminas, totidem inftar parietum, copit. Cryftalli certe non in cavernofis duntaxat receffibus, tumulisque alternis protuberantibus, fed in latere etiam utroque exftantium laminarum, parcius, aut liberaliter magis diffeminatæ funt. Pulveris inftar flavi, more facchari fcintillantis, fparfa undique confpiciuntur inibi minutiffima corpufcula, quæ non nifi armatus denique oculus, cryftallos, paulo ante commemoratis confumiles, in magnitudine feminis papaveris, effe detegit, 


\section{XXII.}

PLUMBUM jpatofum flavum cryftallinum, cryfallis rhomboideis. Tal. 2I. Fig. IO. Et harum Matrix calcareus idem, idemque nativitatis locus S. Matthxus.

Craffitudo rhomborum facit, quod a lamellofis avulfam, in cy nallinarum confum redigam varietatem fpatofi hujus plumbi: hæc major, aut luppar minimum ei, qua pollere parallelepipeda Num. XX. vidimus, cum fit, quis lamellas, \& non veras cryftallos dicat? Longitudo illarum eadem, quæ latitudo; fæpiusque utræque, profunditatem earum excedentes, in obliquum mutuo concurrunt angulum; unde adeo corpus neceffe eft exfurgere regulare rhomboideo-hexaëdrum, binis oppofitis \& æqualibus rhombis maximis, quatuorque parallelogrammis lateralibus, anguftioribus quidem, inter fe tamen æqualibus, interceptum. Triftiore cætera ceræ flavæ colore tinct lunt rhomboideæ hx cryftalli, hoc tamen non obfiftente, diaphanæ adhuc, \& lævibus, nitentibusque fuperficiebus micantes. Situm quod attinet, licet accumulatæ confertim fint; \& fibi præterea in medio quandoque arearum

$$
\text { B } \sqcup \text { ) } 3 \text { nor- }
$$


normaliter mutuo infiftentes; imo fe nonnunquam etiam intercuffantes mutıo; haud đuaquam tamen ita ordinatæ, ut veras cellularum intercapedines efforment.

\section{XXIII.}

PLUMBUM fpatofum viride cryfallinum, cryfallis oetoëdris, utrinque truncatis, hexagono-prifmaticis.

Sola inter omues vartetas hæc eft, de qua utrum ex Carinthia revera fit ? aut non? dicere nequeo; femper dubitavi; \& adhucdum dubius hæreo. Quo potiflumum nata fit loco ? aut vel nafci potuerit ? ignoro; quando ubi demum plumbi cunque funt fodinæ in Carinthia, nufpiam viridis hujus fpeciei vel veftigium me inveniffe memini. Certum vero eft, hoc ipfum denique fpecimen, dum Marrhero in Grofs-Kircheimenfi comes effem itinere, eidem ab fofforum aliquo oblatum effe; ex quo utique arguere me poffe judico, fi Carinthiaca tamen inter producta connumerari debeat, non alibi, quam in concatenata illa altifimorum, \& vere glacialium montium maffa, quærendam effe. Meminere illius inter Autores: 
Linnæus Syft. Nat. edit. Vind. T. 3.p. 134.N.7. Plumbum virens ar fenicatum, cryftallis hexaëdro-(hexagono-) prifmaticis, utrinque truncatis.

Wallerius Syft. Mineral. T.2. p.308. N. 7. Minera plumbi viridis cryftallifata.

Woltersdorf. Syft. Miner. pag. 32. N. 4. Plumbum Jpatofun viride, plerumque prifmaticum, feu cryftallus plumbifera, cut Minera plumbi cryftallina dicta.

Cartheufer Elem. mineral. p. 66. N. 6. Plumb. mineralif. cryftallinum, cryftallis oblongis, columnaribus, hexaëdris, utrinque obtufis, dilute viridibus.

Cronfted. pag. 201. 202. Minera plumbi calciformis pura indurata cryftallina viridis.

Vogel Syft. pract. Mineral. pag. 206. N. 4. Minera plumbi viridis hexagono-columnaris truncata.

Born. Ind. Folfil. T. I. p. 9I. Plumbum fpatofum cryftallis viridibus hexaëdro-prifmaticis truncatis.

Gmelin. Tom. 3. pag. 227. Minera plumbi viridis cryftallis - hexaëdro-columnaribus atque pyramidalibus.

Defcriptio varietatis hujus noftræ fyftematica hæc eft: Matrix illi e filicum fporadicorum, non rupeftrium eft genere; fcilicet: filex vagus, fufcus, opacus, venulis 
nulis Chalcedonii lacteo-cærulefcentibus percurfus, hæmatitæ inftar nodulofus, cortice incruftatus concentricoteftaceo ex ochra ferri indurata flava, tandem fufconigrefcente. Ochra hæc ad fiftulam ferruminatoriam uftulata, addito tantillo pinguis phlogiftici retractoria efficitur: filex vero, qui fractura eft æquabili impalpabili, ad chalybem egregie fcintillat, \& verfus extremitates aliquid diaphaneitatis prodit. Spariæ undique per ochraceun corticem cryftalli funt plumbi fpatofi gramineo-virides, nitentes, fubdiaphanæ, breves, craffiufculæ, plerumque horizontaliter proltratæ, tamen etiam normaliter, aut cum inclinatione ercetæ, oftoedricæ, utrinque truncatæ, feu hexagono-prifmaticæ, planis bafeos verticiscque aqualiter hexagonis, centro ut plurimum umbilicatis; lateralibus vero fex, parallelogrammicis, jam æequalibus, jam alternis anguftioribus. @uærit Wallerius, undenam illis color viridis? crederem haud dubie a ferro. Aliquid faltem arfenici continere fufpicor, tum ex odore leviffime alliaceo, quem fub uftulatione me perfenfiffe, mihi videbar. Quidquid vero alii de facili illius in plumbum reductione dicant; ego nullam plumbi fpatof fpeciem adeo pertinaciter plumbi retinentem inveni. Iteratis $\mathfrak{x}$ pe fæpius vicibus ad fiftulæ ferruminatoriæ acutiffimam 
flamman exploratus eanden fum. Primum cum fridore diffiliit in fragmenta quam plurima: hæc collecta, rurfumque flamm objecta, cum exiguo allii odore, rubra facta funt; fufa tandem hæc ipfa in globum dilutiflime viridefcentem diaphanum; continuata adhucdum flammæ actione, cornei coloris redditus eft globcllus; nullaque porro vi, etiam addito borace, mutatus; donec adfperfo praterea nitro, plumbi denique excuffi funt quam plurimi reguli admodum exigui.

\section{XXIV.}

PLUMBUM fpatofum fulphureum cryfallinum, cryftallis aluminari-octoëdris, parce dodecaëdris, tefferadecaëdris, oftodecaëdrisque mixtis. Tab. 2I. Fig. I I. Cohabitat reliquis plerisque adhuc defcriptis varietatibus in cuniculo S. Matthæi.

Rariffima, imo unica, quam adhuc viderim, obtinuerimque varietas. Calcarea matrix, toties jam commemorata, adeo fubtíli obducitur, qua parte patet, crufta drufica, ut eam non nifi microfcopio, aut oblique infpe¿tam, ex miculis faccharinis rclplendentibus detegas.

$$
\text { C c }
$$

Cal- 
Calcareo-fpatacea ea eft, \& cryftallina, \& pellucida, maximamque partem dilute fulphureo tincta colore, eodem fcilicet, quo cryftalli iple fpati plumbiferi. Hæ prodiga plane manu in fpatiolo utcunque parvo difperf , ftipatim accumulatx, nuniquam triticei feminis magnitudine, fed parvæ, \& parvis minores, imo minimæ, quas inermi vix. diftinguas oculo, armato femper optime. Duplicato-pyramidata, octoëdrica, aluminaris illis forma, ex planis trigonis æqualibus octo, fexque angulis folidis, aut fi mavis ex pyramidibus binis quadrangulis, bafibus coalitis compofita. Nitor diaphaneitasque priorum varietatum. Color dilute framineus, five fulphureus. Atcque harum quidem cryftallorum plurimæ. omnino funt: his quaim parciffime immixtas cernas dodecaëdras ex pyramidibus binis hexagonis, bafibus coalitis, feu ex trigonis æqualibus duodecim, compofitas. Tefferadecaëdras item, ex pyramidibus binis hexagonis, bafibus coalitis, fed apicibus truncatis, \& quod idem eft, ex trapeziis duodecim, binisque oppofitis, \& maxime remotis planis hexagonis conftructas. Denique, de quibus infra uberior nobis fermo erit, octodecaëdras minimas quasdam, ex pyramidibus binis octogonis, absque prifmate intermedio per bafes unitis, apicibus utrinque quam profundiffime truncatis, conftitu- 
tas, in quibus exacte diftinguas triangula plana octo, octo itidem alterna trapezia, \& quadrata duo oppofita remotiffina.

\section{XXV.}

PLUMBUM fpatofum rubrum cryfullinum, cryftallis inordinate octoëdris, fimplicibus, connatifve. Tab. $2 \mathbf{I}$. Fig. 12. Aus der holenifchen Grube am VelacherBerge.

Non nifi Sporadicam dicamus, neceffe eft, peculiarem hanc plumbi fpatofi varietatem. Nulli enim adhuc adnatam matrici, fi grana, lapillosque fabuli calcarei, eidem nonnunquam adhærentes demas, fed vagam femper invenimus in marga ex flavo-rufa, in cuniculo quodam Domini de Hollenia in monte Velacenfi inter Villacum \& Bleybergam: vagam inquam in forma granorum liberorum, magnitudine circiter feminis hordei, eorumque aut folitariorum fimpliciffimorum, aut e pluribus connatis compofitorum. Figura illis cryftallina eft; \& licet nonnunqquam irregularis, fi tamen attentiore confderentur oculo, ut plurimum duplicato-pyramidata, alı-

$$
\mathrm{CC} 2 \text { mina- }
$$


ıninari-octoëdra, faltem inordinate; ex triangulis ifofcelicis obtufis octo fimul compofita. Quod fi plura ejusmodi grana in unum velut corpus ex parte connata fint, tum exflantes ultra eminentiæ, \& ipfæ cryftallinæ, pyramidibus quadrangulis feffilibus aggregatis fimiles omnino funt. Colore a reliquis Carinthiacis maxime recedunt; eft hic, præprimis fi ab adhærente interdum marga lotione depurentur, faturate ruber, diaphanus, \& fuperficies cryftallorum lævigatæ, nitentes.

\section{XXVI.}

PLUMBUM fpatofum flavum cryfallinum, cryftallis felenitico-decaëdris in cellulas ordinatis. Tab. $2 \mathrm{r}$. Fig. I3. In fupremis montis Bleybergenfis cuniculis im Freywald aus der Pofchifchen Grube.

Cryftalli plumbi fpatofi hic propofitæ obfoleto ceræ flavæ funt colore, graves, craffufculæ, vix vel fubdiaphanæ, potius opacx, nitentes tamen. Omnes, paucifimis demptis, felenitico-decaëdra regulari præditæ figura, e planis compofitæ quadratis aut rhombicis binis maximis oppofitis, fummo \& infimo, trapeziisque fubparalle- 
rallelogrammicis lateralibus fimul octo, undique per circumferentiam in acien carinatam confluentibus. Situm earum quod attinet, cellulofus is eft ex intercuftatione mutua earumdem. Neceffe vero eft, haud remotæ a fo invicem, nullaque lege $\&$ ordine fuis quæque locis fparfæ fuerint maffulæ fluidæ, ut in cryftallifationis inftanti in tam inordinatas ordinari potuerint concamerationes, quarum amplitudo, fitus, directio, adeo inter fe differunt. Matricis loco illis eft argilla martialis lateritiorubra, in margam flavo-rubentem denique abiens. unfquam perpete aquarum ftillicidio major calcarearum particularum copia advecta, illique intime hoc vel illo in loco, ubi aqua forti effervefcit, mixta fuit.

\section{XXVII.}

PLUMBUM fpatofum aurantiacum cryftallinum, cryfallis hexadecaëdris, octodecaëdrisque depreffis planiusculis. Tab. 2r. Fig. I4. Ex S. Matthæi vetere fodina, fuper calcareo frpius dicto.

Iterum tenera cryftallino - drufica fpati calcarei crufta, alba, pellucida matrem lapidem fuperinducit; iteCc 3 rum- 
rumque ab effufa defuper marga, rufo aut nigro hæc tincta eft colore. Quod fpatolo-plumbeas cryftallos concernit, hæ quidem aurantiacæ, nitentes, diaphanæ funt, \& fitu fuper ea infiftunt aut perpendiculari, aut certe cum obliquitate quadam erecto. Vides harum aliquas contra geometriæ leges heptagonas, alias vero exacte quidem, fed aut æqualiter; aut ublongo-octogonas; tamen nec oftogonæ reapfe funt, nec heptagonæ, fed binis duntaxat, iisque oppofitis, maximisque hepta - aut oftogonis interceptæ planis, ambitu totu in carinam, feu ancipitem aciem abeunte, unde denique intelligas cryftallos depreffas planiufculas hexadecaërras, octodecaëdrasque promifcue permixtas, quarum fupremum, infimunque planum heptagonum fit, aut octogonum, feptem vero, aut octo peranguftis, \& obliquis parallelogrammis, aut trapeziis fupra, infraque cinctum.

\section{XXVIII.}

PLUMBUM fpatofum flavum cryftallinum, cryftallis octodecä̈ris jublentiformibus. Tab.2I. Fig. 15. Eodem, quo prior varietas, domicilio, eademque matrice.

Qui 
Qui primum varietatem hanc, feftinante cum primis intuitus fuerit oculu, corpufcula fe flara, convexa lentiformia, fuico fuper ftrato videre crediderit; acleo \& magnitudine, \& forma lentibus fimilia funt. Attamen fige fuper ea vel tantillo temporis attenta oculos cum mente, polyedra cernes régularia, non lentes utrinque convexas; cryftallos inquam octodecaëdras, easque non depreffas \& planas, ut eæ prioris varietatis funt; fed lentiformes, quarum altitudo, longitudinis, latitudinisque æqualis aut luppar fit diametro. Dum jam oftodecaëdricas. cryitallos, feu corpora regularia, inter plana geometrica duodeviginti in angulos folidos plures concurrentia, intercepta dicimus, nemo cryftallos has, prout faltem in præfente occurrunt ipecimine, unius ejusdemque fpeciei omnes exiftimaverit effe; quadruplices imo, easque inter te non parum differentes deteximus. Harum aliæ planis binis regularibus fummo \& infimo octogonis, fexdecimque parallelogrammis trapezinis lateralibus conftant, altitudinem five craffitudinem cujusque cryftalli ea lege efformantibus, ut eorum octo ex ofto fuperioris octogoni lateribus oblique defcendant, reliqua vero octo ex inferioris octogoni octo itidem lateribus fub eadem cum prioribus obliquitate afcendant, donec fuperiora cum inferio- 
ferioribus in proftantem carinam concurrant.: Pone jam, cetogonæ utriusque fuperficiei latera æcqualia inter fe effe cmnia, oftodecaèdrica quæ inde nafcitur cryftallus, fubglobofa velut erit; \& paralledlogramma illa fexdecim (quæ cryflalli corpus per ambitum ftipant) omnia item inter fe mutuo æqualia. Oblongo-ovalem autem referet cryftallus lentem, quoties (ut non raro \& iftud evenit) alterna duntaxat oftogonarum arearum latera inter fe æqualia erunt; ac tum quidem, de univerfis quoque parallelogrammis, alterna præcife elongata magis, alterna contra contractiora exiftere neceffe eft. Intermixtæ his funt $\&$ aliæ cryftalli; octodecaëdricæ \& ipłæ quidem, \& fublentiformes etiam, verum aliis longe interceptæ, circumfcriptæque planis. Apicem bafinque cryftallorum iftarun non oftogona, fed quadrata occupat area, de cujus lateribus fupra, infraque in proftantem communem aciem parallelogramma oblique procurrunt univerfe octo, omnia inter fe æqualia mutuo, fed fingula cum totidem triangulis, jam æquilateris, jam ifofcelicis alternantia, prout nempe triangulorum horum apex aut ipfo in angulo quadratarum arearum terminatur, aut paulo infra eumdem deprimitur. Denique \& hexadecaëdra, quamvis unica, reliquis immixta eft cryftallus. Sexdecim triangulis ifo- 
fcelicis hac conftat, feu pyramidibus binis octilateris, quarum bafes absque intermedio prifmate junctr funt: ut adeo in exiguo licet hocce calcarei lapidis frufto quintuplices cryftallos plumbi fpatofi habeas diffeminatas, fupra cruftam fpatofam druficam nodulofam albam quidem \& pellucidam, fed marga flavo - fufcefcente deturpatam, quæ fuperficie lævigata fint, \& nitente, colore vero ceræ flavæ tinctæ, \& diaphanæ.

\section{XXIX.}

PLUMBUM fpatofum cryftallinum, cryftallis ocfodecaëdris, partim rubro - aurantiacis maximis, partim citrinis exiguis. Ex. fancto Matthæo fuper calcareo dicto.

Poteram equidem omittere fpecimen ifthoc, propterea quod nihil admodum novi, nihil quod dictum nondum fit, in eodem denique invenire fit; attamen peculiaris plane ejusdem venuftas, \& cryftallorum octodecaèdrarum multiplex omnino, tam ratione coloris, quam pelluciditatis, \& foliditatis, \& magnitudinis varietas, \& illud verbo, quod Italus un non sò che dicere tolet, 
quodque oculis duntaxat videri, mente etiam concipi, fed lingua haudquaquam, aut vix, exprimi fatis poteft; hæc enimvero momenta fimul omnia, vel invitum, \& rerutantem impulerunt, ut ne eruditis fpecimen longe elegantifimum, atque fuo in genere forfan unicum, fubtraherem. Fuit tamen præterea, ut ne quidquam diffimulemus, \& alia rei caufa, apud me fane, utcunque fentiant alii, ponderis nunquam non maximi, fcilicet, quod in mineralogicis inftuctiva fpecimina, licet vilioris nonnunquam afpectus, femper tamen præferam fpeciofiffimis aliis, per quæ litterariæ rei utilitatis accedat nihil. In fpecimine noftro etfi momento temporis crytallifationem reapfe cmnem, five confrictione, coagulatione, aut attractione natura perfecerit, ut præcife prout plus aut minus maffæ fluidæ cryftallifandæ, fingulis in punctis exfitit, eadem quoque ratione cryftallus quævis, aut major, aut minor; gracilis magis, aut craffior; depreffa magis, aut magis protuberans, exiftere debuerit; tamen fi non veram, veri certe fumilem cryftallifationis octodecaëdricæ inaginem efformare nobis videmur poffe aliquam, vel fola ex figuræ hujus infpectione, in qua per gradus intermedios omnes, a minima ad maximam, cernimus. Sunt enim præter pauculas irregulares tabellas plun- 
plumbi fpatofi (nums. XVIII.) laminofi, fuper calcareo toties jam recenfito, tenerrima rurfum inftrato crufta fpati calcarei drufico-nodulofa, lætius flavente, aut aliter picta; funt inquam lamellæ primum octogonæ fpatofo-plumbex adeo tenellæ, ut fubtilius illis cogitari vix pofit aliquid; hæ non fubdiaphanæ modo funt, fed pellucidifima etiam, ut in vivo exemplari, cruftam quoque mox dictam, trans eas fitam, haud difficulter per eas videas; nitore refplendent præcellente; de colore vero dubites an flavas adhuc? aut jam excolores, \& hyalinas? dicas, adeo modica, imo levifima tinctæ funt flavedine. Interjacent his, non amplius lamellæ octogonx, fed ex lamellis octogonis velut factæ cryftalli octodecaëdræ, quarum craffitudo adeo adhuc modica eft, ut vix aliunde eam dignofcas, quam ex ambitus, feu extimi marginis taturatiore colore, minoreque inibi transparentia, propter multiplicatam in multiplicatis ambitus fuperficiebus refractionem; \& quas cryftallos, difco magis transparentes, quam ambitu, feneftratas haud injuria dicas. Concipe jam, lamellan octogonam quamvis motu centri femper parallelo utrinque fluere, \& quuantum centri fluxus identidem utrinque elongatur, tantumdem radios ab octogoni angulis ad centrum ductos, equabiliter utrinque

$$
\mathrm{Id} 2 \text { decre }
$$


decrefcere, pone; cryftallos; quas fpecimen exhibet, fingulas, fub quavis magnitudine, \& craffitudine, fimul concipies, aut etiam ortas videbis; quarum color flavohyalinus, citrinus, ceraceus, aut rubro-aurantiacus, vix nifi majori, aut minori metalli heterogenei admixtæ portioni adfcribi poteft.

\section{XXX.}

PLUMBUM fpatofum flavum cryfallinum, cryfallis octodecaëdris plano-compreffis, fpato drufico, feleniticodecaëdro, ex toto, aut parte incrufatis. Tab. $2 \mathrm{I}$. Fig. I6. Itidem ex S. Matthæo.

Extimam calcarei prædicti faciem, bellariorum faccharo conditorum more, obducit crufta craffior fpati calcarei cryftallino-drufici, cryftallis pellucidis, albis, nitentibus, rhombeis, felenitico-decaëdris, magnitudine differentibus, inordinate confluentibus, connatisque, ut rariufcule integram extricare valeas, plerumque hoc aut illo plano laterali, five angulo, ultra fuperficiem exfantem, \& micantem difcernas. Cruftæ huic, quæ interdum lapidem ipfum, venæ aut rivi mæandriformis inftar pererrat, 
errat, infident parcius, aut copiofius fparfæ teffulæ, aut cryftalli plumbi fpatofi flavi exigux, aut majufculæ, quadratæ, oftogonæ, rhombeo-decaëdræ feleniticæ, ut plurimum.octodecaëdræ plano-depreffr, haud admodum craffæ, colore citrino, diaphanæ, nitentes. Quod vero mirum maxime, \& non eodem natas tempore, evidenter evincit, illud eft, quod earum nonnullæ totæ ultra memoratam cruftam emineant nudæ, uno eidem latere oblique aut normaliter, femper tamen leviffime infidentes; aliæ media, aut plusquam media fui parte intra eamdem demerfæ fint; nonnullæ, five proftratæ, five erectæ intra eamdem penitus confepultæ, \& incruftatæ, per tranśparentem precife drufico-cryftallinam cruftam obfcuriore colore traluceant. Vidi etiam \& poffideo fpecimen, in quo oblique exftantium cryftallorum oftodecaëdrarum pars fuperior, crufta facchari confectionarii velut, obduEta fuit tota, parte earumdem inferiore nuda exiftente; manifefto utique indicio, trillicidio materiæ marmoreofpatofæ fluidæ, nuper duntaxat, incruftata fuiffe cryftallorum plumbiferarum præexiftentium dorfa, non partem a fillicidio averfam. 


\section{XXXI.}

PLUMBUM fpatofum favum femifatifcens cryfallinum, cryffallis octodecaëdris planiusculis, in cellulas ordinatis.

Hanc quoque, non tam ipfa re, \& cryftallifatione, quam cryftallorum potius octodecaëdrarum cellulofo fitu, ab aliis, hactenus enumeratis, diverfam plumbi fpatofi flavi varietatem, vetus fancti Matthæi fuo in finu fovet cuniculus. Ita autem octodecaëdræ plano-compreflæ, neque admodum craffæ cryftalli, dum a fluiditatis, ad foliditatis tranfierunt ftatum, fuper calcareo toties laudato, ordinatæ confiterunt, ut aliæ fuper alias fub quo demum cunque infilterent angulo, fefeque mutuo decuffarent, \& decuffatione hac reciproca intercapedines inter fe relinquerent cellulis omnino perquam fimillimas. Cryftal1i, quæ cellularum formant parietes, atrofubrubentes, nitoris expertes, \& opacr. Fuiffe autem quondam flavas, nitentes, \& diaphanas, eo cumprimis ex capite non fufpicor modo, ted certus etiam fum, quod in diffracto lapide matre fparfas inveni per internam ejusdem fubftan- 
tiam fimiles plane, fimiliterque figuratas cryftallos non paucas, quæ flavæ, nitentes, \& diaphanæ erant, licet ejusdem cum prioribus, aut provectioris etiam ætatis; ut dubitari denique nequeat, fqualentem huncce cryftallorum colorem, non tam ab earumden ætate (quamvis \& ætas ad hoc facere poffit aliquid) quam ab aëris vicifitudinibus, \& inclementia loci, perennique in fubterraneis cavernis humorum metallicorum ftillicidio repetendum effe, \& fatifcentix earumdem, futuræque deftructionis totalis manifeftiffimum effe prognofticon. Poffideo fane \& aliud fpecimen, in quo inchoatæ hujus deftructionis longe evidentiora cerni poffunt veltigia. Lamellæ in eo quadratæ, parallelogrammicis mixtæ, aliæ aliis nigriores funt; quædam obfcure flaventes, fed halitu, fumove nigro afflatæ; nonnullæ anthracinæ. Vidi etiam ex cuniculis montis regii in Rabl tenerrimas plumbi fpatofi flavi lamellas quadratas penitus nigras.

\section{XXXII.}

PLUMBUM Spatofum aurantiacum cryfallinum, cryfallis inordinate polyedris. Tab. 2I. Fig, 17. Ex eadem 
2 I6 MINERA PLUMEISPATOSA

fancti Matthxi fodina, fuper eodem femper calcareo.

Tot plumbi fpatofi flavi propofitis varietatibus, quarum lamellæ, cryftallique certo laterum, certo itidem angulorum numero, regularique præterea arearum in angulos folidos concurrentium figura præditæ funt, jungere etian vifum eft fpecimen e pluribus unum, in quo plumbiferæ cryftalli, utut \& ipfæ non imperita artis manu feहtæ, ad artis tamen leges elaboratæ minime funt. Certe hic eodem fuper calcareo, marga aurantiaca obducto, grana potius cryftallina, quam ordinatas cryftallos vides, \& quæ græcanica voce non immeritu polyedra dixeris, fed polyedra irregularia, propterea, quod fuperficies, quæ eorum extimum undique circumfcribunt ambitum, nec regulares omnino funt, nec unius omnes generis, nec denique angulos, quos folidos dicimus, efficiant five æquales, five ejusdem in fingulis numeri. Si enim plana eorumdem latera diligentiore examinaveris oculo, trapezina paflim triangularibus, quadratis, pentagonisque nulla lege mixta videbis, e quorum promifcuo pariter nexu, qui hac ex parte exfurgit angulus, iis, qui alias verfus plagas exoriuntur, nec æqualis, immo neque fimilis effe poteft; 
poteft; \& hac demum de caufa, corpora quocque talibus comprehenfa areis, tąlibuscque limitata angulis, neque exacta dodecaèdra, neque octodecaëdra perfecta, fed e cubis velut, prifinatibus, parallelepipedis, felenitis, hexadecaédrisque confufe mixta, opus" eft enafci, quibus haud opportunius aliud nomen exprimendis invenias, quam polyedrorum inordinatorum. Peculiares eæ funt varietates binæ in fpecimine quodam Marianæ Auftriacæ nuper a dignifimo fodinarum Bleybergenfium Præfecto, Domino de Ployern, Viro mineralogiæ æque, ac chemiæ intelligentiffimo, inter rariffima quævis, plurimaque $\mathrm{Ca}$ rinthiæ producta, transmiffo; quasque in naturali magnitudine expreffas vides; peculiares inquam, non propter cunei duntaxat, quem utraque refert, formam; fed ob infignem magnitudinen præprimis; ad fex linearum parifinarum altitudinem affurgit utraque; craffitudo femialteram æquat lineam, duasve; contra longitudo, ubi verfus bafin convergens eft, unius eft, \& dimidix linex; qua vero parte apicem verfus divergit, trium cum dimidia. Earum altera angulos habet decem, cum fuperficiebus feptem; fex autem plana lateralia, cum angulis octo, altera. Iftius bafin, verticemque rectangula occupant parallela, ejusdem inter fe latitudinis, fed non longitudi- 
nis ejusdem; e planis autem lateralibus ea, quæ longitudini infiftunt, ampliffima formant trapezia parallela, \& parallelarum bafum; contra quæ fuper latitudine utrinque eriguntur, parallelogramma lunt, altitudinis latitudinisque ejusdem, fed neque ejusdem longitudinis, nec ejusdem inclinationis. In illa vero quadrata fuper bafi ad angulum rectum oppofita bina \& parallela affurgunt pentagona oblonga \& irregularia, binaque rurfum \& ipfa oppofita, fed fub fcalæno a fe mutuo divergentia angulo parallelogramma inter fe æqualia, donec binis aliis brevioribus parallelogrammis, a fuprema cunei acie inftar planorum inclinatorum divergentium defluentibus occurrerint.

\section{XXXIII.}

\section{PLUMBUM fpatofum citrinum cryfallino-druficum.}

Sic appellare libuit fpatofi varietaten plumbi: quodnam enim idoneum magis, quam drufarum, demus nomen cryftallis, quæ non folum confertim natæ lunt, fed connatæ etian, imo confluentes in unam velut cruftam glandulis, tuberculis, nodulisve eminentibus afperam? nam quamvis earum nonnullæ, a reliquis avulfæ fingillatim per 
calcareum lapidem fparfæ inveniuntur; quamvis præterea exdem, \& forfan pleræque omnes, fi penitius armato infpiciantur oculo, cubicam, aut haud multum a cubica diverfam in cryftallifationis factæ inftanti nactæ funt figuram; tamen quia major earumdem pars per phalanges velut diftributa, proprio quæque loco cumulatius aggregatæ, parte fui aliqua etiam connatæ, anguli quoque folidi abrafi, \& lateralium acies arearum detritæ funt, atque inde cryftallorum fingularum verticibus fphæroidica, aut qua demum cunque ratione rotundata fuperinducta eft convexitas, incruftatum, neceffe eft, dicamus calcareum lapidem glandulofo cortice, feu ut expreffione utar, minus quidem latia, in mineralogia tamen civitate jam donata, crufta cryftallino - drufica diaphana, dilute citrina, \& nitente. Elegantior hac, illa eft, \& ipfa cryftallino-drufica plumbi fpatofi citrini varietas, in qua cruftæ eminentiæ non nodulofæ, \& convexæ funt, fed fingulæ in fingulas dimidiatas abeunt octodecaëdricas cryltallos exiguas, acie laterali carinata uniuscujusque furfum fpectante; indicare hanc fuffecerit; quis enim omnes varietatum omnium recenfeat varietates? 


\section{XXXIV.}

PLUMBUM Jpatofum album folidum amorphum, rivofe galenam folidam pererrans. Bleybergæ ex S. Ofwaldo. Ex Maria Lichtmeffe. Ex Gandolffche Grube.

Eft hoc (ut non vane fufpicor) cum plerisque deinceps defcribendis varietatibus, illud plane, quod in Auftria reperiri inquit Linnæus: Plumbum pellucidum hyalinum rafile effervefcens facie quarzi. Etfi enim ex Auftriaco quarzum mentiente, aliam longe $W$ allerius ( $T .2$. p. 3 Io. N. ro. lit. b.) plumbi faciat fpeciem, a minera plumbi fpatofa alba diverfam, \& quæ lapis præcife fit calcareus, aut fpatofus minore plumbi quantitate fotus; tamen quoniam omnes \& notas, \& proprietates plumbi pellucidi Linnæani, hoc noftrum poffidet, \& Linnæi præterea interpres Gmelinus T. 3. p. 233. N. Io. pellucidum Linnæi plumbum non nifi varietatem fpatofi afferat effe; nelcio, cur ab eo abftractum Carinthiacum, cui exacte convenit, inter lapides potius referan, tantillo plumbi imprægnatos, a çuibus cæterum \& facie, \& proprietatibus aliis longe eft diverfiflimum. Eft vero $\mathrm{Ca}$ - 
rinthiacum a me nondum in matrice inventum pure lapidea; femper, tam in Bleybergenfibus fodinis, quam in illis alpium Ovirenfum fupra Ebriach in valle Junonia \&.c. aut in Plumbi galena folida, textura chalybea, majufculis zmicante areis Wallerii, aut in ejusdem Plumbagine, id eft in Plumbo compacto Linnæi; etfi, hifce in cafibus, fatendum quoque fit, cryftallos nonnullas plumbi fpatofi albi, per matrices etiam utriusque hujus plumbi fpeciei, difperfas inveniri. Quod jam præfentem folidan \& amorpham plumbi fpatofi albi varietatem in $\mathrm{fe}$, ut ab aliis diverfa eft figuratis, concernit, rectiffime quarzo affimilatur facie externa; etenim non compąta modo, fed folida etian eft; textura æquabili, impalpabili, chalybea; figura peculiari prædita nulla; imo informis potius infar corporis; plerumque venarum, aut rivorum more internam mineræ plumbi fubftantiam pererrans; ac ficubi hæc, in cavernas dehifcit; aut erofam faltem nancifcitur fuperficiem, in cryftallos, pariter more quarzi, abiens. Sed \& fractura inæquali, afpera, aut fcabra faltem, quarzo, quam corpori cuivis alteri, fimilis magis eft; duritie tamen minore multo; fiquidem cultro rafilis; rafura pulverem largiens niveum. Supereft, ut de colore, transparentiaque addam paucula. Uni-

$$
\text { Ee } 3
$$

verie, 
verfe, ut jam fupra breviter innui, foleo plumbum fpatofum album ratione coloris dividere in album, \& excolor. Hoc non tam quarzi, quam vitri facie eft, hyalinum femper, nec, nifi dum puriffimum, pellucidum; alias dum fumatum velut, aut levi quadam faturatum tin£tura, præcife femipellucidum, aut fubpellucidum. 11lud contra colure albo, ejus plane, quo alumen aut borax arte parata, raro pellucidum, plerumque fubdiaphanum. tantum eft, \& hoc mihi illud denique eft, quod in proprio magis fenfu plumbum fpatofum quarzi facie dicere confuevi: in aquam fortem injectum, illico efferbuit; quievit poftea, nec folutum ex toto eft; faltem non breve intra tempus. Experimentis fiftulæ ferruminatoriæ fubjectum, primum fridendo diffiliit; tum fragmenta, lateritio opaco tincta funt colore, atcue continuata flammæ actione, fingula in fingulos plumbi regulos haud difficulter abierunt.

\section{XXXV.}

PLUMBUM fpatofum albido-hyalinum folidum amorphum, nucleorum, aut fornicis inftar, jcrobes plumbi compa$\varepsilon . i$, ex toto, aut parte replens. Ex Windifche Höhe 
prope fanum $S$. Antonii in valle Gilienfi; tum ex cuniculo S. Nicolai Bleybergæ.

Minera plumbi, quam Linnæus compactum; $\mathrm{W}^{\prime}$ allexius Plumbaginem, compellant, vulgari apud nos Bleyfchweif vocabulo falutatur. Species, fi quæ alia, vifu pulchra; recente fractura, eleganter albido-cœrulefcente. Liquato, \& molli adhuc metallo fimilis, nitore refplendet de fe nullo; nifi quidem ubi ftriata eft, aut fquamofo-lamellari galænæ facie, teffulis micans. Sed ( hoc tamen (pace Wallerii dicam optima) non tam diverfas ejusdem fpeciei indicat varietates, quam unius ejusdemque \& fpeciei \& varietatis, diverfas ex diverfo impactu, aut fitu fracturas. Certe fpecimen habeo, quod notas, ex quibus luas $\mathrm{W}$ allerius repetit Plumbaginis varietates; unum idemque omnes fimul poffidet, at in diverfis duntaxat fingulas fracturis. Solidum primo eft, compactumque, colore plumbeo, nitoris experte, qua horizontaliter in longum fefe extendit; ftriatum vero, ftriis denfe ftipatis, longitudini parallelis, \& micantibus, fi altitudinis ejusdem confideraris ductum; avelle jam vi ab eo partem aliquam, fed directione, quæ longitudinem, altitudinemque oblique fecet, maxime fi diffractio partis a toto, 
toto, non uno, eoque valido ex impactu, fed repetitis fæpius, iisque minus vehementibus fiat ictibus, fquamofam, lamellarem, teffulis micantem, cernes fracturam. Sed \& nigro-maculatam camdem plane, quæ folida, ftriata, \& lamellofa fit, periæpe invenies. Quid autem reapfe maculæ illæ nigræ? maculæ profecto haud funt. Foveolas imo, fimplices, compofitas, aggregatas, \& introlaptos microfcopium exhibet fcrobiculos, quorum fundus jam perquam fubtiliter erofus, \& ex eminentiis minimis fcabriufculus eft; jam marga martiali, aut zinco five ochraceo, five vitreo drufico repletus; alias cryftallulis pellucidis micantibus plumbi fpatofi, quas inermi non diftinguas oculo, inftratus; rurfumque alias plumbo fpatolo fubalbido, aquei coloris, feu verius hyalino, fubpellucido, folido, amorpho, aut nucleorum, aut fornicis incruftantis inftar, ex toto, aut parte refertus. Videor autem mihi diverfas has five varietates, five fracturas plumbi compacti ab ipfa mineræ hujus interna textura repetere poffe; hanc mineralogi omnes continuam dicunt, \& talis profecto etian primo, ut dicimus, intuitu videtur effe; fi microfcopio tamen infpicio, minime continuam, æquabilem, filicinam, $\mathbb{\&}$ quæ partibus fit impalpabilibus, fed fubtiliffime potius cotaceam invenio, ex 
granulis infinite, ut ita loquar, exiguis compofitam, in quæ etiam abit, quoties cultello fcinditur, non absque aliquali ex rigiditate orta refiftentia fubftridente, utut veftria fectionis plana, continua, xquabilia, impalpabilia fint, \& nitentia. Cronftedtus fulphure folo, Wallerius fulphure fumul \& arfenico mineralifatam contendit; noftram, quam toties ope fifulæ ferruminatoria reduxi, præter fulphuris copiam, tantilla arfenici etiam portiuncula mixtam, ex perquam levi allii odore crederem.

\section{XXXVI.}

PLUMBUM Jpatofum album fiffli - lamellofum, lamellis craffufculis imbricatis, aut etiam ex intercufatione cellulofis. Elegans hocce fpecimen e cuniculo venit Gandolfiano.

Eft autem fruftum Plumbi galænæ folidæ textura chalybea, tres pollices longum, fuper femialtero latitudinis, profunditatisque pollice. Pars inferior oblique defcendens, craffitudinem frmul fpeciminis dimetiens, marga martiali rufa fordefcit; ei oppofita, recentem exhibens fracturam galænæ nitore refplendet, atque partim ftriata, 
226 MINERAPLUMBISPATOSA partim, ut verbis utar Wallerii, areis micat majufculis; antica denique pars galænæ ejusdem faciem exprimit erofo-cavernofam, vix, nifi perpaucis in locis, areis, teffulis, fibrisve micantem; imo partim opaco molybdænæ colore veluti fqualentem, partim ochra plumbi cinereo-fufca obfitam. Videbis in ea, fi attente confideraris, venarum plumbi fpatoì albi folidi fupra defcripti veftigia non pauca; plura earum haudquaquam videbis, utpote liberaliter inftrata lamellis majufculis, craflufculis, planis, informibus, fiffilibus plumbi fpatofi albi diaphani nitentis, quarzum mentientis. Lamellarum iftarum aliæ fub angulo ad horizontem perquam acuto femiprocumbunt, aliasque imbricum more fibi fuperincumbentes fuccolant; aliæ contra ex anfractibus profundioribus ortæ fitu affurgunt rectu, jam verticali, jam horizontali, etiam cujusque alius inclinationis; tum fibi occurrentes mutuo, fefe interfecant, fpatiaque inania, verius cellulas, extrorfum apertas, $\mathbf{~} æ-$ tera non communicantes, efformant. Eadem earumdem natura, licet non eadem cum varietate folida amorpha, facies externa; eadem quoque cum acidis mineralibus, \& ad flammam filtula ferruminatoriæ dedit experimenta, 
Liceat ctiamnum, quoniam de galæna, fpati plumbiferi albi Carinthiaci matrice communi, facta eft mentio, atque deinceps læpius fiet, eandem quoque ipfam paucis defcribere, \& quæ de eadem hactenus recte, aut perperam fcripta funt, referre. Omnis ergo, quæ e vifceribus montis Bleybergenfis, omnis etiam, quæ e cumulatis venis montis Regii in Rabl, maximo eruitur cum emolumento plumbi galæua, non granularis, nec proprie teflularis, fed compacta folida \& denfa eft, texturaque chalybea. Vidi unum, duos, tresque pollices craffam; vidi etiam fpithamam craflitudine æquantem. Rigidior plerumque Regiomontana; mollior ( $f i$ ita loqui fas eft) Bleybergenfis, imo cultro nonnunquam etiam, alicqua faltem ratione, fectilis, \& fcriptura inquinans cinerafcente, effe folet vel rudis. Colore eft admodum dilute, feu albido-cærulefcente; recens fracta, nitore refplendens, non tamen eminente eo fplendore micans, quo galæna argenti magis dives alia. Soliditate qualiquali fua haudquaquam obfiftente, lamellofam tamen fimul dicamus neceffe eft, utpote quæ malleo percurla, in fragmenta diffiliat cuborum, rhomborum, aut parallelepipedorum forma, in quibus etfi lamellas oculo detegas nullas, in lamellas tamen fiffilia effe debere, \& ex fubtilifimis compofita lamellis, ex eo

$$
\mathrm{Ff}_{2} \text { con- }
$$


concludas, quod flammæ fiftulæ ferruminatoriæ fubjecta, plerumque fpati more ftridendo diffiliat; tum, quod recente fractura hinc areas micantes, interdum etiam fquamas imbricatas, illinc vero frias approximatas parallelas detegas plurimas. Autores tantum non omnes, omnis prorfus argenti expertem fcribunt; hac de caufa Cronftedtus, tanquam plumbi compacti Linnæi varietatem recenfet, \& Villaci in Aufria provenire inquit, quæ Bleyber$\mathrm{g} æ$ in Carinthia degit: omnis nihilominus argenti expers minime eft, etfi adeo exigua ejusdem frta quantitate, quæ pro nulla demum haberi poffit, \& quam vix, aut ne vix quidem communi docimaftices arte educas. Vidi ego certe ipfe mundiffimi argenti unciam unam, quam laüdatus fupra Hanftadius e refiduo fuforiarum fornacum foco, fcoriisque plurimorum plumbi iftius centenariorum eliquavit. Fallitur itaque Vogl, qui peculiari duntaxat methodo, non tam fufionis, quain præviæ uftulationis id tribuere videtur, quod præfens hac in galæna deperdatur argentum; re enim vera deperdi femper debet, quod non nifi in tantilla quantitate eidem ineft. Quid? quod nec Bleybergæ, nec in Rabl ulla fufioni præmittatur uftulatio, præterquam cuin mineris plumbi galænici Strucklianis, quæ folæ intime copiofiffimeque mixtæ funt Pyrite $f$ gurato 
gurato nodulofo Linnæi; lapide hepatico Cronftedti; \& Zinco tum calaminari, quam vitrato drufico $\mathrm{W}^{\text {a allerii. }} \mathrm{E}$ t igitur in galæna Bleybergenfi, \& ca montis regii ( $K \ddot{o}-$ nigsberg ) in Rabl, præter plumbi in centumpondio libras circiter feptuaginta, portiuncula argenti quavis affignanda fere minor, tum fulphuris quantitas hand exigua; denique (hæc mea hactenus præcife fufpicio eft) Zinci quoque portio aliqua. Dicam, qux in hanc fufpicionem me adduxerunt rationes. ( $\alpha$ ) Maxima quotannis e monte Regio Rablenfi paulo infra Vitriol-W'and effoditur copia tam lapidis calaminaris e flavo obfcure rubri, ( rother Gallmey) qui fatifcens, albus denique evadit, paffimque weiffer Gallmey audit; quam Zinci vitrati laminofi, druficique Wallerii, refcher Gallmey inibi dicti. Parietes quoque fodinarum illarum Zinco abundant falactitico niveo, jam $c y$ lindraceo fiftulofo, jam cruftofo, alias teftaceo-nodulofo, etiam racemofo, \& botryoidico: fed \& minera ipfa plumbi galænica Zinco vitrato folido tamquam matrici inhæret fæpe; aut promifcue eidem mixta eft. Bleybergæ itidem multiplex \& elegantiffima Zinci minera paffim cum galæna occurrit, ut puta: Vitratum folidum textura chalybea $\mathrm{W}$ allerii ; vitratum druficum nodulofum; vitratum dendroideo-ramulofum; ochraceum pulverulentum niveum ; ochraceum

$$
\text { I f } 3
$$

firatofo- 
fratofo-laminofum album, falactiticum folidum niveum fuperficie fuchum irftar undata, aut tuberculata, aut jpeculari dendritis piffa: tum Pfenlogalcna cubico-cryftallina, attritu phofphorefcens, colore granatino, aut fquamofa teffulis micans flava $\mathcal{E}$ ip/a phojphorejcens; denique Zincum fpatofum pellucidum lamellofum, $\mathcal{S}$ cryjtallinum, diverfe coloratum, diverfeque figuratum. Eamdem præterea mineræ Zinci copiam paffim in Carinthia inveni, ubi demumcunque Plumbi galæna folida, areis magnis micans, provenit; nempe in monte Jauken, intermedio inter Valles Dravanam \& Gilienfem; tum in fodinis Bleybergenfibus non fuperioris, led inferioris Carinthiæ, vulgo Bleyberg in Loibel dictis, ab iis Bleybergenfibus prope Villacum longe diverfiffmis: \& hæc demum una fufpicionis meæ ratio eft; altera ea eft : ( $\beta$ ) Parietes furnorum fuforiorum in Kaltwafferthal, in quibus galæna regiomontana eliquatur, obfitos inveni pulvere denfifimo e cinereo albo; arfénicales alferebant effe, qui in fundendo plumbo occupabantur operarii; domum tamen relatos, zincolos inveni, \& proprietates florum Zinci habere, cum aliqua adhuc plumbi portione, arfenici vero nulla. Denique $(\gamma)$ iteratis frpe frpius vicibus e folida galæna hacce excufi fragmenta diveriæ magnitudinis, omnis, quantum fieri potuit, hete- 
rogeneæ materiei expertia, pura, munda; fuper carbone emortuo ope fiftulæ ferruminatoriæ eliquavi eadem, \& in regulum denique fudi; fumus exortus eft perquam copiofus e cæruleo albus, non alliaceus \& arlenicalis, fed odore potius fulphureo \& pungente; qui proxime regulum cinxit annulus citrini coloris, at vero quæ iltum fafcia annularis ampliffima circumdedit, nivea, candidiffimaque fuit: hæc vel folo oris flatu illico diffipata eft, avolantibus undique floccis five fquamis niveis; non vero ille. Collegi floccofas illas fquamulas; prunis vivis \& ignitis inftravi; ac fubito flavum induerunt colorem, fugacem tamen, utpote qui emortuo denique carbone, refrigeratisque rurfum floccis, in niveum denuo colorem mutatus eft. Hæc fufpicionem meam an fatis roborare valeant argumenta? aliis, quorum pluris intereft, quam mea, quibusque, quam mihi, otii plus eft, inquirendum, $\&$ difcutiendum relinquo.

\section{XXXVII.}

PLUMBUM fpatofum album femipellucidum lamellofum, lamellis planis, oblongis, linearibus, anguftis, decuffatis. Bleybergæ e cuniculo Gandolfiano in galæna. In plumbo compatto L. vero, e cuniculo fancti Nicolai. 
In eo hæc a priore differt varietate, quod dehifcentem in galæna folida cavitatem lamellæ repleant non amplæ illæ, \& fquamarum fibi mutuo fuperincumbentium inftar imbricatæ, verum graciles admodum, vixque dimidia latiores linea, planæ, oblongæ, lineares, ad fe mutuo lub obliquo quovis angulo inclinatæ, nonnunquam etiam perpendiculariter fe decuffantes, \& fi quas cellulas efformant, utrinque perviæ, \& communicantes illæ fint. Cæteroquin \& illud hic notatu dignum credidimus, quod lamellæ hæ, etfi \& ipfæ quarzi fint facie, \& albidæ, tamen non obfcure diaphanæ dumtaxat, ut eæ prioris varietatis, verun \& femipellucidæ.

\section{XXXVIII.}

PLUMBUM fpatofum album reticulatum. Ex fancto Sebaftiano in Rabl.

Qui plumbi fequitur venas in Rabl, calcareus eft æquabilis, albus, poft moram non nifi aliquam effervefcens (marmor tardum Linnæi) in quo particulas difcernas nullas five granulares, five cotaceas, fractura autem fit plana, aut angulata, jam opaca, jam majufculis fpati, 
aut quarzi pinguis ad inftar areis micans. Tamen $\&$ intermixtum effe, aut innafci eidem perfrequenter folet gypfum $W$ allerii hepaticum, nunc rofeum \& fquamofum per zonas parallelas \& undulatas eumdem pererrans; nunc fufcum folidum, \& amorphum; alias cruftofum teftaceumve concavo - convexum fufcum; aut nodulofum fuperficie plumbeo-metallicolore; vel denique fulphureo-flavum, lineisque angulatis parallelis nigris eleganter piEtum. Sed \& globsli pyriticofi $W$ alleriani in botrytem concreti, galænam ipfam aut certe nunc dictum hepaticum lapidem teftaceo-glandulofum, velut cortice incruftare folent. Hac tali compofita in matrice galæna, quæ $\&$ ipfa maximis ut plurimum fquamofo-ftriatis micat areis, nonnunquan tamen, utcunque itidem magnis ftratis erofa eft, nigroque cærulefcente, \& opaca facie; atque tum quidem, nefcio quo? inftrata fimul reticulo confipicitur albo, \& fibrofo. Spatum calcareum ftalactiticum diu credidi, \& neglectim habui. Curiofitate tamen ductus, majore cum attentione confiderare, microfcopio etiam perluftrare, demum $\&$ ad fuforiæ vim flammæ explorare cœpi; plura enimvero tum vidi, aliterque de vifis, \& tentamini fubjectis fenfi. Exefæ galænæ fuperficiem inæqualem, fcrobiculofam, fcabram, undique vidi reticulo obductam albo,

$$
\text { G g }
$$

non 
non e filis, fibrisve acaulibus, proftratisque; fed e laminulis, aut bracteis admodum teneris, dimidiam lineam altis, perpendiculariter erectis, cohærentibus, continuis, analtomofantibus, diaphanis contexto ; feminatamque preterea inter reticuli inanes areolas granulis rotundatis, polyedro-cryttallinis exiguis inæqualibus plumbi fpatofi. Minufcularum harum cryltallorum (de quibas mox plura) nonnullæ aquofiffime erant albidæ; hyalinæ, pellucidæque \& ex transparente fundo nigricantes aliæ, alia denique metallicolores; fingulæ ex aliis aliisque, prout convertebantur, polyedrorm punctis lucem reflectentes, \& ex ejusdem reflexione refplendentes. Sed neque calcareo-fpatofam amplius credidi reticuli materiem, poftquam præconceptum hunc folo ex vifu errorem fiftula detexit ferruminatoria, \& avulfæ ab eodem partes, non minus, quam prædictæ cryftalli poft brevem dumtaxat calcinationem, plumbi regulos globolos una quævis largitæ lunt fuos.

\section{XXXIX.}

PLUMBUM fpatofum album cryftallinum, cryfallis cubicohexaëdris pellucidis. E fodinis Lellingenfibus, in hæmatite.

Info- 
Infolens prorfus Iuittenbergenfibus in montilus apparitio plumbi galæna! Ferro, quanti quanti funt, fæti, nemo fane in illis plumbum quæfierit. Inventam tamen in Lellingenfi parte argentiferam.galcenam teffulis minoribus, particulisque micantem Wallerii, in Spato calcareo cinerafcente, ipfe mecum indidem retuli. At vero illud majore longe dignum admiratione adhuc, galænam fuæ inhærentem matrici, cum eadem fimul hæmatitæ flarefcenti innatam, eumdem viciffim fuo in finu, ætitici adinftar nuclei, fixum includere. Hæmatitem hunc, utut extus nigrum, ob trituram tamen flavefcentem potius, quam rubram, cum Cronftedto, Wallerio, Bornioque, flavefcentem \& ipfum dixi. Eft ille compactus folidus amorphus, fractura arida, parce mica argentata fquamofa Linnæi, intime vero magnefia mixtus fuliginofa friabili $\mathrm{M}^{\top}$ allerii, fuperficie indurata atra, partim bracteato-cellulola, partim botrytico-nodulofa, tuberculis fubmammillaribus prominentibus afpera, \& quod fingulare plane, atque ad propolitum noftrum unice, \& plurimum facit, fparfis per eam cryttallis exiguis plumbi fpatofi, albis cubicis pellucidis nitentibus.

$$
G_{g} 2
$$

XL. 


\section{XL。}

PLUMBUM fpatofumalbum cryftallinum, cryfallis crafjiufculis inordinate rhomboideo - prifmaticis, connatis. E fodinis plumbiferis alpium, Ovirenfium fupra Ebriach inferioris Carinthiæ.

Deformiter gibbam, inque vagos monftrofe fefe extendentem ramos folidam plumbi galænam, venæ adinftar pervadit plumbum fpatofum folidum ex hyalino-albefcens; in fluiditatis adhucdum exiftens ftatu, obviam cum forte habuiffet cavernam majufculam, in qua diffundere fefe potuit amplius, cryftallifatum enimvero fuit, inque cryftallos majufculas oblique tendentes, inordinate rhombeas, parte fui aliqua connatas, altera liberas, fordidius albentes, \& fubdiaphanas.

\section{XLI.}

PLUMBUM Jpatofum excolor hyalinum pellucidum cryftallinum, cryftallis felenitico - decaëdris. Bleybergæ e cuniculo fancti Chriftophuri fuper galæna. 
Solidam plumbi galænam undique mæandriformibus latiufculis rivis pererrat gypfum ponderofum folidum particulis inpalpabilibus amorphum niveum opacum Bor- " nii. Ind. forf. P. I. p. 14. Superficies galænæ extina, ad tres, quatuorque pollices in longum, latumque extenfa, denfiffime accumulatis inftrata eft cryftallis plumbi fpatofi, non albis, fed excoloribus, hyalinis, pellucidis, verbo vitreis, \& vitri inftar tralucentibus, \& nitentibus: harum figura etfi cubica primo videatur effe intuitu in dimenfione unius lineæ parifienfis, tamen attente infpecta, non hexaëdra, fed decaëdra omnino eft, \& ut vulgo dicimus exacte feleniticav

\section{XLII.}

PLUMBUM fpatofum album cryfallinum, cryfallis dodecaëdris, octodecaëdrisque utrinque pyramidatis, prifmite intermedio breviffmo. Bleybergæ ex cuniculo Gandolfiano fuper galæna folida.

Specimen fruftum fiftit galænæ lolidæ, cui ad latus finiftimurn acuto fub angulo aliud, quod imminebat, inde abruptum, recentem fracturam, \& majusculam ibidem

$$
\mathrm{Gg} 3
$$

aream 
aream micantem ejusdem galænæ exhibet: fuperficiem reliquam femifatifcentem, indeque expertem nitoris, ver-

- fus dextrum cumprimis latus, ampla, quarzi inftar, plumbi fpatofi albi folidi vena, five rivuse, percurrit; difco medio obfito cryftallis fparfis inæcqualibus, plumbi itidem fpatofi albi femipellucidi, quarzum mentientis. Utut autem, fi properante cryftallos has intuearis oculo, nullam in is tibi obfervare videaris determinatam figuram, \& inordinate polyedras exiftimes; tamen exacte regulares pleræque funt, fimiles plane iis fequentis varietatis, paucis irregularibus mixtæ; regulares quæ funt, duplicis funt generis, nempe partim dodecaëdrx, partim octodecaëdræ; verum tam hæ, quam illæ utrinque pyramidato vertice, prifnate autem intermedio breviffimo, vixque lineam parifinam æquante, duplo triplove pyramidibus breviore.

\section{XLIII.}

PLUMBUM fpatofum allum cryftallinum, cryftallis dodecaëdris, of Todecaëdrisque, utrinque pyramidatis, p feudogalena cubico-cryftallina incruftatis. Tab. 2I. Fig. I8. Lleybergæ ex cuniculo S. Antonii. 
Replent introlapfan galænæ folidæ cavitatem accumulatæ plumbi fpatof cryftalli majufculæ, albæ, quarzi facie, diaphanæ, regulares, paucis miftæ irregularibus; hæ inordinate polyëdræ; illæ contra aut dodecaëdræ, aut oftodecaëdræ; utrisvis utrinque pyramidatis, prifinate intermedio breviflimo. Harum illæ e planis quadrilateris quatuor æqualibus anguftis, corpus medium con . ftituentibus; octoque æqualibus triangulis, in binas terminales quadrangulas pyramides convergentibus, conftant; iftæ prifinate funt intermedio, annularis inftar fafcix, parallelogramma gracilia fex æqualia complectente, pyramideque terminali una, \& altera æquali hexagona, $\&$ triangulis fex æqualibus coalita. Infident plumbiferis hifce cryftallis, cryftalli zincofæ; p feudogaliena videlicet cryfallina cubica, colore granatino, fubdiaphana, frictione phofphorefcens: idque rarum fatis; nam quanvis minime rara Bleybergæ eft pfeudogalæna phofphorefcens compacta, textura fquamofa, teffulis nricans minoribus, majoribusve colore jam flavefcente, jam granatino-rubente, aut etiam ex rubro fubfufcefcente; tum pfeudogalæna phofphorefcens granatina cryftallina partim cubica, partim (idque rariffime) aluminari-octoëdrica; tamen haud facile plumbo fpatofo cryftallino immixtam, aut infiden- 
tem vidi; plerumque per ftrata vaga, aut parallela, aut per venas mæand riformes ampliores, five contractiures illa, quæ amorpha eft, \& fquamofo-lamellari textura, calcareum æquabilem grifeum; calcareum arenarium cinereum; aut etiam ipfam galænam folidam, pererrare; hæc vero, quæ cubicam aleæ affectat formam, galænæ pyramidali infidere, \& a gypfo fpatofo cubico-cryftallino hyalino incruftari, aut contra, infidens galænæ pyramidali gypfum fpatofum cubicum, nunc album, alias hyalinum, aut virens, incruftare ipfa folet.

\section{XLIV.}

PLUMBUM fpatofum album cryfallinum, cryftallis inordinate polyëdris, plumbo fpatojo flavo lamellari incrufatis. Bleybergæ e cuniculo Gandolfiano.

E millibus unum, rariffimumque fpecimen ! Fruftum fcilicet galænæ folidæ areis magnis ftriatis micantis, quatuor pene pollices longum, fuper tribus latitudinis, duobusque profunditatis pollicibus. Speciofifima vero illius ea eft fuperficies, quæ nonnihil equidem exefa, fatifcens, ac ochra plumbi cinerafcente pulverulenta infperfa, tamen 
men \& areis, \& friis ex recente fractura micat, \& undique rivis, mutuo fe decuffantibus, plumbi fpatofi albi folidi, quarzum mentientis, notabilis. Eminent e rivis his, quotiescunque alveum velut formant nonnihil humiliorem, præprimis dum in voraginem dehifcunt profundiorem, ejusdem fpatofi plumbi cryftalli polyedræ, vel etiam pyramidatæ feffiles; nifi quidem dicere malis, plumbum fpatofum album folidum, fimilibus in locis, cryftallilari inordinate. lllud fingulare omnium maxime, quadrangulas plumbi fpatofi flavi lamellas, non folunı cum plumbi fpatofi albi cryftallis, in eadem plumbi galænæ folidæ morari fede, fed etiam has ab illis incruftari, \& fpatum plumbiferum album, plumbi fpatofi flavi exiftere matricem.

\section{XLV.}

PLUMBUM Jpatofum allum cryftallinum cryfallis rotundato - polyedris. Bleybergæe ex cuniculo Maria Lichtmeffe.

Galæna plumbi folida, cui cryftalli illico defcriben$\mathrm{d} x$ infident, nulli lapidex adhæret matrici; defoffa imo 
in marga fuit albente, fporadica. Pondus librarum aliquot fola fufpendit, elegantem omnino excelfi rupeftris, \& anfractuofi montis exhibens imaginem; nitor in ea extus nullus; cæruleo-cinerafcente potius fqualet colore, nifi ubi ab adhærente prædißtæ margæ pulvere per exftantium jugorum fummitates canefcit; id, quod cavernofos illos anfractus, antrorum inftar undique fparfos, tanto elevat amplius. Videre etiam eft intercepta inter jugorum capita, acclivia paffin dorfa lateralia, velut totidem alpiụm prata, lente, aut præcipite magis afcenfu affurgentia; tam hæc, quam cavernarum aditus, parietesque, \& fornices, confita quam denfiffime funt grandinis inftar cryftallis plumbi fpatofi albi diaphani femipellucidique, quarum magnitudo vix dimidii feminis milii fit, fed minor etiam, \& minima; figura vero fphæroidica. Et tales quidem, fi inermibus afpiciantur oculis, cryftalli hæ funt. Microfcopio exploratæ, granulis adhucdum rotundatis, fed polyedricis fimul fimiles, quarum fuperficies convexa infcriptas habeat quantumcunque exiguas areolas triangulas, nullo ordine quadrangulis mixtas, \& quas haud melius me uno denique verbo exprimere poffe judicavi, quam fi rotundato-polyedras dicerem. Similes plane plumbi fpatofi albi cryftallos, libere accumulatas, aut parte fui aliqua 
connatas, quin \& ex albo hyalinas, frepius vidi, ac etian poffideo, non galænæ innatas, fed intra rimas, cavitatesque plumbi compacti nidulantes auf der W'indifchen Höhe; tum ex cuniculo tancti Nicolai Bleybergr; maxime vero e fodinis Comitis a Thurn prope Bleyburgum inferioris Carinthix.

\section{XLVI.}

PLUMBUM fpatofum ex albo rofeum cryftallinum, cryfallis inordinate polyedris. Bleybergæ ex cuniculo Maria Lichtmeffe.

Et hoc pariter pulcherrimum fpecimen ex Purificationis fumptum eft cuniculo; nulli \& ipfun innatum lapidex matrici; \& ipfum fporadicum, intra memoratam dumtaxat confepultum margam; dicas montes montibus fuperimpofitos, adeo prerupta tindique eft, \& fcopulofa facie, in parte cumprimis averfa. Proprium galænæ in eo nitorem fruftra (nifi ubi recenter avulfa funt fragmentula aliqua trriis aut fquamulis micantia) quafieris; nusquam in femifatifcente, aut margaceis obfito pulvifculis invenies. At vero quantum ex nitoris hujus eidem decedit defectu, 
tantumdem profecto ex cryftallorum elegantia fplendoris participat. Hæ liberaliffune undique difperfæ, magnitudine admodum funt differentes, pellucidæ potius, quam diaphanæ, polyedræ, planis tamen lateralibus nec numero, nec figura æqualibus; \& quod fingulare prorfus, neque in hunc usque diem mihi vifum adhuc, ex albido dilutiflime rolex.

\section{XLVII.}

PLUMBUM jpatofum excolor hyalinum cryftallinum, cryfallis partim inordinate polyedris, partim in orbiculum planum depreffis. Bleybergæ e cuniculo fancti Ruperti.

Sane, nifi fingulare ifthoc, rariffimumque fpecimen iple poffiderem; \& toties inermi, toties etiam armato exploraviffem oculo; vix exiftere poffe credidiffem. Calcareo æquabili Wallerii, ex grifeo cinerafcenti infidet plumbi galæna folida texturæ chalybeæ, in fpithamæ longitudinem extenfa, latitudine duos ternosve æquans pollices; unum contra aut femialterum profunditatis pollicem, ubi craffiffima, nec nifi lineas tres, quatuorve, ubi 
craffitudine minina eft, habens. Superficies ejus illa, qua alii lapidum generi obviam facta, non plus ultra metan hanc fefe potuit extendendo diffundere, plana, fpeculique ad inftar politiflimi refplendens eft; vere fpecularis $\&$ ipfa. Verum non hoc denique illud erat, quod admiratione in ea maxime inveni dignum. Specularem plumbi galcenam Wallerii frepe alias vidi. In regio Rablenfi monte plures etiam, multoque raras magis ejusden vidi varietates; fcilicet: galænam fpecularem nitentiflimam, objecta ex reflexione repræfentantem, fluctuum maris ad inftar undulatam, ftriisque approximatis parallelis plurimis, totam ejus longitudinem percurrentibus, per undulas exaratam: tum galænam fpecularem calcareo æquabili albo $W$ allerii innatam, ita fuper eodem craffitudine decrefcentem identidem, ut tandem fuperficialis, ejusque facta fit tenuitatis, fub qua $\&$ ipfa, remanente quanvis metalli nitore, transparens evaferit. Hinc illud profecto maxime rarum phænomenon proprium eft, ut fub recto in eamdem fi intenderis oculos angulo, nil metallici in ea nitoris detegas, \& transparentem præcife calcareum album videas; quod fi oblique eamdem afpicias, metallicum fpecularis galænæ nitorem, nec præterea aliud quidquam cernas. Tantum lamellarum tenuitas fumma! tantum al-

$$
\mathrm{H}_{3} \mathrm{H}_{\text {ternx, }}
$$


246 Minera PLUMBI SPATOSA

ternæ, ut dicimus, vices, præfare poffunt ! Igitur quod præfente loco de galæna fpeculari loquendi potifimum dedit occafionem; quodque in ea maxima dignum admiratione femper effe credidi, cryftalli plumbi fpatof, non tam albæ, quam hyalinæ, excolores, vitro, quam quarzo fimiliores, eidem infidentes erant. Oblervaveram primum, nefcio quas? rotundatas, planas, depreffas, plumbicolores \& opacas maculas per fpecularis galænæ fuperficiem fparfas, quas detergere cupiens, firmiter eidell hærentes, fimulque exftantes aliquantum inveni; diligentius dein cum easdem infpicerem, adfita illis, multoque humiliora, vitri tralucentis modo micantia detexi, \& angulofa corpufcula alia, verbo, cryftallos exiguas, oblongas, inordinate polyedras, vitri facie, \& pelluciditate fpati plumbiferi; fed \& ipfas, quas pro maculis habui, jam reniformes, jam orbiculatas, aut trapezinas areolas, etfi fupra infraque plano-depreffre, opacæ, \& plumbi muti effent colore, ora tamen ambitus totius vitreas, \& vitri more refplendentes vidi; fufpicatus exinde, poffe easdem etian effe cryftallos orbiculares plumbi fpatofi hyalinas, ochra plumbi pulverulenta cinerea obductas. Ergo avulfas illarum aliquot in aquam fortem injeci; \& fufpicionem hactenus meam, illico per experimenta plene confir- 
matam comperi, poftquam in eadem elatis in fublime nonnullis exiguis effervefcentix teftibus bullulis, opacam illam cæruleo-cineralcentem, ut ita dicam, cuticulam difparere; orbiculatas contra cryftallos, hyalinas, excolores, \& transparentes denique fieri vidi. Sed \& flamma fiftulæ ferruminatoriæ exploratæ tam cryftalli, quam cryAtallini orbiculi, absque mora regulinos plumbi dederunt globellos. Sublefta hac ex Charybdi utcunque eluctatus, in Scyllam haud minus moleftam me rejętum iterum intellexi; quomodo enim fi fpecularis plumbi galæna exfitit antea, eamdem inter $\&$ calcareum, cui arctiffime appreffa fuit, lapidem, cryftalli plumbeo-fpatofæ enafci potuere? aut fi cryftalli antea in galæna exftitere, quam illa in calcareum impacta fpecularis facta eft, quomodo, inquam, hæ non diffrait funt? fed mollis inftar corporis complanatæ? cur complanatis hisce, aliæ, illis contiguæ, malleum inter \& incudem, in cryftallorum tamen polyedrarum fe conformaverunt figuram ? Videtur mihi, eodein plane, quo materia, plumbo conftituendo apta, per fulphuris acceffum mineralifata, \& verbo, fpecularis plumbi galæna effecta eft, eodem inquam temporis momento, \& glebulæ adhucdum molles \& tluidæ, fpato plumbifero deftinatæ, undique per priorem fparfæ, per calcis admix-

tionem 
tionem ex attactu calcarei lapidis, ex fluiditatis ad confiftentiæ ftatum cryltallifatione transiviffe; qua in fimultanea, prioris mineralifatione, \& pofteriorum cryftallifatione, fieri neceffe erat, ut quæ majore erant volumine glebulæ, plusque maffr fuo fub volumine comprehendebant, planos in orbiculos comprimerentur, dum interea temporis adfitæ illis proximæ bullulæ five glebulæ minoris voluminis, \& maffæ, in minimas cryftallos, quarum altitudo craffitudinem prædictorum orbium non adæquaret, abire potuerint. Sic, inquam, mihi facta hæc fuiffe, aut faltem fieri potuiffe, videntur; diem tamen propterea nemini dixero, qui contrarium fentire, aut afferere, in animum induxerit.

\section{XLVIII.}

PLUMBUM fpatofum pellucidum cryftallinum, cryfallis par- tim granojo-druficis rugojo-friacis cinereis, partim inordinate polyedris excoloribus, cinerex plumbi ochree infidentibus. Bleybergæ ex fancto Chriftophoro.

Compendium multarum, rariffumarumque in mineralogicis pulchritudinum exhibet hoc fpecimen. Innafci- tur, 
tur, aut comnafcitur verius gypfo ponderofo folido niveo, anorpho, fractura impalpabili femivitrefcente, \& nitente, galæna plumbi pariter folida, quam fparfim hinc inde erumpentem, \& areis majufculis, minoribusve micantem confpicis; ne undique, qua ultra matricem prominet, fuo fe iplendore prodat, cinerea ejusdem facit ochra pulverulenta, quæ compactæ inftar argillæ, cohærentem eidem fuperinducit cruftam, ad flammam fiftulæ ferruminatoriæ illico in plumbum ex toto fundendam. Plumbo ifti larvato, feu ochraceo, averfam fpeciminis partem undique incruftanti, \& altera fuperinducitur præterea crufta flavo-rufa, martiali-zincofa, more hæmatitæ in eminentias hemifphæricas mammillares zinci fpatofi cryftallini efforefcens : in parte vero oppofita præter confimiles plane glandulas hemifphæricas ejusdem zinci fpatofi cryftallini, duplex quoque varietas plunbil fpatofi cryftallini occurrit. Exfe(quar jam fingula: fparfæ primum per turmas, jamque ochræ plumbi cinereæ, jam matrici gyplaceæ infidentes confpiciuntur cryftalli, nulla certa lege polyedræ, fed \& magnitudine differentes, plumbi fpatofi, non tam albre (quamvis \& albæ dici aliqua poffint ratione) quam excolores, pellucidiffimæ, nitentes, verbo, ut fere folet limpidiffima, quam lagenæ vitreæ mundiffinæ incluferis, 
aqua. Hæ infimo potifimum occurrunt $10 c 0$, liberæ, accumulatæ quidem, non tamen connatæ. Aliam ejusdem plumbi fpatofi cryftallini varietatem drufrcam, dilute cineream in fuperiore finiftro angulo vides præterea; hæc longe a priore diverfiflima eft. Cryflalli nempe non fimplices, folutæ, \& liberæ, fed drufarum more connatæ in cruftam unam, cohærentem, vitream, nodulofam, nodulis convexis, non in äpxs, feu areolas planas fectis, fed rugofo-ftriatis, ftriis undulatis parallelis. Crufta hæc cryftallino-drufica dilute cinerea omnino eft, \& nitens; indubie a tralucente, quam obducit, cinerea plunbi ochra; nam avulfam ejus partem aliquam (ut in plumbum ope fiftulæ ferruminatoriæ funderem) pellucidiflimam, \& excolorem pariter inveni. Cur autem priores cryftalli polyedræ, etfi \& ipfæ cinereæ plumbi ochræ infideant, non etiam, ut druficæ hæ, cinereo tinctæ videantur effe colore? rationem fcio nullam, nifi forfan hæc ex fuperficie priorum rugofo-ftriata, undulataque, $\&$ alia prorfus inde exiftente refractione, repetenda fit. Quod demum ad tumulos illos convexos, hemifphæricos, lamellofos, e centro radiantes attinet, eminentix ( ut fupra dictum eft) funt, adinftar nodulofi hæmatitæ, mammillares zinci fpatofi cryftallini. Solet enim Bleybergenfibus in fodinis 
quadruplex ut plurimum zinci minera (vitrea drufica Wallerii; calaminaris fatifcens ; ochracea ; ftalactitica) fua in fuperficie in novam hanc zinci fpatolo-cryftallini fpeciem efflorefcere. Plures \& ipfa complectitur fubalternas varietates, de quibus forfan alias, fi otii \& fumptutm fuerit fatis. Hæc quam præ oculis habemus, hemifphærica, felfilis, vitrea, pellucida, \& ranunculi afidtici polypetali L. adinftar, lamelloła eft, lamellis telenitico-decaëdris, oblongis anguftis, linearibus, multorum ordinum, in centrum commune convergentilus, undique, præter apicem ipfum in peripheria terminatum, connatis; id, quod ex diffractis perpendiculariter, \& horizontaliter ejusmodi rofulis clarum eft videre. Lamellarum iftarum feleniticarum bafes e centro radiantes aquofe virent, $c \mathfrak{c}$ tera excolores lunt, \& pellucidæ; ex transparente tamen crufta ochracea flavo-rufa, \& ipfr flavo velut tinctx colore videntur effe.

\section{XLIX.}

PLUMBUM fpatofum pellucilum cryfallinum, cryfallis inordinate prijmaticis mellei coloris, cinere.e plumbi ochr.e infidentibus. Bleybergæ ex eodem lancti Chriftophori cuniculo.

$$
\text { I i } 2 \quad \text { Nihil }
$$


Nihil hæ a prioris varietatis cryftallis plumbi fuatof diverfæ funt, quam quod earum plurimæ oblongæ, inordinate prifmaticæ, utrinque truncatæ fint, \& mellei, feu obfolete, fimulque aquofe flavi coloris; pellucidæ quidem, at non pellucidiffimæ, utpote levi coloris tinctura imbutæ. Matrice quoque gaudent eadem, \& eodem nativitatis $10 \mathrm{co}$, fuper ochram plumbi cineream rariter fparfæ inter acervos cryftallorum minimarum plumbi fpatof metallicoloris, galæna fuperficiali nitentifima obductarum, de quibus brevi uberius.

\section{I.}

PLUMBUM fpatofum pellucidum cryftallinum, cryftallis inordinate polyedris minimis, in cavitatibus exefis plumbi compacti nidulantibus. Auf der Windifchen Höhe in valle Gilienfi.

Jam lupra meminimus maculas illas nigras, quæ variegatam plumbo compacto faciem conciliant, fiquidem microfcopio infpiciantur, nil nifi fcrobiculos diverfæ magnitudinis, \& circumfcriptionis effe, quorum fundus exefis cum fit, alternantibus inter fe foveolis microfcopicis, 
\& eminentiis admodum lumilibus, fcabriufculus, \& abforbendis lucis radiis perquam idoneus reddi, verbo, niger \& ipfe denique videri omnino debet. Solent autem perquam frepe, ut in propofita videre eft, hisce in foveoJis minimæ plumbi fpatofi nidulari cryftalli, inordinate angulof $x$, feu polyedræ, excolores, vitri ufualis \& facie $\&$ pelluciditate, quas oculus vix difcernat, nifi aut microfcopii ope, aut certe ex micante nitore, dum fpecimen tale contra lucem convertitur. Compactum, cui infident, plumbum, fupra defcripfi; reliquum eft; ut cui inhæreat ipfum matrici in cuniculis Windifche Höhe vulgo dictis, recenfeam. Hanc triplicem omnino inveni; ac primo quidem argillam martialem flavo-rufam, non effervefcentem; tum zincum vitreum druficum in botrytem concretum albido-luteolum, aut rufum etiam $W$ allerii; denique calcareum æquabilem particulis impalpabilibus, tarde effervefcentem, coloris albidi, aut ex albido-grifei, punEtis, maculisque afteroideis, \& clendritis hypnun filicinum L. referentibus, nigris, quam elegantiffune pictum. Sed quod calcareum iftum longe reddit celeberrimum, $\mathrm{pa-}$ pyrus eft montana tenerrima, nivea, dendritis \& ipfa atris picta, feu Asbefius membranaceus Cronftedti, aut ut Linnæo \& Wallerio dicere placuit: Amianthus corticofus

$$
\text { I i } 3
$$$$
\text { flexi- }
$$ 
254 MINERA PLUMBISPATOSA

fexilis membranaceus natans, aluta montana vulgo dicfus. Papyrus inquam hæc membranacea, continua, impalpabilis, dendritica, igni indomita, fenio in fila, aut floccofum abiens pappum, utut teneritudinis, tenuitatisque fit fummæ, durifimum tamen, folidiflimumque pervadit, \& inflernit calcareum lapidem, cum eodem per ftrata parallela ad unius, aut linearum aliquot diftantiam alternans. Effervefcere fuam aq̣ua forti afferit $\mathrm{W}$ allerius, at non $\mathrm{Ca}$ rinthiaca certe ifthæc; frquidem cum experimentum iftud iteratis caperem vicibus, imbibi quidem ab eadem aquam vidi fortem, fed absque motu omni; absque emergentibus bullulis fpumantibus; absque dendritarum evanefcentia; absque coloris in papyro mutatione. Porro cum papyrum hanc eisdem plane cum calcareo fuperbire viderem ornamentis dendriticis, fciendi fueram cupidus, neque tamen aliquo eruere poteram tempore, cuinam potiffimum caufi dendriticas hasce picturas adfcriberem in Bleybergenfi, \& hocce tam calcareo, quam asbefto? Ferro? quæ communis faltem maxime earumden origo videtur effe Cartheufero in eleganti fua de Dendritis dilfertatione pagina $\mathbf{I}_{58}$. Nefciebam. Illud certa tenebam fcientia, Dcndritas Hiittenbergenfes tam argentéos, quam cinereos, atros nigros, fufcosve (num flavi, rufique reli- 


\section{CA R I N T H A CA.}

Eta dumtaxat nunc dictorum, poftquam evanefcere cœperunt, funt veftigia) qui ornamentum longe pulcherrimum non calcarei folum micantis $L$. funt, verum etiam diverfiffmarum Chalcedonii fpecierum, imo \& hæmatitæ nigri glandulofi fpecularis, \& quarzi cryftallino-drufici, \& gypfi ponderofi fpatofi, \&c. non ferro, fed uni adfcribendos effe Magnefice parum martiali floccofo-fquamofix, argentex, in fuliginem tandem nigram abeunti. Nam \& naturam (ut ita loquar) eosdem elaborantem, frepe ipfo in opere deprehendi in fodinis exiftens, \& cum eorundem materiem cum borace funderem, vitrum femper rubro-hyacinthinum diaphanum obtinui. Verebar autem, ut eadem utrisque, Huittenbergenfibus nempe, \& iftis foret origo, cum nulla adhuc veftigia præfentis magnefi Bleybergæ $\&$ ad fanum fancti Antonii auf der Windifchen Höhe detexerin. Hoc propriis, a me ipfo inftituendis, ut fcirem experimentis, tentandam pariter vel cum dendritis hisce aleam judicavi. Decorticavi igitur a calcareo prædicto foliola papyri hujus asbeftinæ, egregie dendritis onultæ aliquot; asbeftum cum borace illico fundi debere fcivi; fudi igitur fuper carbone ope fiftulæ ferruminatorix foliolá hæc cum borace fimul; \& fufa etiam protinus funt in vitrum, non album, neque nigrum, aut nigro-fufcum, 
vel viride, fed elegantifime rubro-hyacinthinum. Ex his non immerito concludendum jam cenfui, ipfos etiam, qui calcareo huic, \& Bleybergenfi inhærent, dendritas magnefiacæ pariter naturæ effe debere. Utinam vero, quæ cum dendritis Hiittenbergenfibus, tum cum asbeftinis iftis inftitui experimenta, alii quuque Mineralogi fuis cum dendritis capiant! non vane enim fpero fore, ut ex. illis omnis denique dendritarum hiftoria plenam in lucem: protrahatur.

\section{LI.}

PLUMBUM jpatofum pelluridum nigrum cryffallinum, cry-ftallis inordinate polyedris promifcue gypjo cubico-cry-fallina albo, E p feudogalcena pariter cubica-cryltallina. granatina incrufatis. Bleybergæ ex fancto Chrifto-phoro.

Contradictionem involvere videntur idea pellucidi, \& nigri; quo tamen fumam fenfu, cum utramque conjungo, illico patebit. Denfe accumulatæ infident galænæ folidæ, calcareum arenaceum cinereum Wallerii undique. percurrenti, mediocres, led inordinate fimul polyedræ cry- 
cryftalli plumbi fpatofi; hæ vitro fimiles, utut reapfe excolores, pellucidæ \& nitentes fint, tamen matrici inhrerentes, nigra dumtaxat apparent effe; procul dubio, quia plumbo immediate inhærent, nec alio tinetæ funt colore, $\&$ adeo ftipate accumulatx, ut connatæ dici poffint, licet liberæ revera fint; avulfi enim nonnullas a reliquis, \& vitro, non nigro, fed excolori, hyalino, transparenti erant quam fumillimx. Confepultæ quondam fub alius naturæ cryftallis fuerunt, quarum vel hodieque non pau$c æ$ hinc inde cernuntur fparfæ; duplicis iftæ funt generis, promilcue inter fe mixtæ; cubico-cryftallina utrævis conveniunt figura, colore, quam plurimum inter fe diffidentes; dum harum aliqux, quæ albæ funt, ad gypfi pertinent genus; reliquæ mineras inter zinci, pfeudogalænam rubro-granatinam conftituunt.

\section{LII.}

PLUMBLM Spatofum pellucidum nigrum cryfallinum, cryftallis inordinate polyedris galenam pyramidalem inter gypfum ronderofum lamellare niveum incruftintibus. Tab. 21. Fig. 19. Bleybergx ex S. Chriftophoro. 
Ditiffimus ille plumbi cuniculus, qui a $S$. Chriftophoro nomen tulit, perquam fpeciofas plumbi ompigeni fuo in finu recondit varietates. Jam in calcareo æquabili cinereo, aut cuniculo arenaceo, albo, grifeove $\mathrm{W}$ allerii; jam in gypfo ponderofo folido niveo; alias in pfeudogalæna fquamulis ninoribus nitente colore flavefcente; plumbi galænam itidem folidam aut infidentem habet, aut eosdem pererrantem undique. Extima galænæ fuperficies fæpe admodum in pyramides utcunque magnas abit quadrangulas; altiores, aut humiliores; acuto magis vertice, aut obtufiore, etiam truncato terminatas; rectas, aut obliquas; etiam confufe accumulatas, \& fe mutuo interdum decuffantes. Rarius accidere folet (accidit tamen nonnunquam) ut et in duplicatam, contractiorem, utut majufculam, quadrangulam pyramidem fe furmet, quarum fingularum bafes, absque intermedio prifmate uniantur, figura aluminari octoëdrica. Pyramides hæ nudæ quandoque funt; $\&$ dum nudæ aut opacæ omnino, \& obfolete nigro-cxrulefcente colore, cryftallis promifcue mixtæ calcareo-fpatofis albis diaphanis erectis, quarum prifina hexagonum, apex vero obtufiffime trigono-pyramidatus ex pentagonis tribus æqualibus; aut eliquati inftar plumbi continuæ particulis impalpabilibus cinereo- 
cærulefcentes, lævigatæ quidem \& politæ, non tamen nitore ullo refplendentes; vel denique fuperficie funt tota ex iquamis imbricatis loricata. Sed plerumque tamen incruftatas cernas has galænæ pyramides; \& quidem

I. Ochra zinci albida, aut argilla zincolo-martiali rufa.

II. Cryftallis gypfaceis cubicis hyalinis diaphanis, albis, virefcentibusque fubdiaphanis, denique flavo-rufis opacis.

1II. Pfeudogalæna cubico - cryftallina phofphorefcente granati colore.

IV. Cryftallis cubicis tam gypfaceis albis, quam pleudogalænæ - rubro - granatinæ promifcue mixtis.

V. Cryftallis gypfaceis cubicis hyalinis, \& ipfis pariter obfitis cryftallulis minimis fpatofo - calcareis hyalinis, conditi adinftar facchari. 
260 MINERA PLUMBI SPATOSA

VI. Cryftallis pfeudogalænæ rubro-granatinæ cubicis transparentibus per cryftallos alias \& ipfas cubicas hyalinas gypfaceas prioribus infidentes.

Vli. Aut vice verfa, cryftallis gypfaceis, infidentes fibi habentibus cryftallos preudogalænæ nunc dictæ, utrisque cubicis, his rubro-granatinis, illis albis.

VIII. Gypfo ponderofo, fpatofo-lamellari, niveo, opaco, lamellis horfum vorfum per turmas tendentibus; aut certe hæmatitæ adinftar glandulofo, glandulis hemifphæricis, aggregatis, lamellatis, lamellis femicircularibus parallelis, in centrum convergentibus, usque fere ad peripheriam connatis; atque tum

IX. Aut granulis pellucidis calcareo-fpatofis cryftallinis, bellariorum more; aut

X. Plumbi galæna granulari nigricante opaca infperfis.

XI. Zinco vitreo drufico in botrytem concreto fufco Wallerii ; denique 
XII. Cryftallis plumbi fpatofi omnis generis, folis, aut ipfis quoque obductis cryftallifatione ex prædictis aliqua. Tale aliquod fpecimen hic defcribo: Calcareo arenaceo grifeo $W$ allerii infidet cum gypfo ponderofo folido amorpho niveo opaco Bornii, folida \& ipfa plumbi galæna Linnæi, fuperficie fua extima cryftalliata, in cryftallos tetragono - pyramidatas plerasque humiles obtufiffimas, nonnullis tamen duplo triplove altioribus, acuto vertice terminatis. Pyramidali huic galænæ, quanta quanta eft, perquam denfe accumulatæ infident cryftalli plumbi fpatofi inordinate polyedræ duplicis generis, fcilicet pellucidx, nitentes, excolores, vitro fimillimæ, quæ tamen nifi contra lucem afpiciantur a matrice avulfre, nigerrimæ effe videntur; hæ denfiflime undique accumulatæ $\&$ fatis funt exiles; tum hyalinæ, aquæ velut colore, obfcurifime albidæ, \& diaphanæ dumtaxat; atque iftx majufculæ, parcius hinc $\&$ inde fparfe cernuntur. Utrasque, maximam certe partem, crufta obducit MIarmoris metallici drufici criftati nivei Cronftedti, feu gypfum ponderofum niveum opacum lamellare, ad fiftulam ferruminatoriam poftquam diffiliit, \& phofphorea refplenduit luce, furbile, absque tamen prævia zeolitica, aut boracina expanfione. 


\section{LIII.}

PLUMBUM fpatofum femipellucidum metallicolor fplendentiffimum cryftallinum, cryftallis partim hexagono-prifmaticis, partim inordinate polyedris, galenam pyramidalem incruftantibus. Tab, 2r. Fig. 20. Bleybergæ ex fancto Chriftophoro.

Paradoxa fateor, vixque fide digna fibi narrari crediderit, qui elegantias hafce ipfe haud confpexerit. Studiofe autem fpecimen, inter plurima elegantifima minus elegans, defcribam, fcilicet in quo galænæ pyramidalis fuperficies ab ochra zinci fordide ex luteolo-albida fqualeat, \& cryftalli plumbeo - fpatofe rariter dumtaxat fparfæ eidem infideant. Calcareus arenaceus grifeus Wallerii (Linnæo Marmor fectile) matrix galænæ eft folidæ areis magnis micantis; adhærentem fibi tamen habet calcareum arenaceum album, percurfum paffim pfeudogalæna granatino - rufa phofphorefcente, partim etiam crufta albida diaphana cryftallorum cubicarum gypfacearum cohærentium. Galæna ipfa in magnas absque ordine accumulatas abit cryftallos tetragono-pyramida- 
tas, quibus nonnunquam aluminari octoëdricæ immixtæ funt, quarum tamen pyramis inferior, parte fui aliqua (id eft verticis inferioris parte) reliquam intra galænam abforpta, confepultaque eft. Dixi fuperficiem harum pyramidum leviter oblitan ochra zinci, funt tamen \& inter trigona earum latera, faltem aliqua, in quibus triftia cryftallorum quondam peeudugalænæ cubicæ granatinæ, ex integro jam fatifcentis, legas veftigia. Venio ad peculiarem illam plumbi fpatofi varietatem, quam cryftallinam, femipellucidam, fimulque metallicolorem, \& refplendentem dixi. Et fane tales plane funt, quibus incruftatam cernis pyramidalem galænam; vitrex nempe, \& hyalini quidem, fimul tamen infumati (feu fumo dilutiffimo tineti) vitri inftar transparentes; quapropter nec pellucidas ex integro, fed femipellucidas præcife appellandas cenfui, quia tales fe onmino exhibent, quoties five ipfa in matrice, five inde avulfas, contra litcem afpexeris. Quod miratus in illis femper fum maxime, fplendor, non vitri, fed metalli omnino nitentiffimus eft. Transparentia hac non obfiftente, refplendere tamen folent, dum dilutiores funt, inftar galænæ; dum vero faturatiores, ut ferrum micaceum fubretractorium lcmellare ex infula Elba. Splendorque hic metallico- 
264 MINERA PLUMBISPATOSA

lico-fpecularis iisdem vel a galænæ matrice avulfis inhæret, in aqua præcife forti illico difperiens, ubi cryftalli ejusmodi immerfæ, hyalino-albefcentes, fubpellucidæ evadunt; cum tamen, quas fupra pellucidas \& nigras compellavi, fi a matricibus avellantur fuis, nec nigræ amplius, multo minus metallicolores fint, fed cryftallini excoloris vitri inftar pellucidæ, in aqua forti folum prioribus fimiles. Judicent nunc mineralogix me peritiores alii, num recte, aut perperam, femipellucidas metallicolores dixerim? atque unde demum metallicus ille fplendor provenire poffit, qui cum tranfparentia earumdem in eadem, ut ita dicam, fede moretur? an re. vera, ut ex fupra adductis deduci poffe videtur, a galæna fuperficiali, ad tenuitatem quantumcunque exiguam redacta iisdem inftrata? Exfequar nunc cryftallorum harum, fub quibus mihi hactenus vifæ funt, figuras nonnullas; regulares inter fequentes funt: Hexagono-prifmatica proftrata, feu octoëdra æquabilis utrinque truncata, confans planis duobus maxime diftantibus æqualibus hexagonis, quorum latera aut omnia æqualia, aut alterna alternis paulo longiora; tum parallelogrammis fex lateralibus, itidem aut omnibus æqualibus, aut alternis nonnihil anguftioribus. Solet autem parallelogrammorum unแm? 
unum, fria interdum longitudinali impreffa exaratum effe. Rarius, fed tamen occurrit etiam cryftallus parallelepipedi forma. Selenitico-decaëdras aliquot itidem vidi; at non nifi unam alteramve octodecaëdram; quæ tamen perquam frequens inter cryftallos plumbi fpatofi flavi effe folet. Irregulares, feu inordinate polyedras, quis recenfeat? pleræque funt; utque lateribus, \& angulis, ita magnitudine quoque maxime differentes. . Minimæ quævis videntur in Num. 38. inter interftitia plumbi fpatofi reticulati, \& univerfim in galæna erofa Rablenfi, quamvis \& in Bleybergenfi fæpius occurrant. Plurimum heteroclitæ illæ funt, hac tamen in fpecie adnodum frequentes, qux cunei, fuperne inanis, aut fi mavis libri plus minusve aperti, faciem habent. Summe parallelogramma, aut etiam parallelepipeda duo, non admodum craffa, vel denique cryftallos binas felenitico - decaëdras; junge eadem uno eorum latere fub angulo quovis acuto; $f_{1} \mathrm{jam}$, ubi convergunt mutuo, in linea juncturæ communi connafci eadem facias; cryftallos cuneiformes, fuperne inanes, quales in figura ad latus expreffas habes, magis, minusve apertas, enafci intelliges. Anonalos dein cuneos vccitare foleo illos, dum cryflallus aluminari-oftoëdra \&c. excifum fuperne habet utrinque declivem, pro-- 
fundiorem canalem, ut in figura 20. aut cryftalli figuræ I3. fummo in dorfo unum longitudinalem ter abruptum (per utramque fcilicet declivem pyramidem, \& intermedium prifma) ejusmodi canalem impreffum habent. Addam denique metallicum illum refplendentem nitorem nonnunquam toti cryftallo fuperinductum effe, fæpius vero non nifi per fuprema latera, aut per cuneorum acies \& margines laterales fefe diffundere.

\section{LIV.}

PLUMBUM Jpatofum Jemipellucidum lamellofum, lamellis parallelogrammicis, acie marginali metallicolore longitudinaliter ftriata. Bleybergæ ex cuniculo S. Nicolai in plumbo compacto.

Confundere cum priore varietate hanc nulla potui ratione; non enim fola differunt matrice, \& habitatione, verum etiam configuratione; quæ hacce in varietate non tam cryftallina, quan lamellofa potius eft. Sunt vero lamellæ oblongæ, anguftæ, parallelogrammicæ, tres lineas longæ, unam aut femialteram latæ, fitu perpendiculari, uni longitudinis lateri infiftentes, temere accumulatæ, 
quaquaverfum refpicientes, vitri infumati fimillimæ, ideoque non nifi femipellucidæ; harum acies aut margo longitudinalis fuperior; colore \& nitore metallico refplendet, ac licet vix quartam lineæ partem æquet craflitudine, ftria tamen longitudinali impreffa exaratus eft, lamellas bifidas reddens, id quod varietati huic faciem præbet ftibii cryftallini acicularis.

\section{LV.}

PLUMBUM fpatofum fufcefcens cryftallinum, cryfallis fubcubicis, aut inordinate polyedris galenam pyramidalem incruflantibus, ipfis gyp fo cubico - cryflallino incruftatis. Bleybergæ ex cuniculo fancti Chriftophori.

,Fufcas quidem, \& ex fufco dilute badias cryfallos exhibet, quæ contra lucem afpectæ, rufæ \& fubdiaphanæ furit; tamen neque rufas, nec fufcas, vix \& hyalinas dumtaxat; ted pellucidas omnino \& excolores quondam fuife, forfan etiam parte fui alicqua, metallico refplendentes nitore, illud argumento mihi eft, quod tales plane ad finifimam fpeciminis partem, vel hodie- 
268 MINERA PLUMBISPAUSA que confpiciam plurimas; tum quod cum cæterarum aliquas iteratis probe laviffem vicibus, ad limpidifimæ cryftalli montanæ pelluciditatem vel fola redierint 10tione; ut adeo omnis, 'qua coloratæ funt tinctura, aliena prorfus ab earum fubftantia fit, neque ultra extimam illarum fuperficiem fefe extendat, atcue a martiali mutuatam habeant ochra, quam deftillantes fuper eas identidem fubterraneæ, ferro faturæ depofuerunt aquæ. Quod figuram earumdem attinet, cubicam, fubcubicam, tetragono-pyramidatam, at profundiffime fimul truncatam, denique inordinate polyedram inveni. Cryftallis hifce talibus denfe incruftata undique eft galæna tetragonopyramidalis ; fed neque ipfæ cryftalli plumbifero-fpatofre fua carent cryftallina crufta; infidentes fcilicet \& ipfæ habent gypfaceos cubos, quondam albos \& diaphanos, nunc ab eadem martis ochra rufos \& opacos.

\section{LVI.}

PLUMBUM fpatofum corneo-cinerafcens cryftallinum, cryfallis rhombeo-hexaëdris, felenitico-decaëdris, inordinateque polyedris, fiffili-lamellatis. Bleybergæ ex cuniculo S. Ofwaldi. 
Nullam habet fpecies hæc cum ulla prædictarum plumbi fpatofi, five albi, five flavi, varietate, præter cryftallifationis figuras, fimilitudinem. Nifi illico ad fiftulæ ferruminatoriæ flammam in plumbum fufa fuiffet tota, rhomboideas fyati calcarei cryltallos credidiffem; adeo facie externa, texturaque calcareo fimilis eft fpato. Certe fpatum pure calcareum fæpe huic plumbifero vidi, ut ovum ovo fimile; etiam funma illi cum ferro fpatofo albido - cinerafcente cryftallino diaphano Gertrudano in valle Lavantina intercedit fimilitudo. Sed jam ad fpeciminis defcriptionem iplam. Calcareo arenacen grifeo toties commemorata infidet galæna, extus admodum cavernofa, cavernis partim preudogalæna zinci fquamofa flavefcente phofphorefcente; partim ex fatifcente calcareo niveo orta creta arenofa, repletis; quæ medio, reliquis major, eft loco, profundioris inftar antri caverna, cryftallorum plena eft plumbeo-fpatofarum, coloris aquofe cornei, \& ex corneo, minus, aut fature magis cinerafcentis, cum diaphaneitate, etfi non perfecta, aliqua tamen, verfus earumdem cumprimis extremitates: pingues eas dicas, adeo exacta fuperficiei fuæ funt lævitate, \& refpondente lævitati nitore. Ut plurimum rhombeo-hexaëdram, etfi non ordinate adeo, affectare obfervavi figu-

$$
\text { L1 } 3 \text { ram; }
$$


ram; aut certe felenitico-decaèdram; cæteroquin vero, nulla certa lege polyedræ funt; \& perquam fæpe explicati inflar libri, feu obtufffimum referentes cuneum, fupra inanem. Earum textura interna fiffli-Jamellata fit, necelfe eft, cum, utut folida, in lamellas tamen fracta, abeat, \& extus quoque perfæpe ltriata fit facie. Humbi admodum dives.

\section{LVII.}

PLUMBUM fratofum nigrum fubccerulefcens fquamofum, micx, aut limature ferri facie. Circa Iokleuten interioris Bleyberg fub dio fupra calcareum æquabilem albidum.

Videtur maxime rara hæc, atque a congeneribus aliis longe diverfifima plumbi fpatofi varietas, non tam in terræ vifceribus nata, quam potius nuper admodum in telluris fuperficie, fub jove ut dicimus aperto, progenita fuife. Fofforum certe hunc usque in diem nullus e Bleybergenfibus fe cuniculis eduxiffe hujuscemodi meminit varietatem; cum tamen faxis, cruftr adinftar, inftratam, abundantiflime circa Pokleuten invenerit Durmerus, di- 
menfiones geometricas montis Bleybergenfis nuper capiens. Multa funt, quibus a reliquis fui generis plurimum difidet; facies primum externa; ut qui primum eandem viderit, ne fufpicari quidem poffit, fpatofi virietatem plumbi fe præ oculis habere; adeo illa fquamulis ferri micacei, aut etiam limaturæ martis, per ampla effufæ ftrata, \& ftipatim accumulatæ, fimilis potius eft. Squamulæ dein hx, plerumque miculis faccharinis haud majores, admodum graciles funt, nitentes, planæ, trigonæ, aut qualiter demumcunque quadrilateræ, etian interdum fubrotundæ; vifæe etiam nonnullis cuneiformes, \& trigono-pyramidatæ. Color illis de fe nullus; hyalini potius \& excoloris vitri fimiles, transparentes etiam, \& pellucidæ funt; verum quia aut fuper crufta ex fufco nigrefcente profratæ penitus funt, aut intra eandem ex parte deforfr, non nifi parte fui aliqua oblique ultra eandem exftant, \& ipfæ coloratæ videntur effe, \& quidem colore ex nigro fubcærulefcente, eodem plane, quo limatura ferri. Guttas aqquæ fortis aliquot fuper easdem diverfis in locis ftillavi; alssque ullo effervefcentix motu fe iftx fuper easdem diffuderunt; poftero die ubi fluidum nitri exficcatum denique fuit, tam crufta, quam fquamu- 
$1 æ$, iisdem in locis ex flavo virebant, \& ex læto hoc colure, in triflem denique olivarum virorem degenerarunt; manifet?o folutionis alicujus factæ indicio. Ad fiftulæ ferruminatoriæ flammam exploratæ, illico absque prævia diffiliticne \& ftridore in totidem, utut minimos, plumbi regulos abierunt. Quid vero crufta illa fufcefcens, unam tertiam lineæ partem craffa, quæ calcareum late olducit, cuique tanquam matrici fquamulæ plumbi fpatofi innatæ, \& quæ eadem cum fquamulis in aqua forti dedit phænomena? quid inquam? terra \& ipfa plumbeo-fpatofa? affrmare nondum aufim, illico \& ipra quidem ad flammam fifulæ ferruminatoriæ funditur, fed non nif in fungofam ejusdem coloris fcoriam; \& quamvis, fi cumprimis Loracis aut nitri falibus utaris, vel ipfa hac in fcoria maxime exigui plumbi detegantur reguli, an hi tamen ex cruftr ipfus fubftantia educti fint, vel potius latentibus intra cruftam fquamulis plumbi fpatofi, \& cum ea fufa reductis, tribuendi? nondum fatis fcio: fufpicor pofterius; idque eo potiflimum ex capite, quod plenam earundem lemper invenerim, ita quidem, \& etfi externe ne vefligium quidem illarum te videre exiftimes, fi nihilominus eamdem foli objicias, \& eidem objectam conver- 
vertas, undique facchari inftar micantem confpicias. Calcareum denique quod attinet, in quo cruftæ inftar peculiarem hanc plumbi fratofi varietatem habitare vidimus, æquabilis eft, partibus impalpabilibus, opacus, albidus, \& ex albido tulgrifefcens; fed non talis certe credatur, fi de externa ejus facie ab oculis fumptum feras judicium; imo cinereum, \& cotis inftar granularem, vel arenarium dicas; nifi memineris ex vegetabili demum regno hanc illun mutuatum effe larvam; rei autem iftius memor, faxatilem Linnæi byffum pulverulentam cineream, rupes aëri diutius expofitas, operientem illico agnofcas.

\section{Dabam Clagefurti zmo die Fanuarii 1780.}

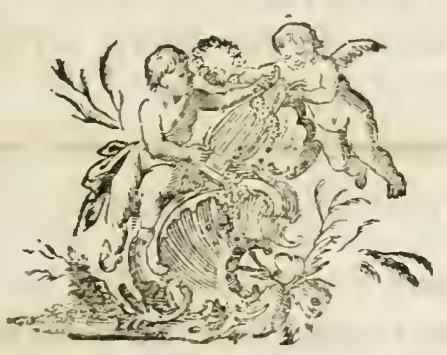




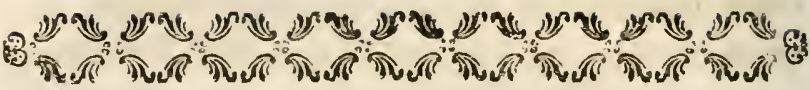

\section{V.}

\section{CRAMBE TATARIA.}

DISSERTATIO INAUGURALIS、 $\cdot$

M E D I C A

PUBLICE DISQUISITIONI

$\begin{array}{llllllll}S & U & B & M & I & S & S & A\end{array}$

A B

ALEXANDRO SEBÉOK DE SZENT - MIKLÓS, NOEILI HUNGARO.

Vienne 5. die Funii 1779.

A U C T A.

CRAMBE TATARIA foliis multifidis.

Tataria Ungarica, Cluf. hift. pag. CXCI. Tataria Ungarica edulis, Panacis Heraclei folio, femine Libanotidis cachryoferæ. Bauh. hift. vol. 3. part. 2. pag. $1 \sigma_{3}$. 
Panaci Heracleo fimilis Ungarica, Bauh. pin. 153.

Cachrys Ungarica, Panacis folio. Tourn. inft. pag. 325.

Omnium primus, celeberrimus \& indefeffus ftirpium Pannonicarum Auttriacarumque indagator, Carolus Clufius, plantæ hujus notitiam orbi literato exhibuit; -cujus totam hic adtuliffe delcriptionem, haud erit incongruum. Hæc ejus funt verba:

Non vulgaris eft hæc planta, quæ radicem habet craffifimam \& longiffimam; nam brachialis craffitudinis \& cubitalis longitudinis, aut etiam ampliores aliquot accipere memini ab illuftriffimo Domino Balthafare de Bathyan, qui in meam gratiam ex Ungaria transdanubiana adferri jufferat, ut in hortum Vienuæ transferrem. Illis autem folia emerferunt rapi foliis non valde diffimilia incifuris \& laciniis, breviora tamen, \& verius ad Panacis Heraclei fuliorum formam accedentia, rudi atque afpera lanugine prædita, ex viridi pallentia, alia deinde paulo minoribus incifuris divifa, nec minus afpera, inter quæ affurgebat caulis cubitalis aut amplioris longitudinis, pollicaris vero craffitudinis, ftriatus, concavus \& nodofus, perinde afper ac folia, quem lato pediculo amplecteban- 
tur minora folia \& multifida, afpera etiam lanugine obfita. Summus caulis in umbellam definebat, Panacis Heraclei umbellis fimilem, in quibus tlores \& forma pares \& colore; quibus evanidis fuccedebant rara, (nam fingụli flores non funt fœcundi,) femina valde craffa, nec valde abfimilia femini illi magno \& ftriato Libanotidis cachryferæ. Biennio quidem eas radices alui, antequam una illarum. \& caulem, floremque \& femen proferret: deinde corruptæ funt, tamque fotidum odorem exhalarunt, ut ex horto fuerint ejiciendæ.

Hujus porro radice Ungari Agriæ vicini, atque etiam ulteriores Daciæ cuntermini, in annonæ caritate \& inopia vefcuntur alterius panis penuria; ut mihi afferebant, non modo heros ille illuftris, fed etiam alii nubiles viri, qui in ea Provincia vixerunt. Quæ adeo res effecit, ut dubius effem, an eadem effet cum Baltracan in Tartaria nafcente, cujus meminit Jofaphat Barbarus, Patritius Venetus, in epiftola ad Petrum Barocci, epifcopum Patavinum, quæ adjecta eft ad calcem ultimi capitis narrationis ipfius, quæ evulgata eft ejus in Perfidem profectione.

A Tar- 
A Tartaris forte hujus radicis ufum edocti funt $\mathrm{Un}$ gari, propterea Tatariæ nomen illi dederunt; Tatár enim (ut \& Germani) vulgo appellant, qui nobis Tartari dicuntur.

Atque hactenus Clufius; quem exfcripfit in fua plantarum Hiftoria Joannes Bauhinus. Sed nec hunc, nec præter Clufum autorem alium ex citatis ullum Tatariam Ungaricam vidiffe, credibile eft.

Hinc omnes, Clufium fecuti, umbelliferis illam perperam adnumeraverunt. Fatendum omnino eft, in primo caulefcentiæ menfe, dum planta folia adhucdum fua rugofe complicata, floresque in ramulis claufos conglobatosque gerit, faciem præ fe ferre cujusdam Heraclei, ut vel Botanico imponere poffet; at vero debite evoluta longe fe aliam præftat; ut Clufum, exactiffinum cætera virum, fatis mirari nequeam, quo potuerit pacto cruciformem plantam cum umbellifera confundere.

In ultimis demum, quos Viennæ vixit, annis viro eximio innotuiffe illa videtur; nam nullam ejusdem faEtam mentionem in Stirpium Pannonicarum Auftriacarum$\mathrm{Mm}_{3}$ que 
que hiftoria, anno I583 edita, legimus; \& iple I587 Vienna, non reverfurus, difceflit. Unde forte minus ab illo hæc defcriptio fuit debite elaborata; forte poft plantæ interitum ex recordatione demum chartæ mandata; quæ quidem conjectura firmari videtur ex eo, quod nec figura plantæ rariffimæ adjiciatur, nec de fapore aut odore quidquam, nec de tempore florendi fermo fiat, contra morem Clufianum.

Jam diu vídendæ examinandæque plantæ, ex Clufio fibi cognitæ, defiderio tenebatur clar. Frofeffor a Jacquin; quare ante aliquot annos occafionem opportunam nactus, a reverendo Maximiliano Hell, Aftronomo cæfareo, Agriam, (Germanis Erlau, Hungaris Eger) Comitatus Hevefienfis in Hungaria civitatem, profecturo, petiit, ut Tatariam fi quam ifthic incolis vocatam offenderet plantan, benevole ipfi aut redux adferret ipfe, aut transmitteret. Celeberrimus vir illico effofras duas radices curavit Viennam transportandas; ipfe fpecimina florentis plantre ficca fecum adtulit, radicibusque in reditu prævenit, quæ dum per fex hebdomadas æftivas in itinere hæfiffent, totæ putridæ fotidæque appulerunt. Harum altera quatuor pedes longa, \& tamen truncata inferne, 
cruris ferme craffitiem habebat. Specimina ficca præter exfpectationem indicabant cruciformem plantam.

Felicius vero egregius atque dexterrimus Caramelliæ legionis chirurgus, H. EngeIsdorfer, menfe Octobri $\mathbf{1 7 7 7}$ hoc negotio perfunctus eft; qui plures radices, quas invenire poterat \& breviores \& graciliores, ad clar. Profefforis rogatum in hortum botanicum transmifit; quir omnes ibidem lætiffime germinarunt, floresque \& fructus maturos produxerunt quotannis.

Ad propofitas plures quixftiones, dum reliquis fatisfacere ob inopinatum ad exercitum in Bohemiam difceffum non poterat, refpondit: primo, vocari vel hodiedum ab incolis Tatariam. Secundo, crefcere in agris inter fegetes, in folo ex terra fertili nigra ad unius pedis profunditatem, cui alia fubjacet argillofa flavefcens ad tres pedes; tandem tabulofa; atque in hanc usque penetrare folere radicen adultiorem; quæ propterea vix integra effodi poteft, quod foffa, fimul atque ad fabulum perventum fit, fcaturiente copiofa aqua impleatur.' Tertio, radices quotannis aratro lædi ac amputari, fed vel fic læa denuo germinare. (Jarto, in nullum circa Agriam trahi ufum, 
ufum, præterquam a pueris, qui ob dulcedinem radicem coctam edunt. Puinto, a leporibus, maximo numero illic degentibus, arrodi \& comedi.

Non folum circa Agriam crefcit, fed etiam aliis Hungariæ in locis. Adlatam confpectamque radicem famulus clariffimi Profefforis, natione Hungarus, illico agnovit, \& Hungarice Tatàr-kenyér, five Panis Tartarici nomine falutavit, feque illam Debrecini comediffe afferuit. Ad ejus præforiptionem mox ex decorticata difciffaque transverfun in tenues lamellas recenti radice cruda, oleo, aceto \& fale condita, ferculum, quod omnibus fapuit, confectum eft.

Cocti tenelli ante florum expanfionem caules, \& brafficæ caulifloræ adinftar præparati, gratum dedere quidem cibum, fed propter fibras corticis numerofas \& tenaces, nec facile mandendo lubigendas, nec ante feparandas, ufui ineptum.

Tum etiam in Moravia inventam hanc ftirpem cum clar. Profeffore communicavit rev. Norbertus Boccius, Ordinis S. Joannis de Deo Præpofitus Feldfpergenfis, plan- 
tarum Moravir indefeffus indagator. Hic copiofam illam. in vineis crefcentem invenit, in folo argillaceo, ad pagum Hurtau circa Auffitz; ibidemque fub nomine Hieronymus-W'urzel feu radicis Hieronymi notam effe, \& inde a rufticis Bohemis, qui vaccis fuis ad lactis augmentum porrigunt, in Bohemiam transferri, dixit.

Clufii conjectura, eandem effe noftram plantam cum Baltracan Tartarorum, deftruitur ex eo, quod. Jolaphat Barbarus, corticem caulis in Baltracan per maturationem findi, \& a ligno fecedere, (unde loqui de caule perenni $\&$ frutefcente videtur, ) femenque validi effe odoris, jucundi tamen faporis, narret; quorum omnium nihil noftra habet.

Quod apud' eundem Clufium, ex aliorum tamen relatione, legimus, in quibusdam Hungariæ locis incolas, in annona caritate \& inopia, bac radice vefci, longe majori dignum attentione cenfeo. Omnino perennitas radicis, moles adultæ ingens, vitæ conftantia etiam in læfione notabili, in climatis noltri frigore hyemali duratio, \& alia, culturam, aut faltem in fylveftribus propaga- 
tionem uberiorem contra improvifam annonæ penuriam quan maxime commendant.

Tatariæ ungaricum nomen, quod Clufus a Tartaris derivatum conjecerat, clariflimum Profefforem movit, ut iconem plantæ ad celeberrimum Pallas Petropolin mitteret, rogaretque illum, an obviam habuifet in itineribus fuis? En viri humanifini refponfum : " Crambe, cujus , iconem adjecifi, omnibus punctis convenit cum illa, " quæ crefcit apud nos per vaftam illam planitiem aufra„ lem, quæ a Boryfthene usque ad Jaikum, antiquorum ^ Rhymnum, continua eft; nullibí gradu 5 I latitudinis ๓ borealior. Siccos amat campos, limofos pariter, mo${ }_{n}$ do ne fint falfi, \& arenofos, \& humo fœcundos. In n ficciore tamen planitie depreffiora plerumque loca affe„ Etat, \& varia reperitur magnitudine, nunquam in ficco $n$ folo altitudinem iconis transmiffæ exæquans. Sed $æ$ n quat in fucculentis, fecundum fluvios, ubi pariter ocn currit; tumque radices maximas producit, \& magis n acres. In ficco crefcentis habent fimilem napi guftum, „ \& a Cofaccis noftris, Tanaënfibus in defertis, avide n comeduntur crudæ coetæque. Hinc etiam nomen pleso bejum obtinuerunt Katràn, addito epitheto bjeloi five , album, 
n album, ut diftinguantur a fingulari quadam Statice in

iisdem regionibus proveniente, multicauli, raniofiffima, $n$ craffasque faciente radices, quas, defectu quercini corn ticis, copiofe colligunt, \& pro parandis coriis, utpote n huic negotio aptiffimam, adhibent; quamque rubros n propter flores krafnoi Katràn appellant. Ad Irtin ra. m. rulculas Itirpes Crambes inveni, foliis multo minus lan ciniatis, nec ullas floridas, ut de diverfitate judicari on potuiffet. Cæterum in Crambe noftra Volgenfi florente n peculiaris Meloë obfervatur copiofe, quæ cum Linnæi $n$ Meloë fyriaca omnino convenit, femper tamen minor "Meloë veficatoria, \& capite atro, nec, ut reliquum „ corpus, cæruleo. "

Defcriptio plantr, ad fecimina horti viva, ficcataque fylveftria transmiffa, adumbrata, nunc fequitur.

Radix perennis, longe fufformis, brachium adulta craffa \& ultra, a duobus ad quatuor pedes longa, teres, aut fimplicifima, aut inferne in crura divifa; foris fufcefcens, recensque etiam atra, lota autem ficcataque magis cinerea, fibrillas paucas in progreffu emittens; intus firmiter carnofa, albida cum tantilla fordente flavedine, cb-

$$
\mathrm{N} n 2 \quad \text { fole. }
$$


foletis lineis radiata, \& fapore dulci prædita cum nulla vera acredine. Confervata in aëre, contrahitur fucceffve, rugofa \& coftola evadit, indurefcit, fitque fui diffimilis ac inutilis.

Caulis duos tresve pedes altus, angulatus, ereetus, glaber, medulla allsa farctus, totus ex ramis eleganter paniculatus, modo unicus, modo ex radice multicipite plures.

Folic radicalia primo prodeuntia frpe parva funt \& integra; deinde autem \& hæc \& caulina atque ramea inferiora funt diverfimode $\&$ inordinate multifida, quandoque ampliffima, decompofite vel fupradecompofite pinnatifida, divifa tandem in lacinias oblongas dentatas \& acutas, cum quadam glaucedine virentia, utrinque glabra. Summa in caule ramisque funt fimplicia \& oblonga. Petioli angulati funt in foliis majoribus glabri; in minoribus autem, uti \& coftæ, hic valde craffæ \& protuberantes, tum quoque venæ, pilis albidis hifpidula, At ipfa hæc hifpiditas, foliorumque figura, adeo variant in diverfis non tantum plantis, fed vel in ejusdem diverfis partibus, ut deicriptio, quæ conveniat onmibus \& fingulis, fruftra hic extpectari poffit.

Flores 
Fiores numerofiffimi in corymbis ramofis terminalibus digefti fortiflimum fpirant gratumque mellis odorem, ut admotas aperto apum alveo nares credas; calyce ex flavo virente; petalis lacteis; antheris fubvirentibus; germine viridi; ftigmate flavo; fructu magnitudine pif, conftante ex cortice viridi nitido carnofo, fed maturitate ficco rugolo \& pallente, \& ex femine cum cortice nigrefcente $\&$ nucleo ex flavo pallente faporisque pauci fubacris \& ingrati. Incipit florere circa medium Aprilem. Fructus maturefcunt Junio; qui pauci ad debitum perveniunt incrementum; dum plerique parvi \& fteriles perftant. In fructificatione character obfervatur nunc fubjungendus.

CAL. Perianthium tetraphyllum : foliolis oblongis, obtufis, canaliculato-concavis, patulis, deciduis.

Cor. Petala quatuor, obverfe ovata, obtufiffima, plana, calyce ferme duplo longiora, ex ungue brevi \& erectiufculo patentifima.

Stam. Filamenta fex, craffula, erecta; quorum dud oppofita longitudine calycis \& fimplicia; quatuor reliqua

$$
\mathrm{N}_{3} \quad \text { prio- }
$$


rrioribus longiora \& fuperne bifurcata, furcæ crure altero. ad germen porrecto \& fterili, altero extrorfum leviter inclinato \& antlierifero. Antheræ incumbentes.

Glandula viridis ftat inter quælibet filamenta proxima longiora.

Pist. Germen ovatum. Stylus nullus. Stigma capitatum.

PER. globofum, uniloculare, non dehifens.

SEm. unicum, fubrotundum.

In tabula ( fed hac ob fummam amplitudinem in Mifcellaneis oniffa fuit, confpicienda in Iconum Fafcicu10) repræfentatur radix ex mediocribus integra, fed multoties imminuto volumine; deinde ejusdem in magnitudine naturali portio fumma, in cujus vertice plura confpiciuntur capita, foliis orba, prouti hyemem tranfigunt. In uno aliquo capite, præter rei veritatem in hac anni tempeftate, fiftuntur depictæ trium foliorum bafes ad pleniorem intellectum. Caput autem caulefcens caret plerumque 
que foliis radicalibus. Deinde eft ramus floriger ex caule princeps aliquis. Hos ex toto caule tot vidi in culta planta exortos, ut hæc aream occuparet diametri quatuor pedum denfifimam. Adftat etiam folii majoris pars dimidia. Folium radicale ex novo juniori capite integrum dentatumque. Tandem ramulus fructefcens, \& nucleus feminis.

Præter exfpectationem radix in analyfi chemica per deftillationem ex retorta, longe alia exhibuit phænomena, quam plantæ cruciformes exhibere folent. Dedit enim phlegma aqquofum, fpiritum acidum, oleum empyreumaticum; \& poft hæc educta omnia, in novo appofito excipulo, per protractam funmo igne operationem, tantillum fpiritum alcalinum volatilem, uti fieri hoc folet in aliis vegetabilibus fpiritum acidum largientibus. Caput mortuum per incinerationem continuit falem alcalinum vegetabilen fixun copiofum.

Non poft Clufum nunc primum plantæ hujus memoria renovatur; culitur enim illa jam diu in pluribus Furopæ hortis, fed quoad fciam fub Crambes orientalis titulo. Eft certe Royeni Crambe quinta; uti autoptes ex horto 
me docuit; adeoque foret \& Linnæi Crambe orientalis; fed an propterea eft Tournefortii Rapiftum orientale. acanthi folio, ad cuam folam pertinere nomen Crambes orientalis poteft? Apud Tournefortium præter hunc titulum nulla amplior reperitur defcriptio aut dilucidatio. Titulus eŗ̧o ille folus nos ducat. Acanthum procul omni: dubio'Tournefortius apprime noverat; quo itaque poterat pacto flirpi tribuere noftræ folia Acanthi, tam toto cœlo. difcrepantia? Sed non credo, tribuiffe; tribuit ftirpi, quam ante oculos habuit, a Tataria diverfæ, $\&$ forte eidem cum illa, quæ in hoc Mifcellaneorum volumine defcribitur, Facq. objerv. num. 30., foliis gaudens acanthi adæcquatiffune ( $\&$ perpetuo inferioribus omnilisus) figura, magnitudine, incifione. Nec caufam magis affequor, quæe Botanicos movit, ut Tournefortianum fynonymon traxerint ad noftram firpem.

Unum, quod adhuc addam, habeo, propterea quod non leve dubium excitet fuper veritate afferti, noftram plantam effe re ipfa Clufii Tatariam; dum magni ponde. ris argumentum, hanc ipfam uno ore ab incolis hodie fic appellari, miffum interea facio. Inter plantas in horto. botanico Lugduno - Batayo hofpitantes recenfentur a clar. Roye- 
Royeno, \& Crambe orientalis in claffe filiquofarum, \& Tataria Clufii ceu Cachrys in claffe umbelliferarum. Oportet igitur utramque effe diftinctifimam. Objectioni lucem fortaffis affunderet infpectio herbarii Royeni; qua opportunitate deftitutus, fequentia confideranda propono.

In horto Leidenfi jam ante annum I7I9 colebatur ex fide Boerhaavii Rapiftum orientale, acanthi folio; an tunc genuina Tournefortii planta? fic fufpicor. Anni demum I 735 autumno Boerhaavius (*) gavifum fe dicit, vifo Tatariæ pannonicæ a Baffando transmiffo femine. An tempore Baffandi, folos ante triginta annos hodie elapfos, aliam, quam hodie, Hungari plantam 'Tatariam falutabant? Ergo hæc primum fata in horto Leidenfi anno 1736 fuit; dum tertio inde anno, primo poft Boerhaavii mortem, prodromus horti Leidenfis prolo dabatur. At jam eodem præcife anno 1736 die I $7 \mathrm{No}$ vembris fibi Tatariam a Royeno communicatam narrat celeberrimus Linnæus in Horto Cli.fortiano pag. 94.,

eam-

(*) Vide Boerhaavii Epifolas ad Baffandum, a clar. Jacquinio editas, pag. 230.

O o 
eamque etiam ibidem poft Tournefortium, uti in Prodro: mo Royenus, Cachryn vocat; quod plane non eft mirandum. En! verba Linnæi:

n Eo, quo hæc fcribo, die protulit e radice duo nfolia infidentia longiffimis teretibus petiolis, parum n villis patulis pubefcentibus. Folia ad cordatam acce${ }_{n}$ debant figuram hinc inde utrinque finubus aliquot, in$n$ determinatæ profunditatis $\&$ inæquali incifo margine motata, inter fe valde diffimilia; venis tamen craffis m fubtus prominentibus conveniebant, ut $\&$ denfa hirfutie " alba obveftiebantur. " Nec fane aliter in Tartaria noftra in infantili ætate (planta Linnæi unius anni fuit,) fefe folia habent; cujusmodi unum in icone etiam fifttur ; dempta tamen hirfutie nimia.

n In divaricatione foliorum prodibant utrinque duo nfulcra plana, parva, ovata, acuta, eręto-patentia, r minus hirfuta, integra, inter qux excrevit caulis bre"vis, involucro umbellæ univerfalis aliquot foliolorum $\rightarrow$ ovatorum \& hirfutie afperforum; at die proximo fupern veniens frigus flores defideratiffimos deftruxit. $n$ Quod dolendum eft; nam meliora edocti fuiffemus. 
An involucrum cum umbella fua fuit caulis cum panicula corymbifera redum evoluta, tunc globofa \& foliis rameis externe munita? Sed cur ad hyemis adventum floruit, quæ apud nos primo vere? cur planta Agrienfis, (detur etiam alia effe, quam noftra, \& fumme autumnalis,) in Hollandia magis frigore afficietur quam Agrix? Ego hæc non capio felicius, quam ipfe videtur cepiffe Linnæus, qui hujus tuæ Cachryos poftea penitus fuit oblitus, nec fpeciebus illam luis, quantumvis hic hortum Cliffortianum citare paffim affectaverit, nec fyftemati ultra inferuit. 


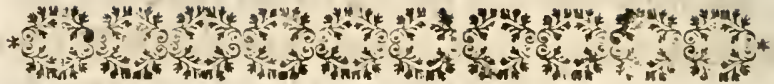 \\ V. \\ NICOLAI JOSEPHI JACQUIN \\ O B S E R V A T I O N S \\ B O T A N I $Æ$.}

CASSIA ALATA. Linn. Syft. pag. 289.

Caffia filiquis quadrialatis; fpicis terminalibus; foliis plurimis, pinnatis, majoribus, obovatis. Brown. Fam. pag. 224 .?

Caffia fylveftris foetida, filiquis alatis. Plum. /pec. 18. Herpetica. Rumph. amb. 7. p. 35. t. 18.

Juglandis folio, fruticofa, filiquofa, foliis pinnatis, cofta media membranulis utrinque exftantibus alata; fili$7 y$ 
qua 'quadrangula. Slótne hift. jam. vol. 2. pag. 59. tab. i 75 . fig. 2.

Celeberrimus Linnæus in fynonymiam Cafix fur alatæ intulit Fabam dulcem dictam Sibyllæ Merianæ plantem, inter Surinamenfes pagina \& tabula oftava \& quinquagef:ma depictam; quam Meriana arborem effe proceram dicit, cujus fructus fint capfulæ fabas continentes nigras cinctasque inedulla albicante \& fuavifima dulcedine grata. Fructus hicce ibidem pingitur viridis, nec vere alatus, etiamfi videatur quadrangularis. Hæc neutiquam cadunt in plantam, quam in America videram, defcripfique in Obfervationum Botanicarum parte fecunda pag. 24. Ex adverfo Sloaneus a Linnæo non citabatur, Plumierus figura caret, \&, quem confulere potuifem, deficiebat mihi Rumphius; quare novam exiftimans propofueram fub Cafise herpetice titulo. Nunc re bene explorata, fynonymiam legitimam reftituo; Brownei tamen plantam dubitanter adden's, qui, Sloaneo omiffo, Caffiam, a Dillenio in tabula 63. propofitam, pro fua excita vit, quæ tamen Dilleniana certiffime Caffia Tora Linnæi eft, ab ejusdem alata admodum diverfa. Caffix itaque Merianæ hic expungenda novam fortaffe fpeciem conftituet.

$$
\mathrm{O} \circ 3 \text { De- }
$$


Defcriptioni a me in Obfervationibus jan datæ addo fequentia. Caulis inferior fæpe in diametro fefcunciam habet. Foliorum majcrum cofta interdum eft tripedalis, \& tunc foliola fumma femipedalia. Coftæ apex terminatur in mucronem durum, craffum, acutum, retrorfumque curvatum. Ipfa etiam foliola fæpe mucrone exiguo reEtoque in apice donantur ; \& poft folis occafum fibi mutuo incumbunt, fricte appreffa ad coftam, quacum tunc nervi ipforum medii coincidunt, uti optime hoc jam Rumphius adnotavit, expreffitque in folio quodam fuperiori, tabulæ numerum refpiciente. Stipula utrinque ad folia plus minus oblique eft fubcordata, acuminata, viridula; perfiftens, crafla, patentifima, rigidiufcula, cum oris plerumque revolutis. Racemi funt fimplices, \& utrinqque flori fubjacet bractea ovata, obtufa, valde concava, ex flavo virens, magna, poft florem expanfum decidua. Omnes fumul conum formant imbricatum, racemi apicem femper terminantem, quum ille ab inferioribus fucceflive floreat. In fructu nulla medulla five pulpa eft; qui niger -eft, \& in quatuor alas membranaceas excurrit. Semina compreffo-plana figuram potius ovato-acuminatam habent. Denfe juxta invicem crefcit, forte a feminibus delapfis, quod tribueram radici repenti \& germinanti ; 
Rumphius enim ait, haud ultra duos annos vivere. In horto noftro botanico fæpius ex feminibus in caldario enata, perire folet quotannis cum ipła radice, idlque fanuario menfe, dum jam fexpedalis racconis nedum florentibus probe eft onufta. Semel unicum florem ante interitum expanfum vidi. Semel etiam radix hyemen fufulit, proximo anno tres novos caules fundelis, haud feliciores. Inter Caffias numerari fpeciofifimas meretur.

Notatu dignum occurrit, quod ob virtutem fuam, qua folia herpetem curare feruntur, æque in India orientali atque occidentali, apud diverfifinas difitasque nationes, Herpeticæ nomen fuerit adepta, dum Gallis americanis Dartrier audit, Anglis ibidem Ringworm-Bulh, Batavis orientalibus Douwwurms-Boompie, \& Javanis Daun - Curap.

II.

CRASSULA COTYLEDON. Tab. 19.

Cotyledion major, arborefeens, Afra; foliis orbiculatis, glaucis, limbo purpureo \& maculis viridibus ornatis. Boerh. ind. alt. pig. 287.

Ele- 
Elegans planta, pro Cotyledonis fpecie habita, paffim in lertis botanicis occurrit, ex defectu florefcentix nedim rite determinata. Certe jam a quinque $\&$ viginti annis in nofris hortis per plurimam ex plantatis ramis obtentan fobolem familiaris, nunquam foruerat ulla, donec tandem anno I778 fub finem menfis Aprilis in tepidario unica arbufcula in horto cæfareo ex omnibus ramulis ingentem florum vim produxit. Horum vero dum dimidia circiter pars explicata fuiffet, cœperunt ramuli florentes omnes fucceflive \& ultro decidere, folutis, quibus cum ramis adultioribus conneefebantur, articulationibus. Vivere tamen arbufcula perrexit, \& vivere ac florere non minus vegete decidui in terram ramuli; fed fructus nullus fequebatur. Defcriptionem concinnavi fequentem.

Glabra tota eft. Truncus carpi craffitie fufcefcit, teres, in ramos inconcinne divifus teretes, plurimos, $\&$ ex fufco virentes. Et truncus \& rami ad parvas diftantias funt articulati, articulo fuperiore obtufo ingrediente cavitatem articuli inferioris. Folia funt diftincta, oppofita, craffa, carnofa, fubfeffilia, fpathulato-rotunda, integerrima, glauca, patentia, facie nec dorfo viridi- 


\section{B O T A N I C E.}

punctata, alia obtufiffima, alia minimo mucrone acuta. Cymæ dichotomæ, terminales in omnibus ferme ramulis. Pedunculi compreffuli \& ex glauco virentes. Bracteæ divifionibus pedunculorum adfident parvæ. Flores inodori, numerofi, fucceffive fefe explicantes. Perianthii parvi glauci \& quinquefidi lacinix funt lanceolatæ, acutæ, erectæ, concavæ, ad apicem ferrugineo-rubræ. Petala quinque, lanceolata, magna, plana, acuta, unguibus donata nullis, fupra calycem patentiffima, in principio alba, demum rofea. Filamenta alba, quina, fubulata, bafibus latis inferta utrique contiguo lateri proximorum quorumlibet petalorum. Et reliqua ad characterem Linnæi.

In floribus dichotomiarum principum plerumque una quinta pars numeri quoad omnes partes deficit, \& hi, quum primi florent, planta tunc diceretur tetrandra tetragyna. Contrarium itaque hic obtinet ac in Ruta, ut lex Linnæana, de ftabilienda ex primario flore claffe, in hac ftirpe fallat; nifi quis a craftulis feparandam contenderet. 


\section{III.}

\section{SOLANVM STRAMONIFOLIUM.}

E feminibus, ex India orientali allatis, inque caldario fatis, enata hæc planta plurima fuit, jamque per quinque annos perennat, fexpedalis, trunco arboreo, quotannis per totam aftatem copiofe florens, quantumvis fructum nedum dederit ullum; cujus tamen cognitio doceret, utrum fit Merianæ Carduus Maccai furin. tab. 6.? Aculei folia utrinque tum petiolos, caulem, ramosque denfe occupant; in caule plurimi recurvi; reliqui recti. Truncus pallicem craffus, teres, cinereus, ad tactum per inconfpicua tubercula exafperatus. Folia funt ampla, majora cum petiolo pedalia, cordata, alterna, lobata, acuta, utrinque villolula \& mollia; lobis fublanceolatis $\&$ acutis; petiolis teretibus \& villofo-afperis. Pedunculi communes breves in caule $\&$ ramis inter proxima folia enafcuntur, folio fuperiori oppofiti, horizontaliter patentes. Pedunculi proprii plurimi circulariter ex communi porriguntur. Et hi, \& calyces, fubvillofuli funt ac inermes. Perianthii monophylli laciniæ omnium minimæ \& fubrotundæ funt. Ergo non eft folanum ferox 


$$
\text { B } O \text { O T A A I C }
$$

Linnæi. Petali pallide purpurafcentis aut albidi lacinix funt lanceolatx, longæ ac patentifimæ. Antheræ corolla fere duplo breviores lutex. Germen fubrotundum, hirfutiffimum. Stigma fubcapitatum.

IV.

An VICIA LATHYROIDES? Tab. 18. Linn! $\int y /$. pag. 488.

Defcribam ad numerofifima exemplaria hanc plantulam. Radix annua, fibrofa, tuberculis appenfis munita, caulem unum alterumve profert, fuberectum, communiter a duabus ad quinque uncias altum, inferne parum ramofum, hirfutum, \& inæqualiter fubquadrangularem. Folia funt pinnata ex foliolis utrinque fine impari frequentius tribus, etiam duobus, ad caulium bafin ex foliolo jugata folummodo utrinque unico. Sunt autem foliola valde varid. In infimis foliis funt obverfe cordata; in proximis magis oblonga, \& retufa; reliqua angufte lanceolata, longiora, per fetulam acuminata; omnia fubfeffilia \& pilis albis utrinque hirfuta. Petioli in infimis acutis, in fuperioribus plerumque in cirrhum fim-

$$
\text { Pp } 2
$$

plicem 
plicem elongantur. Stipulæ lunt femifagittatæ, villofæ. Flos folitarius in alis \& feffilis erigitur. Calyx hirfutus \& corolla fere duplo brevior denticulos omnes habet etian longitudine xquales. Texillum cum purpura cæruleum eft, fere fubrotundum cum ungue albo canaliculato \& longo, emarginatum cum denticulo, erectum, \& expanfum. Alæ magis cærulex, pauxillo breviores, concavæ, obtuffimæ, erectæ, oblongæ, ungue præditæ tenui alboque. Carina fubrotunda, parva, compreffa, obtufa, pallens cum macula fufca, vix calyce longior; ungue bifido, longo \& pallente. Filamenta longitudine carinæ. Germen oblongum, compreffum. Stylus brevis, recurvatus. Stigma ciliatum, tum fuperne fupra apicem valde barbatum. Legumen oblongum, fubunciale, anceps, obfolete fimul tetragonum, acuminatum, nigrefcens, nitidum. Semina circiter fena, fubcubica, \& cinerafcentia. Crefcit copiofifime in quibusdam pratis fylvaticis infularum Danubialium; ubi floret Aprili.

Determinare non aufim, utrum planta Linnæi fit. Summa fimilitudo cum figuris a linnæo pro fua citatis, effe, fuadet. Sed difcrimina, in quibusdam partibus non yevia, ex adverfo negant. Percurram, ut alii, quibus vivam 
vivan Linnæi plantam examinare poffe dabitur, certius quid fabiliant, celeberrimi viri fynonymiam.

In Floræ Danicæ figura tab. 58. cirrhus omnis abeft; foliola funt nimis lata; caules nimiopere procumbentes; \& figma ad characterem genericum, in mea vero plantula ex oppofito fallentem, fubtus nec fupra barbatum,

Apud Hermannum in Paradifo Batavo tab. roz. pag. 242. radix dicitur perennis, pingiturque mire multicaulis; caules \& folia afferuntur glabra; \& legumen in cauliculo abfciffo laterali obfervo teres, nimiumque craffun vel latum.

Figura Viciæ minimæ apud Rivinum magis quadrat in noftram; fed foliolis tamen latioribus diverfa. Cæterum ex hac incompletiore nihil adeo determinari poterit.

Govanus in Horto Monlpelienfi pag. 372 Viciam, ait, lathyroidem florere per totum annum. Noftra apud nos pure vernalis eft. 
In Flora Scotica Vol. I. pag. 396. rev. Lightfoot mecum annuam effe afferit, præterque caulium proftrationem defcriptionem tradit cum mea omnimode convenientem. At vero, utrum recte ille adduxerit Gerardi Hift. plant, pag. I22 Viciam quartam, merito dubitare nos poterimus, qui in Gerardiana icone videmus cirrhos divifos, ipfam plantam fcandenti fimilem; inque defcriptione legimus, caules fcandere inter fegetem, hancque demum deprimere ad terram, atque ita eidem fuperincrefcere, ut corrumpant, enecentque non triticum folum, fed omne frumenti genus.

Cranzii Viciam lathyroidem fafc. pag. 392. non novi, nifi fuerit forte Viciæ fativæ aliqua varietas, quan fæpe in Auftria inveni cum foliolis infimis obverle cordatis floribusque folitariis, ut hinc Linnæana lathyroidis congsueret definitio; nec immerito (ob auriculæ calcar inferius, fæpe dentatum ibidem diftum ) hoc fufpicor. Tum quod nec in montofis Badenfibus nec in fylvis Schneebergenfibus alia quam hæc varietas ab aliis inventa fuerit. Tandem quod iconem Floræ Danicæ dicat cl. vir optimam; \& iterum hujus iconis folia caulina nulla fur plantæ convenire. 
STELLARIA NEMORUM. Linn. Syft. pag. 352. Flor. Dan.ic. 27 r.

Myolotis foliis petiolatis, cordatis; tubis ternis. Hall. Hiff. helv. num. 886.

Alfine montana, hederacea, maxima. Col. ecphr. x. pag. 239. tab. $=90$.

Alfine albiffima nemorum. Bauh. pin. $=50$.

Hæc planta in Auftrix nemoribus, tum paffim \& copiofius in fylvis umbrofis fubalpinis crefcit, ubi floret Junio \& Julio, fub finem Julii \& Augufti femina perficiens. Stolones, qui in figura Fluræ Danicæ defiderantur, longi fub funmma levi humo repunt, foboliferi, teretes, albidi, fquamulis oppofitis triangularibus acutis \& pallentibus ad genicula inftructi, \& in toto decurfu fibrillas capillares radicales terræ immittentes. Hos ftolones credo perennes. Caules debiles, hirfuti, plus minus pedales, fuberecti, \& teretes. Folia mollia, utrinque hirfuta, frpe cum flavedine virentia, integra, ad oras fubundulata, acuta, oppofita, inferiora petiolata, fumma felfilia 
304 O B S E R V A T I O N E S

\& ovata, infima cordata, Caulis ad apicen dichotomus. Pedunculi proprii unciales \& ultra, in dichotomiis folitarii, tandem bini vel terni (ut in omni dichotomia florali) terminales; in floribus erecti, in fructu toti fricte penduli. Calycis foliola acuminata \& hirfutula ad oras albent. Petala alba, calyce duplo longiora, ferme ad bafin usque bifida in lacinias tublineares \& obtufulas. Filamenta decem, quorum alterna longiora calycem æquant. Antheræ incumbentes \& ochroleucæ. Germen ovatum, glabrum. Styli tres longitudine ftaminum. Capfula conica, tecta calyce connivente, includit femina circiter viginti quinque fubrotunda \& receptaculo in media capfula elongata affixa. Et reliqua ad characterem Linnæi.

In operibus Linnæanis huic fubjungitur alia Stellariæe fpecies fub dichotome titulo, quam auctor celeberrimus in alpibus ait Helveticis Sibiricisque crefcere, nullo addito alterius auctoris fynonymo. Sæpius miffa mihi fub hoc nomine fuit varietas Stellarixe nemorum, etiam apud nos haud infrequens, \& a Linnæana dichotome definitione haud abludens. Hallerus certe, in Hiltoria fua ftirpium Helveticarum, Stellarice dichotome plane non meminit; 


$$
\text { B } ○ \text { TA N I C } \text { モ. }
$$

minit; fed varietatem prædictam optime obfervavit. $U_{t}$ utriusque Linnæana determinatio cadat in eandem plantam, ætate imprimis differentem. Eft tamen genuina Stellaria dichotoma, in Sibirix orientalis campis crefcens, diverfiffima a Stellaria nemorum, caule per dichotomias ramofiffimo, floribus minoribus, aliisque in viva melius ftabiliendis.

\section{VI.}

HIPPOCREPIS BALEARICA.

Radix in truncum exit brevem, lignofum, digiti craffitie, emittentem ramos adfcendentes, vel magis procumbentes, inferne fruticofos \& perennantes. Folia funt pinnata, glabra; foliolis utrinque fere octo cum terminante impari, oblongis, integerrimis, obtufis cum mucrone vix confpicuo, feffilibus. Pedunculi teretes, fubfriati, glabri, \& longi, terminantur in umbellam multifloram, qualem Hippucrepis comufa habet.' Flores funt leniter fuaveolentes. Calyx pallide viret, laxus, \& ad dimidias bilabiatus: labio fuperiore recto \& femibifido; inferiore ex dentibus tribus, duobus lateralibus adfcen-

$$
\text { Q q denti- }
$$


dentibus, omnibus acuminatis \& ferme ejusdem altitudinis. Corollæ 1u:teolæ. Vexillum rctundatum, integerrimum, friatum, ad angulum rekum ex longo \& canaliculato ungue adfcendens, cum oris tandem revolutis. Alæ obverfe ovatæ, obtufifimæ, amplæ, fere longitudine vexilli. Carina pallidius colorata, falcata, alis brevior, adfcendens, acuminata, cum ungue bicipite gracilifimo. Filamenta decem, diadelpha, pallida, longitudine \& fitu carinæ. Antheræ flavæ. Germen lineare, rectum, compreffum, viride, longum. Stylus capillaris, albidus, ad. angulum rectum ex germine adfcendens. Stigma fimplex. Legumen oblongum, obtufum, rectiufculum vel parumper incurvatum, futura fuperiore femel aut bis terve finuata, glabrum \& fufcefcens. Semina nitida, fufca, teretia, arcuata, obtufa. Hyemem in tepidario apud nos agit; \& floret Majo \& Junio. Ex horto Parifino tranfiit in noftrum.

VII.

\section{MARRUBIUM ASTRACANICUM.}

Radix fub dio plures emittit in ambitum caules perennantes, femipedales, ramofos, \& procumbentes, ex 
quibus arnuatim alii plurimi caules affurgunt herbacei, erecti, tetragoni, pedales, vix ramofi, lanate villofi \& incani. Hos folia ornant oppofita, petiolata, incana, rugofifima, utrinque tomentofa, mollia, ovata, obtufa, ferrata, fapore amaro predita, vix odorata; juniora cum hifce caulibus una prodeuntia lanatifima. Florum verticilli plurimorum \& feffilium ad folia denfifimi cum involucri foliolis fubulatis acutis \& 1anatis. Perianthium tubulofum, decemfriatum, incanum, ad oras quam maxime lanuginofum, rigidum, quinquedentatum; denticulis lanceolato-acuminatis \& erectis. Petalum calyce duplo longius. Tubus cylindricus, albus. Limbus purpureus. Labium fuperius lineare, ad medietatem usque bifidum, erectum, dorfo villofum. Labium inferius trifidum, longitudine fuperioris: laciniis lateralibus brevioribus, ublongis \& obtufis; intermedia maxima, late fubrotunda, emarginata, plana, antrorfum porrecta. Filamenta fubulata, alba, brevifima, occultata in fuperiore tubi parte: Antheræ fubrotundæ \& fufcæ. Stylus lon-gitudine ftaminum. Floret Majo. 


\section{VIIl.}

\section{ALLIUM RAMOSUM? Linn. $\int y f_{*}$ pag. 266.?}

Dubitanter fub hoc titulo elegantem hanc Allii fpeciem propono. Linnæana quidem Allii ramofi determinatio fpecifica quadrat exacte in hanc plantam; \& fi tamen non fit, novam effe fpeciem oportebit, quum certe ad aliam ex primo Alliorum linnæanorum ordine, ubi folia caulina plana \& umbellæ capfuliferæ dicuntur, referri fpeciem nequeat. At vero cum Gmelini allio, a Linnæo pro fuo ramofo in fynonymia unice citato, nihil commune noftra planta babet; quam melius tabula Gmelini nona repræfentat, fi foliis flacciditatem umbellæque raritatem demas. Neque multum abludit Gmeliniana defcriptio. Linnæus quidem tabulam nonam citat; fed ejus figuram primam, quæ unica tantum in eadem vifitur; \& defcriptionem undecimæ tabulæ præmittit, duplice figura donatæ.

Plantæ noftræ, omnino glaberrimæ, odor cepæ fortis eft. Bulbus oblongus, ex fquamis denfe compactus, foris 


\section{B O T N I C E.}

foris fufcefcens, cæterum albus, in caulem paulatim abit, vix a bulbo difcernendum, modo folitarium, modo duplicem, digiti craffitie, ereftum, teretem, pedalem, foliofum, faretum, pallentem cum lineis viridibus. Folia alterna, plura, acuta, per unam alteramve fpiram intorta, integerrima, e glauco virentia, ad angulum acutum erecta, amplexicaulia; plana cum medio dorfo leviffime prominente, inferiora enfiformia unamque unciam lata, fuperiora fucceflive anguftiora \& longiora, fumma duo ut plurimum oppofita \& valde erecta. Pedunculus fubteres, terminalis, pedalis, erectus, flores in umbellam globofam denfamque colligens. Sæpe alter fimillimus pedunculus, tandem bipedalis, ex ala folii in medio caule egreditur, \& præcocior ante terminalem floret; quando tunc folii altioris mox fubfequi bafis, pedunculo huic laterali refpondens, in vaginam folvitur, ad eundem totam fiffan. Atque tunc etiam in caule difcifo geminata veluti apparet medulla, quoniam uterque pedunculus ex ipla vere bafi bulbi oritur, caulemque totum ad egreffum usque permeat, a caule liber, unde medullam duplicem mentitur; dum reliqua exterior pars conftat foliorum vaginis, arctifime mutuo circumpofitis, ut folidum caulem referant. Spatha bivalvis; valvulis fubrotundis, concavis,

$$
\text { Q I } 3 \text { ecau- }
$$




\section{0 \\ O B S E R V A T I O N E S}

ecaudatis, brevibusque. Flores numerofiffmi, denfi, brevius pedunculati, cum levifima viridique flavedine fallentes. Tetala lanceolata, obtufula, femipellucida, patentia, alternis brevioribus \& concavis. Filamenta alba, Fetalis duplo longiora, fubulata, fimplicia, æqualia. Antherre luteæ, oblongæ, incumbentes. Germen viret. Stylus fubulatus, Raminibus duplo brevior, albus. Capfulæ congenerum. Nulli in umbella bulbilli. Floret fub dio Majo \& Junio. Non memini, unde in hortum migraverit.

\section{IX.}

\section{ONOPORDUM ACAULE. Linn. $f y$ f. pag. 60\%.}

Onopordon acaule ferme, flore albicante. Vaill. act. I53: Hall. Gött. pag. 357 .

In horto fub dio fata floruit altero anno, ut biennis videatur. Radix fuffornis, femipedalis, recta, foris nigra \& inæqualis. Caulis unicus, duas plus minus uncias altus, erectus, flore feffili terminatus. Folia primi anni radicalia; alterius anni caulina, plurima, conferta imprimis ad caulis fummitatem \& in orbem fparfa, ut hinc plantam, deorfum fi quis fpectet, acaulem credat; cæte- 
rum petiolata, utrinque tomentofa \& incana, oblonga, pinnatifida, craffula, venofa, dorfo rugofula; ad oras dentato-fpinofa, pungentia \& fquarrofa. Petioli quorundam foliorum interiorum florem feffilem gerunt, tunc teretes \& craffi, quum alias fint fuperne plani; ut talis petiolus forte aptius dicatur pedunculus vel ramulus uniflorus, ex caule egreffus, \& ad florem folio donatus. Calyx glaber, viridis, pungens \& fquarrofus; fquamis intimis crectis \& purpureis. Flofculi toti albidi. Semina angulata. Pappus pilofus, ad lentem aculeato-hifpidus. Et reliqua ad characterem Linnæanum., Floret Junio \& ineunte Julio.

\section{X.}

\section{EUPHORBIA DIFFUSA.}

Euphorbia umbella quadrifida; bifida ; foliolis cuneiformilinearibus, tridentatis. Allion. corf. 209. tab.3.

Sponte circa Viennam crefcit, annua planta, a Julio ad Septembrim florens. Radix graciliter fufformis pallet. Caulis teres, erectus, bafi rubens, femipedalis, fupra ipfam originem fic ramofus, ut multicaulis planta videatur. 
tur. Rami infini adfcendentes, toti, ut ipfe etiam caulis, foliis ferme imbricatis tegitur. Umbellæ quadrifidæ vel quinquefidæ; radiis pluries bifidis, fre dichotomis. Rami modo in umbellam folvuntur fimilem, modo valde dichotomi lunt. Planta adulta hinc evadit diffufffima, tamque denfa oritur ramulorum radiorumque congeries, qualem in nulla me vidiffe Euphorbia memini; quo fit, ut juvenem adultamque pro duplici habere fpecie inexpertus poffet. Folia funt alterna, fubfeffilia, cuneiformia, truncata cum exiguo intermedio mucrone, integerrima, plana, nec tridentata aut vere retufa. In adulta folia caulina \& ramorum principum jam delapfa funt; quæ nonnunquam fine ullo mucrone fimpliciter obtufa funt. Involucri foliola, foliis fimillima, tot funt, quot radii. Involucellorum foliola funt oppofita, feffilia, integerrima, obtura cum mucrone, oblonga, fic ut altera pagina ad bafin verfus latus producatur, altera ex adverfo fit obliterata; in fuperioribus divifionibus latiora, breviora, \& fæpe retufa, quandoque bi - vel tridentata. Ficres omnes fertiles, folitarii in dichotomiis, exigui, felfiles. Calyx turbinatus, glaber, pallidus. Petala quatuor, flava, acute lunata, quorum duo duplo latiora, \& inter hæc pedicellus germinis exit, etiam glabri inftar totius 


$$
\text { B O T A N I C E. }
$$

totius plantæ. Styli pallidi cum ftigmatibus obtufis. Capfula glabra. Semina fufca, valde rugofa. Tota planta glabra eft, \& lactefcit.

Habuiffem pro Euphorbia terracina Linnæi; at vero folia non funt lanceolata, nec obliqua, nec margine vel minimum, etiam ad lentem vifa, fcabra; quæ de fua terracina Linnæus afferit. De figura Barrelieri, utpote incompletifima, nihil cónjici poteft. Opinor autem, meam effe eandem cum celeberrimi Allioni Euphorbia citata, quod imprimis icon \& miffa mihi ramuli ficcati pars me docuerunt.

\section{XI.}

RIBES DIACANTHA.'Pallo. it. 3. pag. 722 . tab. I. fig. 2 .

Ex feminibus acceptis jam ante plures annos in horto enata fub dio lætiflime excrefcit, \& quotannis copiofe floret; fed fructum nedum tulit ullun, quod omnes flofculos gerat in racemis erectis mere mafculinos, \& germine carentes, eadem plane ratione, uti in Ribes alpino. 
Hanc polygamiam hic tantum adducere volui, quun aliud, quod addan celeberrimo Pallas, nihil habeam.

\section{XII.}

EUPHORBIA PALUSTRIS. Linn. fyf. ag. 378.

Tithymalus foliis ellipticis, ramis umbellam fuperantibus, capfulis exafperatis. Hall. hift. hetv. num. x054. Tithymalus paluftris fruticofus. Bauh. pin. 292. Morif. hift. 3. Ject. 10. t. 2. f. I.

Efula paluftris. Riv. tetr. irr. t. I 6 .

Efula major. Dod. purg. p. 158. Dalech. hif. p. 1653.

Non tantum in paludofis locis demiffis, fed etiam in Auftriæ alpe Etfchero crefcit; unde forte dubium Halleri folvitur, qui Dodonæum miratur, in montibus illam crefcere afferentem. Floret Julio, \& frutefcit Augufto. Radix perennis, difformis, tuberculata, pollicem \& ultra craffa, foris fufca, \& intus allba, in crura dividitur teretia \& longa, caulesque annuatim promit plures, erectos, herbaceos, teretes, calamum vel digitum craftos, fefquipedem vel magis altos, inferne glabros, inde 


\section{B $○$ I $A$ I C E⿱.}

inde (idque fumma in parte denfus) pilis rariter hirfutos, florentes ut plurimum fimplices, frutefcentes multis ramis axillaribus fterilibus vel ipfum fupra caulem elongatis onuftos, tuncque fæpe hirfutiem plane exutos. Folia funt lanceolato-oblonga, patula, feffilia, ad lentem fuperne argute ferrata, cæterum integerrima, fparfim alternantia, utrinque $\&$ ad oras breviffune pilofa, in facie quandoque glaberrima, infima obtufa \& breviora, fumma acutiufcula. Umbella multifida componitur ex umbella caulina principe quinquefida, \& ex pluribus ramis florigeris, ex fummorum foliorum alis dente egreffis, inque umbellam quadrifidam, trifidam vel bifidam terminatis, ut hoc intuitu caulis nunquam vere fimplex fit. In umbella primaria umbellulæ funt quadrifidx vel bifidæ, Hec ultra, a me fempervif in planta fylveftri. Flores principes centrales funt in omnibus umbellis pedunculati, mafculi, feriles, pentapetali, \& erecti. Reliqui tetrapetali \& hermaphroditi. Involucri foliola funt lanceolata aut oblonga, obtufa vel acutiufcula. Involucella magis ovata \& obtula; alias foliis fimillima. F.t omnia ifta cum foribus eundenr colorein luteum habent. Calyx campanulatus pilis albis rarisque inltruitur. Petala trausverfe fubovata, obtufifima, nec cornuta. Stamina

$\operatorname{Rr} 2$ Iutea. 
lutea. Germen pallide viret cum pilis longis, ad lentem confpicuis. Capfula verrucofa, \& funiliter pilofa. Tota fcatet fucco lacteo \& acri.

\section{XIII.}

\section{TRAGOPOGON MUTABLIS.}

Radix biennis. Tota glabra eft \& lactefcit. Caulis teres, erectus, ab ipfa radice ex omnium foliorum alis ramofus. Folia feffilia, ex lanceolato principio paulatim in acumen longe producuntur, integra, ad oras per innumeros minutiffimos denticulos ad digitum retrorlum fcabra, vix undulata; caulina inferiora \& majora ad bafin duas uncias lata fereque pedem longa. Ramorum fubdivifiones terminantur in pedunculos unifloros. Flores leviter odori \& patentifini folem verfus nutant; tempore matutino expandi folent ferme cum oriente fole, claudi denuo circa horam decimam; ficque per tridum perennare, dum flofculi fucceffive plures explicantur, primo enim die fola panditur corollularum extima feries; atque fic in principio frpe corolla componitur ex radio fimplicifimo \& ex flofculis interioribus adhucdum 


$$
\text { B O T A N I C E. }
$$

in conum ereftum conniventibus nec expanfis. 'Tota corolla etiam hujus tempore protractæ florefcentiæ augetur, ut, qui determinare Tragopogonis fpecies a longitudine calycis ad corollam velint, determinent ex flore in folidum expanfo. Et hoc quidem in reliquis 'Tragopogonis fpeciebus idem contingit. Calycis foliola octo, alterna interiora, \& viridia corollam longitudine æquant. Corollæ quinquelineatæ, quinquedentatæ, utrinque albent ut plurimum. Variant tamen quædan individua corollulis rofeis cum friis rubris; alia iisden flavis cum friis purpureis; idque diverfa cun faturatione. Quare Tragopogona mutabilem vocavi. Antheræ flavent cum ftriis fuperne fulcis. Stigmata funt lutca. Semina glabra, cinerea. Pappus ftipitatus, arachnoideo-plumofus, cum quinque fetis longioribus. Floret a fine Maji ad Julium, fub dio. A celeberrino Pallas femina accepi.

\section{Xit?}

TR IGOPOGON UNDULATUS.

Tota planta lactefcit. Radix fufformis, biennis, digitum crafla. Caulis erectus, a quatuor ad feptem pedes R r 3 altus, 
altus, lanugine brevi ablcedente veftitur, dein glaber. Iolia caulina inferiora pedalia \& ultra, ad bafin vix unciam lata, non undulata; ramorum maxime undulata cum apicibus fre revolutis. Omnia lanceolato-linearia, acuta, ad oras retrorfun fcabra, \& feffilia vel amplexicaulia. Ramuli terminantur in pedunculos unifloros. Calycis folicla ab octo ad tredecim \& virentia longitudinem radii corollæ habent. Hæc utrinque fulphurei eft coloris, fxpe dilutioris. Antheræ fufcefcunt. Styli funt Iutei. Semina funt muricatiffina ad lentem, alpera, cinerea. Pappus plumofus, arachnoideus, cum quinque fetis longioribus, breviffime ftipitatus. Floret Junio \& Julio fub dio. Semina fæpius accepi fub titulo Tragopogonis crientalis; fed certe flos maximus luteus, quem orientali tribuit Tournefortius, \& quem ipfo Tragopogone pratenfi Linnæus afferit majorem, abunde utramqque fpeciem diftinguit.

\section{$\mathrm{XV}$.}

\section{LAVANDULA PINNATA.}

Crefcit in infula Madera. Apud nos xftatem agit fub dio, hyemem in tepidario.' Frutex lignofus, ramofus, 


$$
\text { B O TA N C R. }
$$

fus, humilis, cortice fufcefcente. Folia in ramis junioribus tetragonis (dum enim lignefcunt, teretes evadunt,) circumfcriptione late ovata, petiolata, ubique obtufifima, pinnata, plana, craffula, ad tactum mollia, ad lentem fubpruinofa, oppofita, incana; foliolis oblongis, modo integerrimis, modo fuperne bifidis trifidisve. Pedunculi aphylli, fubpedales, erecti, molles, incani, fuperne tetragoni. - Spicæ ternæ plerumque, terminales, ereAtx, obtule quadrangulares. Brątex ad fingulos flores ovatx, acutæ, concavæ, integerrinæ, erętx, calyce paulo longiores; in fruetefcente planta fquarrofx. Perianthium cylindricum \& obfcure dentatum pallide viret. Corollæ pallide violaceæ tubus calycem ad duplum filperat; faux pilofa eft; \& labium fuperius duplo longior eft inferiori. Antheræ villoræ. Stigma purpurafcit. Semina parva, oblonga, nigra, hilo albo. Et reliqua ad characterem Linnæanum. Flores odorati. Folia perparum, \& vix fapore gaudent. Floret Junio \& Julio. 


\section{XVI.}

SCABIOSA MONSPELIENSIS.

Planta felquipedalis, tota hirfuta, apud nos biennis, a Majo ad Julium floret. Caulis teres \& debilis purpurafcit inferne. Folia omnia funt pinnata, petiolata \& oppofita; pinnis diftantibus, oblongis, acutis, aliis integerrimis, aliis ad apicem rariter incifis. Pedunculi terminales. Perianthii communis foliola hirfuta, acuta, integra. Corollulæ quinquefidæ, æquales, purpureæ, extus pilofu$1 æ$, infundibuliformes; laciniis omnibus ferme æqualibus obtufis. Filamenta vix corollam fuperant. Antheræ purpureæ. Semina hirfuta coronantur calyce exteriore membranaceo amplo pelviformi ftriatoque; tum interiori pedicellato \& abeunte in fetas quinque fubulatas \& patentiffimas. 


\section{XVII}

\section{MALTA BALSAMICA.}

Ante quatuor annos hujusce ftirpis femina ex Hollandia accepi fub titulo: Alcen groffulurix folio majoris. Fro nova Malvæ fpecie habeo, cujus patriam ignoro. Ab odore balfamico, quo fupra Malvam fragrantem folia pollent, nomen triviale pofui. Frutex jam quadripedalis, lignofus, erectus quidem, fed ita debilis, ut, nifi firme. tur, ipfa climidia trunci pars ramique terram verfus propendeant. Truncus calamo crafficr, teres, cortice veftitus fufco, una cum ramis exafperatur cicatricibus extantibus a foliis flipulisque delapfis. Rami juniores villofi \& glutinofi virent. Folia funt fubcordata, acuta, alterna, petiolata, rugofula, fuliangulata, inærgualiter ferrata, villofula, glutinofa, facie laturate virentia. Stipula ad petiolum utrinque ovata, acuta, irtegra, convexula. Pedunctili axillares, fulitarii, uniflori, villofi. Calycis exterioris foliola tria cvata, acuminata, villofula. Interioris emiquinquefidi lacinix funt prioribus foliolis fimiles. Peta'a pallide rofea, cbverfe cordata, patentifina, caly- 
ce duplo longiora, inferne rubroftriata. Filamentorum columna alba \& hirfuta. Antheræ reniformes, ex badio purpureæ. Sticmata purpurea. Arilli circiter duodecim, nigri, rugofuli, fcabriufculi. Semina glabra, fufcefcentia.

\section{XVIII.}

\section{SENECIO GRAMINIFOLIUS.}

Frutex elegans Capenfis, æftatem in caldario, hyemem optime egit in tepidario, totus glaber. Radix ramofa, cinerea. Caulis teres, medulla alba farctus, calamum \& ultra crafius, tres quatuorve pedes altus, debilis, ramis virgatis debilibusque hic illic infructus, in cinerea lignefcente parte a foliorum lapfu cicatriculis inæqualis. Folia denfe fparfa, linearia, acuta, nitida, integerrima, lateribus revoluta, feffilia, quadriuncialia, debilia, patentifima, tandem reflexa, late virentia, ramorum caulisque partem herbaceam fuperiorem totam obveftientia, prædita fapore pauco fubaromatico \& leve veftigium Cacalix ficoidis habente. Flores vix odorati in corymbo compofito terminali. Pedunculi elongati minimis foliolis inftuuntur. Calyx calyculatus viret cum apici- 


$$
\text { B } 0 \text { T A N I C E. }
$$

apicibus fufcis, ad medietatem usque connivet in conum, hinc patulus; in fructu iterum cylindricus, glaber. Flofculi numerofifimi, omnes hermaphroditi \& fertiles. Corollulæ tubulofæ, tubo albo, limbo luteo \& patulo nec reflexo. Antheræ \& ftigma lutea. Radius plane nullus. Reliqua ad characterem Linnæanum. Ex alis omnium ferme foliorum egrediuntur tenella quædam foliola, rudimenta novi rami, qui pauci tamen propelluntur. Floret 2 medio Majo ad Julium.

\section{XIX.}

\section{WALTHERIA INDICA. Linn. Syft. pag. 94I.}

Malvinda ulmifolia, flofculis pufillis mufcofis. Burm. thef. Zeyl. pag. I 49. tab. 68.

Eetonica arborefcens, villofis foliis profunde venofis, floribus ex alis foliorum glomeratis. Plucken. mant. $3 \mathrm{r}$.

Planta elegans, fempervirens, altero anno ætatis jam quinquepedalis; caule arboreo, erecto, per totam longitudinem ornato ramis longis \& horizontalibus, terete, fufcefcente; totoque hirfuto pilis albis $\&$ falciculatis, qui micro- 
324 O E S E R V A T I O N E S

microfcopio confpecti pappum cirdui referunt. Rami funt fimiliter villofi ac molles. Atque hi, tum \& caulis extremus, folent, foliorum forte pondere prefli, nutare plerique. Folia funt alterna, ovata, oltufa, utrinque tomentofa, petiolata, ferrata, ad oras undulata, fubtus incana, venofa, duas tresve uncias longa, majora etiam femipedalia. Stipulæ geminæ, fetaceæ. Flores parvi, inodori. Capitulum breviter pedunculatum; dum prodit, fere feffile; axillare, folitarium; ex fubrotundo paulatim per fuccedentium mutuo numerofifimorum florum feriem elongatur, fitque fubtriangulare \& depreffum. Per plures enim menfes capitula florem quotidie unum alterumve novum emittunt. Floribus interponuntur brakteæ plurimæ, lanceolatæ, acuminatæ, ciliatæ, hirfutæ, \& longitudine calycis. Perianthium cyathiforme, erectum, pentagonum, femiquinquefidum, pallide virens, pilis albis hirfutum; laciniis lanceolatis \& acuminatis. Petala quinçue, lutea, calyce longiora, obtufa, obverfe ovata, fupra calycem patentiffima, integerrima. Filamenta quinque, connata in unum corpus fuperne divifum. Antheræ feffiles, flavæ. Germen ovatum, hirfutum. Stylus pilofus, fupra medium divifus in lacinias circiter viginti. Stigmata fimplicia, obtufa. Capfula obverfe ovata, obtufa, 
tufa, ad rerticem hifpida, calyci inclufa, unilocularis, bivalvis. Semen unicum, glabrum, nigrum, figura capfulæ. In caldario lætiflime crefcit, florens fere per integrum annum. Semina ex infula Domingenfi miffa fuerunt.

\section{XX.}

BROMELIA HUMILIS. Linn. fyf. rag. 259.

Planta perennis, fempervirens, fulacaulis, ex radicibus filiformibus longis plurimisque corpus attollens fibrofo - carnofum, lenté elongandum, aliquot uncias longum, ex cujus ambitu quaquavorfum propelluntur folia, ut videantur omnia radicalia; \& cujus fummitas tandem expanditur in capitulum denfiffimum florum. Folia funt rigidiffima, pungentia, patentia, acuminata, aculeis incurvis recurvisque armata, carinata, pedalia; centralia, dum planta floret, eleganter coccinea, \& brevia. Flores circiter triginta, feffiles in capitulo convexo, fefquiuncialis diametri \& nivea lana obducto cum corollarum folis apicibus eminentibus. Lana hæc affigitur fummæ extimæ parti fpatharum vel palearum, quæ floribus interjiciuntur fingulares fingulis, eosdemque arcte amplectuntur. Sunt

$$
\text { Ss } 3
$$

hæ 


\section{6 \\ O IS S E R V A T I O N E S}

lix oblongæ, valde concavæ, frepe femicylindricx, obtuffiflimæ, albidæ, ex apice ad dorfum valde lanatæ, cxterum glabræ, exteriores multo latiores. Germen inferum, triquetrum, longum, fuperiora verfus craffefcens, tomento fufcefcente obductum. Perianthium fuperum, triphyllum; foliolis erectis, albidis, obtufis, foris fpatharum adinftar lanatis, carinatis, fpatharum longitudine. Petala tria; erecta, ublonga, concava, fpathis pauxillo longiora, glabra, fuperne purpurea, inferne alba, bafi fubconnata. Glandulas ad petala non invenio ullas. Filamenta fex, fubulata, alba, brevia, adnata inferiori parti corollx, alterna ante petala, reliqua ad illorum connatos margines. Antheræ erectx, fulphurex, longiffirnæ, intra corollam. Stylus filiformis, corolla duplo brevior, albus, ereetus. Stigma trifidum. Bacca villofa, figura. germinis, trilocularis, carnofa, intus albida, in'ulfi faporis. Semina matura non offendi. In caldario floret a fine Oetobris ad Decembrim. Januarii fub finem maturos fructus dedit. 


\section{XXI.}

\section{SAXIFRAGA STOLONIFERA.}

Elegantem plantan ante plures annos als illufti atque amicilfimo Spielmanno accepi. Ex radice perenni \& multicipite plurima cefpitofe enafcuntur folia fubrotunda, coriacea, lobato-dentata denticulis castilagineis, ob oras contractas convexa vel ccncara, diametri quadriuncialis, lungifime petiolata; facie fordide virentia cum venis maculisque pallentilus \& hifpicula; dorfo villola, ex purpureo carnea fereque arenia; petiolo hirfuto. Caulis erectus, teres, hirfutus, virens, paniculatus, fupra ipfum exortum folummodo foliis ornatus, cæterum aphyllus. Calyx fubinferus, hirfutus, pentaphyllus; foliolis ovatis, concavis, patentiffunis, vircntibus. Petala funt inæuralia. Tria fuperiora 1 fea cum macula ad bafin lutea, \& ovata, vix calycem fuperant. Inferiora duo longe lanceulata \& priorilus trip!o longiora albent. Omia autem funt acuta \& patentifima. Antheræ flavent. Germen viride habet fuperne accumbentem glandulan luteam. Styli albi defcendunt. Capfula rotundato-ovata, 
biroftris, unilocularis, bivalvis, parva, ad bafin tantum calyci adnafcitur. Semina numerofa \& minuta. Flagella numerofifima, longiflima, teretia, fanguinea, \& ramofa, undique ex radicis capite $\&$ ex infima caulis parte procec'unt, novamque fobolem productint. Tloret a Junio ad Augufum. Semina dat Augufto \& Septembri. Amat umbram, \& fub dio clima noftrum optime fert. Ex Indiis orientalibus eft.

\section{XXII.}

\section{SALVIA VISCOSA.}

Jam a plurimis annis fub hoc titulo mifla planta in horto perennat radice \& caulium infima parte aliqua, hyemem in hybernaculo agens, eftatem fub dio. Caules plures, herbacei, erecti, fefquipedales, tetragoni, parum ramofi, \&, uti tota planta, odorati \& clbfiti villis capitato-glandulofis \& vifcidis. Folia funt oblonga, bafi cordata, petiolata, obfolete crenulata, acutiufcula, vencfa, rugofa. Verticilli diftantes, fexflori, breviter pedunculatis floribus, bractea fufulti fubrot:ndo-cordata, acuminata, \& breviori. Calycis labium utrumque eft 


$$
\text { B }
$$

acuminatum \& bidentaturn, inferiori profundius incifo. Corollæ tubus albet. Galea purpureo-fanguinea, extus etiam villofo-vifcida. Labium inferius dilutius concolor; laciniis lateralibus oblongis. Antheræ favent. Floret æftate.

\section{XXIII.}

\section{SOLANUM COCCINEUM.}

In horto Parifino fub hoc nomine colitur hæc nova Solani fpecies, in caldario fempervirens, unde ad nos delata. Arbufcula bipedalis, trunco jam quinquennali digitum minimum crafto, breviter rariterque aculeato, glabro. Rami patuli, teretes, aculeis rectis fubulatis \& fufcefcentibus armantur. Folia late ovata, utrinque fubtomentofa, fordide virentia, obtufa, repanda, alterna, petiolata; nervo medio utrinque, \& petiolo rariter aculeatis. Racomi oppofitifolii, breves, fubinermes, tomentofi, fimpices. Calyx parvus, tomentofus, fubinermis, profunde fecatur in lacinias quinque ovatas $\&$ patentiffimas. Corolla rolata, profunde quinquefida, calyce multoties lunfior, albida vel leviter puifurafcens, lacinias 
habet ovato-lanceolatas \& acutas. Antheræ funt luter. Bacca pifi volunine, rubra, tandem fordide aurantiaca. Semina cum quadam flavedine pallent. Flores plures, piftillo brevi donati, abortant. Floret fapius intra annum.

\section{XXIV.}

\section{THLASPI ALLIACEUM, Linn. $\int y / t . p a g .491$.}

Thlafpi allium redolens. Morif. hif.. 2. pag. 297. f. 3 . t. $18 . f^{2} 28$.

Scorodo - Thlafpi Ulydis Aldrovandi. Bauh. hift. 2. pag. 932 .

Odor toti plantæ alliaceus eft; fapor fubacris. Tota glabra, \& annua. Folia radicalia plura, fpathulata, longe petiolata, obtufa, modo integerrima, modo leviter inferne denticulata. Caulina \& ramea funt acute haftata \& feffilia. Caules pauci, erecti, teretes, femipedales, parum ramofi, tandem in racemos fructigeros æque longos foluti. Flores corymbofi, exigui. Petala alba, vix calyce majora. Siliculæ obverfe cordato-ovatx, obtufx, utrinque, fed dorfo præprinis, giblæx, cum margine 


$$
B \circ T A N \text { I C } R \text {. }
$$

vix ullo. Semina in quolibet loculamento fere tria, fubacria. Horet Junio, \& iemina perficit Julio. In Auftria femel atque iterum inventa fylveftris fuit in ipfo fuburbio ante plurimos annos. Hodie non occurrit.

\section{XXV.}

\section{HYACINTHUS VIRIDIS. Linn. Syft. pag. 276 .}

Jam per plures annos in horto floruit, a medio Junio ad medium Julium, in pulvillo, hyeme contra frigus feneftris fimoque equino tectis; quem pulvillum Africanum dicere foleo, quod in hoc bulbi ex Capite Bonæ Spei facile ad florem perduci queant. Semina tamen nondum dedit. Tota eft inodora \& glabra. Bulbus fubrotundus ex fquamis craflis, carnofis, albis, nitidisque denfiffime compingitur; figura \& volumine hyacinthi orientalis. Folia pauca, linearia, pedalia, acutiúcula, integerrima, carinata. Scapus gracilis, teres, folitarius, fuberectus, viridis, longitudine circiter foliorum, in racemum longum terminatus, ex centro bulbi ortus. Brąfeæ fubulatæ. Pedunculi proprii breves. Corolla monopetala, tota viriclis. Tubus oblongus, bafi ventricofus. Limbus veluti 
dup!ex. Exterior trificlus longitudine ip tus tubi; laciniis angufte oblongis, autis ex apice appendice longifima \& fubulata, reflexis. Interior femitrifidus; laciniis fubovatis, planis, acutiufculis, patentibus. Filamenta fex brevifima adnafcuntur tubo corollæ; \& gerunt antheras lineares, virides, longitudine tubi corollæ, \& bafi fagittatas. Germen oblongum, triquetrum, viride, poris nectariferis deftitutum. Stylus pallet.

\section{XXVI.}

\section{HALORAGIS ALATA.}

Plantæ hujus femina a quinque jam annis modo fub Cercodeæ, modo fub Cunegundæ novo genere, transmiffa fuerunt. Examinatus fructificationis character me docuit, pertinere illam ad Forfterianum genus, quod Haloragis dicitur; nec enim arbitror, ubi omnia plane congruunt, fructum alato-quadrangularem poffe genere avelli a fructu angulis deftituto. Radix ramofa caules promit plures, ramofos, fefquipedales, purpureos, fcabros, tetragonos, erectos vel adfcendentes, herbaceos quidem, attamen jam per quatuor annos magnam partem perfiften- . 


$$
\text { B }
$$

tes in caldario. Folia funt oppofita, petiolata, lanceolato oblonga, acuta, ferrata, glabra fic ut tamen digitus ruditatem aliquam percipiat. Pedunculi axillares, uniflori, breviffimi, ab unico ad tres. Flores exigui, penduli. Calys \& germen virent. Petala dilute purpurafcunt. Antheræ flavent. Pericarpium albet. N'ux nigrelcit. Floret Junio \& Julio. Semina Augufto perficit. Odor plantæ nullus; \& vix fapor. Crefcit in infula OTaiti. Characterem fubjungo totum.

CAL. Perianthium fuperum, tetraphyllum; foliolis femiovatis, acutis, fuberedtis, germine brevioribus, perfiftentibus.

Cor. Petala quatuor, oblonga, obtufa, valde concava, integerrima, patentilima, calyce triplo longiora, decidus, per lentem confieita dorfo (uti etiam calyx \& germen) albo-muricata.

Stam. Filamenta octo, filiformia, erecta, brevia. Antheræ lincares, obtufæ, tetragonæ, longæ, erectæ. 
Prst. Germen fubovatum, inferum, quatuor gibbulis longitudinalibus infignitum. Styli quatuor, craffuli, erecti, longitudine calycis. Stiģmata fumplicia, clitufa.

Per. Drupa fubrotunda, in quatuor proceffus carnolos in ambitu excurrens, carne pauca, coronata calyce connivente.

Sem. Nux ovata, quadrilocularis. Nuclei folitarii.

\section{XXVII.}

ANTIRRHINUM HIRTUM. Linn. Syf. pag. 466.

Annua planta in Hifpania fponte crefcit. Ex radice gracili \& albicante caulis erigitur unus alterve, fefquifpithamæus, teres, totus villofus. Folia infima funt terna, etiam quaterna; reliqua omnia alterno ponuntur fitu. Cum hæc, tum illa funt feffilia, lanceolata, fubacuta, craffula, integerrima, utrinque ex glauco virentia, \& fic vilIofa, ut villi frepe oculum fugiant non armatum. Spica terminalis, erefta. Bractex ad fingulos flores cvatæ deprimun- 


$$
\text { B O }
$$

primuntur a cornu nectarii. Flores odorati \& vere feffiles Linariam æniulantur. Toti flavent cum folo prominente palato faturate luteo. Galea, faux \& nętarium, quod fubulatum longumque eft, ftriis virentibus variegantur. Calycis villofi foliolum fupremum eft ovatum, acutum, duplo latius \& longius reliquis oblongis \& obtufiufculis. Antheræ fulphureæ. Capfula ovata, obtufa, villofula; quolibet loculamento in apice trivalvi. Floret Majo \& Junio fub dio. Capfula maturefcit Julio \& Augufto.

\section{XXVIII.}

\section{ASTRAGALUS ASPER.}

Ex feminibus ex Aftracan fine titulo transmiffis hæc planta excrevit; radice perenni \& rame?a; caulibus annuis, erectis, bipedalibus, teretibus, ftriatis, foliofis , cum ramis erectis. Folia funt alterna \& pinnata ex foliolis utrinque plus minus decem cum impari, lanceolatolinearibus, acutis, integerrimis, uncialibus, planis. $\mathrm{Pe}$ dunculi elongati, erecti. Spicæ longæ, floribus erectis fuffultisque fingulis bracteola lanceolata, acuminata, albi- 
da \& rigidula. Calyx viridis \& tubulofus, fetis rigidis atris adprefis rarisque veftitur. Denticuli ferme æquales, lanceulato-fubulati, erecti. Corolla tota pallicla. Vexillum oblongum, dorfo firmum. Carina obtufiffima. Antheræ lutex. L.egumen oblongum, fuperne craffefcens, acuminatum, erectum, vix fulcatum, parvum, fubbilocılare, fubafperum. Semina pauca, reniformi-oblonga, compreffula, nitida, cinerafcentia. Caules, folia utrinque \& pedurculi funt afpera \& fubincana. Hofpitatur in horto fub dio. Floret Junio \& initio Julii. Legumina maturefcunt fub Julii finem.

\section{XXIX.}

\section{ANTIRRHINUM VERSICOLOR.}

Sub hoc titulo colitur hæc planta in horto Parifino, unde femina accepi. Radix annua $\&$ gracilis caulem elevat fimplicem, erectum, fpithamæum, teretem, viridem, fupra fummum folium ad flores usque villofulum, cæterum glabrum, terminatum in racemum, cáuliculo uno alterove brevi fterili debilique ftipatum. Folia inferiora terna, reliqua alterna; omnia lineari-lanceolata, integer- 
tegerrina, glabra, acutiufcula, feffilia. Bractex ad pedunculos, tum etiam calyces, villos glandulofos habent. Pedunculi fere longitudine bractearum. Flores inodori ad caulem erecti apprimuntur, uti in Linaria, cujus etiam fere magnitudinem habent figuramque. Calycis foliola oblonga, obtufa, craffula, fubæqualia. Corollæ labium fuperius.magnum, femibifidum, ex ochroleuco pallidum. Labii inferioris concoloris laciniæ funt rotundatæ, intermedia minima. Palatum prominens luteum. Calcar fubulatum, longiffimum, violaceum. Antheræ flavæ infident filamentis ad bafin hirfutulis. Stylus fuperne violaceus. Capfula fubdidyma, bilocularis; loculamentis fingulis ad apicem ore rotundato apertis, per tres valvulas oblongas obtufasquie dehifcente. Semina minutiflima, numerofa, rugofula, nigra. Floret fub dio Junio. Semina jam funt. matura Julio ineunte, $\&$ ante Auguftum planta perit.

\section{$\operatorname{XXX}$}

CRANBE ORIENTALIS. Linn. fyf. pag. 505.

Rapifrum orientale, acanthi folio. Tourn. cor. I4.

Radix foris cinerea, intus albida, inque crura craffa divifa, in horto botanico Vindoboneni jam per annos $\mathrm{U}$ u vigin- 
viginti una eademque fub dio peremat; \& annuatim caules tres quatuorve producit erectos, fubteretes, pallide glaucefcentes, tres pedes \& ultra altos, inferne pilis rariffimis afperos, cæterum glaberrimos, bafi pollicem craffos, fupra medium ramis ad angulum acutun adfcendentibus paniculatos. Folia radicalia \& caulina inferiora funt profunde pinnatifida, circumfcriptione oblonga, fefquipedalia, ad nervos primarios in dorfo pilis rarioribus fcabra, craffula, fapore brafficæ; lobis oblongis, obtufis, inæqualiter denticulatis; cofta principe admodum protuberante; petiolo purpurafcente, fubtus terete, fupra plano cum fulco parvulo. Folia caulina fuperiora magis integra ; fumma ad ramulos integerrima, \& vel lanceolata vel oblonga. Flores fubracemofi figura, colore, odose \& ftructura fimillimi funt floribus Crambes Tatarix pag. 285. delcriptæ. Sic etiam fructus. Floret ab ineunte Junio ad medium Juliun. Semina evadunt matura Augufto. Crefcit fponte in Hungaria circa Budam; fic mihi afferente clariffimo Winterl. 


\section{XXXI.}

\section{CISTUS CANARIENSIS.}

Semina accepi ex infulis Canarienfibus ab illuftri Francifco Maffon, ubi crefcit in Fuertaventura. Apud nos æftatem fub dio, hyemem in tepidario agit. Ex radice perenni caules egrediuntur fruticofi, aut erecti aut adfcendentes, teretes, fcabri, fpithanæi, ramofi. Folia funt oppofita \& alternantia, fubovata, integerrima, glauca, craffula, villofo-fcabriufcula, plana, obtufa, petiolata. Stipulæ lineares vel lanceolatæ, erectæ. Racemi oppofitifolii \& terminales, ad apicem usque ereeti, nec fupra expanfos flores recurvati, multiflori, fecundi. EraEtex lineares. Calycís villofuli foliola cxteriora linearia; interiora lute ovata, acutiufcula, pallida cum friis hirfutulis partim virentibus, partim purpureis. Petala fubrotunda, lutea, oLtufa, patentifima, calycem parumper fuperantia. Stamina numerofa, tota lutea. Capfula longitudine calycis, triangulariter fubrotunda, obtufa, villofa, unilccularis, trivalvis. Semina fulca, compreffula. Floret a Junio ad Auguftum. Flores tantum expanduntur matutino tempore.

$$
\mathrm{U} 12 \quad \text { XXXII. }
$$




\section{XXXIL}

\section{CISTUS MUTABILIS.}

Sub dio per plurimos jam annos hanc plantam colui, haud ultra patriæ memor. Caules ex eadem radice plurimi in ambitum fparguntur ramuffimi; inferne perennantes lignofi, fruticulofi, calamumque crafli; procumbentes, fufci. Ex his annuatim enafcuntur rami adfcendentes, glabri, fubpedales \& numerofi. Folia funt oppofita, petiolata, lanceolato-oblonga, obtufufcula, integerrima, virentia, glabra, plana nec revoluta. Stipulæ utrinque geminæ, lanceolato-acuminatæ, erectæ. Racemi terminales, longi, erecti, ad lentem fubvillof, cæterum uti in affinibus. Foliola calycis duo linearia; tria ovata, concava, pallida cum friis virentibus, \& obfcure villofa. Petala obverfe ovata bafique acuta, ochrolenca vel magis pallida cum macula ad bafin luteola, obtufa. Atque hic color corollæ in horto Vindobonenf frequentior eft, fic ut quandoque rami pauci flores gerant rofeos; dum Schemnitzii in Hungaria culta planta rofeos fine ullo ochroleuco dabat omnes. Stamina tota lutea funt. Capfula triangulari-fubrotunda, villofula, unilocularis, tri- 
valvis. Semina pauca, fufca. Floret Majo \& Junio. Semina maturefcunt Julio.

\section{XXXIII.}

CISTUS FOETIDUS.

Etiam hunc Ciftum per plures annos jam colo, vifum mihi novum, totum Bryoniæ quodam odore fœtentem, radice perenni, caulibus inferne fruticulofis, ramis annuis, toto habitu priori fimilem. Floret fructumque fert eoderin etiam tempore. Rami, folia, racemi \& ca. lyces villis fcabris obfidentur. Folia funt oblongo-lanceolata, petiolata, oppofita, acutiufcula vel obtufiora, virentia, integerrima, ad oras parumper revoluta. Stipulæ anguftæ lanceolatæ. Racemi longi, terminales. Calycis foliola exteriora linearia; tria interiora ovata, acuta, pallicla cum ftriis virentibus \& hirfutis. Petala rotundata, alba vel rarius ochroleuca, ad bafin lutea. Stamina lutea, Capfula, qualis in præcedente. 


\section{STACHYS LANATA.}

Sine titulo femina ex Aftracan transmifla fuerunt. Ex radice perenni caules in ambitum fparguntur fublignofi, perennantes \& ipfi, procumbentes, \& radicantes, unde quadriennalis in horto noftro planta jam cefpitem pedalis diametri efficit. Ex hoc cefpite quotannis plurimi attolluntur rami, vel potius caules ex habitu dicendi, herbacei, pedales aut altiores, tetragoni, parum ramofi, erecti, virentes quidem, fed denfiffima lana obveftiente albiffimi. Hrc etiam eadem lana bracteas, calyces, \& folia utrinque non minus occupat, ut hæc in antica facie vellus referant, pluviamque, fporgiæ adinfar, imbibant, tunc ponderofa. Folia funt ovato-cblonga, acutiufcula, tres quatuorve uncias longa, petiolata, oppofita, minutim crenulata, venofa. Verticilli multiflori, denfi, foliis floralibus breviores, fuperne approximati. Calycis vix angulati \& ad unam tertiam divifi lacinix, funt ovatæ, acuminatæ \& fubæquales. Corolla tota adeo congruit cum Stachyde germanica, ut diftingui fere nequeat, 
nifi quod in germanica dorfum galex pilis ultra porrectis fit barbatum, in lanata autem folummodo hirfutulum. Color etiam paulo faturatior. Odor paucus. Floret fuls dio Junio \& Julio.

\section{XXXV.}

\section{RANUNCULUS CANADENSIS.}

Ex radice perenni fibrofa \& albida caulis recta attollitur bipedalis, teres, fiftulofus, ad bafin digitum minimum craffus, ramis ad angulum acutun egreffis \& axillaribus auctus, totus pilofiffimus \& fubhifpidus. Folia funt omnia ternata, petiolo communi propriisque eodem modo pilofis; foliola ipfa brevius utrinque hirfutula, fulotrilobata, incifa, ferrata, acuta; fumma feffilia. Bafis petioli communis lata eft. Pedunculi oppofitifolii, erecti, teretes, hirfutuli, uniflori. Flores parvi \& inodori. Calyx foris pilofus \& flavefcens reflectitur. Petala quinque vel fex, lutea, obverfe ovata, obtufifima, patentiffima, longitudine calycis. Capitulum feminum oblongum. Semina glabra, compreffa, obtufe \& breviter raftrata. 
frata. Floret a Junio ad finem Augufti. Semina perficit Augufto \&. Septembri.

\section{XXXVI。}

\section{CELOSIA PROCUMBENS.}

Crefcit in infula Domingo; hofpitatur apud nos in caldario. Ex radice annua caules generantur herbacei, bipedales, plures, proftrati, teretes, parum ramofi, geniculati, pilis appreffis fericei, glauci, terminati in fpicam fubpaniculatam, longe pedunculatam \& aphyllam: Folia radicalia \& caulina infima oblonga, bafi paulatim anguftata in petiolum, integerrima, quatuor vel quinque uncias longa, utrinque punctata, dorfo \& ad oras fericea, craffula, \& ad tactum fcabriufcula. Caulina oppofita, minora, remota; fuperiora fubfeffilia \& fubovata. Spiculæ oblongæ, compactæ, laterales feffiles. Pedunculi praprii dumtasat ad lentem confpicui, \& muniti fafcicula Ianato.

Caz. Perianthium triphyllum deciduum, glabrum, erectum, corollam arcte amplectens; foliolis duobus inte- 


$$
\text { B }
$$

interioribus rotundatis, amplis, conniventibus, albidis, membranaceis, pellucidis, exteriori breviori ; foliolo tertio extimo brevifimo, ex lata bafi acuminato. Hoc fi quis pro bracteola florali habeat, erit perianthium diphyllum.

Cor. Petala quinque, linearia, obtufa, calyce ad unam tertiam longiora, albida, erecta fimulque cylindrum formantia cum ore patulo, foris lanatiffima, quæ quidem lana in principio haud obfervatur, mox vero evolvitur, fimul atque calyx leditur, unde cognitio Ptucturæ floris evadit difficillima.

Neftarium cylindricum, monophyllum, apice quinqueficum \& patulum, ortum intra corollam. ceu corolla altera, ejusdemque longitudinis \& coloris.

Stam. Filamenta quinque, breviffima, in tubo netarii. Antheræ oblongæ, luteæ, tandem fulcæ.

PIst. Germen fuperum, orbiculare, glabrum, comprelfum. Stylus brevis, craffus, bifidus. Stigmata capitata, obtufa.

PER. Capfula compreffa, fubrotunda, acuta, ad oras dentata, circumfciffa.

Sen. unicum, luteolum, 
Floruit in caldario menfibus Junio \& Julio; \& Augufto femina perfecit omnia.

\section{XXXVII.}

ARISTOLOCHIA BILOBATA. Linn. fyft. pag. 686. Ariftolochia longa fcandens, foliis ferri equini effigie. Plum. amer.9 I. tab. 106.

In caldario ex fatis feminibus, a me ex infulis Caribæis olim adlatis, læte vegetat, altero ætatis anno menfe Augufto primos flores produxit, fruchusque maturos. Cau. les fruticofi, lignofi, volubiles, cortice veftiti cinereo \& fabfuberofo, frutices vicinos ad decem pedum altitudinem fcandunt. Rami numerofi, teretes, virentes, glabri. Folia alterna, graciliter petiolata, glabra, biloba, fæpe cum veftigio lobi intermedii tertii; lobis oblongis, obtufis, integerrimis, patulis. Plerumque rami fupra ortum petioli callofe \& fufce incraffantur. Petioli ipfi cirrhorum vices agunt. Pedunculi uniflori, axillares, breves. Flores inodori. Corollæ monopetalæ \& fuperæ bafis eft inflata, fubrotunda cum levi compreflione apiceque retufo, ex flavo pallens cum fex ftriis eminentibus fuligineis. 
gineis. Hinc oblique tubus exit anguftior, longe infundibuliformis, foris ejusdem coloris eodemque modo frriatus cum firis fupcrnc in renulas ramificatis; intus latius \& faturatiffime maculatus, maculis pilofis. Limbus in labellum porrigitur ovatum, obtufiffimum, quandoque emarginatum, venofum, friatum, planum, antica inferiore parte pallens, fuperiore autem $\&$ in toto dorfo fufcum. Germen teres, fexfriatum, virens, inferum. Antheræ fex, flavæ. Capfula ovata, fufcefcens, obtufa, fimilis fructui Ariftolochiæ caudatæ.

\section{XXXVIII.}

SCROPHULARIA VERNALIS. Linn. fyft. pag. 469. Flor. dan. ic. $4 \mathrm{Ir}$.

Scrophularia foliis longe petiolatis, cordatis, fubhirfutis; petiolis ex alis ramofis. Hall. hif. helv. num. 327 . Scrophularia flore luteo. Bauh. pin. 236. prodr. II2. Riv. monop. irr. t. ro6.

Scrophularia montana maxima latifolia. Barr. ic. 273. Lamiun pannonicum fecundum five exoticum. Cluf. hifl. pag. XXXVII. 
In Auftria rarius crefcit ad margines fylvarum, florens Majo, femina ferens Junio \& Julio. Ex radice perenni caules pauci exfurgunt annui, fefquipedales vel altiores, erecti, argute tetragoni, fiftulofi, hirfuti, parumper vifcidi, inferne purpurafcentes. Folia fibi opponuntur cordata, acuta, inæqualiter \& profundius ferrata, rugofula, utrinque pubefcentia, inferiora magis rotunda longiusque petiolata; petiolis canaliculatis. Pedunculi funt axillares, oppofiti, teretes, hirfuti, patuli, per dichotomias ramofi, foliorum circiter longitudine, ad omnes divifiones bracteis fuccefive minoribus infructi, occupantes totum fere caulem. Etiam caule hexagono cum foliis pedunculisque ternis variantem obfervavi. Flores funt fubfotidi. Calycis virentis fubrillofi \& fere ad bafin quinquepartiti laciniæ funt oblongæ, fubæquales, obtufæ vel acute, patulæ, fere longitudine corollæ. Hæc eft fubglobofa, flava, tumidumçue coaretatur in limbum breviffumum, quinqueficum \& obtufum, crijus laciniæ quatuor fubrotund æ connivent; quinta autem, quæ fitu inferior eft, longior patet, fibique ttamina habet incumbentia, ultra corollam, e cujus fundo oriuntur, notabiliter porresta. Capfula glabra includit femina numerofa parva \& atra. 


$$
\text { B O T A N I C E. }
$$

\section{XXXIX.}

PO'TENTILLA ASTRACANICA.

Semina fine titulo ex Aftracan accepi; quæ fata primo protulerunt anno fola folia radicalia, fubfequis caules plures, adicendentes, annuos, teretes, villofulos, pedales, in pedunculos paniculatim folutos. Folia radicalia \& caulina infima alterna funt quinata, petiolata, hirfutula, $\&$ ad ortum utrinque per ftipulam lanceolatam acutamqque auriculata; foliolis oblongis, obtufis, feflilibus, incifoferratis. Caulina fubfequa \& ramea funt ternata; foliolis inæqualibus \& incifis. Summa ad pedunculos oppofita, feffilia, \& triloba; vel potius funt ftipulæ trilobæ fine foliis. Pedunculi uniflori, breriufculi. Calyces hirfuti. Fetala flava. Antheræ lutex.

\section{Xl.}

\section{EUPATORIUM SIRLACLM.}

Ex horto Argentoratenfi in noftum tranfiit, ubi per plures jam annos fub dio perennat ractice, quæ annuatim

$$
\mathrm{X}_{3} \mathrm{x}_{3}
$$

eaules 


\section{0}

O E S E R V A T I O N E S

caules plures herbaceos promit, rectos, teretes, quatuor vel quinque fedes altos, purpurafcentes, friatos, ad lentem villofulos, \& medulla alba farctos. Ramuli ad angulum rectum fere per totum caulem exeunt. Folia fibi opponuntur breviffime petiolata vel feffilia, facie mollia, utrinque obfcure villofula, ternata; foliolis fubfeffilibus, lanceolatis, acutis, inæqualiter lanceolatis, quandoque fubincifis; quorum lateralia minora, frpe in ramis minima. Flores fubodori \& purpurei locantur in corymbis compofitis \& erectis. Calycis pentaphylli \& quinqueflori foliola funt oblonga, obtufa, canaliculata, \& ad oras ciliata. Corollularum calyce triplo longiorum limbus quinquefidus dividitur in lacinias oblongas \& foris hirfutulas. Antheræ petalum haud excedunt. Styli longi \& villofuli albent. Seminum pappus eft feffilis, albus, pilofus, ad oculum armatum aculeatus quidem, at minime plumofus. Sapore gaudet ingrato \& fubamaró. Floret Octobri. Semina vix maturefcunt, nifi transferatur in tepidarium. 


\section{XLI.}

\section{PLANTAGO CORNUTI.}

Semina accepi fub hoc titulo, addito celeberrimi Gouani nomine. Sub dio ex radice fufiformi, digitum craffa, albidaque, folia in orbem humi funduntur numerofa, acuta, pilis mollibus adfperfa ciliataque, femipedalia, \& pinnata. His cofta eft canaliculata. Pinnæ feffiles, inæquales, inordinato fitu egrefræ, lineares, acutæ, integerrimæ vel rariter incifæ. Scapi plurimi, adfcendentes, teretes, denfe villofi, fcalori, longitudine foliorum. Spica linearis, triuncialis, teres, aphylla, ereEta, gracilis. Brafteæ ovato-acuminatæ, concavæ, æquantes calycem; cujus foliola funt lanceolata, xqualia, carinata, acuminata, hifpidc ciliata. Petali albidi tubus longitudinem calycis habet; laciniis ovatis \& acuminatis. Filamenta funt brevifima contra affinium morem. Antheræ fagittato-lineares, flavæ, extra corollæ tubum. Stylus longiffimus \& hirfutiffimus erigitur. Fructus congenerum. Floret totam xftatem. 


\section{XLII.}

SIDA MAURITIANA.

Ad nullam cognitam fpeciem reducere potui, quare rovum impofui nomen. Fruticofa, octopedalis, erecta, inordinate ramofa, totum fere annum in caldario floret $\&$ fructefcit. Rami funt teretes, fubtomentofi \& molles. Stipulæ fubulatæ, parvæ, caducæ. Folia cordata, acuta, petiolata, inæqualiter ferrata, utrinque mollia atque fericeo-tomentofa, alterna. Pedunculi axillares, uniflori, folitarii, fuperne geniculati, petiolis longiores. Calyx mollis, pallide virens, femiquinquefidus; laciniis lanceolatis, acutis, patentifimis. Corolla patentifima, lutea, calyce duplo longior: laciniis obliquis, retufis, fulcato - Ptratis. Filamentorum numeroforum bafis conica albet, partes liberæ flavent. Antheræ luteæ. Germen album, molle, ovatum. Styli plurimi, flavi. Stigmata lutea, Capfulæ plus minus quinque \& viginti, in orbem depreffum fubcoalitæ, compreffæ, atræ, pilis villisque fufcis veftitæ, extima fummitate in acumen fubulatum abeuntes, interno margine etiam mucrone donatæ, \& in- 


$$
\text { B O }
$$

fra hunc in futura interiore excifr, calyce duplo longiores, bivalves. Semina in quolibet loculamento duo vel tria, nigra, reniformia \& afperiufcula. Fructus eriguntur. Crefcit fylvelìis in infula Mauritii India orientalis.

\section{XLIII.}

\section{CYNANCHUM EXTENSUM.}

Nomen eleganti huic plantæ celeberrimus Solander dediffe dicitur. In caldario totam æeftatem floret, fruEtumqque fert maturum autumno. Ex radice annua in fibras fefquipedales albidas calamoque graciliores divifa caulis affurgit volubilis, valde ramofus, duodecimpedalis, teres, villofus cum pilis rariter interjectis longioribus, afper, glaucus, adultior etiam leviter purpuralcens. Tales quoque rami. Iolia funt oppofita, late cordata, acuta, integerrima, utrinque ferme glabra; petiolo longo, terete \& villofo. Pedunculi communes egrediuntur inter petiolos oppofitos, nonrunçuam in utraque oppofita parte; femipeda!es, etiam pedales, teretes, fcabri, villofi, patentes, aphylli. ledunculi proprii fefquiunciales ad untervalla aggregation ex priori egrediuntur. Flures pen- 
354 O B S E R V A T I O N E S duli \& fuaveolentes, circa horam fextam vefpertinam pandi incipiunt, dum mane denuo clauduntur; cum virore pallentes. Tota lacte niveo abunde fcatet. Character fructificationis fequitur.

CAL. Perianthium quinquefidum, parvum, villofulum, perfftens: foliolis lanceolatis, acutis, erectis.

Cor. Monopetala, rotata. Tubus fubquinquangularis, calyce longior. Limbi quinquefidi laciniæ lanceolatæ, acutæ, tubo ad triplum longiores, planæ cum lateribus revolutis, patentiffmær, ad oras pilis denfiffine \& nolliter ciliatr.

Nectarii vagina ex corolli tubo, cui accrefcit, elevatur in conum pentagonum quinquefulcatum album \& petalo breviorem; qui conftat ex quinque bracteis erectis, obturis, apice trilobatis cum lobo medio longiori \& ntigmatis vertici incumbente, atque interne, pro locandis antheris, longitudinaliter bifaccatis. Cuilibet bracter ad bafn facci geminati in dorfo adnafcitur appendix lanceolata, convexa, utrinque inflexa, acuta, a media vagina ultra ftigma fe erigens. 


$$
\text { B }
$$

Staм. Filamenta decen, brevia, ex quolibet puncto fufco inter vaginæ bracteas in ftigmate confpicuo. gemina. Antheræ obverle ovatæ, compreffæ, pendulæ, flavæ.

PIst. Germina duo. Styli duo, fubulati. Stigma capitatum, globofum, in ambitu margine obtufe pentagono auctum.

PER. Folliculi duo, lanceolato-acuminati, longe muricati, turgidi, glauci, coriacei, divergentes vel reflexi toti, uniloculares, univalves.

Sem. Plurina, plana, pappo fericeo donata, receptaculo affixa. -

\section{XLIV.}

AXYRIS CERATOIDES. Linn. $\int y /$. pag. 7०6. Gmel. fib. 3. pag. 17. tab. 3. fig. 2.

Urtica foliis lanceolatis, floribus fœmininis hirlutis. Roy. lugd. pag. 2 10.

Ceratoides orientalis fruticofa, elaagni folio. Tourn. cor. 52 .

$$
\text { Y } 22 \text { Au- }
$$


Aufriaca etiam planta eft, ciefcitqque fponte circa oppidum Retz verfus Moraviam, ubi primus reverendus Boujard detexit, mihique attulit. Infipida tota $\&$ inodo. ra caulem habet fruticofum, duos tresve pedes altum, debilem, fupra bafin imprinis ramos emittentem proftratos, juniores totos foliofos \& fubtomentofos. Ramuli plerique eriguntur. Folia funt alterna, lineari-lanceolata, acutiufcula, integerrima, fubpetiolata, utrinque tomento fcabriufculo \& fubincano veftita. Ex axillis prodeunt folia minora fafciculata. Flores mafculi feffiles denfe occupant ipfas fummitates caulis ramorum ramulorumque, ut breves fpiculas foliofas referant:' Føminei infra mares in foliorum axillis, longa ferie, feffiles paucique aggregatim locantur; in principio autem a foliorum rofulis ægre diftinguuntur, lana tunc donati brevi \& preffe accumbente; qุu deinde increfcit \& expanditur quam maxime, ut fere hac occultentur quamvis mole aucti. Seminum amarorum extremitas craffior ex virịdi fufcelcit, eftque in duas femiteretes lamellas, futuras in fatione cotyledones, feparabilis; extremitas tenuior, futura radix, pallefcit. Capfulæ fumma affinitas eft cum Salfola profrata. Floret Augufto \& Septembri; fenina perficit Octobri \& Novembri. Quandoquidem fructificationis 


$$
\text { B O T A N I C E. }
$$

character plurimum differat a Linnæano, eundem extenfum fubjungo.

$$
\text { * Mcrilus }
$$

CAL. Perianthium tetraphyllum : foliolis lanceolato - falcatis, erectis, valde concavis, obtufis, hirfutiffimis. Cor. Nulla.

Staмr. Filamenta quatuor, filiformia, erecta, calyce duplo longiora. Antheræ geminæ in quolibet filamento, obverfe ovatæ, fulcatæ, defcendentes.

* Frminis

CaL. Perianthium monophyllum, perfiftens, bafi lanatum, ex tubo ovato fuperne bicornutum patulumqque. Cor. Nulla.

Pist. Germen ovatum, compreffum, lanatum. Styli duo, capillares, erecti, longitudine calycis. Stigmata fimplicia.

Per. Caplula ovata, acuta, comprefla, membranacea, hirfuta, magnitudine calycis, cui includitur.

$$
\text { Y y } 3
$$


Sexr. Unicum, teres, fubulatum, in formam ferri equini fic incurvatum, ut extremitates in apice capfula fefe mutuo tangant.

\section{XLV.}

\section{RUELLIA PATULA.}

Planta fruticofa ex India orientali, tota foctidififima, infipida, \& una cum calycibus villofula. Caulis pedalis $\&$ ultra, teres, vifcofo-villofus, erectus, ab ipfa jam bafi inftruitur ramis oppofitis decuffatis \& ad angulum acutum patulis. Folia funt rotundato-ovata, obtufa, integerrima, oppofita, petiolata, \& craffula. Floraiia vero lanceolata \& acutiufcula. Flores fubfeffiles, axillares, mutuo fuccedentes, tandem terni vel quini. Perianthii foliola funt fubulata \& brevia. Petali fordide carnei tubus cylindricus; faux campanulata; limbi patentiffmi laciniæ fubrotundx, fuperiores duo paulo minores. Corolla circa vefperam extra calycem prodit, tamque celeriter $\&$ ad oculum ferme increfcit, ut proximo mane jam adulta expandatur, decidatque ante noctem. Antheræ erectæ \& acutæ albent. Stylus eft pilofus. Stigma bifidum 


\section{B 0 I A N I C E.}

dim cum lacinia fuperiore obfoleta, inferiore autem in labellum protracta fuperficieque ad lentem hirta. Capfula cuneiformis, acuta, glabra, fufca, compreffa, calyce perfilente triplo longior, biocularis, $\mathbb{\&}$ bivalvis cum unguilus elafticis. Semina in quovis loculamento fere fena, orbicularia, hinc convexula, illinc deprefia, nitida. In caldario floret primo xtatis'anno ab Augufto ad Novembrim, feminaque perficit Octobri \& fubfequis. Provedior autem ætate hæc omnia præcocius.

\section{XLVI.}

\section{PHYSALIS BARBADENSIS.}

Annua planta in calclario floret junio \& Julio, fruAtum perficiens Augufto. Caulis teres, calamum plus minus crafus, villolus, erectus; ramis plurimis divaricatis. Folia cordata, acuta, dentata, inollia, utrinque fubvillola, fed non vif́cida, longius petiolata. Pedunculi breves. Flores cernui. Corolla ochroleuca cum maculis ad bafin quinque fuligineis. Iructus penduli, decidui. $\mathrm{Ca}$ lyx fructiger inflatus, ovatus, acuminatus, glaber, venolis, argute pentagonus, cinereus. Bacca fulsrotunda, nitida, 
tida, glaberrina, pallide virens, calyce multo minor, acidula.

\section{XLVII.}

\section{RICINUS LIVIDUS.}

Varii quidem autores, Rumphius, Rheede, aliique, de Ricino arborefcente albo, deque rubro, locuti in operibus fuis fuerunt; $\&$ videntur omnino plures diftinctas Ricini fpecies enumerafe, quam I innæus aftumfit. Sed nulla ex illis combinari poteft cum Ricino hocce mihi dicto livido, nec magis cum fubfequo inermi; quare ceu novas fpecies propono. Utriusque femina ex India orientali transmiffa fuerunt; unde enatæ plantæ xeftatem fub dio, hyemem in tepidario tranfigunt, jam quinquennales, decompedales, fempervirentes, veræ arbores.

In Ricino livido truncus primo ætatis anno fanguiness \& nitid.ffumus eft; deinde lignofus, carpum craffus, fifuloíus cumfeptis transverfis, medulla farctus alba, ad nodos cicatricibus circularibus a ftipulis delapfis circundatus, cinęreus, interrupte leviterque friatus. 'Tales. 


$$
\text { B O T A N I C F. }
$$

etian rami. Folia ante evolutionen involvuntur fipulis fpathaceis rubris deciduisque. Sunt autem peltata, femioftoloba, rarius decemloba, terrata, acuta, longe petiolata, figura omnino Ricini communis, fed facie atrofanguinea, dorfo livida cum renis fanguineis; trans lucem fi fpeftentur, tamen viridia; ampliora diametro pedali breviora; glaberrima fine omni hirfutie cquacunque. Petioli teretes, parum fifulofi \& fanguinei, inftruintur fupra bafin glandulis duabus remetis, concoloribus, \& oblique truncatis; tum aliis duabus in fumma parte antica infra ipfum ortum paginæ, juxta invicem locatis, fubrotundis, concavis, nonnunquam dumtaxat unica. Preterea una vel plures iterum fimiles glandule in caule ramisque adfident utrique lateri axille foliorum. Iftiusmodi glandulæ defiderantur cmnino in Ricino communi. In frultificatione racemofa mafculi decidui hærent infra fæminas; habentque periantliii profunde divifi foliola quinque, fanguinea, lanceolata, acuta, patentifima, \& concava. Corollam nullam. Filamesta numerofa coalita in decem plus minus corpora, curi antheris globofis, didymis \& flavis. In fæminis perianthium eft tripartitum, finile mari, diu perfiltens. [iflillum fanguineum. Fru-

$$
\mathrm{Zz}
$$

Etus 
Atus congenerum, molliter \& longius echinatus, lividus. Scmina nitida, nigro fufcođue variegata.

\section{XLVIII.}

\section{RICINUS INERMIS.}

Totus habitus prioris, fed eadem rtate robuftior. Truncus primo retatis anno ruber \& nitidifimus; dein cinereus cum maculis purpureo-fufcis. Folia virentia utrinque, ampliora dianetri fere fefquipedalis cum petiolo pedali. Glandulæ prioribus numero fituque fimiles, fod virides vertice cum ambitu rubello, vel virides totæ. In floribus calyx cum rubore viret. Germen rugofulum, atropurpureum. Fructus ovatus, major, nitidus, atrovirens, rugofulus, inermis, nec ullo aculeo vel minimo infructus. Et alia omnia, uti in præcedente. 


\section{XLIX.}

\section{CYNOSURUS DOMINGENSIS.}

Ex radice fibrofa \& perenni culmi recta attolluntur hcrbacei, plures, duos tresve pedes alti, teretes, glabri, nitidi, graciles, noclofi, foliofi, ramum fæpe ex inferiore aliquo nodo emittentes, cæterum fimplicifimi. Folia enliformi - linearia, acuta, plana, in oris ad digitum retrorfum motun aculeato-afpera, facie infra medium pilofa, dorfo glabra; orta $c x$ vagina caulem amplexante \& hirfutula. Panicula terminalis erecta \& filiformis componitur' racemofe ex rachibus alternis vel oppofitis pluribus patentifimisque, ad ortum fafciculo pilofo munitis; quarum alternantibus denticulis fpiculæ infident bifariæ, exiguæ, compreffæ. His gluma calycis eft diphylla, a tribus ad quinque flofculos comprehendens, fine involucro alio ullo; valvulis carinatis, dorfo aculeatis, acutis, muticis, erectis, poft feminum corollæ incluforun lapfun perfiftentibus; altera breviore. Corollæ valvula exterior eft glumæ calycinæ fimilis, fed ariftata; interior plana \& mutica. Arifta purpurea \& afpera ex fummo val-

$$
\mathrm{ZZ}_{2} \quad \text { vulæ }
$$


364 O E S E R V A T I O N E S

vulæ dorfo egreditur, in floc culis fuperioribus gradatim brevior. Stigmata funt atropurpurea. Semon minutum. Floret $\&$ fructefcit in calciario totam æflatem.

\section{L.}

POA ABYSSINICA.

Radix fibrofa \& annua culmum profert gracilem, geniculatum, compreffulum, ramofum, inferne procumbentem, \& ad nodos infexum. Folia fublinearia, acuminata, vaginantia, \& ad oras ob minutiffimos denticulos alperiufcula. Panicula terminalis, laxa, rachibus capillaribus compreffis patulisque. Spiculi, oblongæ, obtufie. Calyx biglumis a quatuor ad fex flofculos fuftinet; valvulis lanceolatis, acuminatis, muticis, erectis, conca- vis, compreflis, albidis cum dorfo virente $\&$ ad lentem obfolete denticulato; altera longiore. Corollularum valvulæ calycinis fimiles. Flofculi locantur alternatim in rachi propria arcuatim flexuofa. Stigmata funt purpurea. Et alia ad characterem. Tota planta eft glaberrima, \& fub dio, lætius tamen in caldario, floret per totam xiftatem. 


\section{LI.}

PANICUM COLORATUM. Linn. fyft. prg. 91. mant. Fogs. 30 .

Radix perennis conliat fibris crafis longis albidisque. Culmi annui, plures, aggregati, bafi veluti in bulbillum incraffati, ibiclemque connexi \& radicantes, bipedales, erceti, teretes, glabri, nodofi, absque omni vel minino ram lo fimplicifimi. Apud Jinnæum culmi in Panico colorato dicuntur valde ramofi; in noftra hac planta funt omnes perpetuo fine ullo ramulo fimplicifinui; fed fupra ipfam radicen dumtaxat connati. Folia longe per totum culmum ad proximos useque nodos vaginantia, enfifurmi-linearia, plus minus decem uncias longa, lata lineas cuatuor, acuminata, lævia, glabra, nonnunquam inferne rariter pilofa, laxa, fubtus in nervum medium acutum prominentia, modo plana, modo conniventia, ad oras cartilagineo-dentata quidem, at tam obiter, ut oculus armatus aliquid, tactu manus nihil fere percipiat. Vaginæ funt pilofe \& afperæ; in fummis foliis frepe glaberrima. Culmus folvitur in paniculam patentiffimam,

$$
\mathrm{Z}_{3} 3
$$

fili- 
366 O B S E R V A T I O N E S

filiformem, ramolam, amplam. Flores fparfi, folitarii, in pedunculis propriis capillaribus, qui plerumque ramulis paniculie fic apprimuntur, ut oculos fugiant, floresque feffiles mentiantur. Glunæ calycinæ unifloræ; valvulis duabus interioribus muticis, ovatis, obtufis, oftofulcatis, pallide virentibus cum feptem ftriis purpureis; valvula tertia exteriore exigua, acuta, pallente, nec fulcata. Corolla albida, bivalvis, pellucida, obtufa, fere magnitudine calycis; valvulis fubovatis; quarum altera concava \& lineata eft, altera planior. Filamenta alba purpurafcunt ad apicem. Antheræ didymæ, oblongæ, luter. Stigmata plumofa, purpurea. Floret fub dio menfe Augufto \& Septembri ; in caldario femina perficit. Semina: transmiffa fuerunt ex infula Domingo.

\section{LII.}

SALVIA VIRIDIS. Linn. $\int y$ f. pag. 64. hort. upf. pag.: I . num. 8 .

Salvia coma viridi. Tourn. inft. I78.

Odur plantæ graveolens. Radix annua. Caulis erectus, fubpedalis, parum vel vix ramofus, tetragonus, \& hirfu- 


\section{B O T A N I C E.}

hirfutus. Tolia orata, obtufa, venofa, villofula, viridia, tenuiter crenulata, inferiora petiolata. braftex ad verticillos fexflcros cordatx, acutx, felfiles. Peilunc. ii proprii brevifimi. Calyx fere cylindricus, viridis, flriatus hirfutus pilis vifcidis \& capitatis; in frufu fuperne comprefius or horizontaliter jatens vel quandoque magis reflexus. Corollæ galea oblonga, obinfa, foris hirfutula, violacea, connivens. labim trifilum, caruleum, cbtufum; lacinis lateralitus oblongis; intermedia concara \& fubrounda. 'Tubus pallet. Stigma eft violaceum. Semina orata, comprefula, nigra. Floret fub dio Junio \& Julio. Senina maturefont Augufo.

\section{III.}

ARENARIA CIIIATA. Linn. Jyff. pag. 353. Flor. kin. ic. $34^{6}$.

Aline, ferpilli folio, multicaulis \& multiflora. Seg. ver. ז. $g_{0} \cdot 420 . t a b \cdot 5 \cdot f g, 2$.

Frequentillima in fummis nudis alpium Auftriacarum rupibus plantula ex radice perenni, qua faxorum fiffuras tenui humo impletas penetrat, ramofa \& valde multicipite 
368 O B S E R V A T I O N E S

pite denfum furculorum cefpitem generat, diametri biuncialis acl femipedalem fere, in numerofos ramulos fubrillofulos graciles \& unifloros abeuntium. Folia funt lanceolata, craffula, acutiufcula, parumper concava, utrinque glabri, oppofita, felfilia, ad oras a bafi ad medietatem uscue ciliata pilis albis. Flos ratione plantulæ magnus, patentifimus. Calycis foliola funt lanceolata, acuminata, glabra, concava, virentia, non ftriata, paulo breviora petalis. Hæc obverfe ovata, vel oblonga, integerrima, alba. Filamenta longitudine calycis, antheris albentibus. Caplula ovata.

\section{LIV.}

LICHEN ELONGATUS. Tab. I I. $f_{g^{\prime}} \cdot \mathbf{I}$.

In itinere a celeberrimo Commerçonio collectas accepi plantas plurimas rarifimas elegantifinasque, quas inter Lichenes funt tres, quos hic defcribam. Primus, quem a fiatura elongatum voco, pertinet ad Scyphiferos Lirnæi, \& ad ejus I ichenen gracilem accedit. Ex bufi fufca \& tabefcente viletur elle terreftris, atque mulcis aut humo putridæ innafci. Eft lichen cylindricus, filtulofus, teres, 


\section{$B \circ \boldsymbol{A}$ N I C $x$.}

teres, mollis, cinereus, quatuor uncias altus, fubereftus, aut fimplicifimus, aut fuperne furcatus. Summitates modo fubulatæ funt, acutæ \& fteriles; modo autem \& ipfæ trunco craflitie frmiles, \& apice in fcyphum expanfi. Hic plerumque breviffime denticulatus eft cum denticulis fufco-capitatis; aut (forte nedum debite expanfus, $t u$ berculo majore fufco tegitur totus. Crefcit ad Fretum Magellanicum.

\section{LV.}

LICHEN AURANTIACO-ATER. Tab. ri. fg. .

Elegans Lichen ad ordinem Linnæanum filamentoforum pertinet. Erectusne creverit in arbore, an pendulus, ex fpecimine nequit determinari. Patria non additur. Paniculatiffimus totus ex pluribus videtur caulibus conftare, teretibus, folidis, duris, firmis, ramofiffmis, fefcuncialibus; qui una cum ramis fuis craffioribus, dum in aqua humefcunt, coloris funt ex rubro aurantiaci; dum ficcefcunt, magis flaventis. Ramuli ultimi breves acuti capillares \& numerofiffini femper funt atri \& lucidi. Infra hos egrediuntur fcutellæ orbiculares, integerrimæ, A a a 
planiufculæ, omni radio deftitutæ, facie atræ lucidæque, dorfo aurantiacæ, feffiles, plurimæ. In icone color exhibetur madefacti. Totus Lichen glaber eft.

\section{LVI.}

\section{LICHEN ANTARCTICUS. Tab. то. fig. r.}

Hic inter Linnæi coriaceos Lichenes locandus eft, corticibus arborum innafcens ad Fretum Magellanicum. Folium coriaceum, molle, glabrum, inordinate undique lobatum, fubtus albuin bullatumque, fupra lacunofun \& olivaceum. Lobi fubtus gerunt peltas ampliffimas, planiufculas, fuborbiculares, glabras \& badias. In madefacto ficcoque idem ferme color eft, nifi quod facies magis fufcelcat in ficco.

\section{LVII.}

\section{HIERACIUM CYMOSUM. Linn. $\int y$ ?. pag. 597.}

Hieracium murorim angutifolium, non finuatum, Bauk. pin. I 29. prodr. 67. t. 67 .

Pilo- 
Pilofella montana hifpida, parro fore. Bauh. pin. 262 . Pilofella minori flore, hirfutior \& elatior, non repens. Bauh. hifl. 2. pag. 1040.

Pilofella major umbellifera $\mu x x \rho^{\prime} x x \nu \lambda$ os montana \& pratenfis. Cul. ecphr. I. pag. 248 . tal. 249.

Planta lactefcens in collibus agri Vindobonenfis frequens occurrit, florens Julio Auguftoque. Radix perennis, plerumque præmorfa, calamum vel digitum craffa, nunquam ftolonifera, nigra, fibrisque longis fufcefcentibus capillata. Folia radicalia plura, ex oblongo lanceolata, utrinque attenuata, integerrima, acuta, craffula, afpera, \& utrinque pilis longis albidisque hifpida. Caulina pauca, feffilia, prioribus fimilia, fed minora. Caulis unus alterve, fuberectus, teres, ftriatus, hifpidus totus, vel fuperne glaber, pedem vel fefquipedem altus, ut plurimum fimplex, terminatus pedunculis fubcymofe divifis, hirfutis vel glabris. Flores parvi. Calyces imbricati, hirfuti \& incani. Corollulæ funt luteæ, argute quinquedenticulatæ. Semina oblonga \& atra pappum gerunt pilofum.
Aas 2
LVIII. 


\section{LVIII.}

TRAGIA INVOLUCRATA. Linn. Syft. pag. 7o\%.

Ricinocarpus zeylanica hirfuta, foliis lanceolatis ferratis. Burm. thef. zeyl. pag. 202. tab. 92.

Urtica fruticefcens malabarica. Raj. hif. 1. p. 160. Schorigenam. Rheed. mal. 2. pag. 73. tab. 39.

In caldario læate vegetat, $\&$ ex radice ramofa annua caulem attollit decempedalem, volubilem, teretem, ex alis foliorum valde ramofum, pilis albidis atque urentibus hifpidum, virentemque. Folia funt alterna, petiolata, ovata vel lanceolata, ferrata, acuminata, fubtus pallide virentia \& venofa, iisdemque urentibus pilis hifpida. Stipulæ feffiles, acutæ, \& integerrimæ. Pedunculus folitarius, oppofitifolius, brevis \& patens, florem fæmineum fert unicum, pendulum, breviffime pedunculatum ipfum, fupraque hunc in extremitate flores mafculos plures exiguos feffiles inque capitulum amentaceum oblongum collectos. Ad frminæ ortum bracter tres adftant lanceolatæ, acutæ, parvæ, integerrimæ, quarum infima 
longior eft. Ad fingulos mares oft bractea folitaria, lanceolata, acuta, concava, parumper hifpida, \& feffilis. Flori frmineo, toti hifpido perianthium eft hexaphyllum, perfiftens; foliolis oblongis; germen amplexantibus, ita ut tria alternantia ejusdem fulcis incumbant, tria reliqqua ejusdem gibbis; pinnatifidis cum laciniis utrinque quatuor cum impare, oblongis, oppofitis, ad oras rigide hifpidis. Corolla nulla. Germen fubrotundum, triquetrun, hifpidum. Stylus unicus, craffus, brevis. Stigma trifidum, reflexun. Capfula tricocca, elaftice diffliens. Maribus perianthium eft triphyllum, vel tetraphyllum; foliolis ochroleucis, late ovatis, acutis, planis, patentiffimis. Corolla nulla. Filamenta tria, breviffima, erecta. Antheræ didymæ, flavæ. Flores fructusque fert a Julio ad Decembrim.

\section{LIX.}

OPHRYS MYODES. Scop. carn. pag. 193.

Ophrys infectifera myodes. Linn. fyjf. pag. 678.

Orchis radicilus fubrotundis; labello fericeo, bilulco; brachiolis brevibus, fubulatis. Hall. hift. helv. num. I265. tab. 24 . 
Orchis mufcæ corpus referens minor, galea \& alis herbidis. Vaill. bot. pag. 147. tab. 31. fig. 17. E 18 . Bauh. pin. 83 .

Cum Hallero aliisque contra Linnæi fententiam feparo hanc plantam ceu fpeciem ab Ophri arachnite. Bulbi funt ex oblongo rotundati. Folia funt oblonga, acutiufcula, integra, craffula, lineata, ad bafin vaginantia, pauca, glabra, fubradicalia omnia. Scapus eft teres, glaber, fpithamæus, aut paulo altior. Spathæ pallide virent, lanceolato-oblongæ, erectæ, convolutæ, \& florum longitudine. Hi fuaveolentes a quatuor ad octu fpicam raram abfolvunt. Germen oblongum, fulcato-ftriatum. Petala tria exteriora funt oblonga, obtufiffima, craffula, patentiffima, \& viridula: duo interiora funt linearia, anguftifima, paulo prioribus breviora, obtufa, antrorfum erecta, atropurpurea, \& ad lentem villofa. NeAtarii calcar adeft nullum. Labium inferius magnum, purpureo-atrum, holofericeum cum difco cinereo, trifidum: laciniis lateralibus oblongis; intermedia ampliffima \& ad apicem emarginato-bificla, ad latera obiter reflexa. Cucullus viret. Antheræ flavent. Crefcentem co- 


$$
\text { B } 0 \text { T A N I C } \text { E. }
$$

piofe inveni, \& fub Junii fine florentem, in pratis fubalpinis Aufriæ.

\section{LX.}

ORCHIS MASCULA. Linn. Jyjl. pag. 674. Flor. dan. ic. 475 .

Orchis radicibus fubrotundis; petalis lateralibus reflexis; labello trifido; fegmento medio longiori, bifido. Hall. hift. helv. num. 1 283. tab. 33 .

Orchis morio mas, foliis maculatis. Buth pin. 81. Vaill. bot. pag. T5I. tal. 31. fig. I1. Eु I2. Seg. ver. 2. pag. 124. tab. 15. fig. 5 .

Bulbi gemini, fubrotundi vel magis oblongi. Folia radicalia tria vel quatuor, oblonga, obtufa, craffula, lineata, niticla, bafi raginantia, late virentia, inferne utrinque afpera punctis fanguineis rel atropurpureis. Caulem præterea fulium unum alterumve inferne veftit, ferme totum raginans, acutum, \& quandoque non punEtatum. Scapus fuperne nudus, teres, pedalis \& ultra, terminatur in fpicam longam cylindricam nec denfam. 
Spathe purpurex, anguftifime lanceolatx, acuminatx, conniventes, infmæ germine duplo longiores, reliquæ ejusdem longitudinis. Flos inodorus, totus ex rubro purpureus, labio faturatius tincto magisque cærulefcente. Fetala tria exteriora funt lanceolato - acuminatifima, concava, æqualia, patentia, nec reflexa. Interiora duo ova. ta, cbtufufcula, concava, exterioribus fere duplo breviora, in cucullum conniventia. Labium inferius eft quadrilcbatum; Iobulis cbtufffimis, obiter crenulatis; nonnunquam dumtaxat trilobum eft cum lobo intermedio magis minusve emarginato. Difus ad lentem villofus eft. Calcar obtufum, germinis circiter longitudine, rectumque, cblique pergit. Germen intortum incurvatumque ex atropurpureo viret. Sic etiam fructus immaturi. Crefcit in Aultrix pafcuis montanis \& fubalpinis, ubi floret julio.

\section{LXI.}

MUCOR ARANEOSUS. Tab* 20.

Hunc fungum ante plures annos inveni in fylvis fubalpinis, increfcentem lignis putridis, in terra jacentibus. 
Fruftra deinceps quæfivi; quare nunc defcribo, qualem tunc inveni, forte jam fenefcentem. Singularis fungo eft fructura, ut ad nullum apte genus reducatur, nec bene ad mucores. Conftabant fungi mero pulvere rufo minutiffimo, in cumulum femiovatum aggregato, fine ullo confpicuo cortice, magnitudine uti digiti apex eft, \& cujusmodi in fuperiore figura exhibetur. Sed una circa fungum ad diftantiam aliquam ligno affixa confpiciebantur in orbem fila nigra capillaria \& elaftica, quæ ad centrum commune fungi dirigebantur, 'primo procumbentia, deinde per fungi fubftantian pulverulentam affurgentia, rigidula; cujusmodi plurima, etiam interiora verfus, totam fungi aream occupabant. Alia præterea aderant fila ad peripheriam priorum, contrario prioribus fitu, veluti lineæ tangentes circuli. Hæc non ubivis, fed aliquibus tantum in locis fpectabantur. Omnia hæc per annos in ligni frufulis perfifunt, pulvere brevi fponte delapfo, qualis fiftitur auctus in figura inferiore. Firmiffime fila adhærent ligno, qua illud tangunt; $\&$ ad lentem fuperficies tota veluti glutine videtur obducta, haud aliter, ac fi limaces fuper illa repfiffent. 


\section{LXII.}

IICHEN SARCOIDES. Tab. 22.

Menfe Augufto ineunte in fylvæ fubalpinæ loco fubaprico inveni hunc Lichenem, qui undique corticem trunci arboris vaftx, in terram dejectæ \& putréfcere jam incipientis, obducebat. Subftantia fungi gelatinofa, tresnula \& mollis, inftar Tremelle, ex fufco carnei coloris five rufi, raro ultra fcutellas protenfa, has tamen femper in fundo connectens ceu membrana una continua, cui fcutellæ infident; cortici arboris adhærens fine radiculis, nt facillime absque læfione tolli queat. Sic femper tenuiffima eft, animalem quandam membranulam egregie mentita ; fed ultra fcutellas dum quandoque protenditur, tunc hic incraflatur admodiun, \& modo animalem membranam craffiorem æmulatur, modo affurgit in gyros mefenteriformes. Hujusmodi figura inferior eft ; dum fuperior lichenes fiftit cum membrana ultra fcutellas non pergente, quales etian, a cortice arboris avulfos, figuræ $c$ demonftrant, antice \& a tergo confpectos. Scutellx eadem confifientia ac colore donatx, concavx, \& fubro- 


$$
\text { B O T A N I C } \pi \text {. }
$$

tundæ, aut feffiles funt, aut bafi in pedunculum veluti elongantur. Juniorem feffilem figuræ $b b^{\prime}$ repræfentant, alteram in naturali magnitudine, microfcopio auctam alteram, in qua margo limbi eft planum inclinatum. In figuris a a exhibetur fcutella pedunculata, cum naturalis, tum aucta ad lentem.

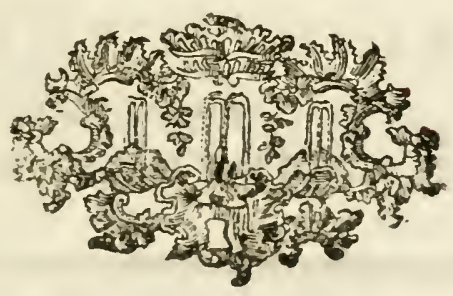




\section{VI. \\ J A COBI A WELL,}

HISTORIÆ NATURALIS IN UNIVERSTATE VINDOBONENST PROFESSORIS,

A D D I T A M E N T A Q U E D A M

A D

E N T O M O L O G I A M.

\section{I} nfectorum hiftoriam, extenfiffmam illam Zoologiæ partem, cum a remotis inde temporibus, tum hoc præfertim frculo, a peritis viris indefeffo ftudio multaque incluftria pertractatam fuiffe, neminem latebit, qui vel obiter in inveftigatione Entomorum verfatus eft. Imprimis vero, 
ut alios celeberrimos Entomologos taceam, nofro ævo illuftis a Linne in Syftematis Nature I omi primi fecunda Parte edit. 12 , ut $\mathbb{E}$ jam antea in Faunæ Succicæ altera editione, Infera in leptem 1)ivifiones fou Crtines, filicet in Coleoptera, Hemiptera, Lepiloptera, Neliroptera, Hymenopiera, Dipcera \& Aptera difpofuit; horum Ordinum contenta notis infignivit characterifticis brevioribus, ita ut generum ac fpecierum determinatio cuilibet lucide pateat.

Interea tamen omnem $f_{c}$ in hac re exhaufife operam, quin pofteris nil addendum nihilque mutandum relinqueretur, minime gloriabatur, nec ideo fuam, etfi olmi exceptione majorem, Infectorum ordinationem effe prorfus naturalem jactitavit; verum ingenue faffus eft, hunc conatum non tam facilem, quidquid nonnulli, moliendo fefe effecifre, pompofe magis quam vere, dictitent; quandoquidem infectorum, quæ hodiedum innotuerunt, genera $\&$ fpecies fortafis minimam eorum efficiunt partem, quæ adhucdum cognofcenda, adhuc determinanda funt. Unde indics nova infectorum genera, novæçue fpecies, deteguntur. Ejusmodi igitur nonnulla adjungere \& ego hic confitui, quatuor videlicet nova \&,

Lb) 3

quan- 
quuantum fcio, nullibi rite defcripta infecta cum Hiforize Naturalis cultoribus communicaturus. Horum tria ex ordine Coleopterorum funt indigena; unum ex Lepidopteris exoticum eft, ad Equitum Troum cohortem fpectans. Hæc ergo pauca, quum materiem fufficientem, ad differtationem peculiarem confcribendam, non fuppeditent, hifce Mifcellaneis, annuente editore, intercalare placuit; qux fi mea determinatione, utpote novi coloni, inter cæxtera nunc debite locata fuam quoçue ftationem invenerint, multum gaudebo.

Hanc Hiftoriæ Naturalis partem, de Infe:tis fcilicet agentem, effe etiam homini emolumento, effe utilita$\mathrm{ti}$, a plurimis naturæ fcrutatoribus jam evidenter demonftratum eft, quare eam laudibus extollere fupervacaneum duco; nec recenfere hic locus eft, quæ Naturalis Hiftoriæ ftudium non modo in fpeciofioribus naturæ productis, verum etiam in hifce animalculis, cum ad Medicinam, tum ad Oeconomiam, bona $\&$ utilia detexit, dum hæc fine diligentiori difquifitione rerum qualiumcunque naturalium diu adhuc abfcondita diuque ignorata manfiffent. Nil enim in tota natura, quantumvis ad adfpectum nonnuilis vils aprareat, contemnendum.

1) Pri- 


\section{an Entomologiam.}

1) Primum in tabulæ 23. figura $r$. exhibitum infeEtum e Coleopteris apterum novum conftituere genus, atque in ordine Linnæano inter Attelabum \& Ceranbycem locari polfe autumo; cui fit nomen genericum Scotias, ideo quod loca tenebrola amet; triviale vero nomen ob aliqualen cum pulice funilitudinem \& colorem pfylloides. Definiatur genus

Scotras Antenne fetaceæ, articulo ultimo fublanceolato.

Caput exfertum, inflexum.

Elytra convexo-gibba, connata.

Scotras pfylloides fpecies fit, in qua fequentia præfertim obfervanda veniunt.

Caput verfus collum angultius, depreffum, nigrum. Oculi relative ad caput magni. Antenine fetaceæ, pallidæ, articulis conoideis decem (raro undecim) ultimo articulo fublanceolato. Labium porrectum, villolunn. Palpi quatuor, filiformes.

Thoràx teres, nitens, picens. 
Eýtrit rufo-badia aut cuprei quafi coloris, ad microfcopium in apice tridenticulata, nitida, connata, abdomine nigro contracto longe ampliora, faccum quodammodo formantia, \& ob abdominis minutiem quafi vacua, ideoque fulsdiaphana.

Pedes longi.

Reliqua in amiei mci dilectiffimi, Domini Doctoris Czenpinski, auditoris mei olim diligentiffimi, ac Hiftoriæ Naturalis cultoris folertiffimi, differtatione inaugurali fufe defcripta leguntur; qui etiam meum in defcribendis animalibus ordinem, quo jam ab anno 1775 Hiftoriam Naturalem tradere foleo, fecutus eft; inchoando nempe in regno animali ab animalculis minimis, ad fenfum utpote fimplicioribus, pergendo per reliquas animalium claffes usque ad hominem, qui huic regno coronidem imponit. Unde patet, ordinem Linnæanum quafi inverfum a me tradi.

Noftrum fupra defcriptum infeetum legne, loca obfcura amans, vitæ pertinacioris, etiam vitrello inclufum diutiffume inedia vivere poteft. 
AD ENTomologian.

Tabulæ 23. figura $\mathbf{I}$. in $a \& b$ infectum naturali magnitudine reprafentat; in $c$ idem lente auctum.

2) Alterum infectum eft Buprefis fpecies, quam ob non vulgarem, quo fuperbit, nitorem fafluofam dicere volui. Definiri poteft

BUPKESTIs fafuofa viridi-cærulea, nigro-punctata, nitidiffima, ad marginem aurata.

Caput, Thorax \& Elytra per medium ex cæruleo virent, ad latera vero aureo fulgent colore. Oculi funt aurei. Elytra leviter ftriata, punEtisque nigris infperfa. Subtus omnia ex flavo virent. Corpus integrum metallico undique micat nitore.

Hoc infectum copiofe inveni circa Laxemburg, \& quidem folummodo in Tilia, nec in alia planta; fi quis igitur eam Bupreftem Tilix dixerit, non errabit. Ego tamen ob elegantiffimum nitorem faftuofam dicere malui.

In tabulæ 23. figura 2. 1ub a confpicitur infectum in naturali magnitudine fuperne; fub $b$ iden refupinatun!; fub $c$ microfcopio actum:

$$
\mathrm{Ccc}
$$


3) Tertium infectum eft Dity/ci nova, ut opinor, fpecies, cui nomen triviale anaftomozans effe poteft, fuls fequente definitione:

Dityscus anaftomozans elytris obfcure fufcis, fulcatis, fulcis nonnullis in gyros retortis, anaftomozantibus.

Caput \& Thorax nigricant. Thorax limbo flavo circumcingitur. Sternum bifurcatum.

Elytra umbrata, fulcis parallelis, longitudinaliter decurrentibus aliis, aliisque furfum ac deorfum flexuore confluentibus.

Palpi, Antenne, Pedes, uti \& totum Corpus fubtus rufi coloris; margo autem fordide flavus.

Hoc infectum prope Iglaviam in Moravia e quadam pifcina extraxi.

Figura tertia tabulæ 23 fub $a$ infectum pronum exhibet; fub $b$ idem refupinatum.

4) Tandem venit Papilio, quem, dim ab alio Entomologo nedum inveniam defcriptum, aut nomine triviali 
viali infignitum, Antenorem vocavi. Erat enim Antenor ex Trojanorum principibus, qui dicitur legatos Græcos, Helenæ repetendæ caufa miftos, hofpitio excepiffe, interque illos Ulyfem, habitu licet falfo, a fe tamen cognitum, popularibus fuis non indicaffe; hinc patriam prodidiffe creditus; dum alii nihilominus funt, qui illum hoc crimine liberent, illum folummodo una cum Enea autorem pacis \& reddendæ Helenæ fuifle rati. Ideo habitu quidem lugubri, aft incruentato veftitus confpicitur. Ejus definitio fit:

Parruro Antenor alis nigricantibus; anterioribus coftatis, pallide radiatis; pofticis margine interiore villofis, exteriore luteo-maculatis.

Alce primores fupra nigræ, fubtus fuligineo-nigricantes, utrinqque friis albicantibus pinnarım inftar radiatæ. Alce fecundarix fubdentata; lupra obfcure cinerafcentes, margine exteriore nigro, maculis tribus majoribus, tribusque minoribus confluentibus luteis cincto; fubtus albefcentes, margine interiore pilis nigris longioribus denfe ciliatæ, exteriore margine maculis feptem lutei coloris intra limbum nigrum ornatæ, tribus 
388 Amditamentum Quiedam ad Entomol.

fcilicet majoribus angulatis diftinetis, quatuor minoribus confluentibus.

Abdomen fupra nigrum, maculis quatuor croceis triangularibus linea crocea interfinctis notatum; fubtus albens.

Habitat in Indiis.

Tabulæ 23 figura cuarta exhibet fub $a$ papilionem fulbtus fpectatum; fub $b$ ejusdem partem fuperiorem.

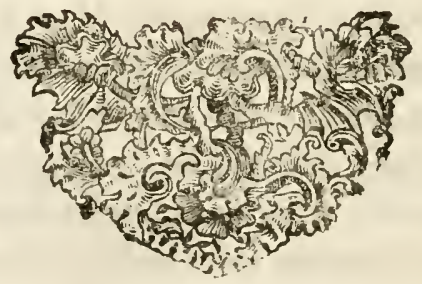




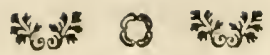

क

\section{VII.}

\section{NICOLAI JOSEPHI JACQUIN}

\author{
EXPLORATIO CHEMICA \\ PL U M B I S P A T O S I F L A V I
}

C A R I N $\quad$ T II I A C I.

\section{§. I.}

Haud incongruum me facturum exiftimo, fi experimenta quadam a me inflituta, ut pateret natura plumbi fjatofi Carinthiaci, tam vere quam eleganter a reverendo Wulfen in hoc volumine defcripti, hic adjiciam, \& publicæ tradam luci. Qui fpecimina lujus plumbi fpatofi Mineralog̣us poffidet, næ ille noverit tenuitatem cryftallorum fummam in plerisque fpeciebus five varietati-

$$
\mathrm{CcC}_{3} \text { bus, }
$$




\section{0 \\ Exploratio Chemica}

bus, fummanque hinc enatam difficultatem earumdem oltinendarum in pondere illo, quod ad experimenta debite inftituenda requireretur. Doleret etiam ille deftruEtionem elegantifimorum fpeciminum. Propterea felegi plumbum fpatofum a reverendo Wulfen numero XVI. defcriptum, quod, utut rarius fit, raritatem tamen fuam egregie compenfat in noftum fcopum abundantia materiei examinandæ. 'At vel fic tandem defecit, ut protrahere tentamina, quo defideraffem, haud licuerit. Novan copiam nactus pergam ad ulteriora, atque alia occafione, fi digna luce videbuntur, proferam.

\section{2.}

Hæc fpecimina non omnia eodem modo compacta funt, nec fingulorum æqualiter compactæ ubique fingulæ partes; inter lamellas enim modo magis minusve cellulofa funt, modo vacuis interftitiis ferme carent in integrum. Fruftulum, quantum invenire potui, compactifimum gravitate fpecifica ad aquam gaudebat uti 19 ad 5 ; . ut igitur ipfo plumbo fit circiter triplo levius. 


\section{\$. 3.}

A menfruis acidis exordiendum effe, docebat ipfa plumbi-ipatofa compages. Hic notabo, quantumvis videri forte fuperflua hæc admonitio poffet, ad omnia experimenta me adhibuiffe menttrua finceriffma, acidum nitri deftillatione repetita a novo nitro abfractum; eodem modo depuratum acidum falis; oleum vitrioli excolor; aquam deftillatam puriffimam; \& fic porro.

Plumbum illud fpatofum cum omnibus acidis, fine adjumento caloris artificialis, validifime effervefcit, fed partem dumtaxat folvitur:' In acidum nitri, plurima aqua debilitatum, injeci fruftulum plumbi fpatofi nucis avellanz volumine. Poft effervefcentiam finitam defufamçue turbidam folutionem remanfit compages cellulola ex cryftallulis lamellatis, tenuifimis, obiter cohrentibus, fubdiaphanis; cujusmodi folitariæ fuper lapide calcareo confpici folent, defcriptæ a reverendo $W$ ulfen numero $V$.

\section{ร. 4 .}




\section{\$. 4.}

Comminui manu \& levioribus mallei ictibus idem novum fratum in parva fruftula, nec in pulverem, ut ne figura lamellata fpatofa periret, \& tamen ut in intimam compagem agere açua fortis poffet. Hujus fpati fumpfi grana II52. Superaffudi debilitatum acidum nitri, \& per plures dies frigide reliqui, movendo interea fxpius materiem tubo vitreo, \& novum adderido, dum motus ceffabat, acidum, donec tandem hoc manifefte fuperabundaret. In ipfa folutione acidum nitri turbatur colore aurantiaco; poft eandem peractam priftina liquido redit limpiditas \& aqueus color; atque tunc fedimenta duo fundum occupant, inferius graviffimum \& flavefcens, fuperius leviffimum \& aurantiacum.

\section{\$. 5 .}

Hoc alterum fedimentum levitate fua, \& quod pulveris minuti effet fub forma, per vafis concufiionem mox per liquidum difpergebatur, dum ab illo motu gravius fratum inferius non afficiebatur; atque poterat fic una 
Plumai spatosi flavi Cakinthiacr. 393

cum liquido defufo a ftrato inferiori facile feparari, \& quiete a liquido ipfo, dein ablutione \& exficcatione fifti folum, \& examinari. Pondus fuit 22 granorum. Verus crocus ferri, qui ope phlogifti per ignen in ferrum retraAtariun nigricans reducebatur.

\section{\$. 6.}

Imprimis examinanda erat folutio. In hujus dimidiam partem immifi fpatum calcareum puriffimun, quod folutum in acido nitri nullas fres relinquit. Aliquid de illo folvebatur, \& nubecula enata in liquido fuit, pondere non determinanda. Alian deinde feci folutionem plumbi fpatofi ad libram dimidiam, quam a fedimentis feparatam faturavi eodem fpato calcareo, atque fic præcipitatum acquifivi unius grani. Hoc cum fluxu nigro fccrias paucas fecit nigras, cujusmodi dare ferrum folet, nullum vero dimifit plumbum. Tix quidquam igitur metallici in illa folutione contineri videtur; nam per calcareum inde priecipitatum fuifet.

Ad alteram dinidiam prime folutionis partem affudi - leum tartari per deliquium ad faturationem. Fulvis ni- 
394

Exploratro Chemica

veus præcipitatus ablutus \& exficcatus pendebat grana 160, ut in tota folutione hæferint grana 320 . Erat terra calcarea, quæ igne ufta per. octo horas dedit optimam \& acrem calcem vivam cum jactura 30 granorum aëris fixi in centumpondio.

\section{§. $\%$.}

Sedimentum gravius ( $(5.5$.$) erat 737$ granorum, \& conftabat ex cryftallis plumbi lamellaribus, nitentibus, nullatenus ab aqua forti arrofis. Unde \& ex $\$$. 3. concludo, fpecimina illa plumbi fpatofi componi ex veris cryftallis lamellaribus, fed terra calcarea martiali obducente, atque interpofita, in unum corpus fpatofum lamellatumque varie effictis; neque hanc calcaream terram intrare cryftallorum fubftantiam. Utrum harunce cryftallorum, jam antea ibidem exiftentium, interftitia a terra calcarea, poftea per aquas fubterraneas iftuc delata, repleta fuerint? aut anne potius alibi enatæ illæ cum terra calcarea fimul iftuc depofitæ fint? non determino.

Ex adnotato etiam pondere adhibiti acidi nitrofi (5. 4.) jacturam 137 granorum in lolutione obfervavi, peten- 
Plumie gpatosi flavi Carinthicici, 395 petendam ex aèris fixi de calcareo fuga tempore effervefcentix, \& ex aliqua abrepti una acidi nitrofi parte. Calculus inftitutus huc accedit. Nam fpecimen plumbi fpatofi pependit $(\$ \cdot 4$.$) grana II 52. Poft folutionem re-$ manferunt plumbi cryfiallifati lamellaris (\$.7.) grana 73.7.

Croci martialis fuerunt $(\$ .5.) \quad \cdots \quad 22 \cdot$

Terræ calcareæ præcipitatæ (\$. 6.) - 320. Jaßturæ per effervefcentian (\$. 7.) - - $\frac{137 .}{1216 .}$

Ut fic acquifita videantur grana 64 in exceffi fupra pondus fpeciminis adhibiti. Sed ipfe hic exceflus po-tius jactura fuit; quidquid enim aëris in folutione extricatum fuit de calcareo, expulfumque in aura, illud omne præcipitato calcareo redditum denuo fuiffe credo ab.oleo tartari ; adeo ut folutionis jactura in calculum adduci hası debuiffet, nifi in quantum fpectaviffet ipfun precife folumque acidum menftruum. Deficiunt fic in acquifitis grana 73. An major aëris fixati copia inlixferit calcareo in ipfo fpecimine, quam ille recuperaverit in præcipitatione? Anne verius ex adverfo minorem quantitatem aëris fixi cruda terra calcarea, quam præcipitata, continuerit, ut fuprapondiun calculi prioris debeatur totum, cum fpiritui nitrolo, tum aquæ hunc de$\operatorname{Ddd} 2$ bili- 
bilitanti, naturaliter in vafe aperto per plures dies evaporatis? An alia caufa jacturæ fucrit? Non aufim decernere. Fateor lubens, vix unçuam me per analyfin ex centumpondio mineræ obtinere pótuiffe centum præcife libras productorum five eductorum; dum hic conjecturæ nihil dare foleo. Chartæ autem, in examine corporum ponderandorum, nihil unquam de his adhæret, quod calculum redderet incertum; nam filtro tunc non utor; fed potius, tædiofo \& lentiflimo labore, fedimenti præcipitati exfpecto perfectam fubfidentiam in vafe inverfe conico; defufo menftruo, repetitis vicibus aqua illud edulco, tandemque fponte in loco calido exficcari fino.

Varietas autem obtinet quoad contentorum proportionem in diverfis fpeciminibus. Sic aliud fpecimen examinavi pondere 15 femunciarum; ex quo acquifivi per præcipitationem 29 drachmas terræ calcareæ.

Hoc plumbo fpatofo, poft fpeciminis folutionem in aqua forti feparatumque crocum martialem refiduo, utar in fubfequis tentaminibus, ut femper hoc intelligam, dum fimpliciter plumbum fpatofum dico:

\$. 8. 


\section{§. 8 .}

Hoc igitur plumbum fpatofum, in quod acidum nitrofum frigide vix agit, nunc cum eodem acido pofui in balneo arenæ in calidiffima digeftione. Brevi plumbum flavefcentem colorem perdidit, inque. album tranfivit; tum etiam partim figuram lamellarem amifit, \& cruftæ concretæ fub forma fundo vafis adhæfit. Poft defufam aquam fortem, dun cruftam cultro rumpere tentabam. hrec illico in loco attactus eleganter cærulefcebat. Diffractæ \& in mortario vitreo tantifper tufæ crufæ novuin acidum nitri affudi, \& reliqui per tres feptimanas in digeftione. Sic totum plumbum in pulveren cinereum mutatum vidi, qui edulcatus exficcatusque, ex 5 centumpondiis plumbi fpatofi adhibitis, ponderavit libr. 285 . Solutio acido-nitrofa omnis oleu tartari laturata dedit præcipitatum album 222 librarum. Alio experimento unum dumtaxat centumpondium eodem modo tractavi per I 4 dies, \& reliquit aqua fortis pulveris plumbei albi folas $4 \mathrm{I}$ libras; ut forte protraeta digeftione plus de plumbo fpatofo folvere potuiffet.'Priccipitatum illud cum fluxu nigro dedit in centumpondio 54 libras plum-

$$
\mathrm{Ddd}_{3} \text { bi. }
$$


bi. Ex hujus plumbi fpatofi centumpondio fimiliter 54 libr. plumbi obtinui; ut igitur acidum nitri videatur folvere totum folidumque plumbum fpatofum, nec extrahere tantum partem metallicam.

\section{\$. 9.}

Acetum, quod in calces plumbi optime agere novimus, nunc adhibitum fuit. In hujus deftillati quatuor drachmis digeffi calidiffime per octiduum centumpondi-. um docimafticum (meum præcife drachmam æquat) plum-. bi fpatofi. Nec inveni mutatum acetum, nec plumbum. Color manfit idem utrisque. Acetum faturatum fuit fale alcalino volatili fine ulla præcipitatione. Ex alio fimili experimento acetum faturatum oleo tartari limpidum manfit, poft tridum demum turbidum, præcipitatumqque demittens' vix ponderandum, quod cum tantilla fluxus nigri portione fufum fcorias fine plumbo exhibuit virides. Fræcipitatum illud leviffimum ad minimum vafculi motum per liquidum difpergebatur. Ex tertio tandem repetito experimento acetum faturabatur folutione hepatis fulphuris, \& obtinebatur lac folphuris albidum. Ergo acetum in plumbum minere vim habere nullam videtur. 


\section{Plumer spatost flavi Carinturacr. 399}

In plumbo fpatofo jactura fuit vix unius libræ. Nitor in hoc idem, eadem cryltallorum forma, idem volumen \& color. :

\section{IO.}

Plumbum fpatofum cum acido microcofmico via hitmida uti cum aceto tractatum digeftumque per i4 dies evafit tantum paulo pallidius, cum jactura 2 librarum in centumpondio. Præcipitatus per falen alcalinum frxum ex acido pulvis albus tantillus nullum plumbuna reddidit.

\section{§. II.}

In acido falis concentratiori fumante \& depuratifimo digeffi per biduum centumpondium plumbi fpatofi. Obtinui folutionem faturatifime \& amœne viridem limpidamque, cum fedimento niveo fquamofo \& nitente. Per lentam cucurbitulæ inclinationem feparavi folutionem; \& ad edulcandum fedimentum huic affudi aquam frigidam plurimam. Inexfpectato \& clegantifimo fpectaculo tota açua mox erafit faturate \& fpeciofe cxrulea 
adinftar carulei Berolinenfis. Tingebatir fic aqua a folutione viridi, fedimento adhucdum ilisnifta. Defufa hac tinctura, aliain novam aquam ledimento addidi; - quæ etiam facta cærulea fuit, fed dilutius. Perrexi fic edulcare, donec ultina affufa aqua manfit excolor. Tripla aqua dilui primam folutionem viridem, inde non mutatam, fed a plure affufa momento faturatiffime cærulean. Hæ folutiones cutim ferme indelebili macula tingunt fordide virente aut cærulea.

Sedimentum magis evaferat fquamofum quam ipfum adhibitum plumbuin fpatofum, minoribus fquamis lalis fedativi fimillimum, magisque quam antea cohæfit. Ponderavit libras 60, deditque cum fluxu nigro libras plumbi 38 ; ut itaque intraverint in acidum falis libræ 40 fpati, in quibus latuerunt proportione inæquali libræ 16 plumbi. Uti mox patebit, inutiliffima fuit hæc ponderum obfervatio.

\section{I2.}

Admiratus quantitatem aquæ tinctæ a pauca copía tincturæ viridis, fummam hujus divifibilitatem, oculo 
Plumbi spatosi flavi Carinthici. for confpicuam, metiri volui. Novam fimilem fulutionem viridem paravi cum drachmis duabus acidi falis. Non potui delere colorem cæruleum fic, ut plane excolor mifcela evaderet, nifi pofteaquam aquie drachmas Ic9056 addidiffem. Ubi vero ex $\$ .20$ elucefcet, de materie colorante hæfiffe in hac folutione folas $I_{3^{\frac{1}{2}}}$ libras centumpondii docimaftici mei, unam drachman five grana 60 xquantis, adeoque fola fex grana, ftupendæ divifionis calculus exfurget, dum unicum granum mate riei colorantis tingat $807822 \frac{2}{y}$ grana aque.

\section{§. I3.}

Cupidus obtinendæ tincturæ viridis abundantius, ut examinarem, decem centumpondia cum æciuali pondere acidi lalis calidifime in cucurbitula digeffi per tres horas; evafit plus turbida, cærulea, nec viridis. Addidi hinc proximo die alia decem acidi ejusdem centumpondia. Perfitit color cæruleus; qui vero poft novam digeftionem evafit faturatiffune viridis.

Ut citius operarer, poft defufam tincturam viridem, edulcavi fedimentum aqua calida, \& digeftioni expofui Ece per 
per horam. Hanc calidam cæruleam tincturam (a) in vafculum feorfim inmifi, uti in primo experimento etiam feceram. Per novam affufam digeftamque calidam obtinui alteram tincturam (b) crerulefcentem, etiam feorfim fervatam. Sic perrexi tertia \& quarta vice, quando ultima affufa edulcans aqua excolor perfitit. Singularia phænomena hæ tincturæ exhibuerunt.

Scilicet ex tinctura (a) ad primum illico vel minimum refrigerium, elegantiffimo fpectaculo, fponte excutiebantur fquamæ parvulæ, micantes, nitidiffunæ, argentei metallici coloris, leviffimæ; quæ partim ad fundum vafis fecedebant, ibiden veluti natantes, partim parietibus internis vafis accrefcebant cruft tenuifimæ \& continuæ' fub forma, ut redderetur hinc vitrum fpeculo fimile. Digitos etiam pari colore inquinabant. Uum liquidum cum fquamtilis movetur, eft tinfura crorulea ex argenteo micans.

Tinctura (b) nullam refrigerio præbuit funilem fquamam, fed dimifit cryttallos niveas, aciculares, dulcifimas, tenerrimas, fæpe capillares; quales etiam excuffæe ex fubrequis tincturis, fuerunt; at tandem ultra nullæ. 
Plumar spatosi flavi Carinthica. 403

Et cryftalli hæ, \& Iquamæ illæ, ope filtri feparari a liquido poftunt, exficcarique. Squamularum pondus erat 20 librarum. $\mathrm{Ab}$ aqua ebulliente iterum fufcipiuntur, ex frigefacts denuo excutiendæ utræque. Primo in cafu una cum aqua per filtrum chartaceum tranfeunt. A feceffu autem earundem color cæruleus in tincturis nullatenus afficiebatur; neçue igitur quidquam contribuunt ad hunc colorem.

\section{\$. I4.}

Plumbo fratofo edulcato prioris paragraphi affudi norum falis acidum, \& per quatuor feptimanas digeffi. Nulla mutatio fenfibilis fequebatur, nulla coloris mutatio. Poft defufum acidum edulcavi multa aqua fpatum; ad ebullitionem usque digefi per horam; calidifimamque aquan defudi, quæ refrigerio mox numerofas cryftallos aciculares depofuit, prioribus fimiles; fed nullus color cæruleus, nullæ hic fquamulæ micantes. Sic alternis vicibus ufus acido falis \& aqua edulcante, tandem omne reliquum plumbum fpatofum in ittiusmodi cryftallos mutavi, ut ne veftigi'm ejus $f$ pereffet, nec fæcum ullarum. Hinc lequitur, plumbum fratofum effe in acido falis toEee 2 tum 


\section{$\angle 04$

tum quantum folubile; \& vel ipfam etiam mineram plumbi tpatof tpeciminis achibiti, fi folum excipis crocum martialem $(\$ .5$.$) , nam terra illa calcarea, externe plum-$ bo adhærens fpatofo, non minus ab acido falis quam a nitrofo folvi poteft.

Sunt autem illæ cryftalli verus faturnus corneus omni dote, \& debentur partim adhibito acido falis. Hoc operofe agit in plumbum fpatofum, calore protracto adjutum, \& duntaxat fucceffive. Idem tamen acidum, antea jam adhibitun, poft extractum per aqquam faturnum corneum, denuo agere in refidum plumbum fpatofum poteft. Videtur facere plunbum corneum, nec folvere poffe, faltem non copia notabili; quod folvit aqua fere ebulliens, frigidior iterum excutit.

Tæcliola operatione, pro otio interrupte per tres menfes continuata, ut omne plumbum fpatofum in faturnum corneum mutarem, dum etiam omnes aquas edulcationis plurium librarum, in quibus multus faturnus corneus folutus latebat, evaporatione eo deducerem, ut hunc omnem dimitterent, priori faturno plane fimilem, obtinui tandem ex ante memoratis decem plumbi fpatofi centum- 
Plumbi spatosi flavi Carintirici, 405 pondiis libras 974 faturni cornei; quibus fi addantur libræ - - 22 fquamularum,

- - - 133 materiei colorantis \$. 20.

habeo - - II29, adeoque I29 libras "fuprapondii, quod oportet effe acidum falis faturni cornei.

Plumbum hocce fpatofum, docimaftice examinatum, continuit plumbi libras 59; faturnus hicce corneus autem ejusdem libras 6r; five decem centumpondia plumbi fpatofi continent 590 libras plumbi, eademque in faturnum corneum mutata 595 libras; quæ quinque librarum differentia in fimilibus experimentis tanquam nulla confideranda eft.

\section{S. I5.}

Glelsæ plumbi examinatæ fpatofa lamellata compages, (propterea quam maxime, quod nec fquamulæ illæ (\$. I3. a) memoratæ, néc materies illa tingens, quun poft harunce per acidum falis extractionem lamellæ non defruantur, videantur ad,1trucfuram lamellarem quiddam contribuere, debeturne calci plumbex foli? an vero terræ calcareæ vel gypfex, intime cum hac calce unitæ? An Eee 3 non 


\section{Exploratio Chemica}

non defectus ponderis in eductis tale quid innuit? nam ex centumpondio plumbi fpatofi obtinui

$$
\begin{aligned}
& \text { plunbi libras }-\quad 59 . \\
& \text { fquamularum }-\quad 2 . \\
& \text { materiei colorantis }-\frac{13^{\frac{x}{2}} .}{74^{\frac{1}{2}} \text { ut }} \text { fit }
\end{aligned}
$$

defectus $25 \frac{1}{2}$ librarum; quarum pars aliqua omnino tribuenda quidem videtur augmento ponderis folito plumbi calciformis fupra ipfum plumbum metallicum, fed augmentun hic foret nimium. At vero poteritne ftare cum ftabilita acidi falis affinitate, tam diverfa cum plumbo cumque terris calcareis, æquabiliffima illa folutio plumbi 'fpatofi in hoc acido fine ulla precipitatione? Ut certius in rem inquirerem, feqquens experimentum inftitui.

In parva fartagine ferrea nitidiffima ad ebullitionem deduxi aquam deftillatam. Huic tunc injeci faturni cornei prioris paragraphi portionem aliquam. Mox in fundo fartaginis cruftula enata fuit fordentis plumbei coloris; qua per laminam ferream abrafa, nova nafcebatur. Sic perrexi, donec fundus fartaginis nitidus perltitit. Operatio hæc obfolvebatur intra pauca horæ minuta. In liquidum defufum, per fe limpidiflimum, inftillavi oleum 
Plumbi spatost flavi Carinthict. 40 ? vitrioli; nec ulla præcipitatio vel minima vila fuit. Plumbum, per ferrum fartaginis excuflum ex faturno corneo præceps dabatur. Terra autem calcarea, fi una adfuiffet in flumbo corneo, per ferrum præcipitari ex acido falis non potuifet, fed manfiffet in liquore foluta; præcipitanda inde poftea forma gypfi per vitriolicum acidum, propter hujus majorem affinitatem cum terris calcareis præ acido falis, \& propter majorem alteram cum iisdem terris quam cum ferro. Chemice igitur conjicio, atque etiam, fi malis, concludo, terram calcaream in faturno corneo non contineri; nec adeo contineri magis in ipfo plumbo fpatofo, toto quanto (materie colorante excepta) in corneum mutato. Nec gypfum ineffe credo, quod prodere fe in aliquo ex prioribus experimentis debuiffet.

Præcipitatum iftud fordide plumbeum, edulcatum ficcatumque, erat ipfum plumbum forma metallica purifimum in minimis granulis, qux in cochleari ferreo candente, fine additamento ullo mox confuebant in globulum plumbs nitentem; ut adeo phlogifton de fartaginis foluto ferro reduserit calcem plumbi ex faturno corneo excufan.

Repe- 
Repetii idem experimentum cum duobus faturni cornei centumpondiis, ut, quid fieret, accuratius obfervarem. Injectus in aquam ebullientem faturnus petiit medium Sartaginis fundum; ibidem collectus, poft duo jam minuta difparuit totus. Poft aliorum quinque minutorum protractam tamen ebullitionem, liquidum femper limpidum clefudi, nunc omni plumbo privatım. Erat fartago, quo usque aqua adfcenderat, obducta crufta fungofa plumbea, fordentis quidem coloris, quo plumbum aëri diu expofitum!confpici fuevit, fed micis plumbi micantibus nitidisque referta; facillime a fartagine abradenda. Colleftam omnem cruftam injeci in cochlear ferreum candens, fuperaddita, ne qua obtingeret plumbi jactura, terebinthina cocta. Mox obtinui plumbi regulum, 122 libras ponderantem; quo prioris examinis docimaftici. docebar certitudinem.

Idem iterum tentamen inftitui in vafe cupreo; produxique ebullitionem aquæ cum faturno corneo per folidam horam. Manfit ille fub forma pulveris albi in fundo vafis. Aqua excolor perftitit; quæ explorata oleo tartari, fpiritu falis ammoniaci, acido vitrioli, aliisque, meram fine omni cuprea labe fufcepta fe probavit folutio- 
Plumi spatusi flavi Carintuiaci. 409 nem faturni cornei. Quæ quidem res in præconcepta acidi falis affinitate curi cupro \& plumbo exfpectationem measn fefellit.

Alio modo utrumque proceffum adornavi in vafis vitreis cun lamina ferri \& cupri. Effectus utrobique idem. Ferri lamina vellere denfo \& bullato plumbi obducebatur. Cuprea lamina perftitit nitida, \& faturnus corneus, qui hic, per fex horarum ebullitionem, difparuerat totus, ex aqua refrigerata fub folitis fuis fpiculis iterum excidit.

\section{\$. 16.}

Squamularum (S. I3. a.) tantilla fuit copia, ut debitum examen haud admitteret. In patellam argillaceam candentem injectæ, fub fumi albi fpecie totæ quantæ avolarunt. Deftillavi folas ex retortula ad hujus usque ignitionem; fublimabantur, adhæferuntque ejusdem collo ceu pulvis nireus, dum haud notabile veftigium cruftæ faturni cornei fuf in fundo retortulæ perflitit. Etiam hoc fublimatum niveum ex patella candente mox in fumum album difpergebatur. Nullus odor alliaceus arle- 
nicalis, nullus fulphureus percipiebatur; feriebat tamen ille nares modico falis acido. Sapor fublimato, tum \& ipfis fquamulis, erat dulcis, dein acer $\&$ pungens. Opinor, efre fpeciem fingularem faturni cornei, valde volatilem. Unde autem nitor in fquamulis fpeciofus ille, metallicus argenteus, vel potius mercurialis, conftans jam per quatuor menfes, cum in folutioni cæruleæ innatantibus, tum in exficcatis, ortum trahat, fateor, me ignorare.

\section{\$. I\%.}

Enarrabo nunc experimenta fasta cum folutione viridi ( $($. II.) a. In hanc inftillavi fpiritum falis ammoniaci, quæ fiebat momento cyanea. In aliam ob aquam debilitantem factam ex viridi cæruleam, fimiliter eundem fpiritum fucceffive ac guttatim immifi. Color in principio conftabat; dein in virorem inclinans; poftea turbide cærulelcens; tandem poft depofitum fedimentum albidum limpide cæruleus; quiete autem poft bidum aqueus; nec ad affufum novum fpiritum alcalinum de novo cærulefcens. Ut cuprum abeffe videatur.

b. Idem 
Pluaid spatosi flavi Carinthicaci. 4i

b. Idem factum cum oleo tartari fuit. Solutio viridis hinc mox evafit cyanea; debilitata cærulea modo manfit talis, modo amœne viridem colorem affumfit. Ad faturationem perducta pulverem album præcipitem dedit; paulatim magis excolor, cærulefcens tamen adhuc per duas feptimanas.

Præcipitatum pulverem ex $a \& b$, docimaftice exploratum, utrum plumbi quid contineret, ne vel veltigium ejusdem habere, didici. Nec potui ullo alio tentamine detegere plumbum in folutione viridi, modo ne acidi falis copia nimia adhibita fuerit; ut credibile fit, acidum falis, faturatum materie illa colorante, refpuere unionem plumbi. Fluxum autem nigrum a præcipitatis illis mutatum inveni in fcorias atras cumpactas nitidasque, quales ferrum dare novimus.

\section{\$. 18.}

Infillavi in viridem inque cæruleam folutionem acidum nitri, nec ullam in principio obfervavi mutationem; ad majorem autem inftillati acidi hujus copiam, omnis in utraque color momento evanuit; dum viridis illa flaFff 2 vefce- 
vefcebat inftar aquæ regiæ concentratæ vulgaris, cærulea vero fiebat plane excolor, fine precipitatione ulla. A fale alcalino volatili, nunc affufo, in ipfa effervefcentiæ fpuma cæruleus color regenerabatur; qui poft punEum faturationis rediit in integrum, fed indies fponte debilior, tandem evanidus. Cum alcalino fixo fale idem fere phænomenon fpectabatur. - Unde elucefcit, acidum nitrofum impedire materiei colorantis effectum, nec tamen omnino illam deftruere. Huc facit fequens experimentum.

Centum libras plumbi fpatofi digeffi per quatuordecin dies in aqua regia, facta ex æqualibus acidorum nitri - \& falis communis portionibus. Libræ 40 folutæ fuerunt; nam reliqua pars plumbi fpatof, in pulverem album erofi, librarum 60 erat. Solutio colorem aquæ regiæ fervavit, etiam. debilitata per aquam. Neque hic ullæ fquamulæ, nec prodiere cryftalli aciculares. Solutio, faturata fale alcalino fixo in falem neutrum, evafit viridula, dimi- fitque 30 libras præcipitati albi, veri magifterii plumbi, ex quo eduxi hujus libras I7. Decem librarum jactura videtur partim pertinere ad illam, de qua $\$$. \%. egi.

- Præcipitatum pulverem, aqua probe edulcatum, digeffi 
Plumbi spatost flavi Carintmiaci. 4I 3 cum acido falis, qquod inde colore viridi tingebatur. Ergo materies colorans in aquam regiam intravit, fed ob acidi nitrofi præfentiam fine indicio fui. Fuit etiam pro parte inde præcipitata per falem lixiviofum, quia hoc præcipitato tingebatur acidum falis. \&c.

\section{§. 19.}

a. Immifi in folutionem debilitatam cæruleam laminam cupri, \& frigide reliqui. Pont decimum denique diem pulvis ad fundum delabebatur cæruleus, \& folutio ex fubcyaneo in cupri folutionem magis cærulean (a cupro foluto) vergebat, talisque manfit limpida. Per filtrum chartåceum feparavi a folutione pulverem, quem clum aqua frigida edulcare volebam, in filtro adhuc hærentem, mox in eadem folutam per filtrum tranfire vidi, tincturamque conftituere cæruleam limpidam, altero die excolorem cum præcipitato albo valde pauco nec explorando.

b. Idem feci cum immerfa lanina ferri. Color liquidi, brevi profundiffime \& $\&$ eleganter cyaneus, a ferro fufcepto intendi augerique quam maxime videbatur, per-

ftans 
ftans fic fine precipitatione per oftiduum. Sed nunc liquidum nigrefcebat turbide, 'tandem fuligineum, nec pellucidum; aqua autem quam plurima dilutum, pellucidifimum \& fuligineo - badium, poft.aliquot demum dies primum dans præcipitatum fuligineum, dum ipfum evafit plane excolor. Nulla ex hifce folutionibus, five ab affufo oleo tartari, five a fupcrfaturante affufo falis acido, cæruleum aut viridem colorem recuperavit. Ex liquuore nunc excolore per falem lixiviofum excutiebatur præcipitatum martiale. Primi vero illius præcipitati flocculenti fuliginei, cum oleo preffo ufulati in pulverem nigricantem, nulla particula fuit a magnete attractilis. Pulveri carbonum immixtum in crucibulo tecto detinui in ralido candefcentiæ-igne per tres horas; nec potuit inde extrahere magnes vel leviffimum ferri.veftigium.

In alio experimento per immiffum ferrum folutio intra paucas horas atramenti adinftar evafit nigra; ab ingenti aquæ diluentis copia virefcens leviter \& fordide. Reliqua uti ante.

c. Tertio repetii experimentum fruftulo zinci. Híc effervefcentia mox excitabatur valida, quæ cum cupro \& 
Plumbi spatosi flavi Carintilaci. 4is

ferro vix fuerat ad oculum obfervabilis. Solutionis color nigro-fufcus. Ex eadem poft paucos dies excutiebatur præcipitatum fufcum, leve, voluminis in liquido hærens magni, exficcatum vero exigui; dum ipfa excolor evafit, qualis effe folutio zinci folet. Præcipitatum ab acido falis illico folvebatur in limpidam tincturam badiam. Uftulatum cum oleo preffo nullum ferri fignum magnete applicato exhibuit; nec cum pulveré carbonum.

\section{\$. 20 .}

Deftillavi folutionem viridem ex retorta vitrea; inque excipulum tranfivit acidum falis excolor fere \& purum. Caput mortuum erat crufta, terræ fimilis cum pauco virore cinerafcente, cujus' maxima pars occupabat fundum retortæ, hinc tenuiffima \& vix abrafilis adfcenderat in collum usque, ut videatur, aut per fe, aut ab abfracto falis acido, fuife tantifper volatilis. Saporis ex-pers. Ponderabat ex folutione decem centumpondiorum plumbi fpatofi libras 135 . Ut hujus materiei notabiliorem poffiderem copiam, quinquies experimentum repetii; in quibus quantitas capitis mortui haud abludebat a priori ; in uno tamen experimento ex decem centumpon- 


\section{Exploratio Chemica}

diis duo centumpondia capitis mortui accepi. Intererat omnino, hanc materiem noffe; en tentamina! quæ mex exfpectationi neutiquam fecerunt fatis; at plura inftituere vetuit ipfe materiei defectus.

\section{§. 2 I.}

An hæc fit materies colorans acidum falis? A priori fic fulpicari poteram. Digeffi per paucas horas cum acido falis; folvelbatur in illo tota, \& recuperabam priftinam folutionem virentem, onnibus fuis proprietatibus donatam; quo folo experimento omne dubium tollebatur. At elegans hæc materies, dum ficca, eft cinerea \& fordida; dum foluta in acido falis, rodentiffima; hine picturx inepta. Ut redderem idoneam, plura incaftum tentavi; una tandem methodus fucceffit. Abftraxi acidum falis in vafe aperto; vidi, illam, ficcitati proximam, effe fpeciofe cyaneam. Interrupi evaporationem, \& affudi aquanı calidam, in qua duntaxat exigua ejusdem pars nuinc folvebatur, dum in fundo manebat reliqua. Hanc edulcavi fic, ut ne vel veftigium acidi falis ultra adhæreret; atque obtinui pigmentum pulcherrimum, conftans, cum aqua in pultem tenerrimam mifcibile, cya. 
Plumbi spatosi flavi Carintiuiaci, 4I? neum, cæruleo Berolinenfi quoad colorem æmulum; femel magis caruleum ad ultramarinum accedens.

\section{\$. 22.}

Cum fluxu nigro tentavi; nec plumbum extrahere valui.

Cum Boracis calcinati uno centumpondio libræ quatuor ejusdem fulæ, dederunt vitrum ex fufco topazinum; fex libræ magis fufcum; fedecim libræ atrum.

Totidem libræ fufæ cum vitro albo, hoc plane non tinxerunt. Ergo nihil hic Cobalti.

Ex uftulata cum oleo preffo magnes nihil attraxit; nec magis ex mixta cum pulvere carbonum, \& candefacta per tres horas.

Per horam ufulata in vafculo argillaceo, vix aliquid de pondere amifit, fed paulo magis flavefcebat; iterum cinerea in igne candefcentiæ decem horarum, quando absque omni fluxu firmiter adhæfit patellæ, per tutam ejus concavitatem ferme diffula, nec tamen ullatenus mutati.

$$
\text { Ggg Re- }
$$


Retortæ venter, in defillatione paragraphi precedentis, hinc incle maculas cyaneas cærulcasque monfirabat; in media autem colli parte cruftam tenuifimam flavefcentem, quam pro fulphure adipectu habuifem; led non ardebat admota flamma, erat faporis acidi, \& in libero aëre fponte volatilis. Retorta, fubere occlufa, fervat fatum; per collum autem apertun fi detur aëri acceffus, maculæ illæ cæruleæ fparguntur per totam, excepto ipfo fundo, ubi caput mortuum hæret, ut eleganter hinc picta variegataque appareat.

\section{\$. 23 .}

Ex hoc phænomeno in animnm induxi tentare plumbum fpatofum materiem ́que colorantem fale ammoniaco. Illius \& falis ammoniaci partes æquales fublimavi in curcubitula vitrea, tandem? forti igne. Accepi fpiritum alcalinum volatilem paucum; flores falis ammoniaci niveos, inferne tantisper \& obfolete fulphurei coloris, cum mediocri valde macula cærulefcente. Reliqui apertam cucurbitulam per tres feptimanas; \& indies magis cærulefcebant flores, mediocriter tamen femper. Diffracto vafe, inveni in fundo maffam ex faturno corneo, partim fufo, 
Plumbi spatosi flati Carinthiaci. 4i9 partim adhuc aciculari \& dulci. Martem in floribus detegere non yotui.

Sic tractata cum fale ammoniaco materies colorans, vix caput mortuum reliquit, fed fublimata dedit flores ammoniacales magis cæruleos \& verficolores; qui poft triduum in vafe aperto nec diffracto fervati, obtulere fpeहtaculum floribus falis ammoniaci antimonialibus haud inelegantius, variegati fpeciofiffime ex cyaneo, albo, fufco, flavefcente, cinereo; dum fundus cucurbitæ magis flavefcebat cum maculis viridibus.

\section{§. 24 .}

Tandem etiam actioni acidi vitriolici plumbum fpatofum fubjeci. Hujus fex centumpondia cum I 6 centumpondiis dicti acidi concentratiffini digeffi per tres feptimanas in balneo arenæ calidiffmo. Solutio amœne virebat; \& guttæ cæruleæ confpiciebantur collo cucurbitæ adhærentes profunde :rruleæ, deplucntes volumine auEto in folutionem, \& continuo renatæ novæ. Viridis illa: folutio per aquam debilitantem mutatur in faturatam $\mathrm{cx}$ ruleam, Berolinenfi fimillimam. Hæc poft diei quietem:

$$
\mathrm{Ggg}_{2} \text { in. }
$$


in duo ftrata abiit; in fuperius plane excolor, atque hoc tenue; inque inferius, quod altiffimum, in colore conftans. Concuffione ftrata iterum fuere mixta, quiete denuo feparata, repetito per plures dies experimento. Solutio debilitata plure aqua tincturam exhibuit fpeciofe cyaneam, quam comparatam, a folutione faturata æris in fpiritu falis ammoniaci, nullo potui momento diltinguere.

Plumbum fpatofum refiduum, niveum \& pulverulentum factum, ponderavit 560 libras, ut folæ 40 libræ intraverint acidum.

\section{\$. 25 .}

Ad fpiritum falis ammoniaci concentratifimum, fucceffive affufum, eodem gradu fucceffivo evanuit omnis color in priore folutione, tam viridi, quam cærulea; ut fuerint inftar aquæ excolores. Ad fuperabundantem autem affufum fpiritum alcalinum rediit color cæruleus, fed inulto debilior, minusque elegans.

Cum oleo tartari mox folutio evafit etiam excolor; cum eodem fuperfaturante primo fordide \& turbide vi- 
Pluimi spatost flavi Carintirict. 421

rens; polt aliquot horas dein iterum cærulea cum pauco fedimento albido; \& modo fic faturate cærulea, ut pelluciditate careret, quan recuperabat a plurima addita aqua, tamen femper eleganter cærulea, nec nunc ultra turbanda aut mutanda nec ab affufo excedente acido vitriolico, nec a fale lixiviofo; modo autem tantummodo cærulefcens, in qua reliqua memorata tentamina fallebant.

Solutiọ æque viridis atque cyanea ab affufo acido nitrofo reddebatur excolor, a fuperfaturante addito fale alcalino volatili iterum cærulea.

Solutionem paragraphi prioris deftillavi in balneo arenæ ad candefcentiam retortæ. Accuifivi oleum vitrioli excolor in excipulo; in retortæ fundo caput mortuum tantifper falfum, terreæ formæ, \& ex cinereo fldvefcens. .Reliqua pars retortæ manfit nitida. Digeftum caput hocce mortum cum acido falis, in eodem folvebatur, \& tinfturam faciebat viridem, cum aqua cæruleam, \&c.

\section{\$. 26.}

Eandem paragraphi 23 folutionem repetii altera \& tertia vice; atque hic illem obtinui cyaneam, nec viri-

$$
\mathrm{Ggg} 3
$$

dem; 


\section{Exploratio Chemica}

dem; quæ ad æqualem aquæ admiftam copiam fatim fiebat excolor; iterum cærulea, fed multo debilius, -ab affufo Superabundante fale alcalino volatili, nec aqua nunc evane ${ }^{c}$ cens plure admixta.

Charta bibula, tolutioni immerfa, in atmofphæra perdebat, quem cyaneum recuperabat calefacta colorem, ex principio putem prioris experimenti, dum aqua trahitur ab oleo vitrioli in chartain, hinc abigenda calore.

Patet, hæc cum acido vitriolico eodem inftituta tentamina non congruere omnia. In rationem non indagavi, ob defectum plumbi fpatofi.

\section{\$. $2 \%$}

Plumbum fpatofum cum duplo boracis calcinati fufun dedit vitrum æquabile opacum cinereum, fine ullo reducto plumbo.

Idem plumbum, deftillationi fubmiffum in balneo arenæ, ut canderet retortula per fex horas, perdidit in centumpondio folas duas libras, merum vaporem aquolum, forte adhucdum adhærentem ab edulcatione. Diffliit interea in fruftula, cæterum non mutatum. Nullum 
Plumbi spatosi flavi Carintuiaci. 423 veftigium adfuit fublimati aut fulphuris, aut arfenici. Sed contra horuncce prefentiam in corpore minerali fimplex deftillatio nihil evincit. At vero an in corpore, toto quanto in acido falis folubili, fine ullo vel minimo fedimento, fulphur latere potuit? Fudi etiam plumbum $f \mathrm{pa}$ tofum cum puriffimo fale tartari; maftam, in aqua folutam, præcipitavi aceto. Nullum obfervavi fulphuris hepar; præcipitatum fuit niveum.

Plumbi fpatofi centumpondium, modo deftillatum, nunc in vafculo ufulatorio uftulavi per duas horas igne forti ; quo carneum fere colorem fuit adeptum, perdiditque iterum duas libras, nitens femper. Per feptem horas denuo uftulatum evafit albidius; $\&$ alia duarum librarum jactura fuit. Urfi calorem; fed femivitrificatum, \& vafculum una fecum in fluxum incipientem deduxife, dolui.

Repetii tentamina quædam cum aliis plumbi tpatof flavi varietatibus, tum etiam cum eodem amorpho granulari; quæ convenere omnia, imprimis refpectu materiei colorantis, cum enarratis. 


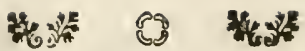

\section{$\begin{array}{llllllll}\mathrm{C} & \mathrm{O} & \mathrm{N} & \mathrm{T} & \mathrm{E} & \mathrm{N} & \mathrm{T} & \mathrm{A}\end{array}$}

IN HOC

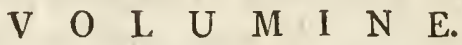

\begin{abstract}
IV. Crambe Tataria - $\quad-\quad-\quad-\quad$ - 274
V. Obfervationes botanicx - - - - 292

VI. Additamenta quædam ad Entomologiam - 330
\end{abstract}

VII. Exploratio chemica plumbi fpatofi flavi Carinthiaci - - - - - - 389

Typis Matthiæ Andreæ Schmidt, Univerfitatis Typographi, 


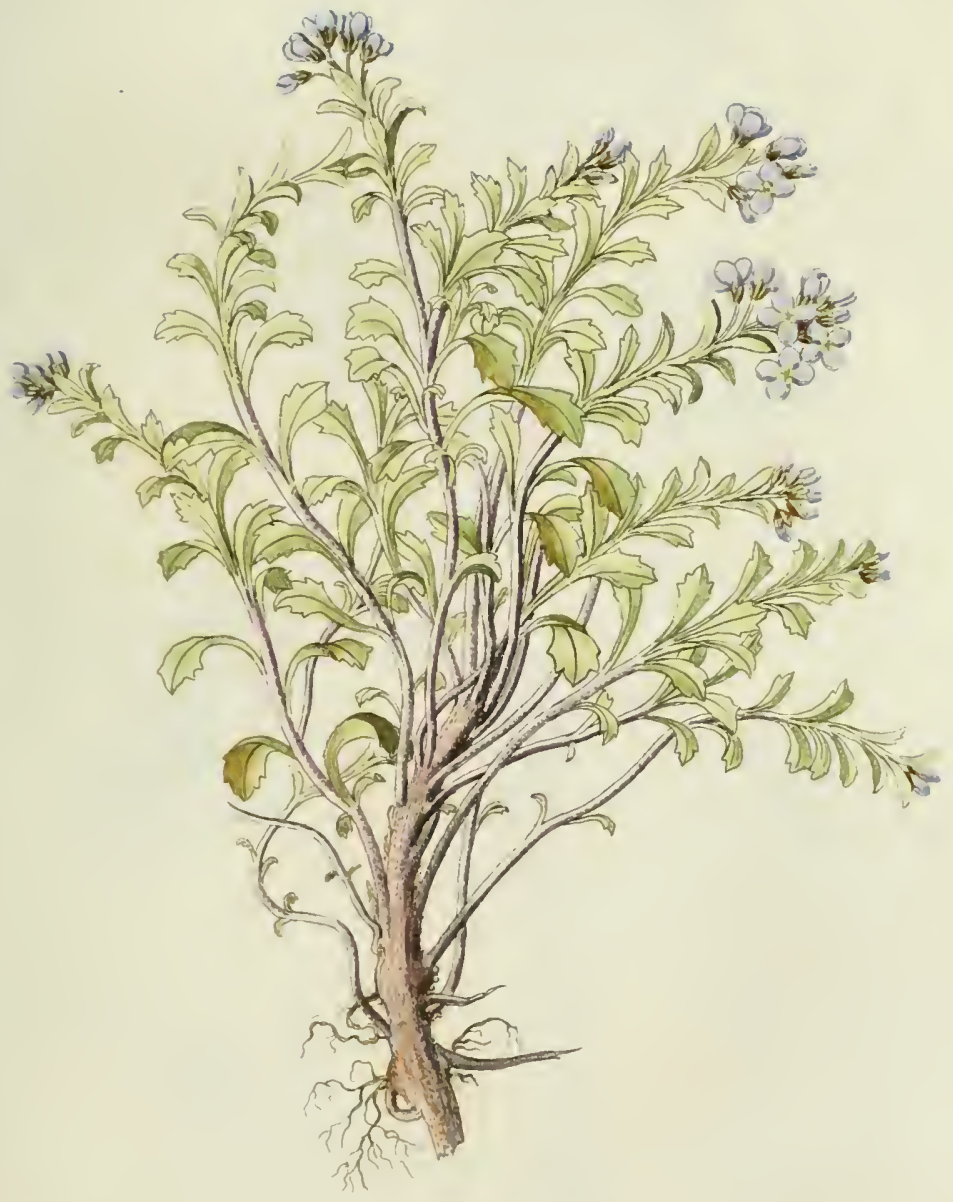

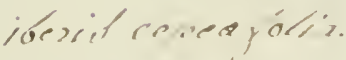





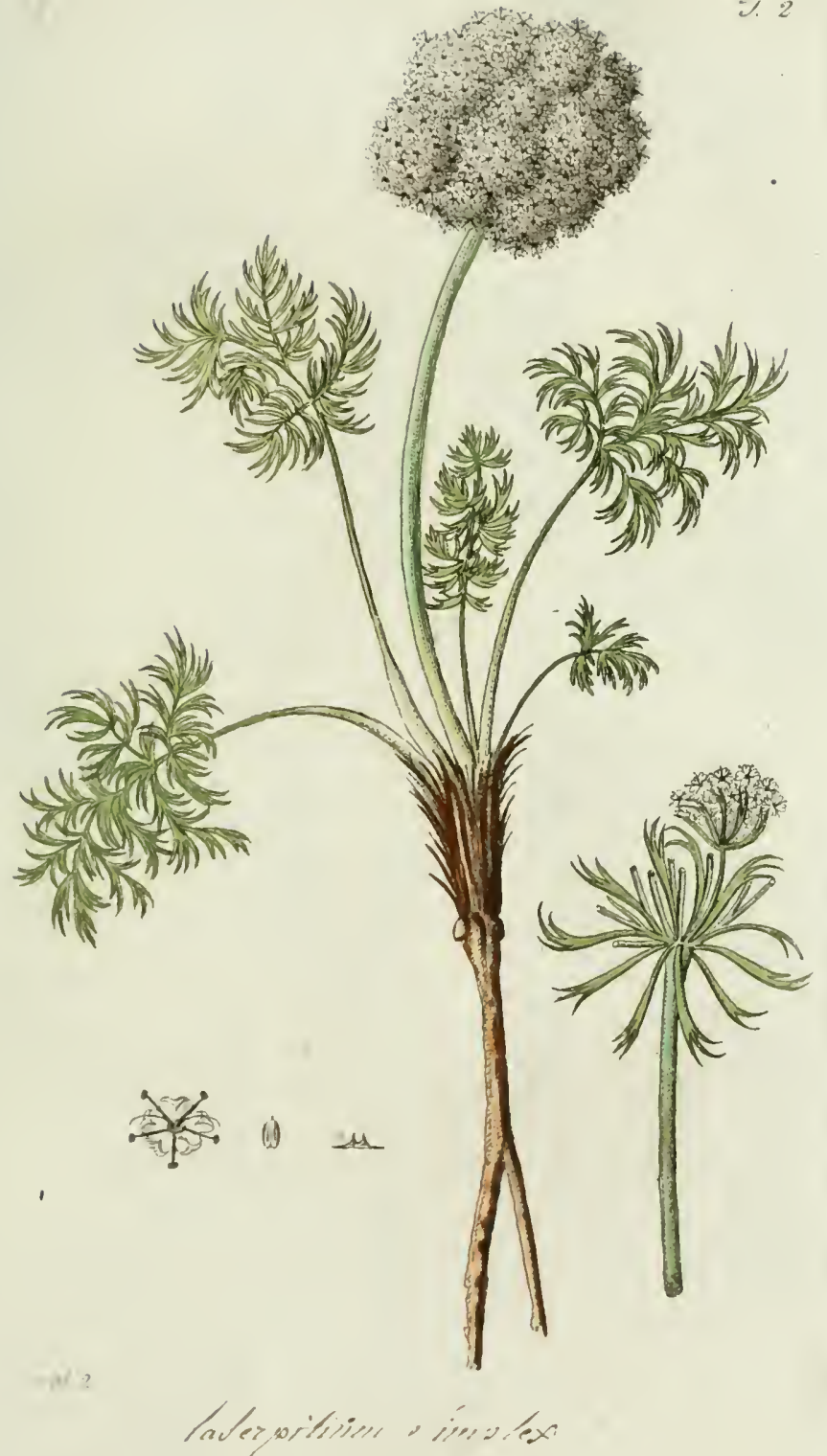



. 


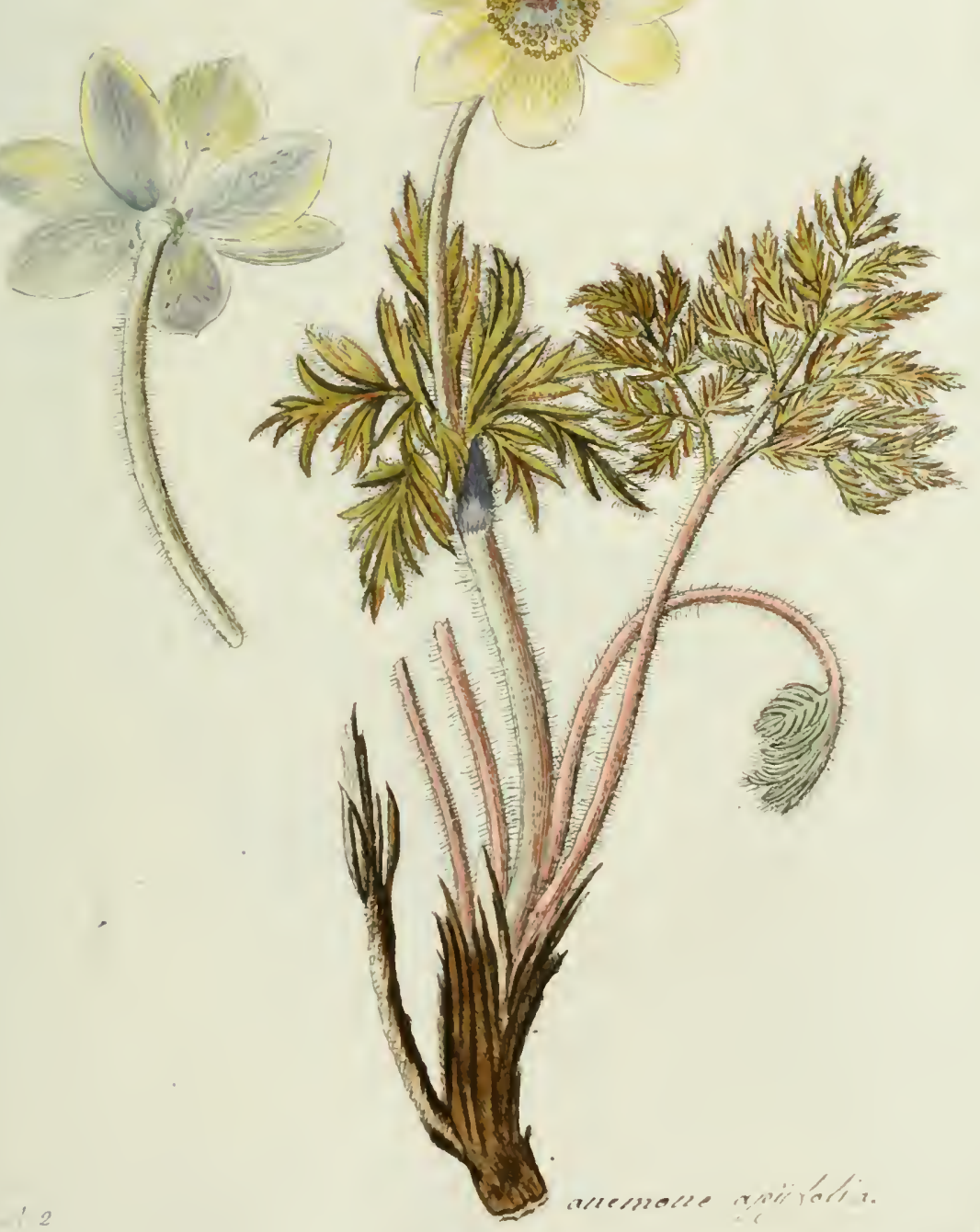



erevingar a

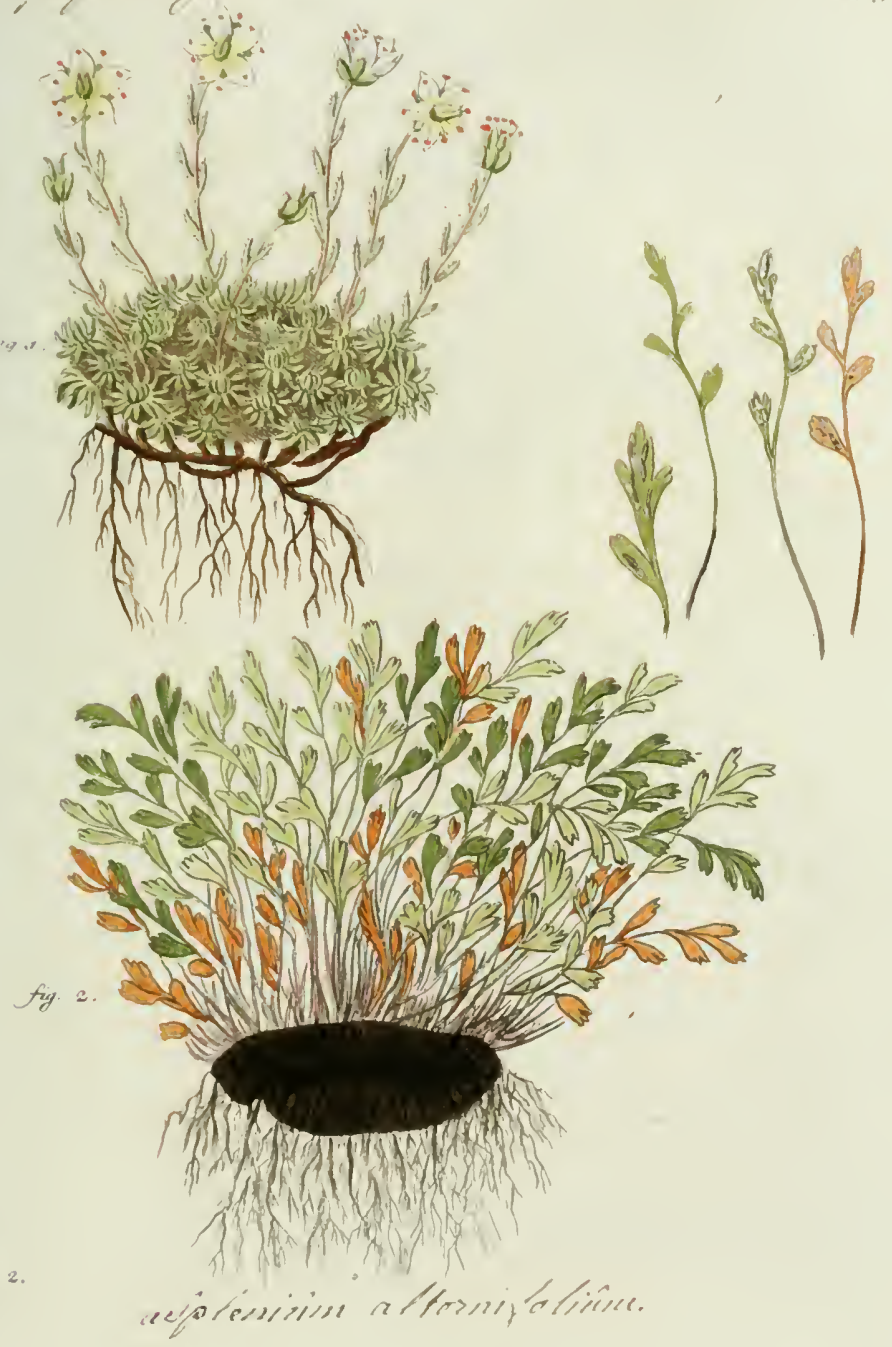





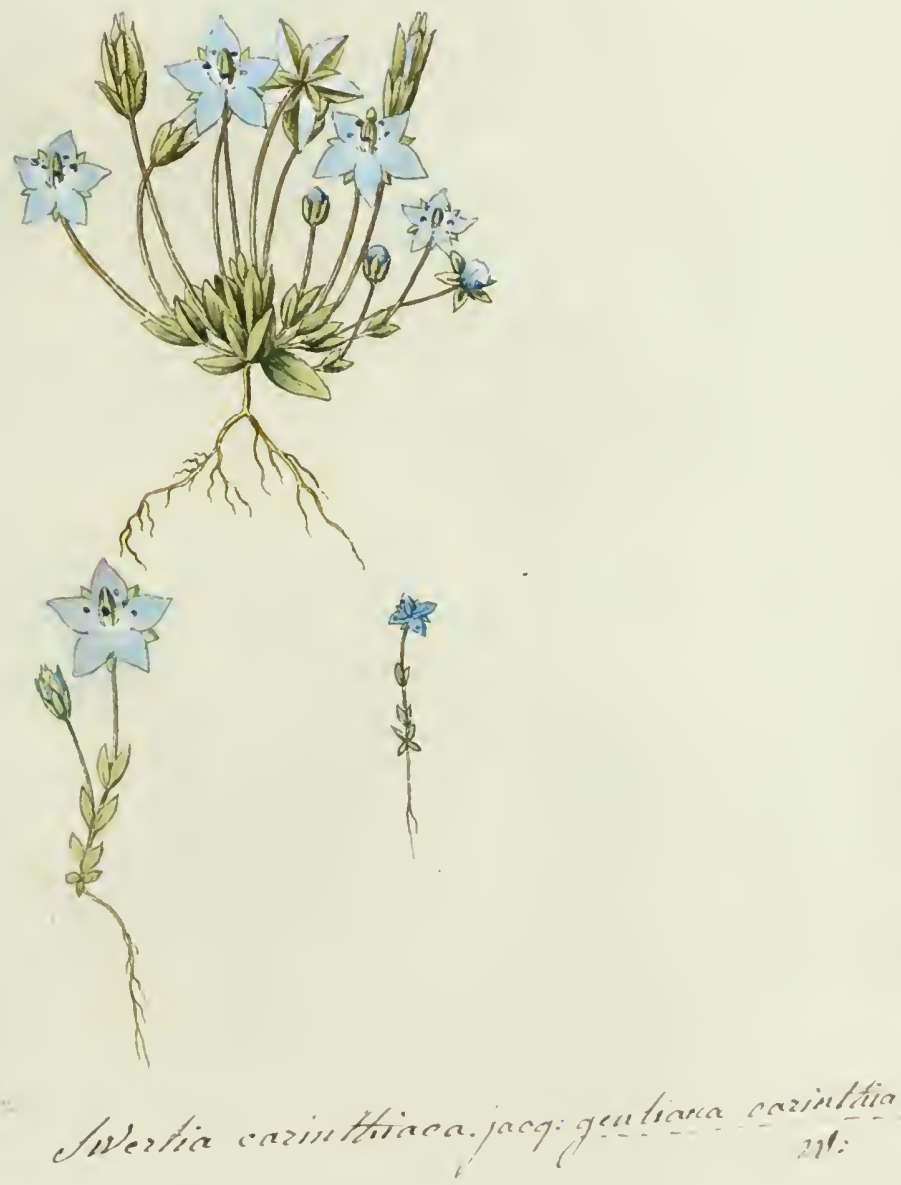






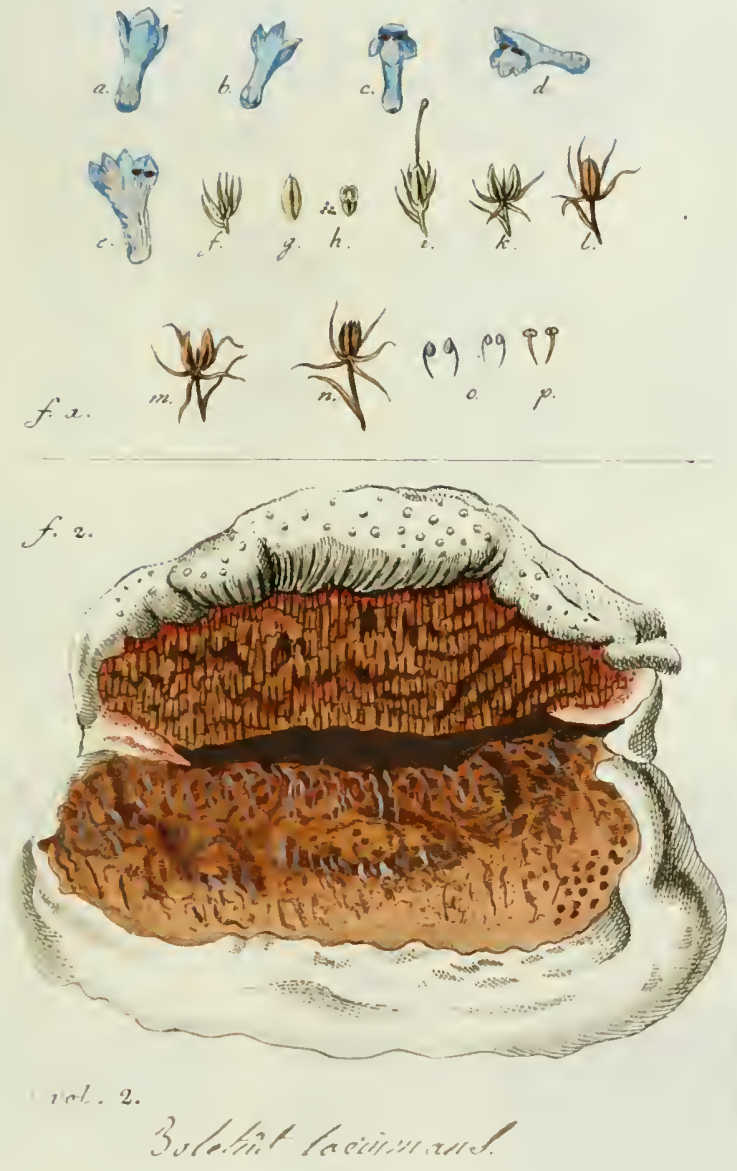





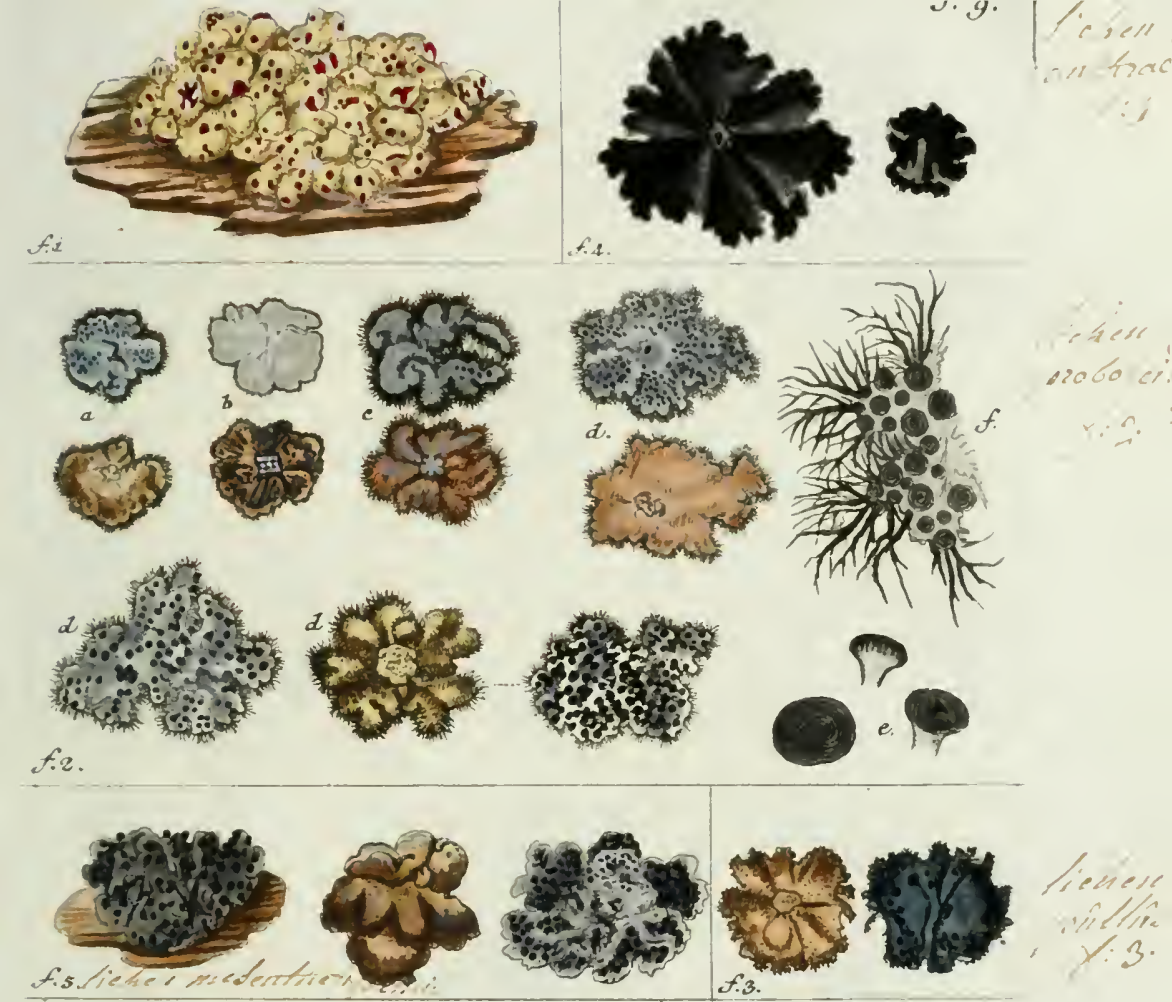

A. 4 .

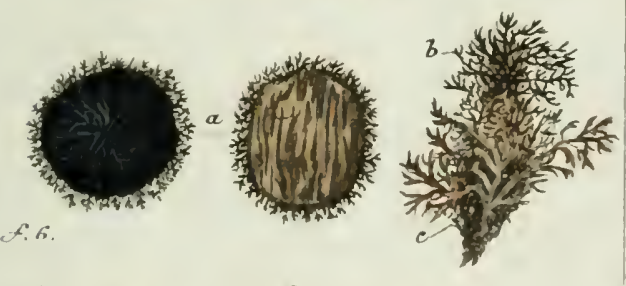

vol a
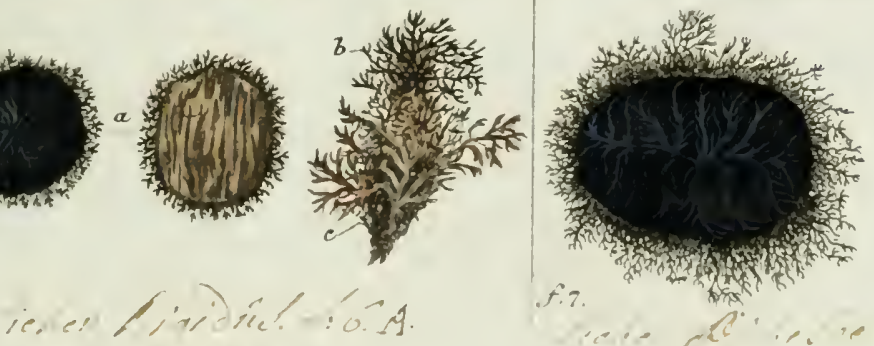




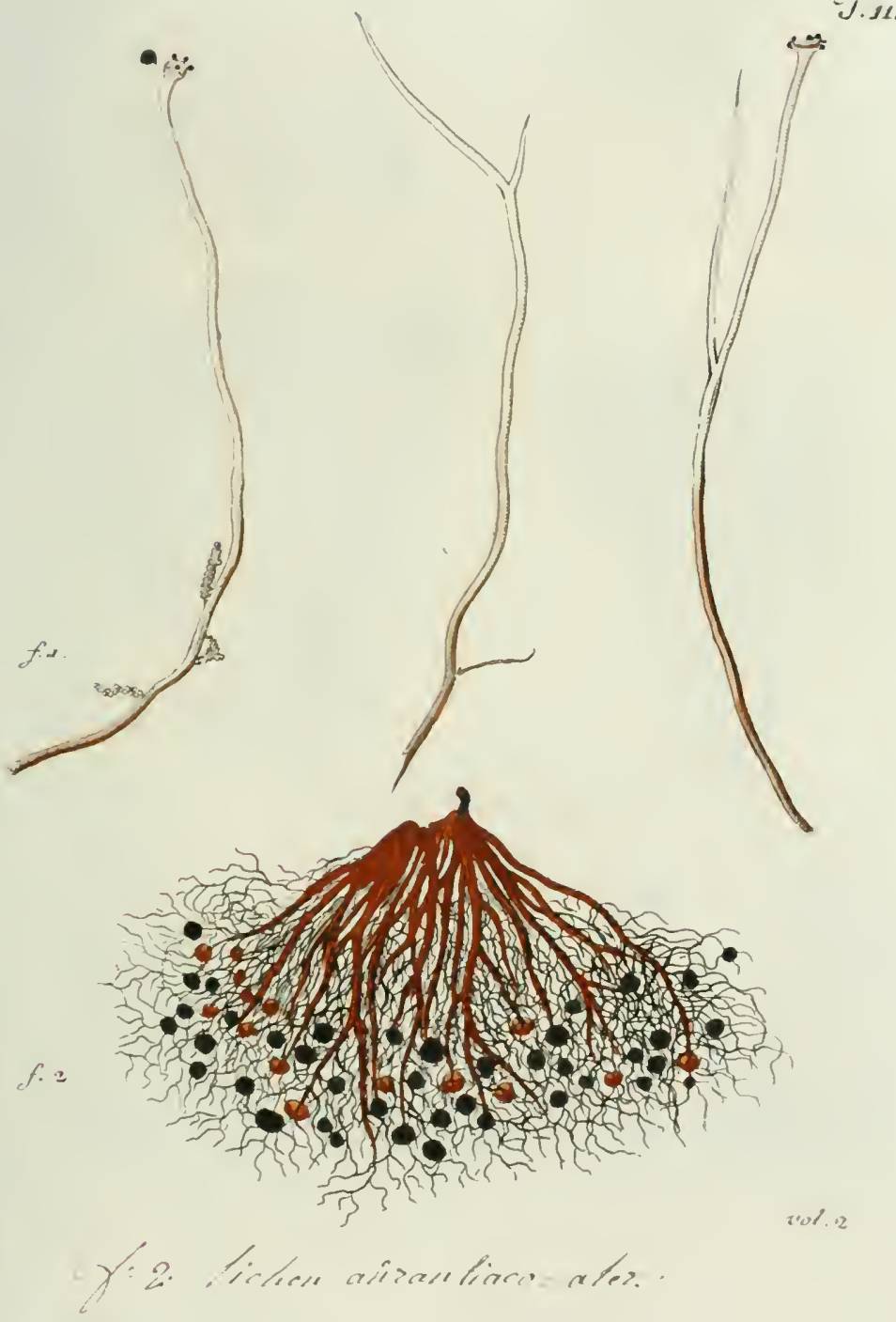



$\% 12$
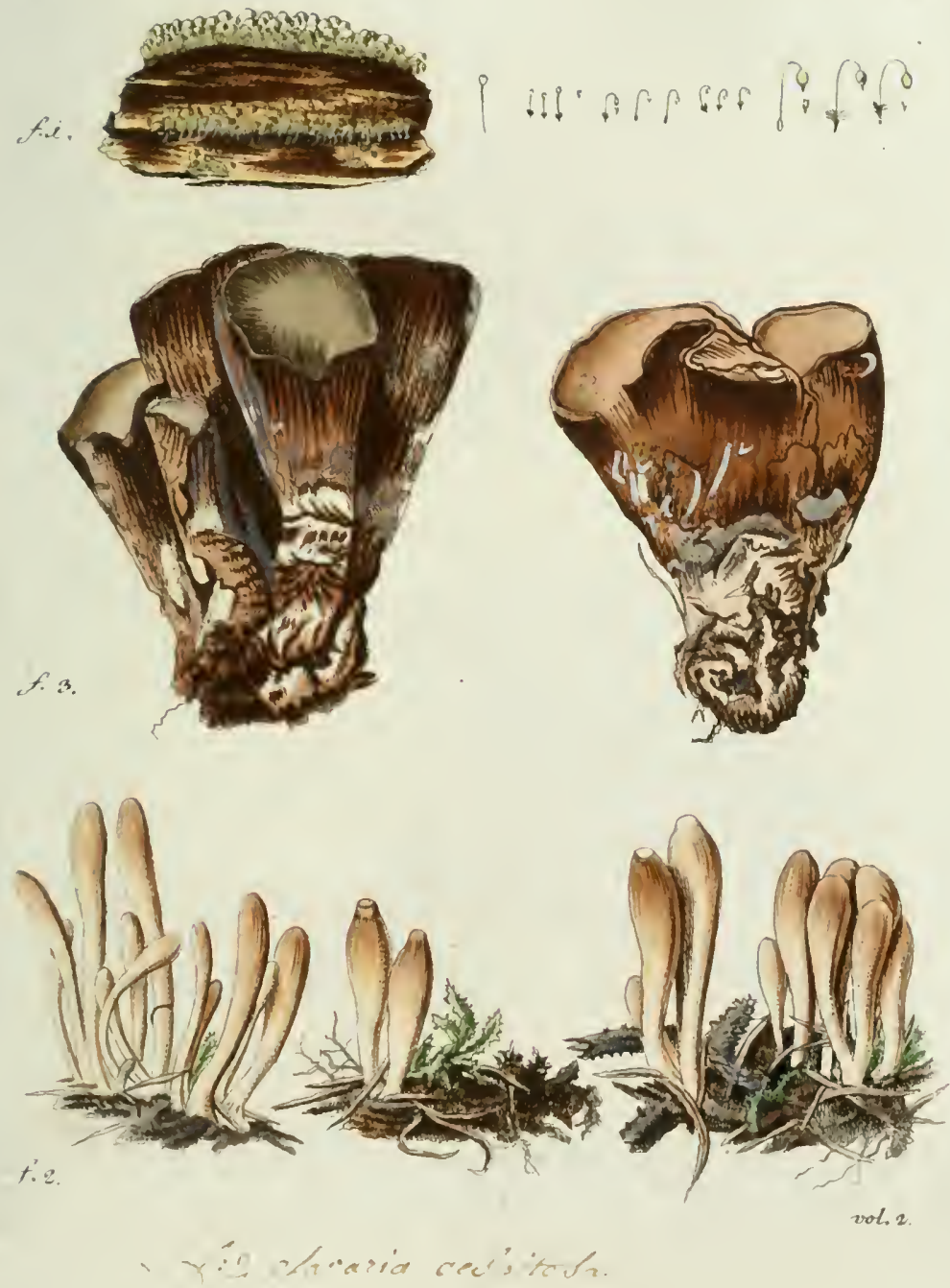


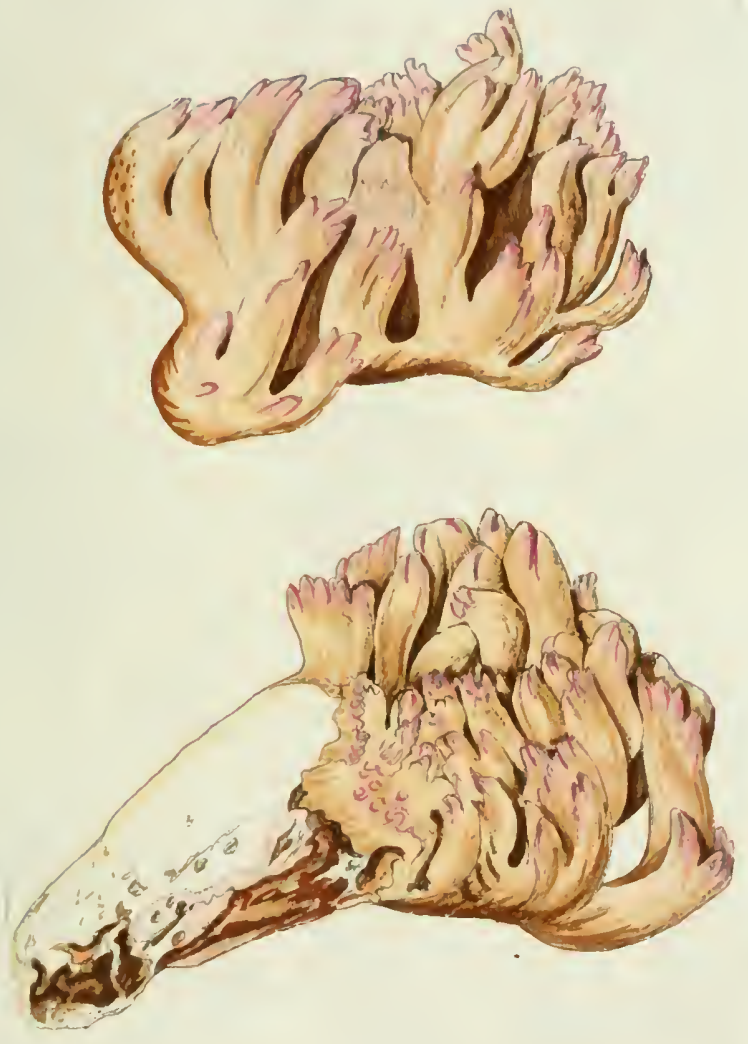

vel. 2.

$$
\text { - Elakazia loseji. }
$$





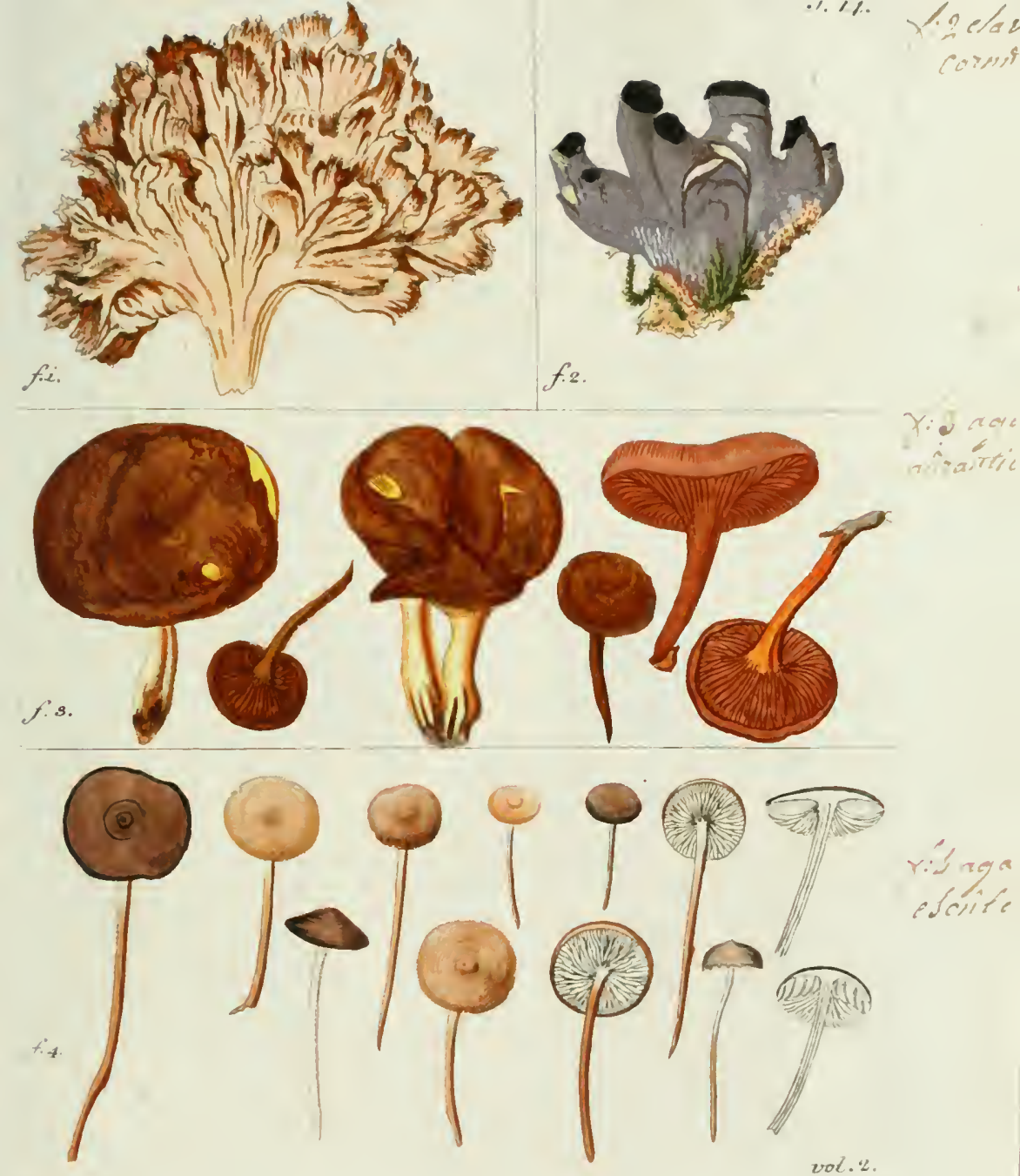





$$
\text { pis }
$$



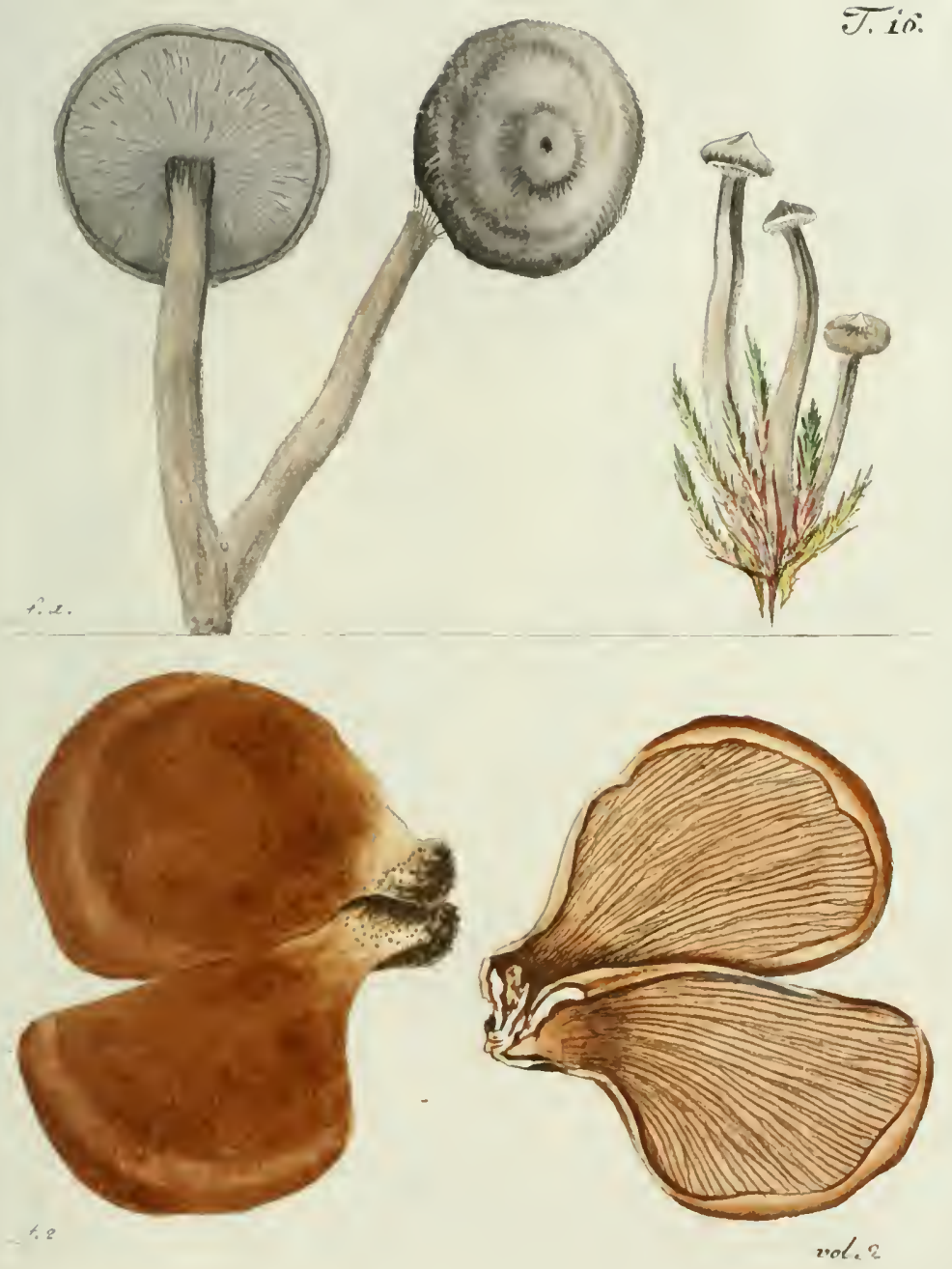



\section{$\pi .7$}

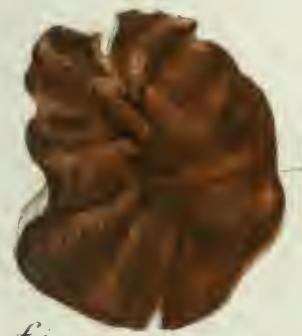

f.i.
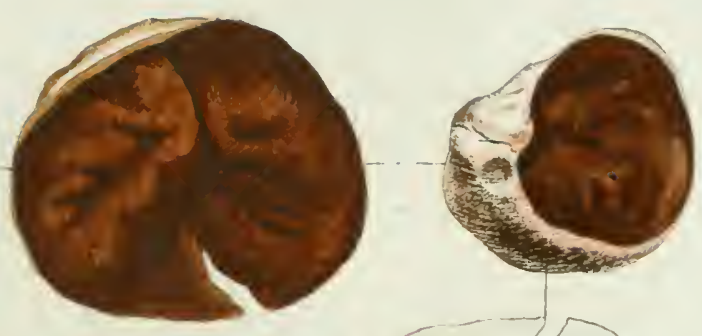

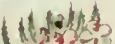

$\sqrt{3} 3$

wat तो sin

in

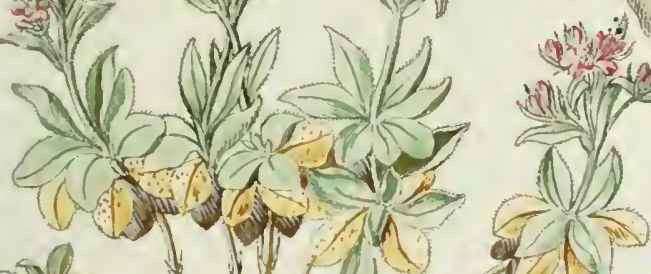

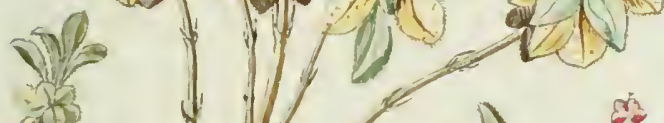

is

$f \circ$

ent 3

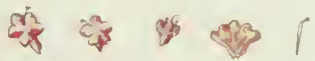

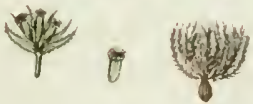





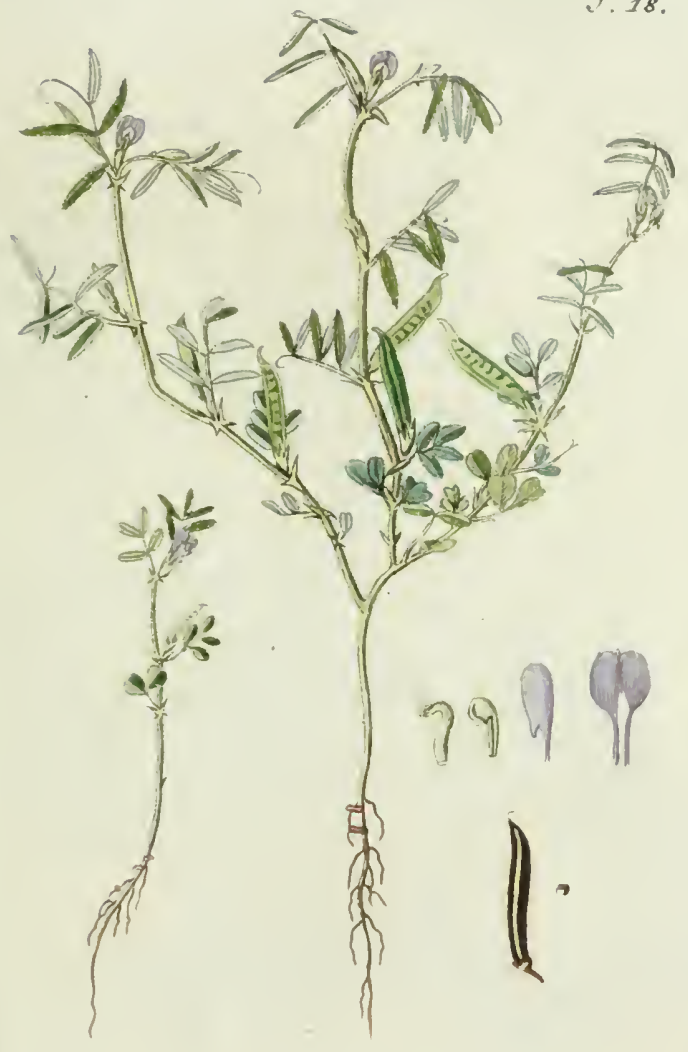

ovi.2. 



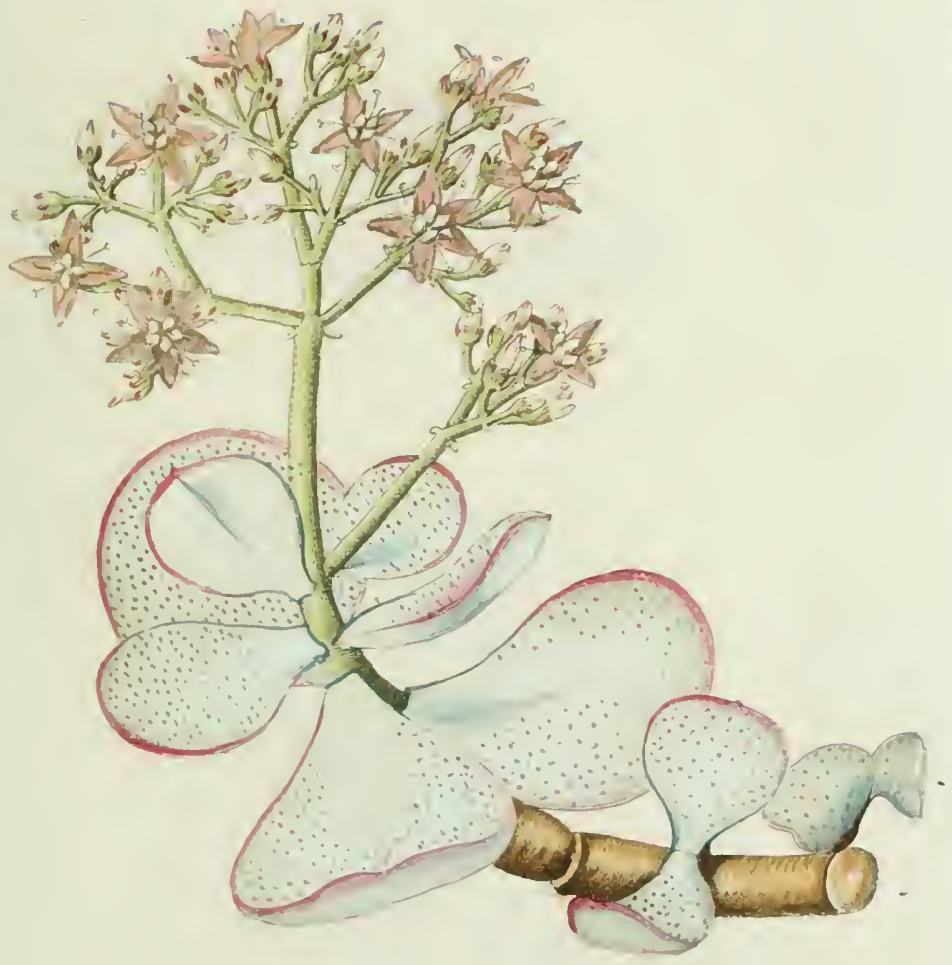

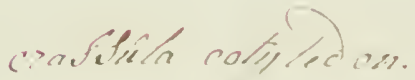





$$
\because \quad 2,
$$
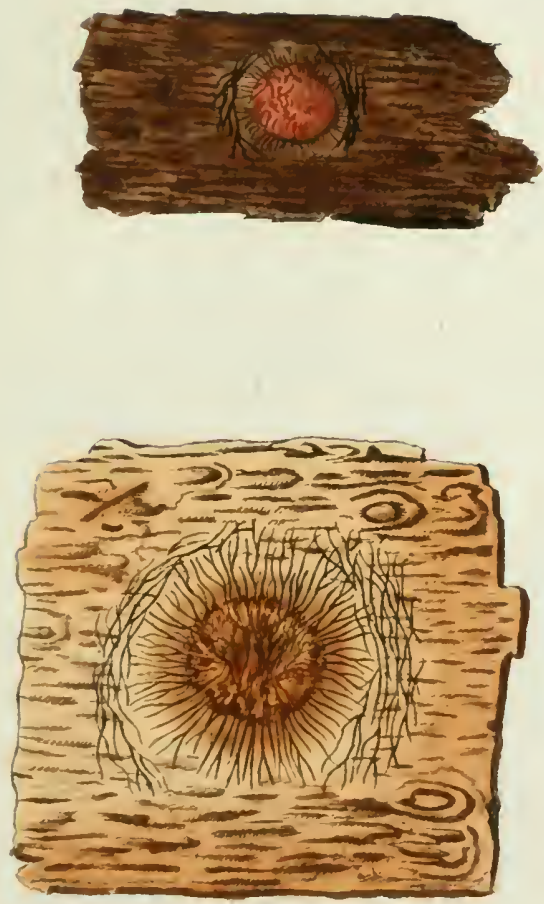

, .11

lilicas arameo, fiel. 




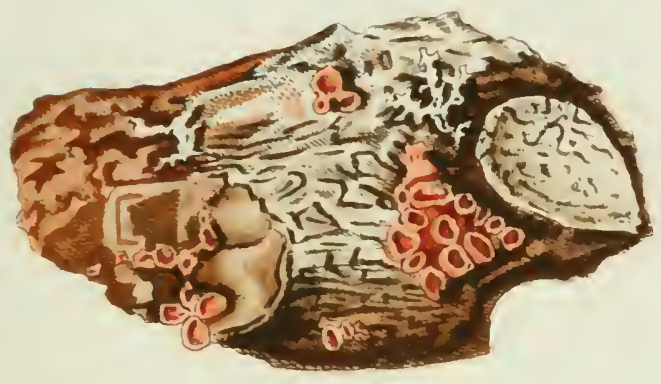

(1)

i

4

Cैं

a

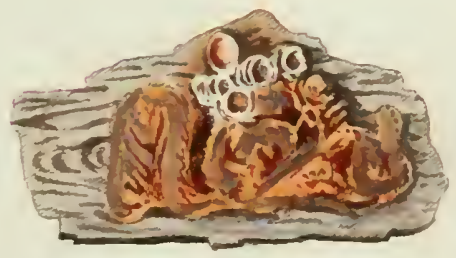

-l. 2

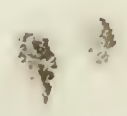





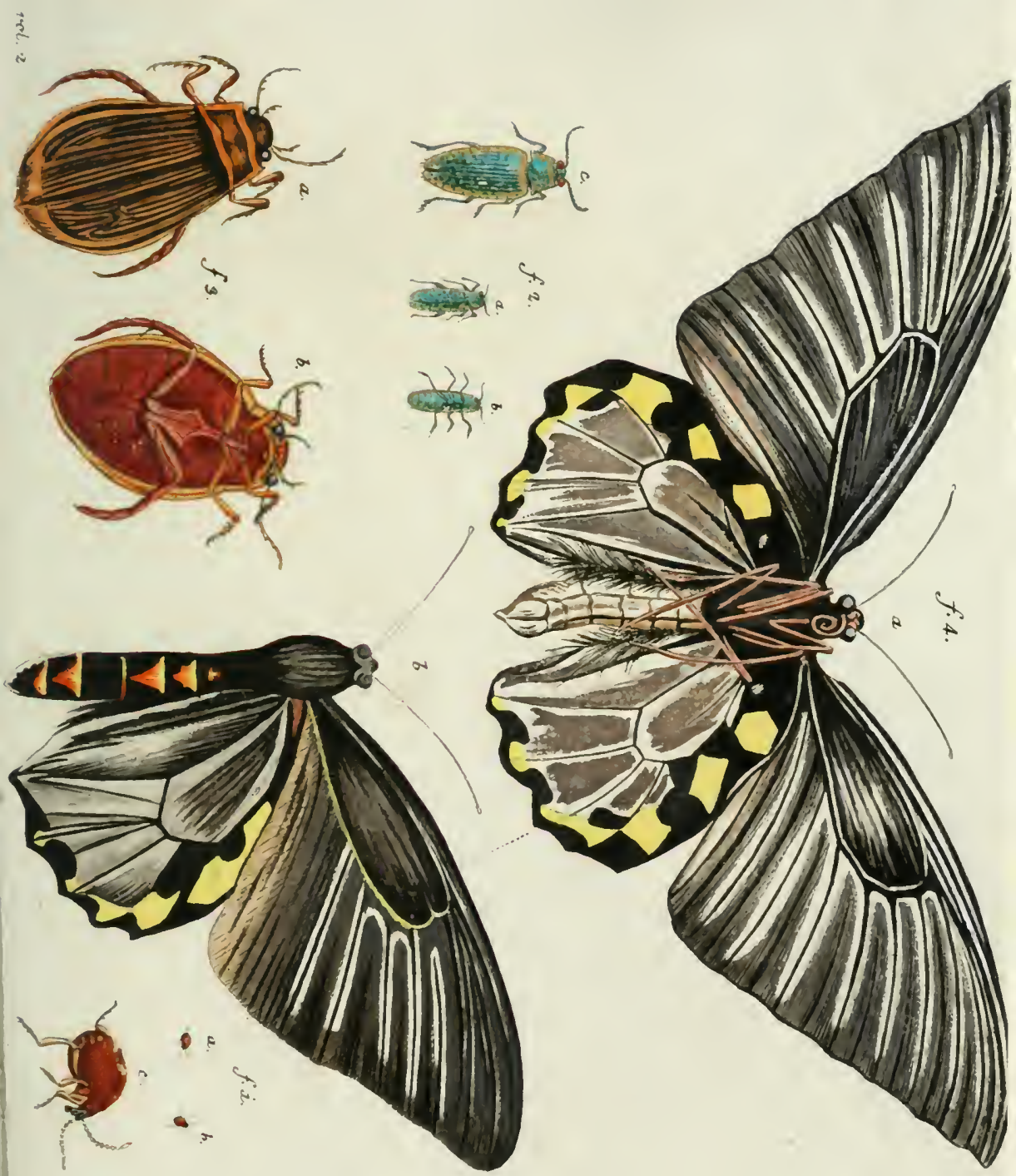







